\section{OAK RIDGE}

NATIONAL

LABORATORY

MARTIN MARUETTA

\section{DOSEXPRT-A Bioassay Dosimetry Code for Martin Marietta Energy Systems, Inc.}

\author{
R. C. Ward \\ K. F. Eckerman
}

MARTIN MARIETTA ENERGY SYSTEMS, INC.

FOR THE UNITED STATES

DEPARTMENT OF ENEEGG 
This report has ben reproduced directly from the best avallable copy.

Available to DOE and DOE contractors from the Office of Scientific and Technical Information, P.O. Box 62, Oak Ridge, TN 37831; prices avallable from (615) 576-8401, FTS 626-8401.

Available to the publlc from the National Technical Information Service, U.S. Department of Commerce, 5285 Port Royal Rd., Springfield, VA 22161.

This report was prepared as an account of work sponsoled by an agency of the United States Government. Neither the United States Covernment nor any agency thereof, nor any of their employees, makes any warranty, express or implied, or assumes any legal llab'ity or responsibility for tha accuracy, com" pleteness, or usefulness of any information, apparatus, product, oi process disclosed, or represents that its use would not intringe privately owned rights. Reference herein to any specific commercial product, process, or service by trade name, trademark, manufacturer, or otherwise, does not necessarily constitute or imply its endorsement, recommendation, or favoring by the Linited States Government or any agency thereof. The views and opinions of authors expressed herein do not necessarily state or reflect those of the United States Government or any agency thereof. 


\title{
DOSEXPRT - A Bioassay Dosimetry Code for Martin Marietta Energy Systems, Inc.
}

\author{
R. C. Ward \\ Computing and Telecommunications Division \\ K. F. Eckerman \\ Health and Safety Division \\ Prepared by \\ Health and Safety Division \\ and \\ Computing and Telecommunications Division \\ Oak Ridge National Laboratory \\ Post Office Box 2008 \\ Oak Ridge, Tennessee 37831
}

Date Published - April 1992

Prepared by the

OAK RIDGE NATIONAL LABORATORY

Oak Ridge, Tennessee 37831 managed by

MARTIN MARIETTA ENERGY SYSTEMS, INC.

for the

U.S. DEPARTMENT OF ENERGY

under contract DE-AC05-84OR21400
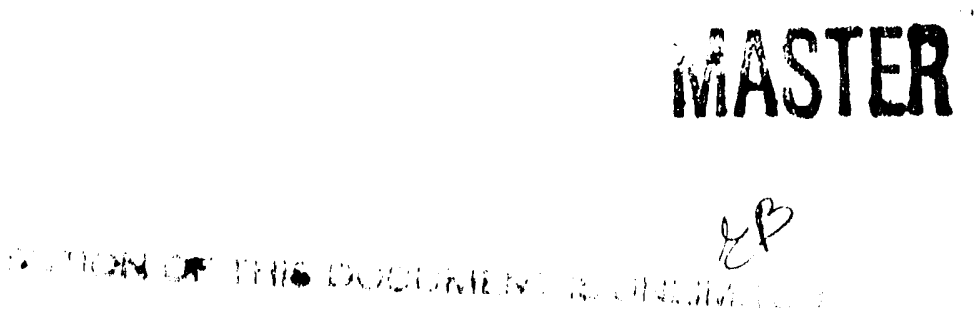


\section{CONTENTS}

ACKNOWLEDGMENTS $\ldots \ldots \ldots \ldots \ldots \ldots \ldots \ldots \ldots \ldots \ldots$

ABSTRACT $\ldots \ldots \ldots \ldots \ldots \ldots \ldots \ldots \ldots \ldots \ldots \ldots \ldots \ldots \ldots \ldots \ldots \ldots \ldots$

1. INTRODUCTION $\ldots \ldots \ldots \ldots \ldots \ldots \ldots \ldots \ldots \ldots \ldots \ldots \ldots \ldots \ldots \ldots \ldots$

2. GENERAL DESCRIPTION OF DOSEXPRT $\ldots \ldots \ldots \ldots \ldots \ldots \ldots \ldots$

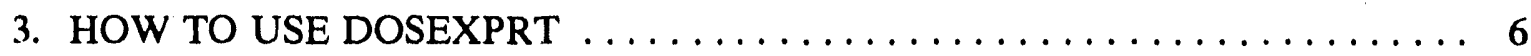

4. OPERATION OF DOSEXPRT $\ldots \ldots \ldots \ldots \ldots \ldots \ldots \ldots \ldots \ldots \ldots$

5. ASSUMPTIONS MADE IN DOSEXPRT $\ldots \ldots \ldots \ldots \ldots \ldots \ldots \ldots \ldots$

6. CREATING BIOASSAY RECORDS USING THE GENREC UTILITY $\ldots \ldots 20$

7. MODIFYING SITE DEFAULT FILE USING THE MODSITE UTILITY $\ldots \ldots 28$

8. DOSEXPRT NUCLIDE DATA FILES AND DOSE-RATE FILES $\ldots \ldots \ldots 33$

9. ALGORITHMS FOR ESTIMATING INTAKE OF RADIONUCLIDES $\ldots \ldots \quad 35$

10. TECHNICAL DESCRIPTION OF NUCLIDE DATA FILES $\ldots \ldots \ldots \ldots \ldots 53$

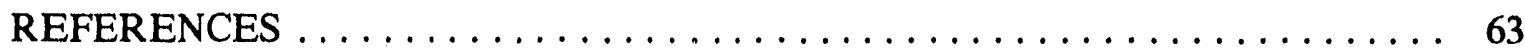

Appendix A: DOSEXPRT BIOASSAY RECORDS FORMAT $\ldots \ldots \ldots \ldots \ldots 65$

Appendix B: DOSEXPRT OUTPUT FILE FORMAT $\ldots \ldots \ldots \ldots \ldots \ldots 68$

Appendix C: SITE-SPECIFIC FILE (SITE.DFT) $\ldots \ldots \ldots \ldots \ldots \ldots \ldots \ldots, 70$

Appendix D: DOSE-RATE FILE CONTROL TABLE (DRS.TAB) $\ldots \ldots \ldots \ldots 72$

Appendix E: DOSEXPRT EXAMPLES-INCIDENT EXPOSURE $\ldots \ldots \ldots \ldots 73$

Appendix F: DOSEXPRT EXAMPLES-ROUTINE EXPOSURE $\ldots \ldots \ldots \ldots 76$

Appendix G: FLOWCHART OF DOSEXPRT $\ldots \ldots \ldots \ldots \ldots \ldots \ldots \ldots$

Appendix H: LISTINGS OF NUCLIDE FILES $\ldots \ldots \ldots \ldots \ldots \ldots \ldots \ldots$

Appendix I: $\quad$ INPUT DATA FOR EXAMPLE PROBLEMS $\ldots \ldots \ldots \ldots \ldots 170$ 
Appendix J: LISTINGS OF DOSEXPRT SCREEN OUTPUT FOR EXAMPLE

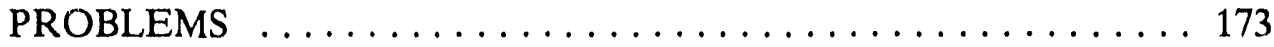

Appendix K: LISTINGS OF DOSEXPRT OUTPUT FILES FOR EXAMPLE

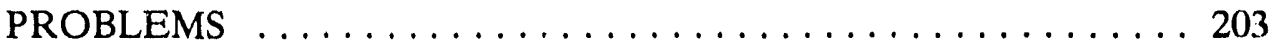

Appendix L: LISTINGS OF DOSEXPRT AUXILIARY OUTPUT FILES FOR

EXAMPLE PR.OBLEMS . . . . . . . . . . . . . . . . . . 209

Appendix M: DOSEXPRT VAX COM FILES $\ldots \ldots \ldots \ldots \ldots \ldots \ldots \ldots \ldots$

Appendix N: EXECUTING DOSEXPRT IN DEBUG/TEST MODE $\ldots \ldots \ldots \ldots 220$ 


\section{ACKNOWLEDGMENTS}

The authors wish to thank the following individuals who, as members of the DOSEXPRT Oversight Committee, provided guidance in the development of the DOSEXPRT software.

Mike Mahathy, Martin Marietta Energy Systems, Inc. (MMES), Central Staff

Ruth Boys, MMES Central Staff

Elizabeth Brackett, MMES Central Staff

Jerry M. Barber, Y-12 Plant

Rhonda Bogard, Y-12 Plant

Elizabeth Dixon, ORNL

Doug Farver, K-25 Site

David McLaughlin, ORNL

Cathy Pugh, MMES Central Staff

Govind Rao, ORNL

Michelle Reichert, Y-12 Plant

The constructive criticism and suggestions of the Oversight committee, chaired in turn by Mike Mahathy, Ruth Boys, and Elizabeth Brackett, were invaluable to the DOSEXPRT

project. In addition, this project benefitted from the comments and suggestions of the Review Committee for the U.S. Army Radiological Bioassay and Dosimetry (RBD) Code, chaired by R. K. Bhat, U.S. Army Belvoir RDE Center, Belvoir, Virginia. The authors would also like to express their appreciation to Mona Harmadi for her attention to the details in preparation of this manuscript and to Catherine Shappert for her attentive editing of the manuscript. Shortfalls in the DOSEXPRT software are attributable to the authors; the success we all share. 


\begin{abstract}
The bioassay code DOSEXPRT was developed for Martin Marietta Energy Systems, Inc., to provide compliance with Department of Energy (DOE) Order 5480, Chapter 11. DOSEXPRT computes the intake of a radionuclide in any year (considering both acute and chronic intakes) from in vivo measurements of the retained activity and/or measurements of the activity in excreta. The committed effective and organ doses for the intake are computed as well as the effective and organ doses expected to be received in each calender year out to 50 years beyond the year of intake. The bioassay records used as input for DOSEXPRT are extracted from the Martin Marietta Energy Systems Occupational Health Information System (OHIS). DOSEXPRT implements a set of algorithms with parameters governing the translocation, retention, and excretion of the nuclide contained in data files specific to the nuclide. These files also contain dose-per-unit-intake coefficients used to compute the committed dose equivalent for the intakes in the year. Annual organ and effective doses are computed using additional dose-rate files that contain data on the dose rate at various times following a unit intake. If measurements are presented for more than one assay for a given nuclide, DOSEXFRT estimates the intake by applying weights assigned in the nuclide file for each assay. DOSEXPRT is accessed off the OHIS MENU No. 4 and designed to be run as a batch processor, but can also be run interactively for testing purposes.
\end{abstract}




\section{INTRODUCTION}

The general principle of monitoring for the radiation protection of workers has been set forth in various reports of the International Commission on Radiological Protection ${ }^{1-4}$ and National Council on Radiation Protection and Measurement. ${ }^{5}$ Monitoring of individuals for internal exposure is based on measurements of radionuclides in the whole body (or in specific organs/regions) and on measurement of excreta. For quantitative assessment of internal exposure the results of these measurements must be translated into quantities that can be compared to the primary radiation protection guidance (limits on committed dose equivalent or annual dose equivalent) or to the secondary quantitics (Annual Limits on Intake - ALI). The relationships between levels in the body or in excreta and the estimated intake and resulting dose can only be established through use of metabolic and dosimetric models describing the behavior of the material in the body.

Interpretation of bioassay measurements in terms of the primary and secondary radiation protection quantities often requires considerable computatic.nal effort, thus necessitating the use of computers. For radionuclides that are tenaciously retained in the body the interpretation of contemporary measurements requires the information of the complete exposure history of the individual to that nuclide. The management of large amounts of bioassay data necessitates the use of a computer program.

DOSEXPRT (shortened from "DOSE EXPERT") was developed by Richard C. Ward and Keith F. Eckerman for use by the Health Physics personnel at Martin Marietta Energy Systems, Inc. (MMES). The DOSEXPRT software is intended to serve as a tool in demonstrating compliance with the Department of Energy (DOE) occupational radiation protection order (DOE 5480.11). ${ }^{6}$ The principal use of DOSEXPRT will be to compute annual effective dose for workers for the Radiation Exposure Information Reporting System (REIRS) report, an annual report to DOE by its contractors. The input and output records used to produce the REIRS report are maintained in the MMES Occupational Health Information System (OHIS).

DOSEXPRT incorporates a set of algorithms for estimating the intake (acute incident) or intake rate (chronic exposure) of radionuclides based on measurement of their excretion rate or activity present in the body. The algorithms make use of contemporary dosimetric and biokinetic data in the interpretation of the bioassay measurements. In formulating the algorithms and developing the software, the needs of quality assurance and the desire to limit future maintenance costs were considered.

The present version, DOSEXPRT 4.2, was completed on March 17, 1992. DOSEXPRT 4.2 was used to analyze intake and dose for Energy Systems personnel for the year 1991 .

- Ver. 4.1 of DOSEXPRT was used for analysis of 1990 bioassay data, and Ver. 3.0 of DOSEXPRT was used for analysis of 1989 bioassay data. The method for computing intake, committed dose, and annual dose has not been altered between Vers. 3.0 and 4.2, although a faster algorithm was developed for computation of annual dose with Ver. 4.1 of DOSEXPRT. Version 4.1 aiso introduced a post-processing program (REPORT) which sorted the output of DOSEXPRT by sum of committed effective dose, for ease of 
interpretation. This program, renamed DOSREPORT, has been improved with ver. 4.2 of DOSEXPRT. The new version sorts by both sum of committed effective dose and presence of any positive annual effective dose for a given individual. Other modifications between the present version of DOSEXPRT and earlier versions are detailed in the report.

Section 2 contains a general description of DOSEXPRT 4.2. This description is followed in Sect. 3 by a discussion of how to use DOSEXPRT. The fourth section discusses the operation of DOSEXPRT, while the fifth section states the assumptions made in DOSEXPRT. Section 6 describes how to create bioassay records using the GENREC utility. Section 7 describes how to modify the SITE default file using the MODSITE utility. The DOSEXPRT nuclide data files and dose-rate files are discussed in Sect. 8. Section 9 describes the algorithms used for estimating intake of radionuclides, and Sect. 10 delineates the contents of the nuclide data files. Appendices contain the format of the DOSEXPRT input and output files and example input and output results. Appendix $\mathrm{H}$ contains listings of all nuclide data files available for DOSEXPRT.

DOSEXPRT was written in FORTRAN 77 for the Occupational Health Information System (OHIS) VAX. A similar code, the Radiological Bioassay and Dosimetry (RBD) ${ }^{7}$ code, was developed for the U.S. Army for use on personal computers. The algorithms for computing intake and committed dose are identical in RBD and DOSEXPRT, although the assumption made when treating results less than the lower critical limit, as discussed in Sect. 5, varies between the two codes. 


\section{GENERAL DESCRIPTION OF DOSEXPRT}

DOSEXPRT is accessed off the Occupational Health Information System (OHIS) menu HPIMS No. 4. On OHIS the DOSEXPRT programs are located in the directory EXE_DIR. The program can be run either interactively or as a batch processor. Designed to be used to process a large number of bioassay records, it is recommended that DOSEXPRT be run as a batch processor.

Table 1 on the following page lists the DOSEXPRT input and output files. As input, DOSEXPRT requires one or two bioassay records files. Each input file must have the extension DAT. Usually there will be two bioassay records files, one for in vitro analysis (S26.DAT) and one for in vivo analysis (S27.DAT). The format for the input records has been established to be consistent with the bioassay data on the Martin Marietta Energy Systems OHIS data base. A VAX COM file first concatenates and sorts the bioassay records files into a single file (DOSEXPRT.DAT) and then executes the DOSEXPRT program.

To compute intake and dose, the code uses separate data files for each radionuclide. One data file (with extension NUC) contains information for computing intake and committed dose, weighting factors with which to weight intake and committed dose for the different bioassays, and control information to determine the progress of the computations. The other data file (with extension DRS) contains dose rate per unit intake as a function of time for computing annual dose. Dose-rate files are not required for nuclides where the clearance from the body occurs within the year of exposure. For Ver. 4.2 of DOSEXPRT, 40 nuclide data files are available:

\begin{tabular}{|c|c|c|c|}
\hline $\begin{array}{l}H-3 \quad \text { C }-11 / 14 \\
\text { Sr }-85 / 89 / 90 \\
\text { Eu }-152 / 154 / 155 \\
y U-234 / 235 / 236 / 238\end{array}$ & $\begin{array}{lr}\mathrm{Na}-22 / 24 & \mathrm{P} \\
\mathrm{Tc}-99 / 99 \mathrm{M} & \mathrm{C} \\
\mathrm{T} 1-201 & \mathrm{R} \\
8 & \mathrm{Pu}-238 / 239 / 24\end{array}$ & $\begin{array}{l}P-32 \\
\begin{array}{l}\text { Cs }-134 / 137 \\
\mathrm{Ra}-226 / 228 \\
41 \quad \text { Anl }-241\end{array}\end{array}$ & $\begin{array}{l}\text { Co }-57 / 58 / 60 \\
\text { I }-125 / 1.29 / 131 / 135 \\
\text { Th-228/232 } \\
\text { Cm- } 242 / 244\end{array}$ \\
\hline
\end{tabular}

and TPU (same as AM-241).

Presently, 18 dose-rate files are available:

$\begin{array}{llll}\mathrm{Co}-57 / 60 & \mathrm{Sr}-89 / 90 & \mathrm{Cs}-134 / 137 & \mathrm{I}-125 / 129 \\ \mathrm{U}-234 / 235 / 236 / 238 & \mathrm{Pu}-238 / 239 / 241 & \mathrm{Am}-241 & \mathrm{Cm}-244\end{array}$

and TPU (same a.s AM-241).

The nuclide data files and dose-rate files for all but the Y-12 Plant are located in HS_DATA:[DX]. DOSEXPRT 4.2 has been set up to take advantage of special inhalation class $Q$ for the uranium nuclides. These files are used presently by the Y-12 Plant. The user is asked by DOSEXPRT whether to use the special Y-12 uranium nuclide data and dose-rate files. The default response is NO. A special data area HS_DATA:[DX.Y12] contains the Y-12 uranium nuclide and dose-rate files. 
Table 1. DOSEXPRT input and output filenames

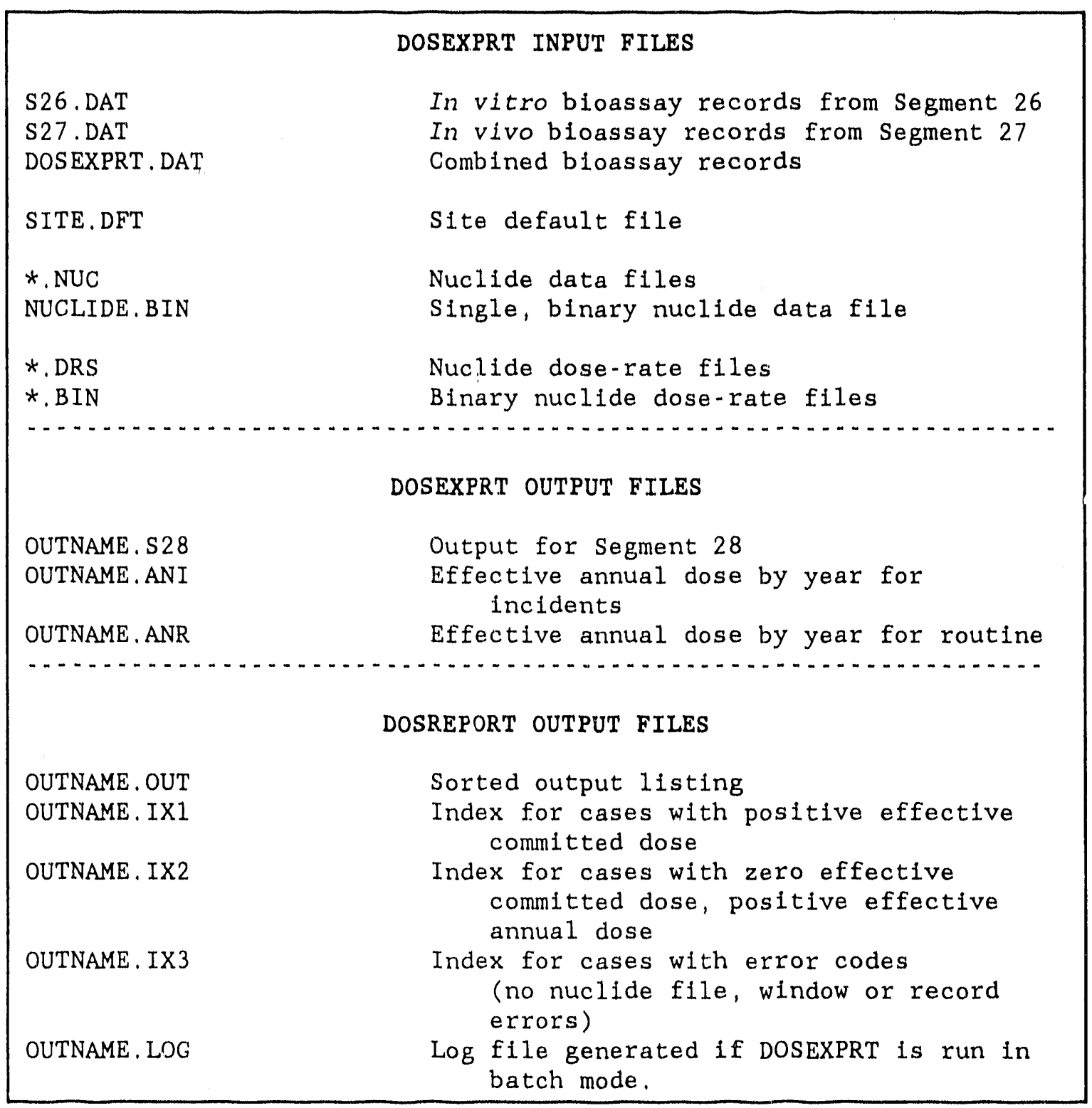


With Ver. 4.1 of DOSEXPRT the nuclide data files were combined into a single binary, direct-access file, NUCLIDE.BIN, for faster execution of DOSEXPRT. In addition, a binary, direct-access dose-rate file (with extension BIN) was created for each of the nuclides with dose-rate files. The structure of the nuclide data files and the nuclide dose-rate files was unmodified for Ver. 4.2 of DOSEXPRT.

In addition to the bioassay records, nuclide data files, and nuclide dose-rate files, DOSEXPRT requires a plant site default file (SITE.DFT), which includes a table of nuclide data files, and a file (DRS.TAB) containing a table of nuclides with dose-rate files.

DOSEXPRT produces three output files: (1) an output listing (with extension S28) to be incorporated into Segment 28 of the OHIS data base; (2) a listing (with extension ANI) of annual dose (in mrem) by year up to 50 years for incident exposure; and (3) a listing (with extension ANR) of annual dose (in mrem) by year for routine exposure. In addition, if DOSEXPRT is submitted as a batch job, a listing (with extension LOG) contzining the assumptions made during the run will be produced. The ANI and ANR ouiput listings are discussed in Appendix L.

The DOSEXPRT post-processing program, DOSREPORT, sorts the DOSEXPRT output (S28) file by the sum of committed effective dose and presence of annual effective dose into a sorted output file (with extension OUT). DOSREPORT also produces three index files (with extensions IX1, IX2 and IX3), that facilitate reading the DOSEXPRT output. The first index file (extension IX1) lists all cases with positive committed effective dose. The second index file (extension IX2) lists all cases with zero committed effective dose but positive annual effective dose. The third index file (extension IX3) lists all cases where errors (no nuclide file, measurement window or record errors) occurred. The index files list the social security number and the information (badge, plant site, nuclide, class, pathway and reason code) that appears on the header for each case in the OUT file. The index files can be used for quickly cross referencing the other DOSEXPRT and DOSP.EPORT output files.

In this manual, the plant letter codes $\mathrm{K}, \mathrm{O}, \mathrm{P}, \mathrm{X}$ and $\mathrm{Y}$ stand for K-25; Portsmouth, Ohio; Paducah, Kentucky; X-10; and Y-12 respectively. The plant letter code S and name SITE have been used in all example problems so that results will not be construed as coming from a particular MMES site. The plant site names are assigned to the plant letter codes in the SITE.DFT file. In addition, negative values were used for badge numbers so that they will not be construed as actual badge numbers. [Note: a badge number of -1 will not work because this number is the flag that indicates to DOSEXPRT the end of the BADGE list (i.e., the end of processing.)] The normal range for badge numters is 1 to 999999.

Throughout this manual screen output is displayed in shaded boxes, and the user's responses to queries are shown in italics. 


\section{HOW TO USE DOSEXPRT}

DOSEXPRT and associated utility programs (GENREC and MODSITE) are executed from OHIS meriu HPIMS No. 4. The OHIS menu appears as follows:

\begin{tabular}{|ll|}
\hline & H P I M S \#4 M E N U \\
& \\
XTRACT & Extract Bloassay Records from Data Base \\
INTERACTIVE & Run DOSEXPRT and Create Output Report \\
BATCH & Submit DOSEXPRT and Create Output Report \\
GENREC & Generate a Bioassay Records F1le \\
MODSITE & Modify SITE.DFT file \\
DIR & Directory Listing \\
LIST & List a DOSEXPRT output file \\
PRINT & Print a DOSEXPRT output file \\
Ho - PRINT & Prints files on HP LaserJet \\
DBM & Data Base Manager \\
EXIT & Exit This Menu \\
\end{tabular}

DOSEXPRT is executed by selecting INTERACTIVE or BATCH from the menu. Selecting INTERACTIVE will run the DOSEXPRT program immediately; selecting BATCH will s bmit DOSEXPRT to be run after the time specified by the user. In either case, assuming the DOSEXPRT cutput files have the form filena ne.ext where ext is the extension, the user is first asked to enter the filename. The extension S28 is attached to create the file for segment 28 of the OHIS data base. The extension OUT is attached to create the sorted output file produced from the $\mathrm{S} 28$ file.

After entering the name of the output files, the user is asked for the number of bioassay records files. The response is either one or two bioassay records files. The user is then asked for the name(s) of these bioassay records file(s). If there are two files (for instance: in vitro and an in vivo bioassay records files), the two bioassay records files will be concatenated together and then sorted.

The user is then asked for a starting date, in the form YYYY, and a duration (in years) for considering measurements for routine analysis. This period is referred to as the measurement window. The measurement window brackets the period of time during which routine measurements will be considered for computing intake rates.

Following this, the user is then asked for a starting date, in the form YYYY, and a duration (in years) for computing the intake. This period is referred to as the intake window. The intake window is the period of time over which the intake for routine assay is evaluated. Incident assays will be computed only if the incident date falls within the intake windo'w. The duration of the intake window must be 1 year when computing annual dose. 
The measurement window and intake window are illustrated in Fig. 1. Consider first a sequence of routine bioassay measurements for this individual. These values are shown by downward-pointing arrows at the top of the figure. For an analysis of radiation exposure in the calendar year 1990, the measurement window was taken to extend over the years 1989 and 1990. This is shown by the horizontal arrow in the middle of the figure. The measurements actually considered for determining the intake are shown below the measurement window. Note that measurements prior to the first of the year 1989 are not considered. Below the measurement window is a second horizontal arrow that indicates the intake window, the period over which the intake is computed for the routine measurements. Note that the measurements in the year 1989 are used to determine the intake rate at the beginning of the year 1990 and therefore will affect the computation of the intake in the year, 1990. The measurement window and the intake window must start at the beginning of a year, and their duration must be an integral number of years. The duration of the intake window must be 1 year when computing annual dose.

Now consider a set of incident measurements in the year 1990 as shown by upwardpointing arrows at the bottom of the figure. For DOSEXPRT to compute intake for this incident, the incident date must fall in the intake window, which it does.

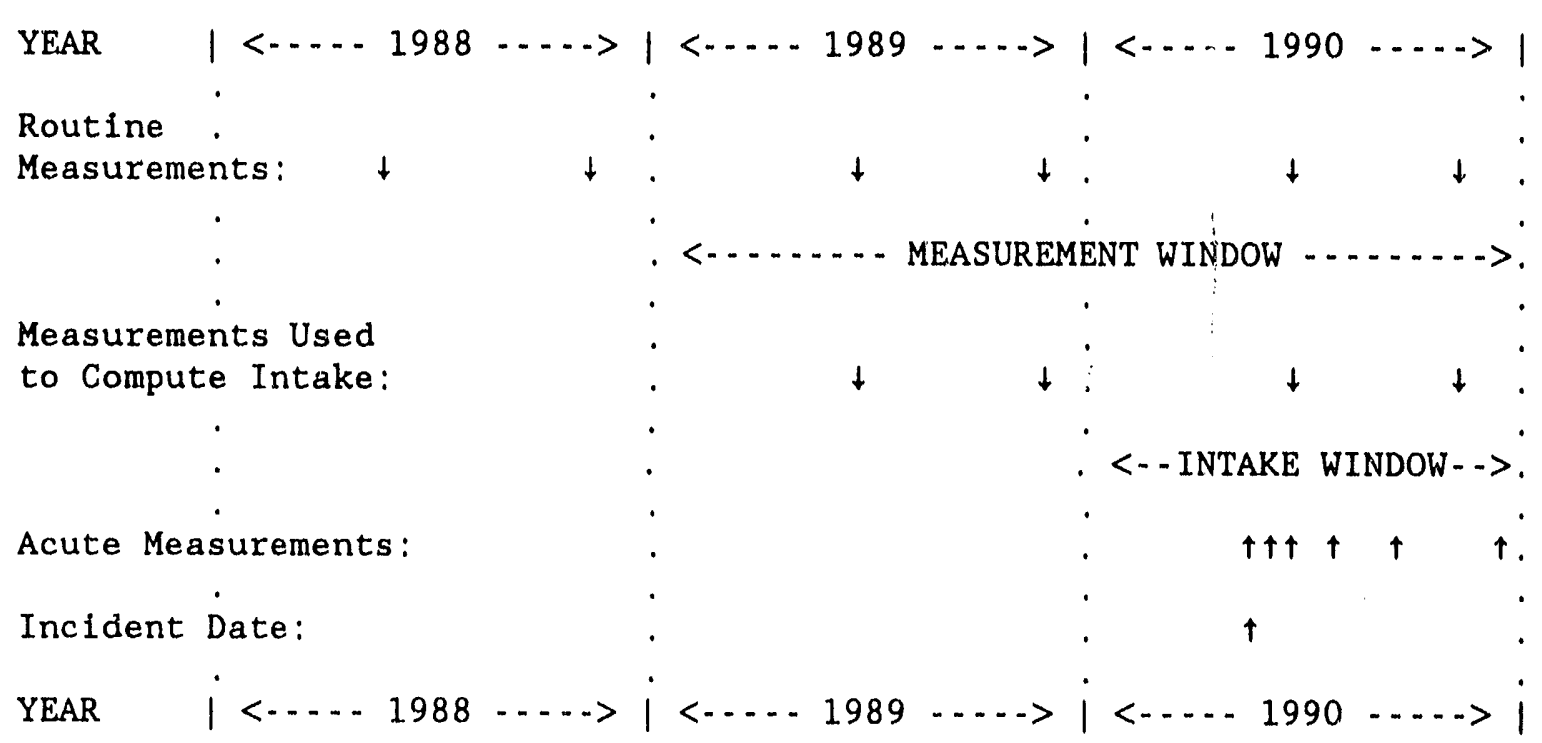

Fig. 1. Illustration of the measurement and intake windows.

After entering the measurement and intake windows, the user is asked to enter a SITE filename (without extension), or to hit return to use the default SITE.DFT file. The SITE.DFT file contains default values for parameters used by the DOSEXPRT program such as volume of urine sample, urinary excretion rate, etc. The user typically selects the default SITE.DFT file. To use a modified SITE.DFT file, see Sect. 7.

The user is then asked whether to use the special Y-12 uranium nuclide and dose-rate 
files. The default response is NO. A special data area HS_DATA:[DX.Y12] contains the Y-12 uranium nuclide and dose-rate files. The regular nuclide and dose-rate files are located in HS_DATA:[DX].

Finally, the user can truncate the listing of the DOSREPORT program by removing the individuals who have only zero intake cases. Since these individuals appear at the end of the listing, the DOSREPORT program can be told not to print any information on them to the OUT file. Cases with error codes are printed to the OUT file. The OUT file header will indicate that the listing has been truncated. The default response is NO-not to truncate printing of zero intake results.

Assuming the user has selected INTERACTIVE from the DOSEXPRT menu and the example DOSEXPRT input file is DEMO.DAT, the output to the screen and the user responses are shown below:

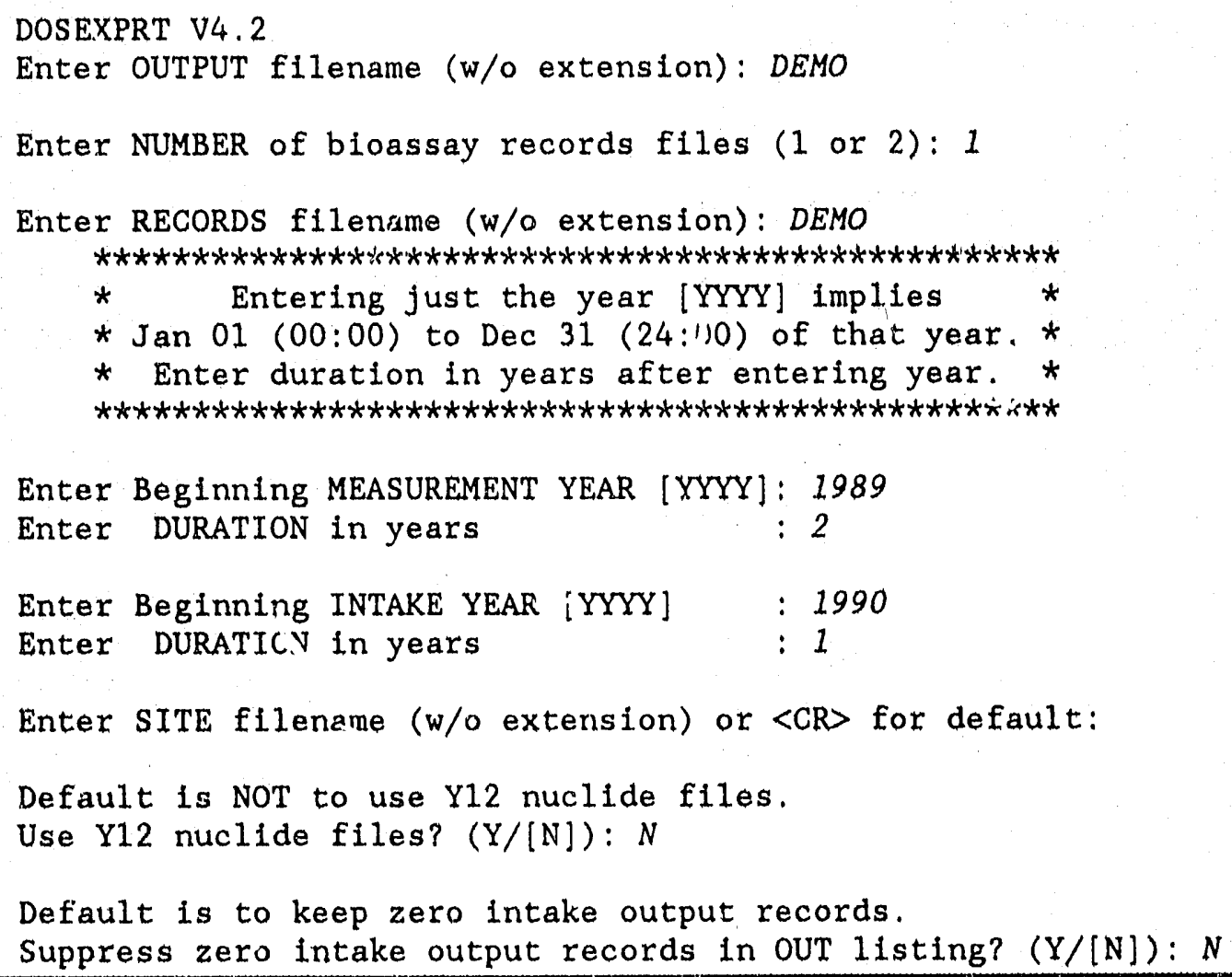

The VAX SORT utility is used to sort the bioassay records into the proper order required by DOSEXPRT. Following this, DOSEXPRT computes the intake, committed dose and annual dose for each case in the bioassay records. The example execution continues on the following page. 


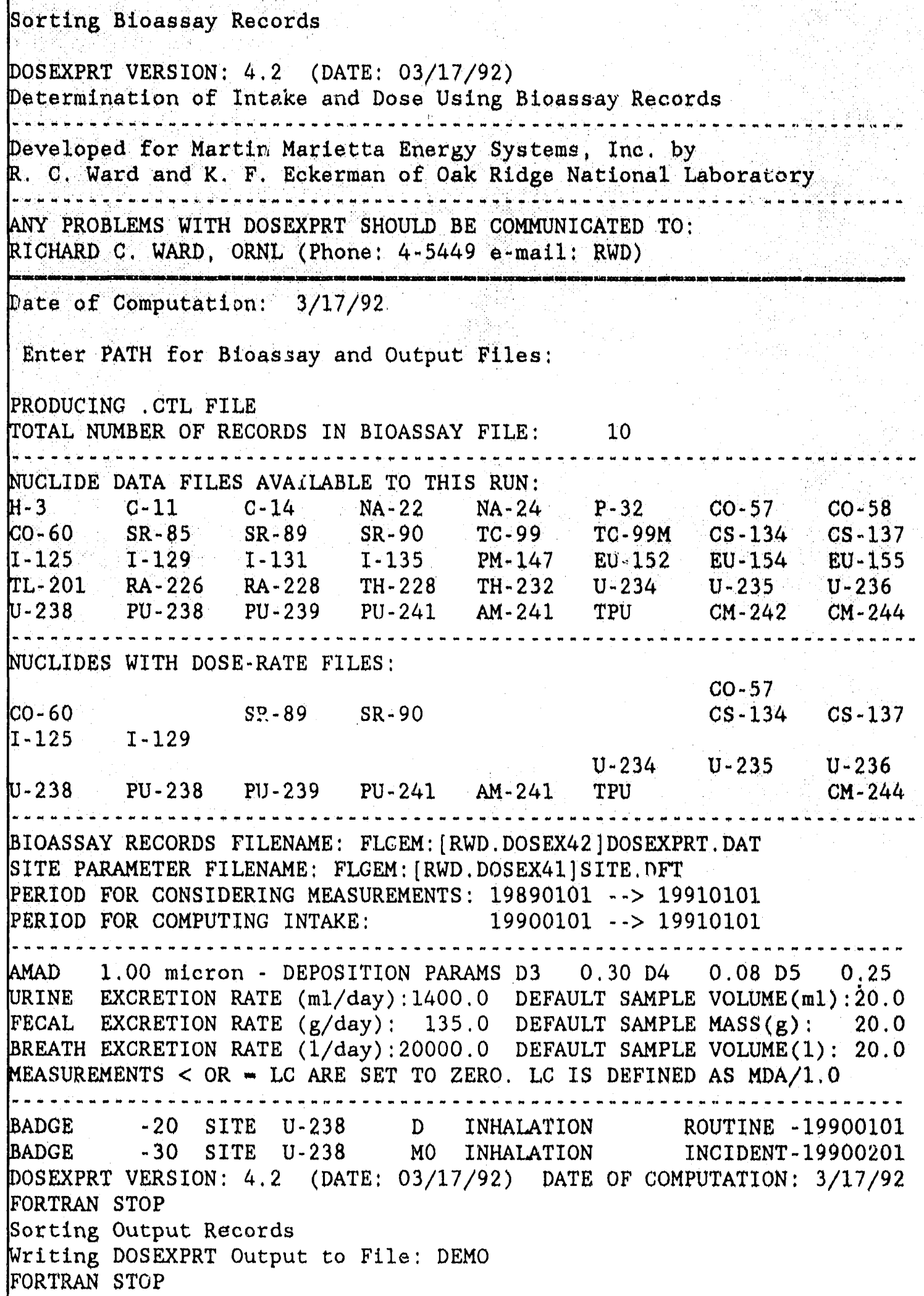


After DOSEXPRT completes execution, the user is returned to the DOSEXPRT menu. To list the sorted output (OUT) file to the screen, the user selects LIST from the DOSEXPRT menu. The results are listed in order of total ccimmitted effective dose equivalent (CEDE) for each badge. For individuals with no committed effective dose, those with cases of positive annual effective dose are listed first.

To print the output file on the mainframe printer, the user selects PRINT from the DOSEXPRT menu. To print the output file on a laserjet printer attached to the users PC terminal, the user selects HP-PRINT from the DOSEXPRT menu. The listing of the DOSEXPRT output (OUT) file for the previous example is shown on the following page. 


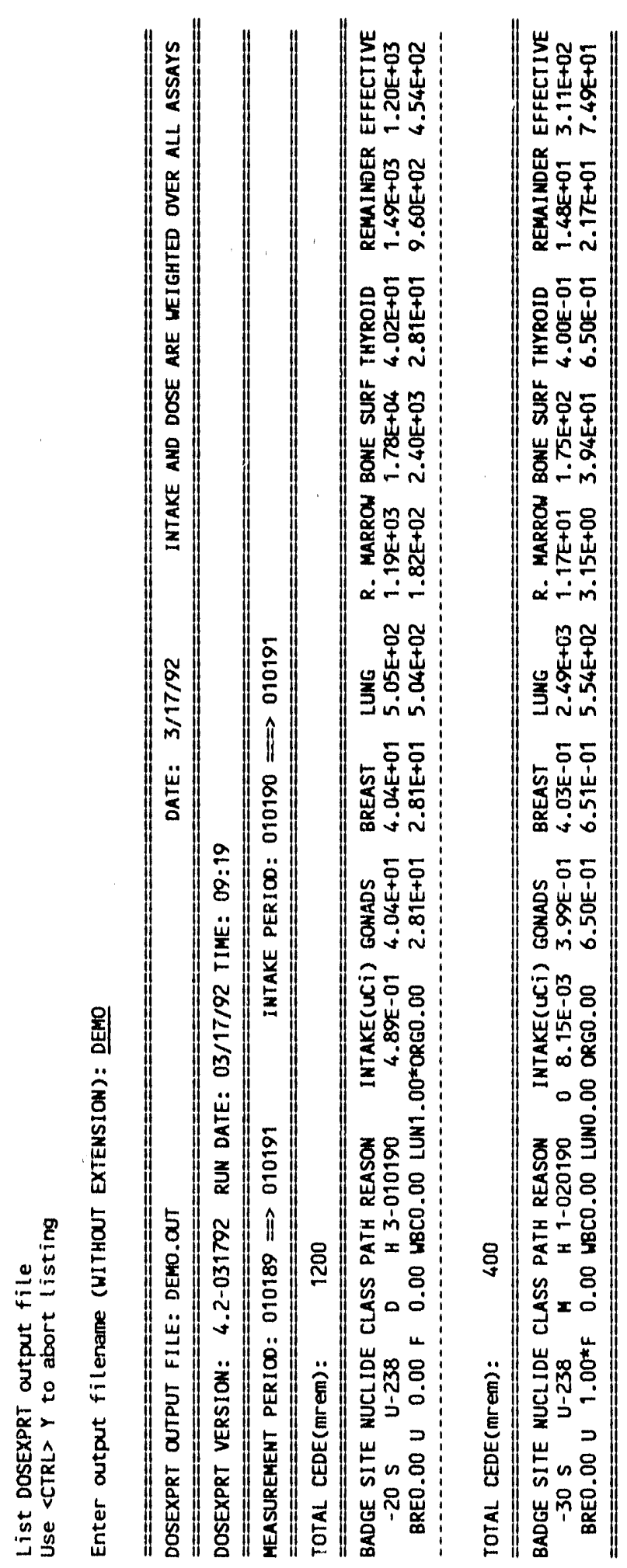


DOSEXPRT can be submitted to run as a VAX batch process after a specified time by selecting BATCH off the DOSEXPRT menu. In addition to the questions asked previously, the user will be asked for a time in the form HH:MM:SS after which the particular job should be run. If no time is entered, the job will be submitted to begin immediately. In addition to producing the output files discussed above, a batch run produces a LOG file that contains what would be directed to the screen when running interactively. The LOG file will have the same name as the S28 and OUT files.

\subsection{DOSEXPRT VERSION 4.2 MODIFICATIONS}

This section describes the specific modifications made to DOSEXPRT Ver. $4.1(5 / 13 / 91)$ to produce DOSEXPRT Ver. 4.2 (3/17/92). DOSEXPRT 4.2 was used to analyze the 1991 bioassay data. Seven modifications and four corrections were made to DOSEXPRT 4.1 to produce DOSEXPRT 4.2. The corrections to produce Ver. 4.2 are as follows:

1. Version 4.1 could associate an incorrect social security number with a badge if errors (no nuclide file, measurement window or record errors) were detected for a given case. This situation did not occur for cases that did not have errors associated with them. This problem has been corrected with DOSEXPRT 4.2.

2. The sorting of input bioassay records has been corrected with Ver. 4.2 of DOSEXPRT. With past versions the records were sorted by reason code as a single, twocharacter field. The present version sorts first by the second character of the reason code (a

blank, $\mathrm{R}$, or $\mathrm{S}$ ) and then by the first character $(1-9)$. This change separates all routine records from all incident records.

3. The incident time field in the S28 output records contained leading blanks causing errors when the S28 output file was loaded into the Segment 28 data base. The leading blanks have been replaced with zeros in Ver. 4.2 .

4. A field in the S28 output record contains the year when the annual effective dose is still above a specified threshold value. The threshold value is set to $1 \mathrm{mrem}$ in the default site file (see Sect. 7). The year was being incorrectly specified in previous versions of DOSEXPRT for certain cases. This has been corrected with Ver. 4.2 of DOSEXPRT. In addition, the year cannot be earlier than the year of computation of intake (i.e., the intake window).

The modifications made to DOSEXPRT to produce Ver. 4.2 are as follows:

1. DOSEXPRT 4.1 would give an error message (NO NUC ERROR) when no nuclide data file existed for the specified nuclide. DOSEXPRT 4.2 has been modified to check all results relative to the lower critical limit (LC). For the past three years, LC has been set equal to the minimum detectable activity (MDA) for the bioassay calculations. For a given case, if all results for all assays are below LC, then a result of zero intake is printed to the S28 file even if there is no nuclide data file for the specified nuclide. The LOG file will 
indicate that the nuclide data file was missing.

2. The name of the DOSEXPRT report program, which produces an output listing (with extension OUT), was changed from R.EPORT to DOSREPORT to avoid a potential name conflict in the directory where the program resides.

3. The DOSEXPRT 4.1 report program produces an output file (with extension OUT) from the S28 file which is sorted by committed effective dose in 100-mrem intervals. DOSEXPRT 4.2 has been modified to sort by presence of any positive annual effective dose iri addition to sum of committed effective dose. The presence of any positive annual effective dose for an individual is determined in DOSEXPRT by setting a flag (IASWCH) which is written to the S28 file. The flag, IASWCH, will be 0 if there are no cases with positive annual effective dose for an individual and 1 if there is any case with positive annual effective dose. The flag is in column 430 of the S28 output record. The DOSREPORT program sorts by this flag, in addition to the sum of committed effective dose for an individual. Thus, of those individuals with zero sum of committed effective dose, those with positive annual effective dose will proceed those with no annual effective dose in the OUT listing.

4. Modification 3 allows for introducing a switch that will let the user forgo printing of output for individuals who have no cases of positive committed or annual effective doses (i.e., indivicluals having only zero intake cases). Since these individuals appear at the end of the listing, the DOSREPORT program can be told not to print any information on them to the OUT file. Cases with error codes are, however, printed to the OUT file. The OUT file header will indicate that the listing has been truncated. The default for this switch, which is read as input when the user executes DOSEXPRT off the MENU, is to print all results to the OUT file including those where all cases result in zero intake. This feature will greatly reduce the amount of paper used in printing DOSEXPRT output.

5. DOSEXPRT 4.2 report program (DOSREPORT) will also print three index files (with extensions IX1, IX2 and IX3) that should facilitate reading the DOSEXPRT output. The first index file (extension IX1) lists all cases with positive committed dose. The second index file (with extension IX2) lists all cases with zero committed dose but positive annual dose. The third index file (with extension IX3) lists all cases where errors (no nuclide file, measurement window or record errors) occurred. The index files list social security number and badge, plant site, nuclide, class, pathway and reason code - the information that also appears on the header for each case in the OUT file. The index files can be used for quickly cross referencing the DOSEXPRT output files.

6. DOSEXPRT 4.2 has been set up to take advantage of special inhalation class $Q$ for the uranium nuclides. These files are used presently by the Y-12 Plant. The user is asked by DOSEXPRT whether to use the special Y-12 uranium nuclide data and dose-rate files. The default response is NO. A special data area HS_DATA:[DX.Y12] contains the Y-12 uranium nuclide data and dose-rate files. The regular nuclide data and dose-rate files are located in HS_DATA:[DX].

7. The year of computation of intake is written to the end of each 528 output record (columns $432-435$ ), increasing the S28 record length to 435 bytes. 


\section{OPERATION OF DOSEXPRT}

This section describes the operation of the DOSEXPRT program and its associated report program DOSREPORT. DOSEXPRT first produces a scratch file for controlling batch execution, which contains all unique combinations of badge number, plant, nuclide, pathway, class, reason code and incident date and time. Each unique combination is called a case. The number of records for each case is indicated in the middle of the control file (columns: 3842). In addition, the number of records for each case at each site is indicated at the extreme right of the control file. This information can be used for determining the average intake and dose received for an individual who has worked at two or more plant sites during the period.

Two typical control files are shown below (with badge numbers replaced by negative numbers to protect the identity of the individuals). The first set is for the incident exposure examples discussed in Appendix E; the second set is for the routine examples discussed in Appendix F.

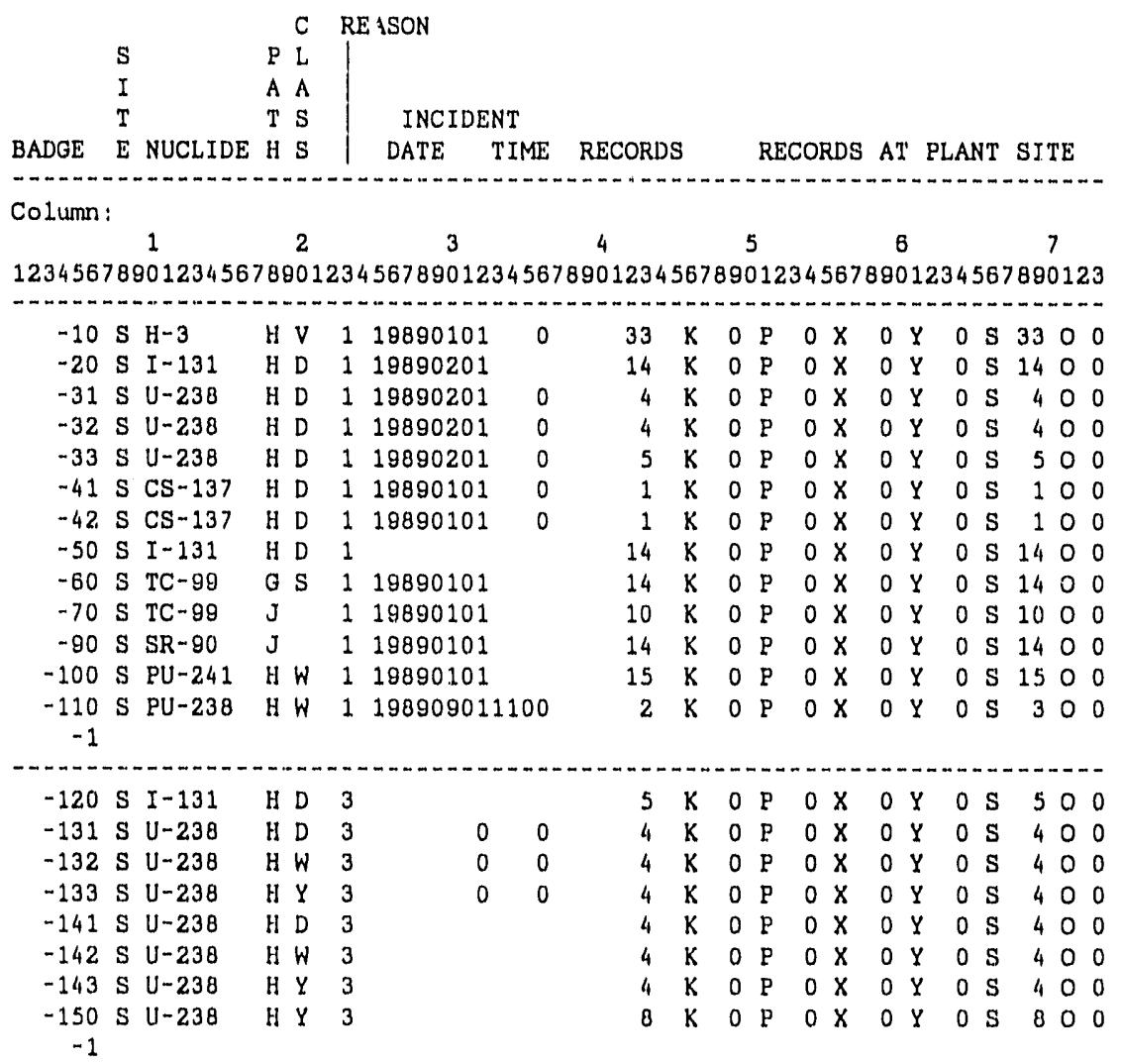

The reason code is used to define whether the computations will use acute or chronic analysis. Reason code 1S (special incident) uses acute analysis. Reason codes 3 or $1 \mathrm{R}$ (routine incident) use chronic (routine) analysis. Reason code $2 \mathrm{~S}$ is follow-up on an incident and uses acute analysis and reason code $2 \mathrm{R}$ is follow-up on routine and uses chronic (routine) analysis. Reason codes 4, 5, 6 are converted to 3 by the DOSEXPRT code and treated using chronic (routine) analysis. Reason codes 8 and 9 are used to bracket start and stop of 
exposure to a given nuclide and class. Code 8 means start of exposure to given nuclide and class, and Code 9 means end of exposure to given nuclide and class.

Internally in DOSEXPRT and in DOSEXPRT output listings, acute analysis is designated with a reason code of 1 and chronic analysis with a reason code of 3 .

The incident date and time field is used to uniquely sort the incident bioassay records. It is important that the user provide the incident date and time for incident records. Incident records which do not contain the incident date and time will be assigned an incident date of $\mathrm{N}$ days prior to the first measurement, where the number $\mathrm{N}$ is specified in the SITE.DFT file (see below). Incident records without an incident date and time may not be sorted properly. The incident date and time field is blank, or contains zeros, for routine records.

The program then reads site default information from the SITE.DFT file. The purpose of this file is to allow each plant to tailor the program to its needs. Character data must be surrounded by single cuotes. A typical SITE.DFT file is shown in Appendix C.

The SITE.DFT file contains the following information:

1. Number of plant sites.

2. List of plant letter codes and plant names.

3. A list of all nuclide data files available.

4. The number of nuclides (with nuclide data files) expected at the site.

5. A list of the nuclide files (in form specified) that are used at the site, direct-access pointer, flag indicating presence of dose-rate file.

6. Default value of activity median aerodynamic diameter (AMAD) (microns).

7. Default value for urinary excretion $(\mathrm{ml} / \mathrm{d})$.

8. Default value for the volume of urine per aliquot sample (ml).

9. Default value for fecal excretion $(\mathrm{g} / \mathrm{d})$.

10. Default value for the mass of fecal sample analyzed $(\mathrm{g})$.

11. Default value for breath excretion $(1 / d)$.

12. Default value for volume of breath sample (1).

13. Default value for the (integer) number of days between the occurrence of an incident and the first measurement. This value is used if the incident date is missing from the record.

14. Ratio of minimum detectable activity (MDA) to lower critical limit (LC).

15. Threshold value for intake. Parameter currently not used.

16. Threshold value for annual dose (mrem). The effective annual dose will be calculated until it falls below this threshold, and the year prior to falling below this threshold will be written to the S28 file.

17. Annual dose calculation control parameter. If parameter is -1 , no annual doses are computed. If parameter is 0 , only annual effective dose is computed. If parameter is 1 , both annual organ and effective doses are computed.

After reading the SITE.DFT file, DOSEXPRT reads records from the combined and sorted records file (DOSEXPRT.DAT) using the control file.

The program then proceeds through the control file, doing the computations for a given 
case (badge number, plant site, nuclide, nuclide class, pathway, and reason code) as listed. For this set of parameters, the program loops over all assays (breath, urine, fecal, whole body count, lung, and, if required, thyrold count) computing intake and committed dose for all records found for that assay. If additional assays are defined in the future, moatification of the code will be necessary to handle them.

For example, for BADGE number XXXXX with nuclides U-235 and U-238, classes D and $Y$ for U-235 and class $Y$ for U-238, routine and incident records for each, the program loops through the assays - breath (BRE), urine (U), fecal (F), whole body (WBC) and lung (LUN). If a special organ assay is present for a given nuclide [e.g., thyroid count (THY) for radioactive iodine], the program does this organ assay after the lung assay. Note that the routine records are sorted ahead of any incident records, and the incidents are sorted by incident date. The assay designation (WBL) is reassigned to whole body count (WBC) or lung count (LUN), depending on assimilation pathway and nuclide as specified in the nuclide data file.

\begin{tabular}{|c|c|c|c|c|c|c|c|c|c|}
\hline Badge: & $x \times x \times x$ & & $U-235$ & & D & Reason: & Routine & Assay: & BRE \\
\hline Badge: & $X X X X X$ & Nuoldde: & $U-235$ & Class: & D & Reason: & Routine & Assay: & U \\
\hline Badge: & $x \times x x x$ & Nuolide: & $U-235$ & Class: & D & Reason: & Routine & Assay: & $\mathbf{F}$ \\
\hline Badge: & $x x x x x$ & Nuolide: & $U-235$ & Class: & D & Reason: & Routine & Assay: & WBC \\
\hline Badge: & $x x \times x x$ & Nuolide: & $U-235$ & Class: & D & Reason: & RoutIne & Assay: & LUN \\
\hline Badge: & $x x x x x$ & Nuclide: & $U-235$ & Class: & D & Reason: & Inoldent -870608 & Assay 1 & BRE \\
\hline Badge: & $x \times x X x$ & Nuolidel & $U-235$ & Class: & D & Reason: & Inoident -870608 & Assay: & $u$ \\
\hline Badge: & $X X X X X$ & Nuoldde: & $U-235$ & Class: & D & Reason: & Inoldent- 870608 & Assay: & $\mathbf{F}$ \\
\hline Badge: & $x x x x x$ & Nuolide: & $U-235$ & Class: & D & Reason: & Inoident -870608 & Assay: & WBC \\
\hline Badge: & $x x x x x$ & Nuolide: & $U-235$ & Class: & D & Renson: & Inoldent -870608 & Assay: & LUN \\
\hline Badge: & $\mathrm{XXXXX}$ & Nuollde: & $U-235$ & Class: & D & Reason: & Inoident-870908 & Assay: & BRE \\
\hline Badge: & $x x x x x$ & Nuolide: & $U-235$ & Class: & D & Reason: & Inoldent -870908 & Assay: & $\mathrm{U}$ \\
\hline Badge: & $x \times x \times x x$ & Nuolidet & $U-235$ & Class: & D & Reason: & Inoldent -870908 & Assay: & $\mathbf{F}$ \\
\hline Badge: & $x \times x \times x x$ & Nuollde! & $U-235$ & Class: & D & Reason: & Incldent- 870908 & Assay: & WBC \\
\hline Badge: & $x \times x \times x$ & Nuolide: & $U-235$ & Class: & D & Reason: & Inoldent -870908 & Assay! & LUN \\
\hline Badge: & $x X X X X$ & Nuolddel & $U-235$ & Class: & $\mathbf{Y}$ & Reason: & Rout Ine & Assay! & BRE \\
\hline Badge: & $x \times x \times x$ & Nuolidel & $U-235$ & Class: & $y$ & Raason: & Routine & Assay: & U \\
\hline Badge: & $x x x x x$ & Nuolidel & $U-235$ & Class: & $\boldsymbol{Y}$ & Reason: & Rout Ine & Assay: & $\mathrm{F}$ \\
\hline Badge: & $x x x x x$ & Nuolidel & $U-235$ & Class: & $\mathbf{Y}$ & Reason: & Routine & Assay! & WBC \\
\hline Badgo: & 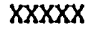 & Nuolide: & $U-23.5$ & Class: & $Y$ & Reason: & Routine & Assay: & LUN \\
\hline Badge: & $x x x x x$ & Nuollde: & $U-235$ & Class: & $Y$ & Rasason: & Inoldent -870304 & Assay: & BRE \\
\hline Badge: & $x \times x \times x$ & Nuollde: & $U-235$ & Class: & $\mathbf{Y}$ & Reason: & Inoldent -870304 & Assay: & $U$ \\
\hline Badge: & $x \times x X X$ & Nuolide: & $U-235$ & Class: & $Y$ & Reason: & Inoddent -870304 & Assay: & F' \\
\hline Badge: & $x \times x \times x$ & Nuolide: & $U-235$ & Class: & $Y$ & Reason: & Inoldent -870304 & Assay: & WBC \\
\hline Badge: & $x x x x x$ & Nuolide: & $U-235$ & Class: & $\mathbf{Y}$ & Reason! & Inc1dent-870304 & Assay: & LUN \\
\hline Badge: & $x \times x \times x$ & Nuolide: & $U-238$ & Class: & D & Reason: & Routine & Assay: & BRE \\
\hline Badge: & $X X X X X$ & Nuclida: & $U-238$ & Class: & D & Reason: & Routino & Assay: & $u$ \\
\hline Badge: & $x \times x x x$ & Nualide: & $U-238$ & Class: & D & Reason: & Routino & Assay: & $\mathbf{F}$ \\
\hline Badge: & $x \times x \times x x$ & Nuolide: & $U-238$ & Class: & D & Reason: & Routine & Ass ay: & WBC \\
\hline & $x \times x x x$ & Nuolide: & $U-238$ & Class: & D & Reason: & Routine & Assay: & LUN \\
\hline Badge: & $x x \times x x$ & Nuolide: & $U-238$ & Class: & D & Reason: & Inoident-870203 & Assay: & BRE \\
\hline Badge 1 & $x x x x x$ & Nuolide: & $U-238$ & Clasa: & D & Reason: & Inoident-870203 & Assay: & $\mathrm{u}$ \\
\hline Badge: & $x \times x x x$ & Nuclide: & $U-238$ & Class: & D & Reason: & Inoldent- $-8 \% 0203$ & Assay: & F \\
\hline & $x x x x x$ & Nuolide: & $U-238$ & Class: & D & Reason: & Inoldent -870203 & Ass ay: & WBC \\
\hline Badge: & $x \times x x x$ & Nuollde: & $U-238$ & Class & D & Reason: & Inoldent-870203 & Assay: & LUN \\
\hline
\end{tabular}

After the intake and committed doses have been computed for all records for all assays, the weighted intake and dose are computed using the assay weights in the nuclide file. 
The total assay weights are computed as the normalized product of the nuclide weight for each assay (specified in the nuclide file) and a numerical weight, defined as the ratio of the number of records for the assay divided by the total number of records for all assays.

For example, for iodine-bioassay with 12 urinalyses and 2 thyroic counts, the nuclide file weights are 0.3 for urine and 0.59 for thyroid, and the numerical weights are $12 / 14=0.857$ for urine and $2 / 14=0.0143$ for thyroid. If the intake is zero for one of the assays (e.g., urinalysis) the numerical weight does not incorporate the number of samples or counts for that assay. The product of the nuclide file weight and numerical weight for each assay, before normalization, is 0.257 for urine and 0.0843 for thyroid. To obtain the total assay weights, the numbers are then normalized so that their sum is 1 . The total weight for urine, $W_{u}$, is 0.753 , and the total weight for thyroid, $W_{\text {thy }}$, is 0.247 . The estimated intake is then computed from the intake obtained from urinalysis, $I_{u}$, and from thyroid count, $I_{t h y}$, as

$$
\text { Intake }=W_{u}^{*} I_{u}+W_{\text {thy }} * I_{\text {thy }}
$$

The same procedure applies for the committed doses. If results from only one assay are used (e.g., urinalysis), the total weight for that would be $\mathrm{W}_{u}=1$. Note that assays that give zero intake are not included in the weighted results.

After computing weighted intake and conımitted doses, the program will compute annual dose. For an acute exposure, weighted annual dose is computed using the weighted intake. For a chronic exposure, weighted annual dose is computed using, for each measurement period, the weighted intake rate for the assay with the greatest number of measurements in that year. The weighting for the intake rates is determined from the ratio of the weighted total intake for the entire measurement window divided by the total intake for the assay with the greatest number of measurements. The annual dose for 1990 is calculated when there are measurements above LC for 1989 even though there may be no measurements in 1990 or all measurements in 1990 are below LC. In this case the OUT file will show'

\section{ESTIMATED INTAKE FOR PERIOD 01011990 --> 01011991 IS ZERO}

followed by the annual organ and effective doses computed from the 1989 measurements.

The program proceeds to the next case until the entire control file is finished.

The LOG file will contain a list of badge numbers and warnings when errors occur. The S28 file will contain the assay-weighted results of the run to be entered back into the OHIS data base. The OUT file contains assay-weighted results sorted by total committed effective dose to individuals in 100 -mrem intervals. 


\section{ASSUMPTIONS MADE IN DOSEXPRT}

The following assumptions are made in DOSEXPRT:

1. Presently, the OHIS bioassay data do not include the value of the activity median aerodynamic diameter (AMAD). The value of AMAD must therefore be set in the SITE.DFT file. The default value of AMAD is assumed to be 1 micron. AMAD can be controlled by the user only when the DOSEXPRT is run in debug/test mode (see Appendix N). However, annual dose can only be computed for an AMAD of 1 micron as the regular nuclide dose-rate files have been derived with that assumption. The default value of AMAD in the Y-12 SITE.DFT file is 8 microns. The Y-12 uranium nuclide dose-rate files have been derived assuming an AMAD of 8 microns. Future modifications will remove the restriction on $A M A D$ when using the dose-rate files.

2. For routine computations the measurement window (between dates ISTART and IEND) is used to bracket selection of measurements to be evaluated in routine assay with ISTART used as the initial date for starting the routine analysis.

3. For routine computations, the analysis is carried out step-wise over the subsequent records encountered between the ISTART and IEND dates, inclusively. Beginning with DOSEXPRT Ver. 4.1, the intake rate derived from the last measurement is used to extrapolate from that date to the end date (IEND) or to an exposure history end code.

4. The protocol for analyzing routine records assumes that the person has been exposed to a constant amount of nuclide from the past measurement (or the ISTART date if the first measurement $\mathrm{cr}$ an exposure history start code) up to the present measurement given by the measured result at the present measurement. For the present operation of DOSEXPRT, the individual is assumed not to have been exposed prior to the ISTART date. Exposure history start and end codes can be used to control the periods of time that the individual was known to be exposed to the nuclide/class.

5. The intake window (between the dates KSTART and KEND) is used to bracket computation of intake for routine assay. The duration of the intake window must be 1 year when computing annual dose. Incident assays will be computed only if the incident date is withi- the intake window. If no incident date is specified, the default incident date is NDAYS prior to the first measurement date where NDAYS is specified in the SITE.DFT file. The default incident date must fall in the intake window for the computation of intake and dose to proceed.

6. For routine or incident computations results are set to zero if they are equal to or less than the lower critical limit (LC) of detection. ${ }^{8}$ For treating the 1989, 1990, and 1991 bioassay records, $\mathrm{LC}$ is set equal to the minimum detectable activity (MDA). Beginning with DOSEXPRT Ver. 4.1, the ratio of MDA to LC (parameter RMDALC) is specified in the SITE.DFT file. 
7. Beginning with Ver, 4.1, DOSEXPRT loops over five assays if no special organ is specified in the nuclide file: breath (BRE), urine (U), fecal (F), whole body count (WBC), and lung count (LUN). If a special organ is specified (e.g., thyroid for radioactive iodine), DOSEXPRT loops over six assays, the sixth one being the special organ assay (THY).

8. If start and stop exposure codes are used for routine analysis, the incident date and time fields in the routine measurement records and the start and stop exposure records must be consistent, either zeros or blanks, for proper sorting of the bioassay records. 


\section{CREATING BIOASSAY RECORDS USING THE GENREC UTILITY}

Bioassay records files compatible with DOSEXPRT can be created using the GENREC utility on the DOSEXPRT menu. The user simply enters data into the fields as requested by the GENREC utility. GENREC is structured with two data entry forms, the first contains badge number, social security number, plant site, assimilation pathway, assay, reason code, nuclide and nuclide class. After all the entries are made to the first form, the user has a chance to modify the entries. The second form contains the information specific to a single bioassay measurement for the information in the first form [i.e., sample date, time, volume (for in vitro assay), result, MDA, and units for result and MDA]. After all the entries are made to the second form, the user has a chance to modify the entries. Additional entries in the second form are entered by typing 0 when completing each previous entry. To return to the first form, type 1 after entering information in the second form. When finished with all data type -1 to quit.

The records file can be given a unique name or defaulted to the name RECORDS.DAT.

The volume, result and MDA can be entered as integer, real number, or real number with exponential notation. The volume of the urine sample has units of $\mathrm{ml}$. The mass of the fecal sample has units of grams. The volume of the breath sample has units of liters.

To enter mixed inhalation class, enter letter code $M$ and a mixed-class identifier (0-9). The mixed-class identifier uniquely describes the set of mixed-class percentages to be used. It is required to properly sort records with mixed inhalation class. After the mixed-class identifier, enter the percentages (0-99) of D, W, and Y classes; entering zero for inhalation classes which are not allowed for the specified nuclide.

The GENREC utility now allows creation of exposure history records. To enter an exposure history record, proceed as usual, entering the badge number, social security number, and plant site. For assay, enter $\mathrm{ZZZ}$ to indicate exposure history record. Then enter assimulation pathway followed by a reason code of 8 to indicate start of exposure or 9 to indicate end of exposure. Following this, enter the date and time of the start or end of exposure. Finally, enter the nuclide and nuclide class. The program does not drop into the second form. At this point the user can select to add another bioassay record, another exposure history code, or to terminate the session.

Table 2, on the following page, contains the codes used in the bioassay records. 
Table 2. DOSEXPRT Bloassay Records Codes

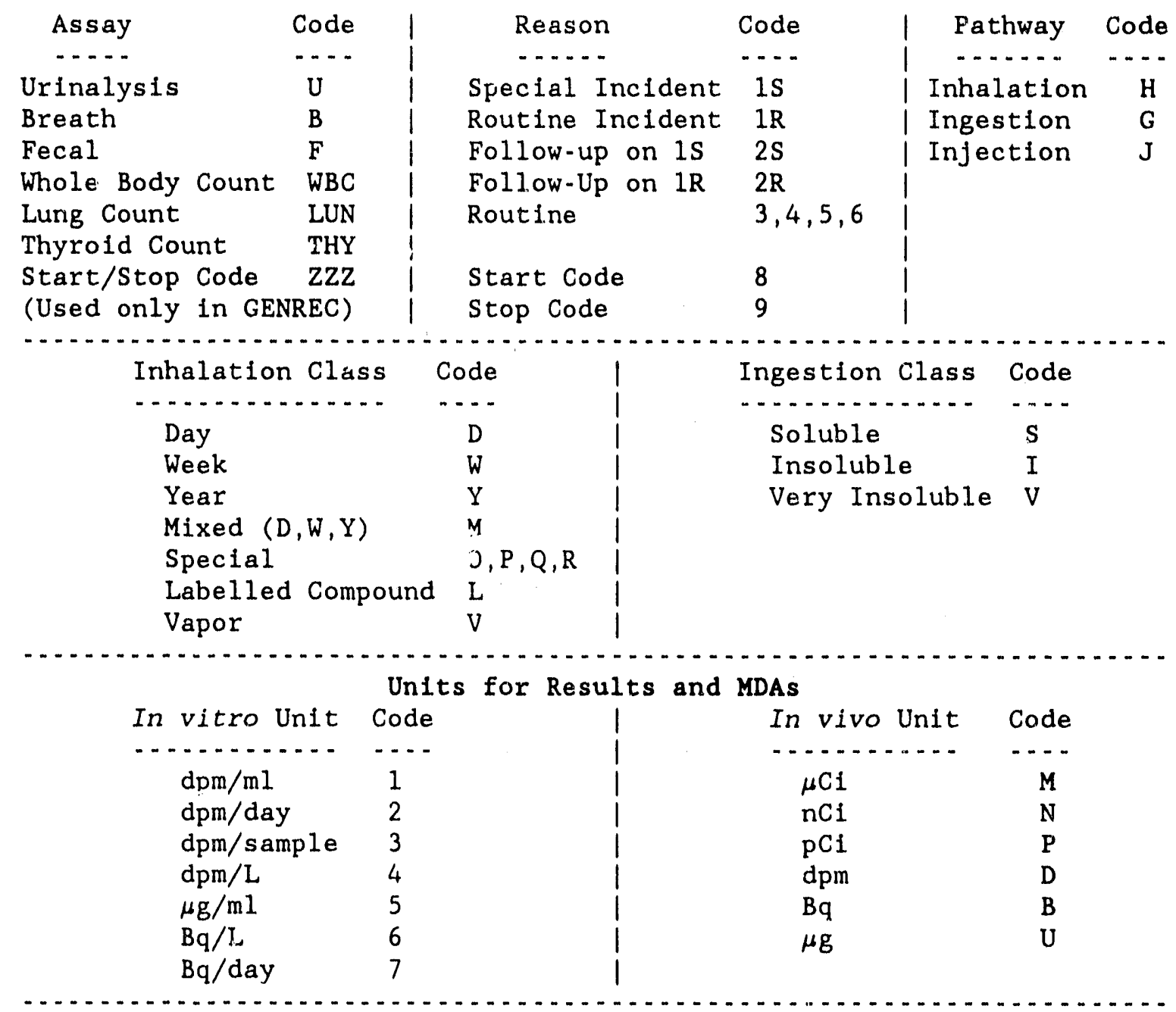

An example session of GENREC is shown below. First, an in vitro measurement for incident exposure is entered. This entry is followed by start and end exposure history records for routine exposure and an in vivo measurement for routine exposure. 


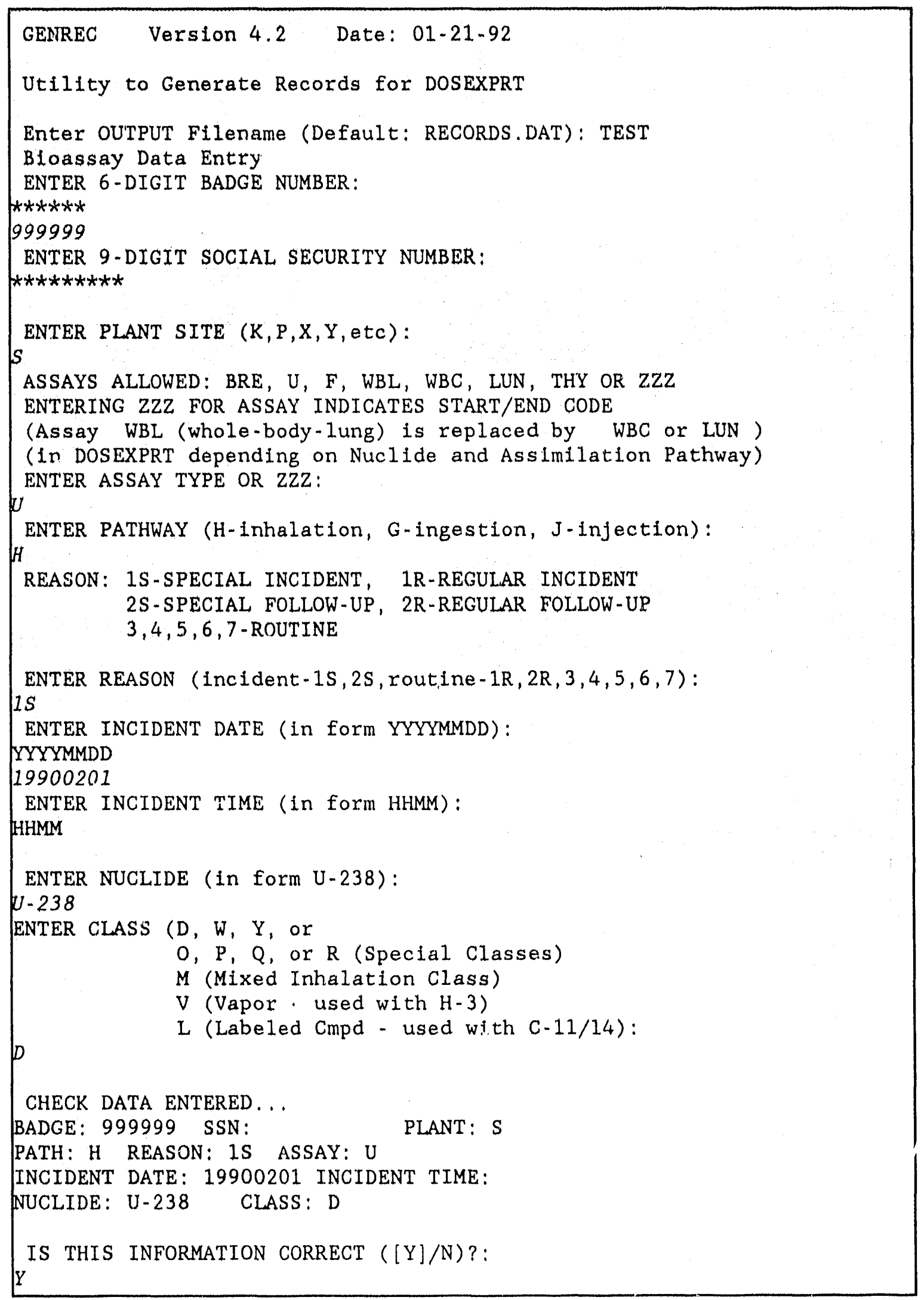




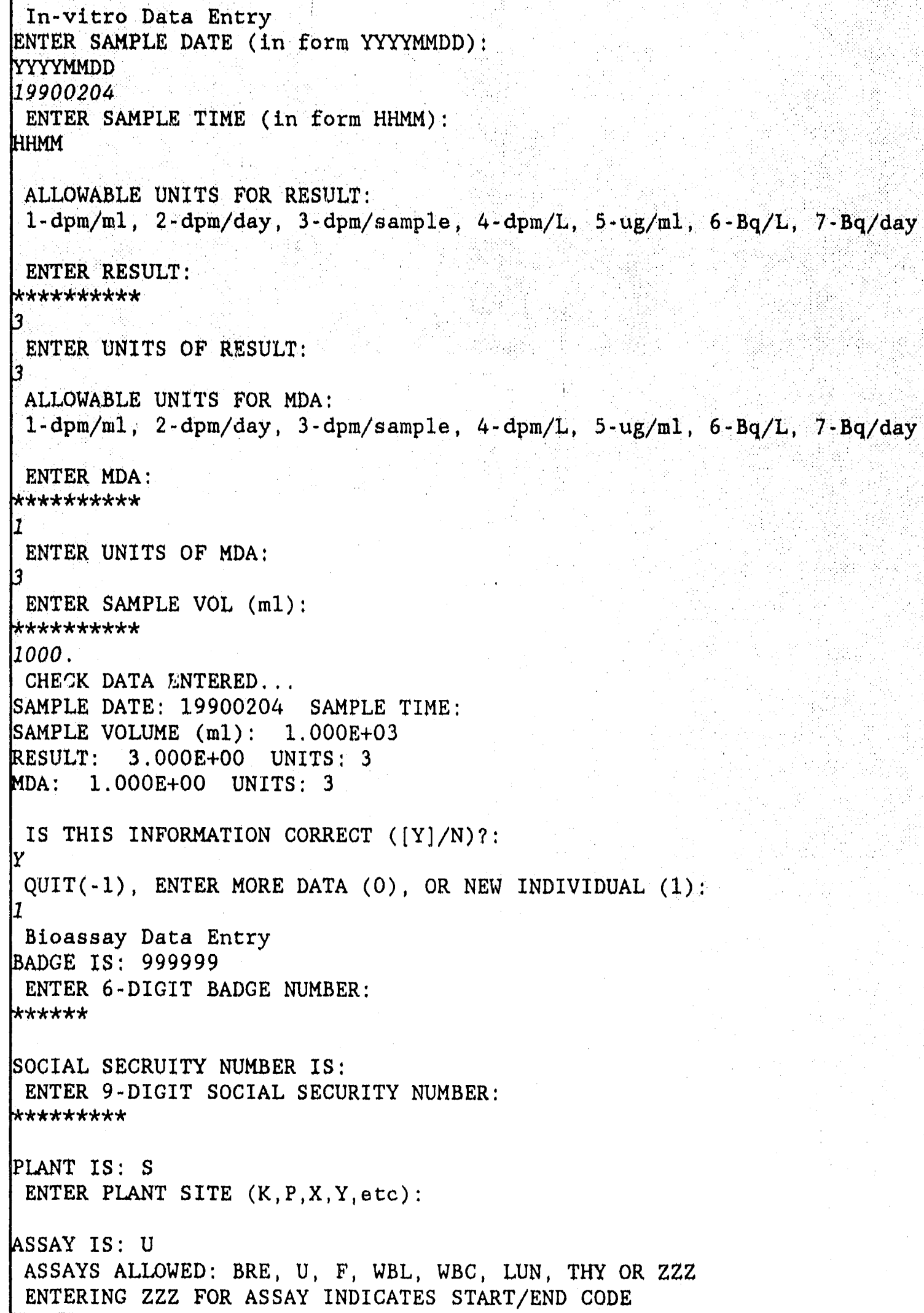




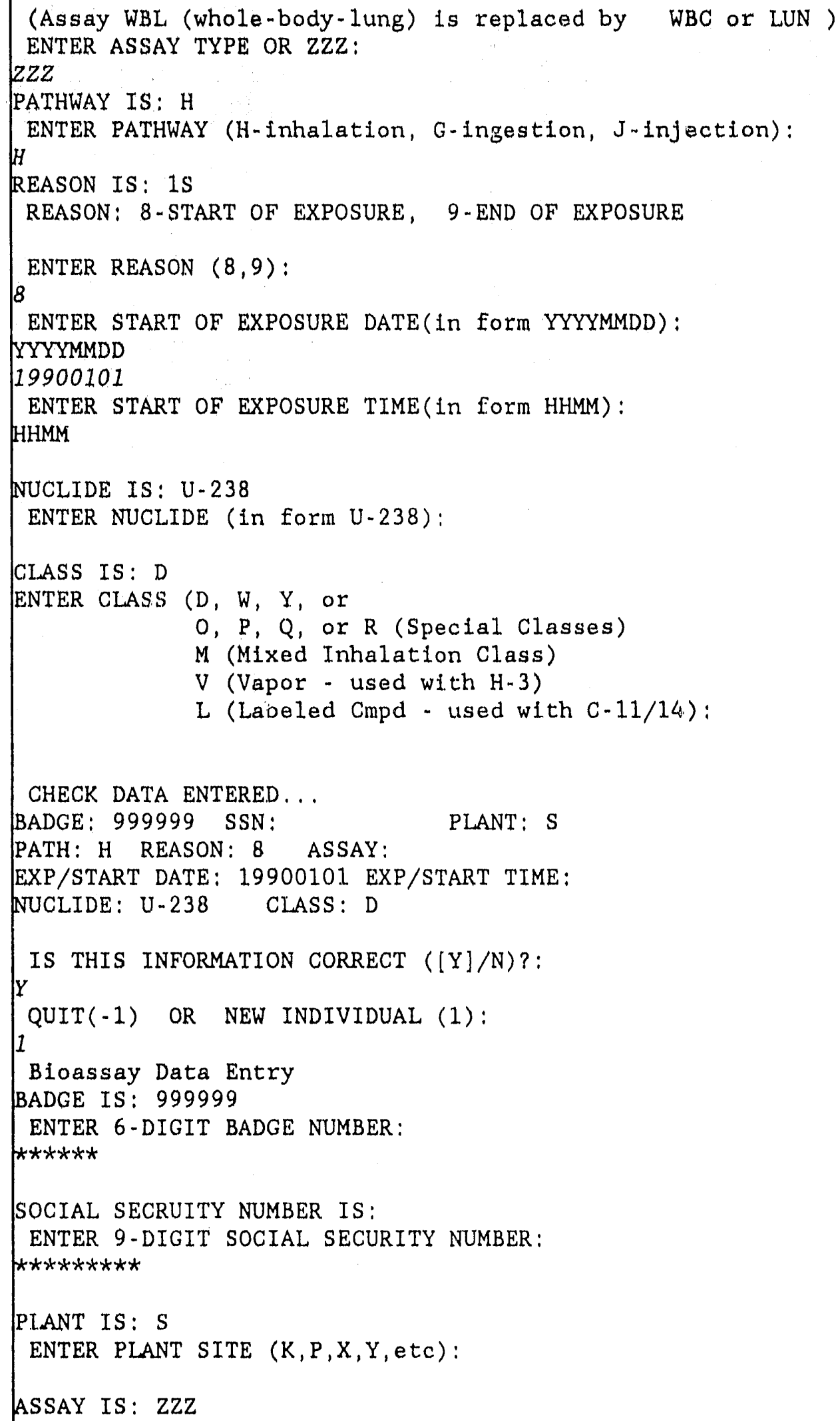


ASSAYS ALLOWED: BRE, U, F, WBL, WBC, LUN, THY OR ZZZ (Assay WBL (whole-body-lung) is replaced by WBC or LUN ) (In DOSEXPRT depending on Nuclide and Assimilation Pathway) ENTER ASSAY TYPE OR ZZZ:

PATHWAY IS: H

ENTER PATHWAY (H-inhalation, G-ingestion, J-injection):

REASON IS: 8

REASON: 8-START OF EXPOSURE, 9-IEND OF EXPOSURE

ENTER REASON $(8,9)$ :

9

ENTER END OF EXPOSURE DATE (In form YYYYMMDD):

YYYYMMDD

19900701

ENTER END OF EXPOSURE TIME(in form HHMM):

HHWM

NUCLIDE IS: U-238

ENTER NUCLIDE (in form U-238):

CLASS IS : D

ENTER CLASS (D, $W, Y$, or

$O, P, Q$, or $R$ ('special Classes)

$M$ (Mixed Inhalation Class)

$\mathrm{V}$ (Vapor - used with $\mathrm{H}-3$ )

L (Labeled Cmpd - used with C-11/14):

CHECK DATA ENTERED...

BADGE : 999999 SSN: $\quad$ PLANT: $S$

PATH: H REASON: 9 ASSAY:

EXP/END DATE: 19900701 EXP/END TIME:

NUCLIDE: U-238 CLASS: D

IS THIS INFORMATION CORRECT $([\mathrm{Y}] / \mathrm{N})$ ?:

QUIT(-1) OR NEW INDIVIDUAL (1):

1

Bloassay Data Entry

BADGE IS: 999999

ENTER 6-DIGIT BADGE NUMBER:

$\star * * * * * *$

SOCIAL SECRUITY NUMBER IS:

ENTER 9-DIGIT SOCIAL SECURITY NUMBER:

$* \star * \star * \star * * * *$

PLANT IS : $S$

ENTER PLANT SITE (K, $P, X, Y$, etC): 
ASSAYS ALLOWED: BRE, U, F, WBL, WBC, LUN, THY OR ZZZ

ENTERING ZZZ FOR ASSAY INDICATES START/END CODE

(Assay WBL (whole-body-lung) is replaced by WBC or LUN )

(in DOSEXPRT depending on Nuclide and Assimilation Pathway)

ENTER ASSAY TYPE OR ZZZ:

WBC

PATHWAY IS: $\mathrm{H}$

ENTER PATHWAY (H-inhalation, G-ingestion, J-injection): $H$

REASON IS : 9

REASON: 1S-SPECIAL INCIDENT, 1R-REGULAR INCIDENT

2S-SPECIAL FOLLOW-UP, 2R-REGULAR FOLLOW-UP

$3,4,5,6,7$-ROUTINE

ENTER REASON (incident-1S, 2 , routine-1R, 2R, 3, 4, 5, 6, 7):

3

NUCLIDE IS: U-238

ENTER NUCLIDE (in form U-238):

CLASS IS : D

ENTER CLLASS ( $D, W, Y$, or

$O, P, Q$, or $R$ (Special Classes)

$M$ (Mixed Inhalation Class)

$\mathrm{V}$ (Vapor - used with $\mathrm{H} \cdot 3$ )

L (Labeled Cmpd - used with C-11/14):

CHECK DATA ENTERED...

BADGE: 999999 SSN:

PLAN'T: $S$

PATH: H REASON: 3 ASSAY: WBC

NUCLIDE: U-238 CLASS: D

IS THIS INFORMATION CORRECT $([\mathrm{Y}] / \mathrm{N})$ ? :

Y

In-vivo Data Entry

ENTER SAMPLE DATE (in form YYYYMMDD):

YYYYMMDD

19900403

ENTER SAMPLE TIME (in form HHMM):

HHMM

ALLOWABLE UNITS FOR RESUL'T:

M-uCi, N-nCi, P-pCi, D-dpm, B-Bq, U-ug

ENTER RESULT:

Hit**********

3

ENTER UNITS OF RESULT:

$M$

ALLOWABLE UNITS FOR MDA: 
M-uCi, N-nC1, P-pCi, D-dpm, B-Bq, U-ug

ENTER MDA:

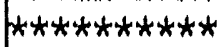

1

ENTER UNITS OF MDA:

$M$

CHECK DATA ENTERED...

SAMPLE DATE: 19900403 SAMPLE TIME:

RESULT: $3.000 E+00$ UNITS: $M$

MDA: $1.000 E+00$ UNITS: $M$

IS THIS INFORMATION CORRECT $([Y] / N)$ ?:

QUIT(-1), ENTER MORE DATA (0), OR NEW INDIVIDUAL (1):

$-1$ 


\section{MODIFYING SITE DEFAULT FILE USING THE MODSITE U'TILITY}

Default values for paramelers of the DOSEXPRT program, such as volume of urine sample, urinary excretion rate, etc., are specilled in the site default tîle (SITE.DFT). The purpose of this tile is to allow each plant to tailor the program to its needs. Character data in the SITE.DFT file must be surrounded by single quotes. The original SITE.DFT file in HS_DATA:[DX] data arca is shown in Appendix C.

The SITE.DFT also contains a list of the nuclide data files available to DOSEXPRT, Note that the name must be in quotes. Next to each nuclide name is a pointer to the location of the nuclide data file in the binary, direct aceess file NUCLIDE.BIN. If this value is set to 0 , the program will use the ASCII nuclide data file with the nuclide name and extension NUC. Note, however, that DOSEXPRT assumes that the file NUCLIDE.BIN is in the data area. Finally, the direct aceess pointer is followed by a llag that indicates whether the dose-rate (DRS) file exists (1) or does not exist (0) for that nuclide.

The SITE.DFT file contains the following information:

1. Number of plant sites.

2. List of plant letter codes and plant names.

3. A list of all nuclide data liles available.

4. The number of nuclides (with nuclide data files) expected at the site.

5. A list of the nuclide files (in form specified) that are used at the site, direct-access pointer, llag indicating presence of dose-rate file.

6. Default value of AMAD (microns).

7. Default value for urinary excretion $(\mathrm{ml} / \mathrm{d})$.

8. Default value for the volume of urine per aliquot sample $(\mathrm{ml})$.

9. Default value for fecal excretion $(\mathrm{g} / \mathrm{d})$.

10. Default value for the mass of 'ecal sample analyzed (g).

11. Default value for breath excretion $(1 / \mathrm{d})$.

12. Default value for volume of breath sample (I).

13. Default value for the (integer) number of days between the occurrence of an incident and the first measurement. This value is used if the incident date is missing from the record.

14. Ratio of MDA to LC.

15. Threshold value for intake. Parameter currently not used.

16. Threshold value for annual dose (mrem). The effective annual dose will be calculated until it falls below this threshold, and the year prior to falling below this threshold will be written to the S28 file.

17. Annual dose calculation control parameter. If parameter is -1 , no annual doses are computed. If parameter is 0 , only annual effective dose is computed. If parameter is 1 , both annual organ and effective doses are computed.

To create a modified SITE.DFT fille, the user must copy the file from HS_DATA:[DX] to the user's root directory. This copy of the site default file can be modified using an editor if one is available or by using the MODSITE utility by selecting MODSITE from the DOSEXPRT menu. A SITE.DFT life must exist in the user's root directory before the 
MODSITE utility is run. The user enters the name of the existing site file including the DFT extension (SITE.DFT) and the name of the new site file including the DFT extension (NEWSITE.DFT). MODSITE proceeds through the list of parameters, inquiring if the user wishes to make any changes.

An example run of MODSITE is shown below. When nuclides are added, as shown in the example, the user must enter the nuclide name, either a pointer to its position in the binary nuclide data file (NUCLIDE.BIN) or zero if using the ASCII nuclide file (with extention NUC), and a flag indicating the presence (1) or absence (0) of a dose-rate file.

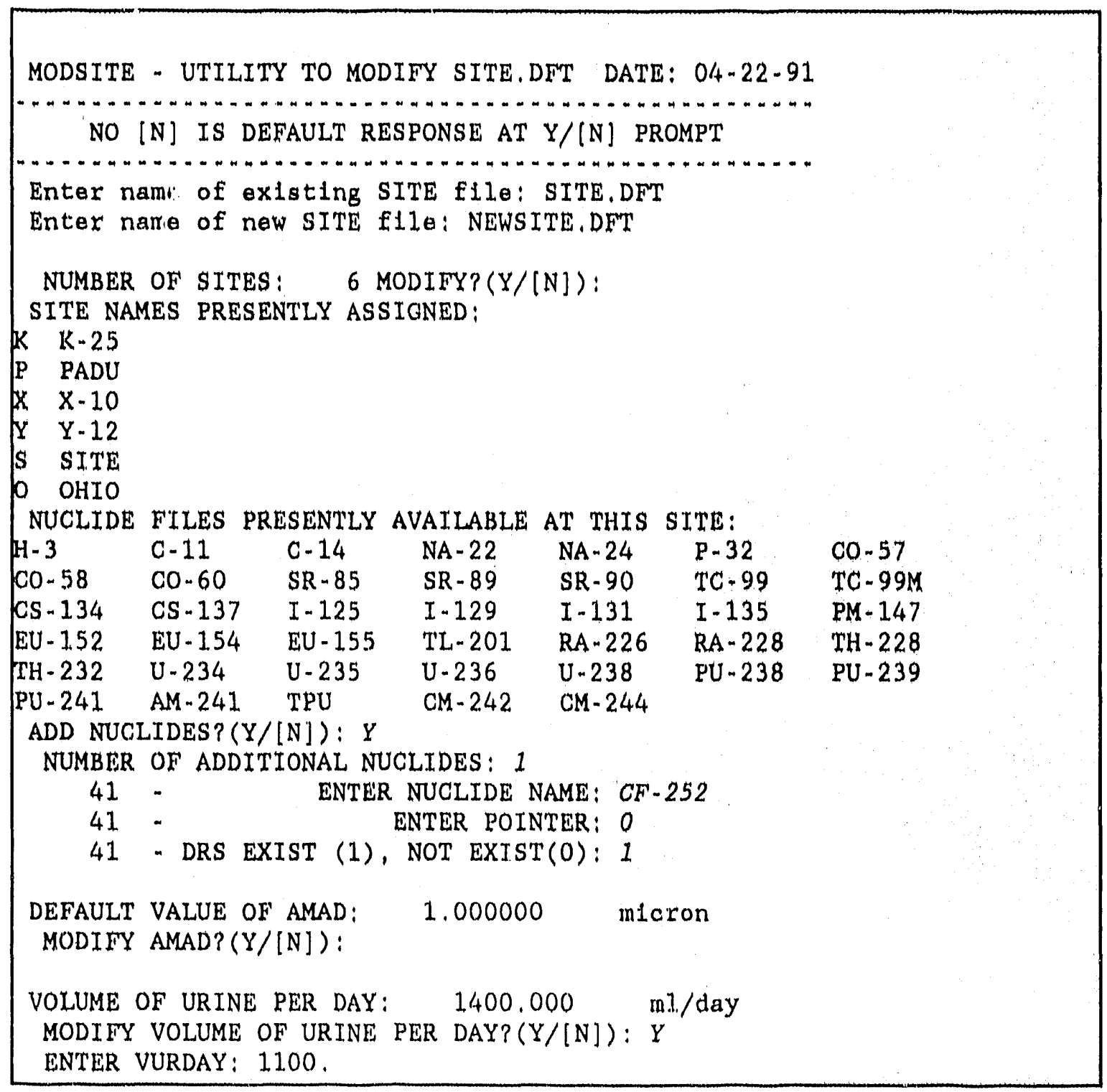




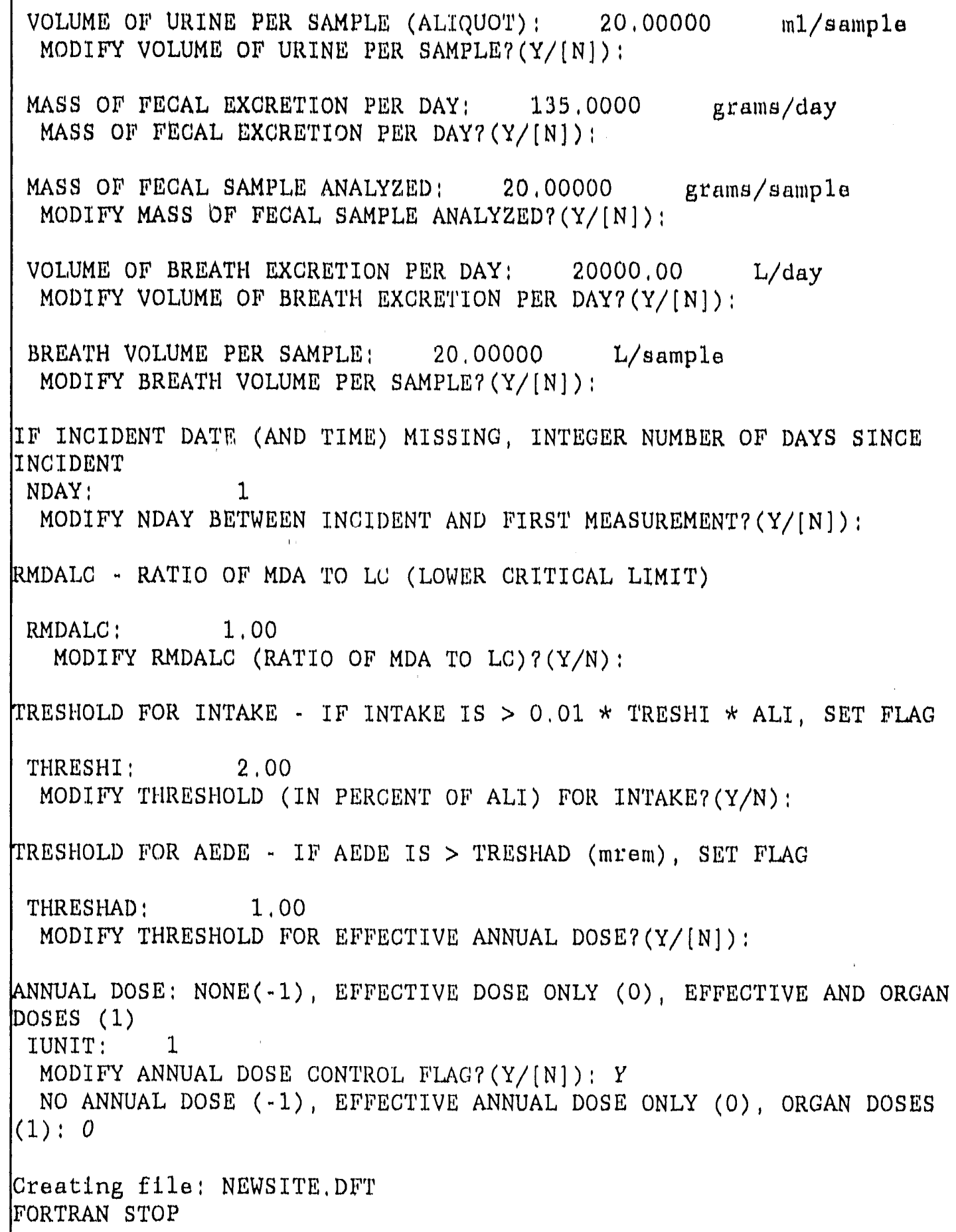


The modified site file is listed below.

NUMBER OF SITES

6

ASSIGN PLANT LETTER CODE TO PLANT NAME FOR SITES

' $\mathrm{K}$ ' ' $\mathrm{K}-25^{\prime}$

' $\mathrm{P}$ ' 'PADU'

' $\mathrm{X}$ ' $\mathrm{X}-1 \mathrm{O}^{\prime}$

'Y' $Y-12$ '

'S 'SITE'

'O' 'OHIO'

NUCLIDES AVAILABLE:

H-3 C-11/14 NA-22/24 P-32 CO-57/58/60 SR-85/89/90 TC-99/99M CS $-134 / 137$ I-125/129/131/135 PM-147 TL-201 EU-152/154/155 RA-226/228

TH-228/232 U-234/235/236/238/ PU-238/239/241 AM-241 TPU CM-242/244

NUMBER OF NUCLIDES AT SITE 41

NUCLIDES (IN QUOTES) - DIRECT-ACCESS POINTER (OR 0) - DRS FILE EXISTS ( 1 )

'H-3'

'C-11'

' C-14'

'NA-22'

'NA- 24'

'P-32'

' $\mathrm{CO}-57^{\prime}$

' CO- 58 '

'CO-60'

'SR-85'

'SR-89'

' SR-90'

'TC-99'

' TC-99M'

'CS-134'

' CS - 137'

'I - 125'

' I-129'

'I - 131'

'I - $135^{\prime}$

'PM-147'

' EU-152'

' EU-154'

' EU-155'

'TL-201'

'RA-226'

'RA-228'

' TH-228'

' $\mathrm{TH}-232^{\prime}$

'U-234'

'U-235'

$\begin{array}{rl}1 & 0 \\ 94 & 0 \\ 187 & 0 \\ 280 & 0 \\ 381 & 0 \\ 482 & 0 \\ 616 & 1 \\ 779 & 0 \\ 942 & 1 \\ 1105 & 0 \\ 1261 & 1 \\ 1417 & 1 \\ 1573 & 0 \\ 1707 & 0 \\ 1841 & 1 \\ 1942 & 1 \\ 2043 & 1 \\ 2153 & 1 \\ 2263 & 0 \\ 2373 & 0 \\ 2483 & 0 \\ 2616 & 0 \\ 2724 & 0 \\ 2832 & 0 \\ 2940 & 0 \\ 3041 & 0 \\ 3165 & 0 \\ 3279 & 0 \\ 3412 & 0 \\ 3545 & 1 \\ 3729 & 1 \\ & \end{array}$




$\begin{array}{lrr}\text { 'U-236' } & 3913 & 1 \\ \text { 'U-238' } & 4097 & 1 \\ \text { 'PU-238' } & 4281 & 1 \\ \text { 'PU-239' } & 4467 & 1 \\ \text { 'PU-241' } & 4653 & 1 \\ \text { 'AM-241' } & 4839 & 1 \\ \text { 'TPU' } & 4975 & 1 \\ \text { ' CM-242' } & 5111 & 0 \\ \text { 'CM-244' } & 5247 & 1 \\ \text { 'CF-252' } & 0 & 1 \\ \text { DEFAULT VALUE FOR AMAD } & \\ & \\ \text { 1.OO } & & \end{array}$

URINE EXCRETION (ml/day) 1100.00

VOLUME OF URINE ANALYZED (VOLUME OF ALIQUOT) (m1/sample) 20.00

FECAL EXCRETION (grams/day) 135.00

MASS OF FECAL SAMPLE ANALYZED (grams/sample) 20.00

BREATH EXCRETION (L/day) 20000.00

VOLUME OF BREATH SAMPLE ANALYZED (L/sample) 20.00

IF INCIDENT DATE (AND TIME) MISSING, INTEGER NUMBER OF DAYS SINCE INCIDENT 1

RMDALC - RATIO OF MDA TO LC (LOWER CRITICAL LIMIT) 1.00

TRESHOLD FOR INTAKE - IF INTAKE IS >0.01* TRESHI * ALI, SET FLAG 2,00

TRESHOLD FOR AEDE - IF AEDE IS > TRESHAD (mrem), SET FLAG 1.00

ANNUAL DOSE: NONE(-1), EFFECTIVE DOSE ONLY (0), EFFECTIVE/ORGAN DOSES (1) 0 


\section{DOSEXPRT NUCLIDE DATA FILES AND DOSE-RATE FILES}

Each radionuclide has a separate nuclide data file that contains information for computing the intake and dose, weighting factors with which to weight intake and dose for the different assays, and control information to determine the progress of the computations. Version 4.2. of DOSEXPRT has 40 nuclide data files. The nuclide data files are listed in Appendix $\mathrm{H}$.

The number of inhalation classes and ingestion classes is specified at the top of each nuclide data file. For example, U-238 (U-238.NUC) has three inhalation classes (D,W,Y) and two ingestion classes (S-soluble, I-insoluble), I-131 (I-131.NUC) has one inhalation class (D) and one ingestion class (S), and tritium (H-3.NUC) has a single inhalation class, which we designate as $\mathrm{V}$ for vapor, and one ingestion class (S-soluble). Assays allowed for each nuclide are breath (BRE), urine (U), fecal (F), whole body count (WBC), and lung (LUN) count. For the radioiodines a systemic organ (thyroid) and corresponding assay (thyroid count (THY) are specified.

Note that for each nuclide, the file (1) contains a default assimilation pathway to use if the pathway is not specified in the bioassay records and (2) assigns GI transfer classes to inhalation classes for use with the inhalation pathway. The file also assigns the assay designation WBL to either whole body count (WBC) or lung count (LUN), depending on assimilation pathway and nuclide.

Weights are assigned to each assay and pathway in each nuclide file to be used to determine estimated intake and committed and annual doses when results are present from more than one assay. The nuclide data file contains committed effective and organ dose per unit deposition $(\mathrm{Sv} / \mathrm{Bq})$ for inhalation pathway and committed effective and organ dose per unit intake for ingested activity. ${ }^{9}$ Dose conversion factors for inhalation and ingestion pathways are provided for the following organs: gonads, breasts, lungs, red marrow, bone surface, thyroid, and remaining tissue. The last item in each nuclide file is a flag to determine whether a dose-rate file exists for this nuclide. Those nuclides that do not have a dose-rate file are those for which the clearance from the body occurs within the year of exposure.

The information for the nuclide data files is taken from ICRP-30 (ref. 4), ICRP-54 (ref. 3 ) and other relevant publications. The nuclide files are listed in Appendix H.

Associated with some radionuclides is a file (with extension DRS) that contains the dose rate per unit intake as a function of time for each class allowed for that nuclide. The doserate file is read whenever the annual dose needs to be computed for that nuclide. Those nuclides that do not have a dose-rate file are those for which the elimination is fast enough that the entire dose will be delivered in the year of exposure. For those nuclides we set the annual dose to the committed dose. Nuclides with dose-rate files for Ver. 4.2 of DOSEXPRT are Co-57, Co-60, Sr-89, Sr-90, Cs-134, Cs-137, I-125, I-129, U-234, U-235, U-236, U-238, Pu238, Pu-239, Pu-241, Am-241, Cm-244 and TPU (same as Am-241). 
The dose rate per unit intake is listed as a function of time distributed over a time grid with four different time intervals:

\begin{tabular}{|c|c|c|}
\hline \multicolumn{3}{|c|}{$\begin{array}{l}\text { Range } \\
\text { (days) }\end{array}$} \\
\hline 0 & to & 3 \\
\hline 3 & to & 73 \\
\hline 73 & to & 1825 \\
\hline 1825 & to & 25550 \\
\hline
\end{tabular}

\begin{tabular}{c}
$\begin{array}{c}\text { Time Interval } \\
\text { (days) }\end{array}$ \\
\hline 0.1 \\
1 \\
73 \\
365
\end{tabular}

The regular nuclide dose-rate files have been derived assuming an AMAD of 1 micron. The Y-12 uranium nuclide dose-rate files have been derived assuming an AMAD of 8 microns. Future modifications will remove the restriction on AMAD when using the doserate files.

The dose-rate file is read whenever the annual dose needs to be computed for that nuclide. Those nuclides that do not have a dose-rate file are those for which the decay is fast enough that the entire dose response will be contained in the year of exposure. For those nuclides we set the annual dose to the committed dose.

Beginning with Ver. 4.1 of DOSEXPRT. the following modifications were made to the nuclide data files and dose-rate files:

Breath excretion and retention functions were added to all the nuclide data files. In addition, a special inhalation class of $L$ for labeled compound was defined for C-11 and C-14. The excretion functions for Am-241, Cm-242, and Cm-244 were modified. Some of the nuclide weights were modified in nuclide data files.

The nuclide files were combined into a single binary, direct-access nuclide file (NUCLIDE.BIN) for faster execution of DOSEXPRT. The pointers to each of the nuclide data files within the direct-access file are specified in the SITE.DFT file. If the pointer is set to zero, the corresponding ASCII nuclide data file will be read. The program that creates the binary, direct-access nuclide file, DIRBIN.EXE, is located in EXE_DIR.

A binary, direct-access dose-rate file (with extension BIN) was created for each of the nuclides with dose-rate files. This greatly' increases the speed of execution of DOSEXPRT. The file DRS.TAB (see Appendix D) contains a table of inhalation and ingestion classes that are used to control reading of these binary, direct-access dose-rate files. If the parameter following the nuclide name in the DRS.TAB file is set to 0, DOSEXPRT will read the ASCII dose-rate file (with extension DRS) for that nuclide. The program that creates the binary, direct-access dose-rate files, MAKBIN.EXE, is located in EXE_DIR.

The structure of the nuclide data files and nuclide dose-rate files was unmodified with Ver. 4.2 of DOSEXPRT. 


\section{ALGORITHMS FOR ESTIMATING INTAKE OF RADIONUCLIDES}

\subsection{INTRODUCTION}

We have developed a set of algorithms for estimating a worker's intake of a radioncolide based on measurements of activity within excreta or within the body at times post intake. In selecting and implementing the algorithms, the needs of quality assurance and the desire to limit future costs associated with maintenance of the resulting software were considered. The algorithms, their reduction to code, and the resulting software have been subjected to extensive testing and verification.

\subsection{GENERAL APPROACH}

It is intended that the software, entitled DOSEXPRT, serve as a tool in demonstrating compliance with the occupational radiation protection guidance presented in the $1988 \mathrm{DOE}$ order 5480.11 (ref. 6). Even though some aspects of internal dosimetry will be further clarified in additional DOE guidance, the major thrust of the order deals with internal emitters, particularly the manner in which intakes and resultant doses are assessed and reported. Thus, we have focused our efforts towards estimating intakes, given measurements of the radionuclide in excreta and in the body.

We assumed that the biokinetics governing the behavior of radionuclides within the body are linear such that the response of the body to an intake scales directly with the magnitude of the intake, and the response to continuous intakes can be viewed as a superpositioning of a series of acute intakes. We describe the biokinetics by mathematical functions and thus do not limit DOSEXPRT to particular models or model structures. DOSEXPRT is independent of the biokinetic and mathematical details upon which the functions are based. The functions associated with each radionuclide are contained in data files, referred to as the nuclide files. To introduce new biokinetic information or to include a new bioassay procedure for a radionuclide one need alter only the nuclide file; very rarely should it be necessary to modify DOSEXPRT itself.

As an example, let $e_{u}(t)$ denote the urinary excretion rate at time $t$ following an instantaneous input of a unit activity into blood at $t=0$. If a unit intake into the body at $t=0$ results in the activity entering blood at a rate $g(t)$, then the expected urinary excretion rate, $E_{u}(t)$, at time $t$ is 


$$
E_{u}(t)=\int_{0}^{t} g(\tau) e_{u}(t-\tau) d \tau
$$

The above integral represents the convolution of two functions; the convolution is defined as $f * g=\int_{0}^{t} g(\tau) f(t-\tau) d \tau$. The function $g(t)$ is often referred to as the forcing function (or stimulus) and $f(t)$ as the unit response function. The latter gives the response of the system to a unit input at time zero, while the convolution integral represents the response of the system to the forcing function.

For continuous intake at a rate $\dot{I}(t)$ during a period of length $T_{e}$, the expected urinary excretion rate $E_{u}^{c}\left(t, T_{e}\right)$ at time $t$ is given by

$$
E_{u}^{c}\left(t, T_{e}\right)=\int_{0}^{T_{\bullet}} \dot{I}(\tau) E_{u}(t-\tau) d \tau
$$

if the intake was at a constant rate, $\dot{I}(t)=\dot{I}$, then

$$
\begin{aligned}
E_{u}^{c}\left(t, T_{e}\right) & =\dot{I} \int_{0}^{T_{e}} E_{u}(t-\tau) d \tau \\
& =\dot{I} \int_{t-T_{e}}^{t} E_{u}(\tau) d \tau .
\end{aligned}
$$

The above equation gives the excretion rate at any time $t$, including times beyond the intake period, that is, for $t>T_{e}$. Note that the lower limit of integration in Eq. (2b) is taken to be zero if $t<T_{e}$. 
Some of the properties of the convolution integral are tabulated below.

\section{Algebra of Convolution}

\begin{tabular}{ll}
\hline Property & \multicolumn{1}{c}{ Definition } \\
\hline Commutative & $f * g=g * f$ \\
Associative & $(f * g) * h=f *(g * h)$ \\
Multiplication & $(k f) * g=k(f * g), k$ is a constant \\
Distributive & $\left(f_{1}+f_{2}\right) *\left(g_{1}+g_{2}\right)=$ \\
& $f_{1} * g_{1}+f_{1} * g_{2}+f_{2} * g_{1}+f_{2} * g_{2}$ \\
\hline
\end{tabular}

The functions describing the translocation of material within the body and the excretion rates can be derived from mathematical models of the biokinetics (e.g., the ICRP Task Group Lung Model) or obtained from mathematical fits to observations (e.g., radon breath analysis for determination of radium). We restricted the functions used in DOSEXPRT to be of the form

$$
f(t)=\sum_{i=1}^{n} A_{i} e^{-a_{i} t} .
$$

The functions as defined in the nuclide data files do not include radioactive decay. 
In relating the rate of excretion (or activity retained in the body) to the amount of material initially inhaled or ingested we encounter convolutions of the form $f * g$ and $f * g * h$. We set out below the resulting expressions for the convolution integrals assuming $f(t)=\sum_{i} A_{i} e^{-a_{1} t}, g(t)=\sum_{i} B_{i} e^{-b_{1} t}$ and $h(t)=\sum_{i} C_{i} e^{-c_{1} t}$. The convolution $f * g$ yields

$$
f * g=\sum_{i, j} \Delta_{i, j}\left[e^{-b_{j} t}-e^{-a_{i} t}\right]
$$

where $\Delta_{i, j}=\frac{A_{l} B_{j}}{a_{l}-b_{j}}$, and the convolution $f * g * h$ yields

$$
f * g * h=\sum_{i, j, k} \Delta_{l, j} C_{k}\left[\frac{e^{-c_{k} t}-e^{-b_{j} t}}{b_{j}-c_{k}}-\frac{e^{-c_{k} t}-e^{-a_{i} t}}{a_{l}-c_{k}}\right] .
$$

For a radionuclide with decay constant $\lambda$ the functions in the convolution must be modified to include radioactive decay. It can be shown that

$$
f(t) e^{-\lambda t} * g(t) e^{-\lambda t}=(f * g) e^{-\lambda t}
$$

$$
\text { and } f(t) e^{-\lambda t} * g(t) e^{-\lambda t} * h(t) e^{-\lambda t}=(f * g * h) e^{-\lambda t} \text {. }
$$

Consideration of chronic intakes involves a time integral of the response during the intake period [see Eqs. (2a) and (2b)], including radioactive decay as given by $e^{-\lambda t}$. Thus one needs to evaluate the integral of Eq. (4a):

$$
\begin{gathered}
\int_{t-T_{e}}^{t}(f * g) e^{-\lambda t} d t \\
=\sum_{i, j} \Delta_{i, j}\left[\frac{e^{-\left(b_{j}+\lambda\right)\left(t-T_{e}\right)}-e^{-\left(b_{j}+\lambda\right) t}}{b_{j}+\lambda}-\frac{e^{-\left(a_{l}+\lambda\right)\left(t-T_{e}\right)}-e^{-\left(a_{i}+\lambda\right) t}}{a_{i}+\lambda}\right],
\end{gathered}
$$


where $\Delta_{i, j}$ is defined above and the summation is a double sum over the indices $i$ and $j$. In some instances one needs to integrate Eq. (4b):

$$
\begin{gathered}
\int_{t-T_{t}}^{t}(f * g * h) e^{-\lambda t} d t \\
=\sum_{i, j, k} \Delta_{i, j} C_{k}\left[\frac{e^{-\left(c_{k}+\lambda\right)\left(t-T_{a}\right)}-e^{-\left(c_{k}+\lambda\right) t}}{\left(b_{j}-c_{k}\right)\left(c_{k}+\lambda\right)}-\frac{e^{-\left(b_{j}+\lambda\right)\left(t-T_{j}\right)}-e^{-\left(b_{j}+\lambda\right) t}}{\left(b_{j}-c_{k}\right)\left(b_{j}+\lambda\right)}\right] \\
-\sum_{i, j, k} \Delta_{i, j} C_{k}\left[\frac{e^{-\left(c_{k}+\lambda\right)\left(t-T_{j}\right)}-e^{-\left(c_{k}+\lambda\right) t}}{\left(a_{i}-c_{k}\right)\left(c_{k}+\lambda\right)}-\frac{e^{-\left(a_{i}+\lambda\right)\left(t-T_{j}\right)}-e^{-\left(a_{l}+\lambda\right) t}}{\left(a_{i}-c_{k}\right)\left(a_{l}+\lambda\right)}\right],
\end{gathered}
$$

where $\Delta_{i, j}$ is defined above and the summation is a triple sum over the indices $i, j$, and $k$. Equations (4) and (5) are the basic algorithms used by DOSEXPRT. As outlined below these equations are repeatedly applied to the various transfer and excretions functions included in nuclide files. The functions contained in the nuclide files are defined on the following page in Table 3. In all cases the functions are normalized to a unit activity at $t=0$. 
Table 3. Functions used in analysis of bioassay measurements

\begin{tabular}{ll} 
Notation & \multicolumn{1}{c}{ Definition } \\
\hline$f_{\text {lung } \rightarrow \text { blood }}$ & Transfer rate from lung to blood \\
$f_{\text {lung } \rightarrow G I}$ & Transfer rate from lung to GI Tract \\
$f_{G I \rightarrow \text { blood }}$ & Transfer rate from GI tract to blood \\
$f_{\text {GI } \rightarrow \text { fecal }}$ & Transfer rate from GI tract to fecal \\
$f_{\text {wound } \rightarrow \text { blood }}$ & Transite aate from wound to blood \\
$\boldsymbol{e}_{\boldsymbol{u}}$ & Urinary excretion rate of systemic activity \\
$\boldsymbol{e}_{f}$ & Fecal excretion rate of systemic activity \\
$\boldsymbol{e}_{b}$ & Breath excretion rate of systemic activity \\
$\boldsymbol{R}_{\text {lung }}$ & Retention of activity in lung \\
$\boldsymbol{R}_{\text {systemic }}$ & Retention of systemic activity \\
$\boldsymbol{R}_{\text {organ }}$ & Retention of activity in organ (e.g., thyroid) \\
$\boldsymbol{R}_{\text {wound }}$ & Retention at wound site \\
\hline
\end{tabular}




\subsection{EXCRETION AND RETENTION EQUATIONS}

Radionuclides are assumed to enter the body via inhalation, ingestion, or through the skin via wounds. The latter intake is assumed to occur as an isolated incident (acute exposure); inhalation and ingestion intakes may be either acute or chronic (continuous) in time. This section details the algorithms for the expected values for each assay considered within DOSEXPRT; namely, urinary excretion, fecal excretion, in vivo measurements, and breath excretion.

\subsubsection{Urinary Excretion}

Inhalation:

Let $e_{u}(t)$ represent the urinary excretion rate at time $t$ following introduction of a unit amount of the radionuclide into blood at $t=0$ (i.e., unit response function without radioactive decay). In the case of inhalation the inputs to the blood are due to activity cleared directly from the lung to blood, at rates denoted by $f_{\text {lung }- \text { blood }}(t)$, and material cleared from the lung into the gastrointestinal tract, at rates denoted by $f_{\text {lung } \rightarrow G l}(t)$, is translocated to blood from the GI-tract at rates denoted by $f_{G I-b l o o d}(t)$. The expected excretion rate, $E_{u}^{a}(t)$, at time $t$ following an acute intake of a unit activity by inhalation at $t=0$ of a radionuclide with decay constant $\lambda$ is

$$
E_{\mu}^{a}(t)=e^{-\lambda t}\left[f_{\text {lung } \rightarrow \text { blood }}+f_{\text {lung } \rightarrow G I} * f_{G I-\text { blood }}\right] * e_{\omega} .
$$

Equation (6) is evaluated using Eqs. (4a) and (4b).

If an individual chronically inhales activity at a uniform unit rate during a period of length $T_{e}$, then the excretion rate at time $t$ per unit intake rate, $E_{\mu}^{c}(t)$, is

$$
\begin{aligned}
E_{u}^{c}(t) & =\int_{t-T_{e}}^{t} E_{u}^{a}(x) d x \\
& =\int_{t-T_{a}}^{t} e^{-\lambda x}\left[f_{\text {lung }- \text { blood }}+f_{\text {lung }-G I} * f_{G I-\text { blood }}\right] * e_{u} d x
\end{aligned}
$$


Equation (7) is evaluated using Eqs. (5a) and (5b). Note that if $t<T_{a}$ then $t-T_{a}^{\prime}=0$.

Ingestion:

For an acute intake by ingestion, the fractional rate at which activity enters blood from the gastrointestinal tract is denoted by $f_{\text {ol-blood }}(t)$. The expected excretion rate, $E_{4}^{a}(t)$, at time $t$ per unit intake at $t=0$ for a radionuclide with decay constant $\lambda$ is

$$
E_{u}^{a}(t)=e^{-\lambda t}\left[f_{G l-b l o o d} * e_{u}\right]
$$

Equation (8) is evaluated using Eq. (4a).

If an individual chronically ingests activity at a uniform unit rate during a period of length $T_{e}$, then the urinary excretion rate at time $t$ per unit intake rate, $E_{u}^{c}(t)$, is

$$
\begin{aligned}
E_{u}^{c}(t) & =\int_{t-T_{t}}^{t} E_{u}^{a}(x) d x \\
& =\int_{t-T_{t}}^{t} e^{-\lambda x}\left[f_{G I-\text { blood }} * e_{u}\right] d x
\end{aligned}
$$

Equation (9) is evaluated using Eq. (5a).

Wound intake:

Let $f_{\text {wound-blood }}(t)$ denote the rate at which activity is absorbed into blood from the wound site. The rate of urinary excretion $E_{u}(t)$ per unit activity initially at the wound site is

$$
E_{\mu}(t)=e^{-\lambda t}\left[f_{\text {wound } \rightarrow b l o o d} * e_{u}\right] \text {. }
$$

Equation (10) is evaluated using Eq. (4a).

\subsubsection{Fecal Excretion}

Inhalation:

Let $f_{\text {lung }- \text { blood }}(t)$ denote the fractional rate at which activity inhaled at $t=0$ is transferred to blood and $e_{f}$ denote the fecal excretion rate following introduction of a unit activity into blood at $t=0$. In addition to the fecal excretion of activity that has entered the systemic 
pool, there will also be a component associated with material that has passed unabsorbed through the GI tract, which is denoted as $f_{\text {al-secal }}(t)$. The expected lecal excretion rate, $E_{f}^{a}(t)$, at time $t$ following an acute intake of a unit activity by inhalation of a radionuclide with decay constant $\lambda$ is

$$
E_{f}^{a}(t)=e^{-\lambda t}\left[\left(f_{\text {lung }- \text { blood }}+f_{\text {lung }-G l} * f_{G I-\text { blood }}\right) * e_{f}+f_{\text {lung } \rightarrow G l} * f_{G l-\text { fecul }}\right]
$$

Equation (11) is evaluated using Eqs. (4a) and (4b).

If an individual chronically inhales activity at a uniform rate during a period of length $T_{e}$, then the excretion rate at time $t$ per unit intake rate, $E_{f}^{c}(t)$, is given as

$$
\begin{aligned}
E_{f}^{c}(t) & =\int_{t-T_{d}}^{t} E_{f}^{a}(x) d x \\
& =\int_{t-T_{d}}^{t} e^{-\lambda x}\left[\left(f_{\text {lung }- \text { blood }}+f_{\text {lung }-G I} * f_{G l \rightarrow \text { blood }}\right) * e_{f}+f_{\text {lung }-G I} * f_{\text {GI } \rightarrow \text { fecal }}\right] d x .
\end{aligned}
$$

Equation (12) is evaluated using Eqs. (5a) and (5b).

Ingestion:

Let $f_{G l-b l o o d}(t)$ denote the fractional rate at which activity ingested at time $t=0$ is transferred to blood. The expected fecal excretion rate, $E_{f}^{a}(t)$, following an acute intake of a unit activity by ingestion at $t=0$ is

$$
E_{f}^{a}(t)=e^{-\lambda t}\left[f_{G I \rightarrow b l o o d} * e_{f}+f_{G I-\text { fecal }}\right]
$$

Equation (13) is evaluated using Eq. (4a). 
If an individual chronically ingests activity at a unilorm rate during a period of length $T_{e}$, then the excretion rate at lime $t$ per unit intake rate, $E_{f}^{c}\left(t, T_{e}\right)$, is

$$
\begin{aligned}
E_{f}^{c}\left(t, T_{e}\right) & =\int_{t-T_{e}}^{t} E_{u}^{a}(x) d x \\
& =\int_{t-T_{e}}^{t} e^{-\lambda x}\left[f_{G l-\text { blood }} * e_{f}+f_{G l-\text { focal }}\right] d x .
\end{aligned}
$$

Equation (14) is evaluated using Eq. (5a).

Wound Intake:

Let $f_{\text {wound - blood }}(t)$ denote the fractional rate at which activity is absorbed into blood from the wound site. The rate of fecal excretion, $E_{f}(t)$, per unit activity initially at the wound site is given as

$$
E_{f}(t)=e^{-\lambda t}\left[f_{\text {mound }- \text { blood }} * e_{f}\right]
$$

Equation (15) is evaluated using Eq. (4a).

\subsubsection{Breath Excretion}

Inhalation Intake:

Let $f_{\text {lung-blood }}(t)$ denote the fractional rate at which activity inhaled at $t=0$ is transferred to blood and $e_{b}(t)$ the rate of elimination of the radionuclide in breath following introduction of a unit activity into blood at $t=0$. The expected breath excretion rate, $E_{b}^{a}(t)$, at time $t$ following an acute intake of a unit activity by inhalation of a radionuclide with decay constant $\lambda$ is

$$
E_{b}^{a}(t)=e^{-\lambda t}\left[\left(f_{\text {lung } \rightarrow \text { blood }}+f_{\text {lung } \rightarrow G I} * f_{G I-\text { blood }}\right) * e_{b}\right]
$$

Equation (16) is evaluated using Eqs. (4a) and (4b).

If an individual chronically inhales activity at a uniform rate during a period of length $T_{e}$, then the excretion rate at time $t$ per unit intake rate, $E_{b}^{c}\left(t, T_{e}\right)$, is given as 


$$
\begin{aligned}
E_{b}^{o}\left(t, T_{c}\right) & =\int_{t}^{t}-T_{c} E_{b}^{a}(x) d x \\
& =\int_{t}^{t}-T_{c} e^{-\lambda x}\left[\left(f_{\text {lung }- \text { blood }}+f_{\text {lung }-G I} * f_{G I-\text { blood }}\right) * e_{b}\right] d x .
\end{aligned}
$$

Equation (17) is evaluated using Eqs. (5a) and (5b).

Ingestion Intake:

Let $f_{G l-b l o o d}(t)$ denote the fractional rate at which a unit activity ingested at time $t=0$ is transferred to blood. The expected elimination rate in breath, $E_{b}^{a}(t)$, at time $t$ following an acute intake of a unit activity by ingestion at $t=0$ is

$$
E_{b}^{a}(t)=e^{-\lambda t}\left[f_{G l \rightarrow b l o o d} * e_{b}\right]
$$

Equation (18) is evaluated using Eq. (4a).

If an individual chronically ingests activity at a uniform rate during a period of length $T_{e}$, then the elimination rate at time $t$ per unit intake rate, $E_{b}^{c}\left(t, T_{e}\right)$, is

$$
\begin{aligned}
E_{b}^{c}\left(t_{y} T_{e}\right) & =\int_{t-T_{c}}^{t} E_{b}^{a}(x) d x \\
& =\int_{t-T_{a}}^{t} e^{-\lambda x}\left[f_{G l \rightarrow \text { blood }} * e_{b}\right] d x
\end{aligned}
$$

Equation (19) is evaluated using Eq. (5a).

Wound Intake:

Let $f_{\text {round-blood }}(t)$ denote the fractional rate at which activity is absorbed into blood from the wound site. The rate of elimination in breath, $E_{b}(t)$, per unit activity initially at the wound site is given as

$$
E_{b}(t)=e^{-\lambda t}\left[f_{\text {mound }- \text { blood }} * e_{b}\right]
$$

Equation (20) is evaluated using Eq. (4a). 


\subsubsection{Organ Burdens}

\section{Lung:}

Let $R_{\text {unng }}(t)$ denote the fraction of the activity inhaled at $t=0$ that is relained in the lung at later times without consideration of radioactive decay. If we assume that $R_{\text {lung }}(t)=\sum_{l=1}^{n} A_{i} e^{-a_{l} t}$, the activity present in the lung at time $t, q_{\text {lung }}^{a}(t)$, following an acute intake of unit activity at $t=0$ is

$$
q_{\text {lung }}^{a}(t)=e^{-\lambda t} \cdot R_{\text {lung }}(t)=\sum_{i=1}^{n} A_{i} e^{-\left(a_{1}+\lambda\right) t} .
$$

Equation (21) is also applicable to retention at the wound site with $R_{\text {wound }}(t)$ replacing $R_{\text {lung }}(t)$.

If the intake occurs at a constant rate during a period of length $T_{e}$, then the lung burden $q_{\text {ung }}^{c}(t)$ per unit intake rate is

$$
\begin{aligned}
q_{\text {lung }}^{c}(t) & =\int_{t-T_{i}}^{t} q_{\text {lung }}^{a}(x) d x \\
& =\sum_{i} \frac{A_{i}}{a_{i}+\lambda}\left[e^{-\left(a_{1}+\lambda\right)\left(t-T_{i}\right)}-e^{-\left(a_{i}+\lambda\right) t}\right]
\end{aligned}
$$

Systemic organs (c.g, thyroid):

Let $R_{\text {organ }}(t)$ denote the activity present in a systemic organ following introduction of a unit activity into blood at time $t=0$, without consideration of radioactive decay. The activity present in the organ, $q_{\text {organ }}^{a}(t)$, following an inhalation intake of a unit activity at $t=0$ is

$$
q_{\text {organ }}^{a}(t)=e^{-\lambda t}\left[f_{\text {lung } \rightarrow \text { blood }}+f_{\text {lung } \rightarrow G I} * f_{G I \rightarrow \text { blood }}\right] * R_{\text {organ }}(t)
$$

If the intake was by ingestion then the activity present in the organ is 


$$
q_{\text {organ }}^{a}(t)=e^{-\lambda t}\left[f_{G I-\text { blood }} * R_{\text {organ }}(t)\right]
$$

If the intake occurred at a constant rate during a period of length $T_{e}$, then the organ burden $\boldsymbol{q}_{\text {organ }}^{c}\left(t, T_{e}\right)$ at any time $t$ per unit intake rate by inhalation is

$$
\begin{aligned}
q_{\text {organ }}^{c}\left(t, T_{e}\right) & =\int_{t-T_{c}}^{t} q_{\text {organ }}^{a}(x) d x \\
& =\int_{t-T_{a}^{t}}^{t} e^{-\lambda x}\left[f_{\text {lung }- \text { blood }}+f_{\text {lung } \rightarrow G I} * f_{G l-\text { blood }}\right] * R_{\text {organ }} d x,
\end{aligned}
$$

and by ingestion,

$$
q_{\text {organ }}^{c}\left(t, T_{e}\right)=\int_{t-T_{a}}^{t} e^{-\lambda x}\left[f_{G I-\text { blood }} * R_{\text {organ }}\right] d x
$$

These equations can be evaluated using Eqs. (5a) and (5b). 


\subsection{APPLICATION OF THE BIOASSAY ALGORITHMS}

The above algorithms form the bases of the DOSEXPRT code. The majority of the numerical calculations center around evaluation of Eqs. (4) and (5) as required by the pathways of the nuclide within the body. DOSEXPRT considers two types of exposure. Acute or incident exposures are considered to be well defined in terms of the time of the exposure, and specific bioassay measurements are undertaken for the purpose of estimating the magnitude of the intake. Chronic or routine exposures arise from expected intake due to low-level contamination in the work environment (e.g., chronic airborne activity). Following is a brief outline of the final steps in these calculations.

Acute intake:

The estimated activity $\langle I\rangle$ of a radionuclide taken into the body in an incident (acute intake) is derived as

$$
<I>=\frac{1}{N} \sum_{i=1}^{N} \frac{Y(t)}{E^{a}(t)},
$$

where $Y(t)$ denotes the measured excretion rate (or body burden) at time $t, E^{a}(t)$ is the expected excretion rate (or body burden) at time $t$ for a unit intake, and $N$ is the total number of measurements. Note that no weighting of the measurements is employed in estimating the intake.

Chronic intake:

Consider $n$ bioassay measurements $\left\{Y_{1}, Y_{2}, \ldots, Y_{n}\right\}$ obtained at times $\left\{T_{1}, T_{2}, \ldots, T_{n}\right\}$ during a period of chronic exposure. Assume that the exposure ended at $T_{f}\left(T_{f}>T_{n}\right)$ and that $m$ additional measurements $\left\{Y_{n+1}, Y_{n+2}, \ldots Y_{n+m}\right\}$ were obtained at times $\left\{T_{n+1}, T_{n+2}, \ldots T_{n+m}\right\}$ postexposure. The intake rate during the period $T_{i-1}$ to $T_{i}$ for $T_{i}<T_{f}$ is computed as

$$
\dot{I}_{i}=\frac{Y_{i}(t)-\sum_{j=1}^{i-1} \dot{I}_{j} E^{c}\left(\Delta T_{j}, T_{i}-T_{j-1}\right)}{E^{c}\left(\Delta T_{i}, \Delta T_{i}\right)},
$$

where $\Delta T_{i}=T_{i}-T_{i-1}$ and $E^{c}(x, y)$ is the expected excretion rate (or body burden) at time $y$ 
for uniform intake at a unit rate during a period of duration $x$. We assign the intake rate $\dot{I}_{n}$ estimated for the period $\left(T_{n-1}\right.$ to $\left.T_{n}\right)$ to the period $\left(T_{n}\right.$ to $\left.T_{f}\right)$, that is, from the last measurement to the end of exposure. The estimated intake, $\left\langle I_{T}\right\rangle$, derived from the measurements for the exposure period is then

$$
<I_{T}>=\sum_{i}^{n} \dot{I}_{i}\left(T_{i}-T_{i-1}\right)+\dot{I}_{n}\left(T_{f}-T_{n}\right)
$$

Eacn postexposure measurement provides additional information regarding the total intake. Using the intake rate vector $\left(\dot{I}_{i}, i=1, n\right)$ estimated from Eq. (28), then the predicted excretion at time $T_{i+n}$ beyond the exposure period is

$$
<Y_{i+n}>=\sum_{j=1}^{n} \dot{I}_{j} E^{c}\left(\Delta T_{j}, T_{i+n}-T_{j-1}\right)
$$

Normalizing the intake rate vector to the current estimate of the total intake, we then obtain a new estimate of the total intake from the postexposure measurement $Y_{i+n}$ as

$$
\left.<I_{T}\right\rangle_{i}=\frac{Y_{i+n}}{\sum_{j=1}^{n} i_{j} E^{c}\left(\Delta T_{j}, T_{n+1}-T_{j-1}\right)},
$$

where $i_{j}$ is the $j$ th component of the normalized intake rate vector and is given by $\dot{I}_{j} /<I_{T}>$, where $\left\langle I_{T}\right\rangle$ is the current estimate of the total intake and $\dot{I}_{j}$ is the intake rate during the $j$ th period. A new estimate of the total intake is obtained as the weighted average of the current estimate and the value derived from the $i$ th postexposure measurement as

$$
\left\langle I_{T}\right\rangle=\frac{1}{n+i}\left[(n+i-1)<I_{T}\right\rangle+\left\langle I_{P_{i}}\right] .
$$

This procedure is repeated over all postexposure measurements. Note that the normalized intake rate vector derived from measurcments during the exposure period is preserved; post exposure measurements only improve the estimate of the total intake. 


\subsection{ANNUAL DOSE}

DOSEXPRT provides estimates of the annual dose, that is, the dose delivered to tissues in a year, for the current year and for each subsequent year (out to 50 years). The estimates are derived using dosimetric coefficients computed for this purpose using the metabolic models of ICRP-30 (ref. 4) and specific effective energy (SEE) values that are being used in the preparation of ICRP Publication 56 (ref. 10). By use of these coefficients DOSEXPRT avoids the numerically intense computation of organ dose.

Incident Intake:

The annual dose for tissue $T$ in the year in which an incident occurred, $A D_{T, 1}$, on Julian day $t_{0}$ is given as

$$
A D_{T_{1} 1}=I \int_{\vartheta_{0}}^{t_{1}} \dot{D}_{T}^{I}(t) d t
$$

where

$I$ is the estimated intake for the incident,

$t_{1}$ is the Julian day corresponding to the end of the first year, and

$\dot{D}_{T}^{I}(t)$ is the dose rate in organ $T$ following a unit intake at $t=0$.

The annual dose in any subsequent year $i$ is

$$
A D_{T, i}=I \int_{t_{1-1}}^{t_{1}} \dot{D}_{T}^{l}\left(t-t_{0}\right) d t
$$

where $t_{i}$ is the Julian day for the end of year $i$.

Routine Intake:

The annual dose in any year from routine intakes of a radionuclide depends, not only on the magnitude of the intake, but also on its temporal pattern. For each year, the total intake 
in the year is obtained by weighting the intake estimates of each bioassay by weights constructed from the assay weights specified in the nuclide file and by the frequency of measurements. The intake pattern for the most frequently employed assay is then normalized to the estimated total intake for the year. Thus each year of the exposure history is treated in isolation with regard to the type and frequency of the assays.

In computing the annual dose, it is necessary to have an estimate of the intake rate in the time period from the last measurement to the end of the year (EOY). The procedure used to estimate the EOY intake rate for the last year of the exposure history is different than that used for other years. For example, the EOY intake in calendar year (CY) 1989, given no measurements in CY 1990, is obtained by extending forward the intake rate of the preceding period in CY 1989. However, if measurements are present for CY 1990, then the 1989 EOY intake rate is based on the first measurement in CY 1990.

Mathematically, let \langle\rangle$_{i, j}$, denote the estimated intake for assay $j$ in year $i$. The intake in year $i,\langle I\rangle_{i}$, is computed as

$$
\left.\langle I\rangle_{i}=\sum_{j} w_{j} \frac{n_{i, j}}{N_{i}}<I\right\rangle_{i, j},
$$

where $w_{j}$ is the weight assigned to assay $j$ in the nuclide file (after normalization for the number of assays in the year), $n_{i, j}$ is the number of measurements in year $i$ for assay $j$, and $N_{i}$ is the total number of assays in year $i$. Equation (35) applies to both routine and incident measurements.

Let $\left\langle\dot{I}_{i, j}\right.$, denote the intake rate vector, of length $n_{i, j}$ for year $i$ and assay $j$. Let $k$ be the assay with the greatest frequency of measurements, that is, $n_{l, k}>n_{l, j}, j \neq k$. The intake rate vector for year $i$ is then

$$
\dot{I}_{i}=\frac{\langle I\rangle_{i}}{\langle I\rangle_{i, k}}\left\langle\dot{I}_{i, k}\right.
$$

at each of the $n_{l, k}$ entries in the vector, defining the intake pattern for the selected assay in year $i$. The annual dose in any year is based on the intake rate vector for all preceding years and the year of interest.

The committed dose equivalent is computed from knowledge of the total intake; the 
annual dose, however, must be computed from the intake rate vector $\dot{I}$. Dose-rate coefficients giving the dose-equivalent rate at various times following a unit intake are accessed by DOSEXPRT to compute the annual dose. Let $\dot{D}_{T}^{l}(t)$ denote the dose rate in organ $T$ following an instantaneous intake of a unit activity at time zero. The dose rate at time $t$ in organ $T$ for the intake rate vector $I$ is given as

$$
\dot{D}_{T}(t)=\int_{0}^{t} \dot{I}(\tau) \dot{D}_{T}^{I}(t-\tau) d \tau
$$

If vector $I$ is composed of $n$ regions of uniform intake rate then Eq. (35) can be written as

$$
\dot{D}_{T}(t)=\sum_{n} \dot{I}_{n}\left(t_{n}\right) \int_{t-t_{n+1}}^{t-t_{n}} \dot{D}_{T}^{I}(u) d u,
$$

where the summation extends for all $n$ for which $t-t_{n+1} \geq 0$. Note that in this formulation $\dot{I}$ is assumed to be constant during the period $t_{n} \rightarrow t_{n+1}$.

The annual dose is simply the integral of Eq. (38) over the year of interest. Thus the annual dose in year $i$ for tissue $T, A D_{T, l}$, is

$$
\begin{aligned}
A D_{T, t} & =\int_{t_{1}} \dot{D}_{T}(t) d t \\
& =\int_{t_{1}} d u \sum_{n} \dot{I}_{n}\left(t_{n}\right) \int_{t-t_{n+1}}^{t-t_{n}} \dot{D}_{T}(u) d u
\end{aligned}
$$




\section{TECHNICAL DESCRIPTION OF NUCLIDE DATA FILES}

\subsection{INTRODUCTION}

The general principles of monitoring for the radiation protection of workers has been set forth in various reports of the ICRP ${ }^{1-4}$ and NCRP. ${ }^{5}$ Monitoring of individuals for internal exposure is based on measurement of radionuclides in the whole body (or specific organs/regions) and on measurement of radionuclides in excreta. For quantitative assessment of internal exposure the results of these measurements must be translated into quantities that can be compared with the primary radiation protection guidance (limits on annual effective dose equivalent, committed effective dose equivalent or committed dose equivalent for specific organs) or to the secondary quantities (Annual Limits on Intake - ALI). ${ }^{4}$ The relationships between levels in the body or in excreta and the estimated intake and resulting dose can only be established through use of metabolic and dosimetric models describing the behavior of the material in the body.

\subsection{MODEL OF THE RESPIRATORY SYSTEM}

This report uses the compartmental model of the respiratory system presented in ICRP Publication 30 (ref. 4) to describe the retention in the lung of inhaled aerosols and the rate of translocation of deposited material to other regions of the body.

The respiratory system is divided into three distinct regions - the nasal passages $(N P)$, the trachea and bronchial tree $(T B)$ and the pulmonary parenchyma $(P)$. Deposition fraction in the three regions is assumed to vary with the aerodynamic properties of the aerosol and is described by three parameters; $D_{N P}, D_{T B}$, and $D_{P}$ which represent the fraction of inhaled material initially deposited in the $N P, T B$, and $P$ regions, respectively. The shortfall $\left(1-D_{N P}-D_{T B}-D_{P}\right)$ is not retained in the respiratory tract and is assumed to be exhaled. The deposition fractions as a function of the activity median aerodynamic diameter (AMAD) of an aerosol with a log-normal distribution of diameters is shown in Fig. 2.

Materials have been classified according to their rate of clearance from the pulmonary region of the respiratory tract; materials with a half-time of less than 10 days are classified as $D$ (day); those with half-times between 10 and 100 days are classified as $W$ (weeks); and those with greater half-times are classified as $Y$ (year). The clearance model of the respiratory tract is shown in Fig. 3. 


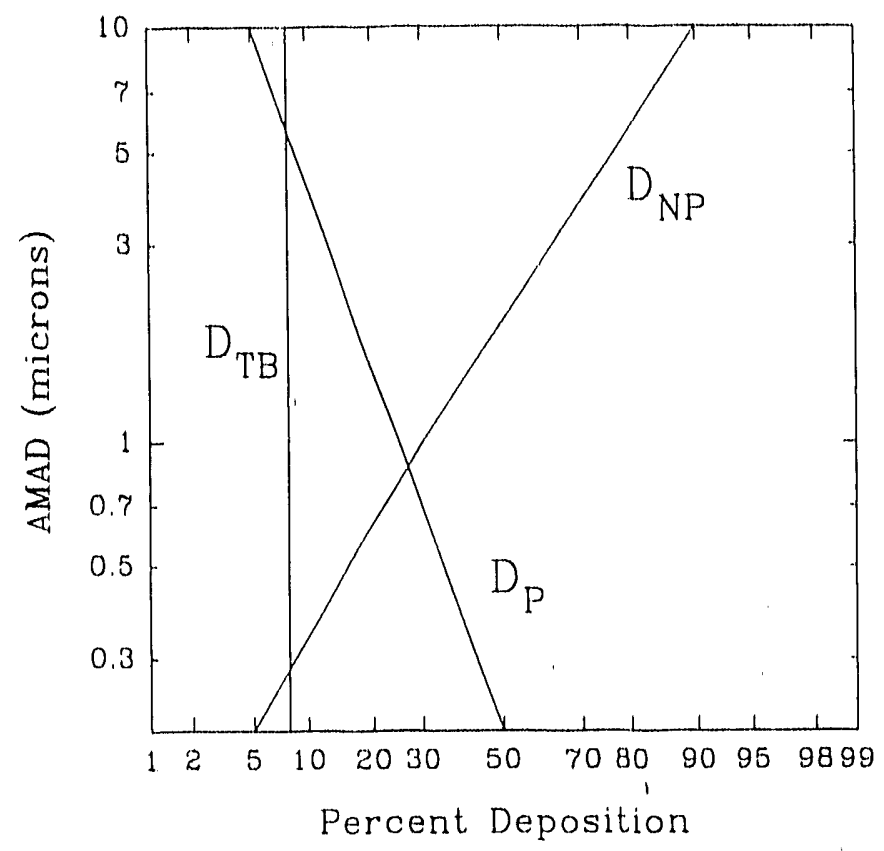

Fig. 2. Deposition of dust in the respiratory system. The percentage of activity or mass of an aerosol that is deposited in the nasal passages $\left(D_{\mathrm{NP}}\right)$, the trachea and bronchial tree $\left(D_{T B}\right)$, and the pulmonary parenchyma $\left(D_{P}\right)$ is given in relation to the activity median aerodynamic diameter (AMAD) of the aerosol distribution (in microns). The default value of AMAD in the normal SITE.DFT file is 1 micron. When DOSEXPRT is used in debug/test mode, AMAD can be modified but must be between 0.2 and 10 microns. However annual dose can only be computed for an AMAD of 1 micron.

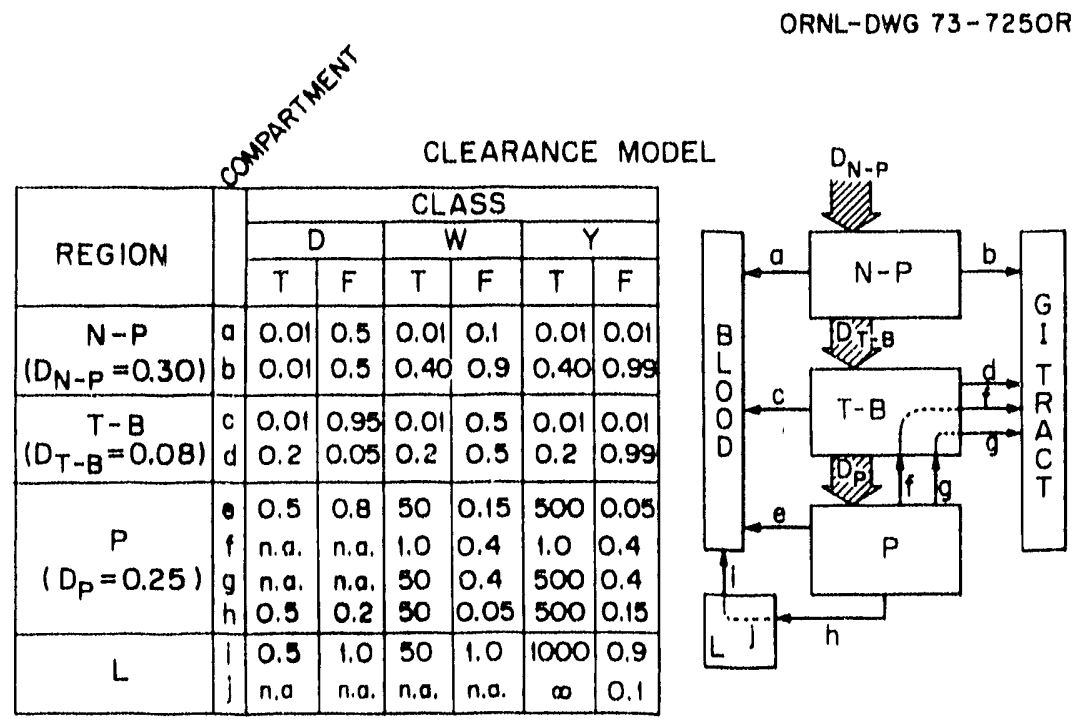

Fig. 3. The values for the removal half-times, $\mathrm{T}$, and compartmental fractions, F, for the ICRP lung model for $\mathrm{D}, \mathrm{W}$, and $\mathrm{Y}$ class material. The fractional depositions are based on an AMAD of 1 micron. The entry n.a. indicates not applicable. The schematic diagram identifies the various clearance pathways $(a-j)$ in the lung model. 
Each compartment $(a-j)$ is associated with a particular pathway of clearance with a half-time for biological clearance of $T_{i}$ and associated pathway fraction $F_{i}$. The values of the parameters for the three clearance classes are given in Fig. 3. Deposiled material is taken up by the body from the respiratory tract through compartments a, $c$, and e. Compartments $b, d, f$, and $g$ are associated with mechanical transport of material into the gastrointestinal tract. The GI tract is discussed below.

The clearance of material from each compartment is assumed to be described by firstorder kinetics at rates given by the rate constant $\lambda_{i}$, which is related to the half-time $T_{i}$ as

$$
\lambda_{l}=\frac{\ln (2)}{T_{i}},
$$

where $\ln (2)$ is the natural logarithm of $2(\sim 0.693 \ldots)$. The half-times for each compartment are given in Fig. 3. The clearance of inhaled material from the lung is therefore described by a set of coupled first-order differential equations.

\subsection{MODEL OF THE GASTROINTESTINAL TRACT}

Radionuclides reach the gastrointestinal tract either directly by ingestion or indirectly by translocation from the respiratory tract, as described above. This report uses the compartmental model of the gastrointestinal tract described in ICRP Publication 30 (ref. 4).

The gastrointestinal tract is represented by four sections. Each section is considered as a single compartment, and translocation from one compartment to the next is assumed to be governed by first-order kinetics. Kate constants, $\lambda_{l}$, for transfer between compartments, are given in Fig. 4. We have assumed that the uptake of material from the GI tract to body fluids will occur from the small intestine (SI). The rate constant, $\lambda_{s}$, for the translocation of activity to the systemic pool (blood), can be estimated from $f_{l}$, the fraction of the stable element reaching body fluids following ingestion:

$$
\lambda_{S}=\frac{f_{1} \lambda_{S I}}{1-f_{1}} .
$$

If an $f_{1}$ value of 1 is assigned then the singularity in the above equation can be avoided by assuming the material enters blood as it leaves the stomach. We have, however, here arbitrarily limited $f_{l}$ to values less than or equal to 0.95 . The $f_{1}$ values are those assigned by the ICRP in Publication 30. 
ORNL-DWG 77-2742R

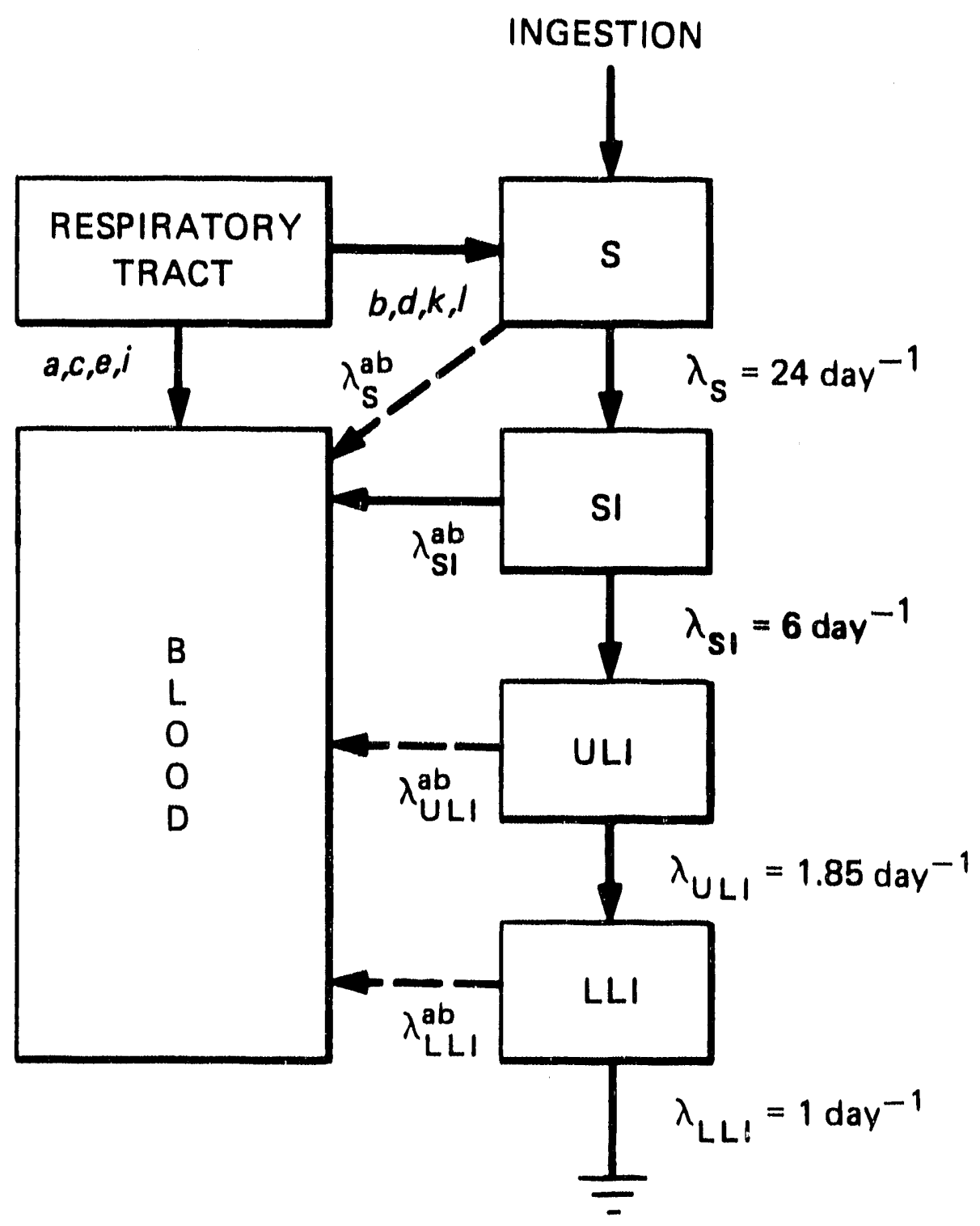

Fig. 4. Schematic representation of radioactivity movement among respiratory tract, GI tract, and blood with transfer coefficients between compartments, $\lambda_{1}$, shown. 


\subsection{DISTRIBUTION AND RETENTION MODELS}

Following an intake by inhalation and ingestion, radionuclides will be translocated to body fluids at a rate determined by the rate constants for the relevant compartments of the respiratory and gastrointestinal tract. Subsequently, the radionuclide may be taken up by the organs and tissues of the body and retained in these regions as discussed in ICRP Publication 30 (ref, 4). The functions, which describe the retention of radionuclides in the organs/tissues of the body, can be expressed as sums of exponentials. These retention functions take into account implicitly all translocation of the radionuclide once it has entered into blood.

\subsection{SYSTEMIC EXCRETION MODELS}

Radionuclides are excreted from the systemic pool via urinary and fecal excretion. For most radionuclides we have used the excretion functions presented in ICRP Publication 54 (ref. 3). In some instances, for example $\mathrm{Pu}$ and $\mathrm{Am}$, we have adopted functions given explicitly in the literature. All the excretion functions are expressed as sums of exponentials.

\subsection{MATHEMATICAL SOLUTIONS TO UPTAKE MODELS}

The system of coupled linear first-order differential equations that describe the behavior of material inhaled or ingested have solutions of the form

$$
f(t)=\sum_{i} A_{i} e^{-a_{i} t}
$$

Functions describing the rate of transfer of material into blood are derived as $\lambda_{1-\text { blood }} C_{1}$, where $C_{l}$ is the content of compartment $i$ which feeds blood with a rate constant $\lambda_{1 \rightarrow \text { blood }}$. If $C_{i}$ is given as $C_{i}(t)=\sum_{j} A_{j} e^{-a_{j} t}$, then the rate that material is translocated to blood from compartment $i, f_{i-b \text { bod }}$, is

$$
f_{i \rightarrow \text { blood }}(t)=\lambda_{i-\text { blood }} \sum_{j} A_{j} e^{-a_{i} t} .
$$

For example, the rate material is translocated from compartments a, c, e, and $i$ of the respiratory tract model to blood is

$$
f_{i-\text { blood }}(t)=\lambda_{a} C_{a}+\lambda_{c} C_{c}+\lambda_{e} C+\lambda_{i} C_{i},
$$

where $C_{v}$ is the content of compartment $v$ at time $t$. 


\subsection{RESPIRATORY TRACT}

Functions describing the retention and rate of translocation of material from the respiratory tract to blood and to the gastrointestinal tract were derived in the manner given in ICRP-30. The solutions were checked using the DIFSOL code of Killough and Eckerman (ref. 11). The coupled systems of differential equations were solved for the initial condition of a unit activity deposited in the $N P, T B$, and $P$ regions, respectively. These functions were calculated for material of clearance class $D, W$, and $Y$, assuming no radioactive decay.

\subsection{GASTROINTESTINAL TRACT}

Functions describing the retention and rate of translocation of ingested material to blood from the gastrointestinal tract were derived assuming a unit activity present in the stomach

at $t=0$. These functions were calculated for values of $f_{1}$ considered to be applicable to the particular radionuclide.

\subsection{CONTENT OF NUCLIDE SPECIFIC DATA FILES}

The following briefly describes each set of data within the nuclide files and provides references, where possible, for the data presented. The functions describing retention in and translocation from the lung and gastrointestinal tract were derived from the ICRP models as discussed above.

Nuclide Name. Radionuclide name in standard notation (e.g., U-238). Metastable notation can be included. The comment on this line indicates the date of last revision of the nuclide file.

Atomic Mass. The atomic mass of the radionuclide. Data are taken from the 1983 atomic mass evaluation of Wapstra and Audi (rel. 12).

Half-life. The half-life of the radionuclide, in days, as given in ICRP Publication 38 (ref. 13)

Default Assimilation Pathway. If no route of intake is identified in the bioassay record then this entry provides an assumed route. $H$ corresponds to inhalation, $G$ to ingestion, and $J$ to injection. The normal default is $H$ (i.e., inhalation).

Number of Clearance Classes. The number of clearance classes considered for inhalation of the given radionuclide. As a minimum, the number of clearance classes considered in ICRP Publication 30 will be included in the file. For each clearance class, functions representing retention in the lung and translocation to blood and to the gastrointestinal tract are specified.

Number of GI-Transfer Functions. The number of different chemical forms considered for ingestion of material (i.c., different $f_{1}$ values). For each form, functions representing retention within the GI tract and translocation to blood are specified. 
Number of Systemic Organs. The number of systemic organs for which retention functions are specified. This value is generally zero since lung is specified separately. For radiolodines a value of 1 is assigned where the thyroid is the organ of interest.

Assign GI-Transfer Function to Inhalation Class (D, W, Y). For each clearance class, the corresponding GI-tract-transfer function is specified. For example, clearance class D and W of uranium use the same GI-tract-transfer functions ( $f_{1}$ values).

Weights for Results for Clearance Class (D, W, Y). Relative weights to apply when computing the inhalation intake if more than one type of assay was carried out. For each clearance class, weights are assigned to breath, urine, and fecal assays, and to in vivo measurements of whole body and lung. If a systemic organ is specified, a weight is assigned to the assay associated with that organ (e.g., in vivo measurements of thyroid for radioiodine). The weights are based on expert judgement and only become important if more than one assay was performed.

Weights for Results for Ingestion Class. Relative weights to apply when computing the ingestion intake if more than one type of assay was carried out.

Assign Classes T, N, U to D, W, or Y. Default old clearance class notation to current clearance classes.

Transfer rate per day from lung to blood. For each clearance class, the parameters of a function describing the rate of translocation of inhaled material from the lung to blood are specified. The data are presented in four columns; the first column gives the rate constants $a_{i}$, the second column shows the coefficients $A_{N P_{i},}$ for deposition in the NP region, the third column gives the coefficients $\mathrm{A}_{T B, i}$ for deposition in the $T B$ region, and the final column presents the coefficients $A_{P,}$ for cieposition in the $P$ region. The function representing the rate of translocation to blood of inhaled activity $f_{\text {lung } \rightarrow \text { blood }}(t)$ is

$$
f_{\text {lung } \rightarrow \text { blood }}(t)=\sum_{i}\left[D_{N P} A_{N P, t}+D_{T B} A_{T B, i}+D_{P} A_{P, i}\right] e^{-a_{i} t}
$$

where $D_{N P}, D_{T B}$, and $D_{P}$ denote the deposition of the aerosol in the $N P, T B$, and $P$ regions of the lung. An AMAD of 1 micron is assumed, thus $D_{N P}, D_{T B}$, and $D_{P}$ correspond to 0.30, 0.08 , and 0.25 , respectively.

Transfer rate per day from lung to GI Tract. For each clearance class the parameters of the function describing the rate of translocation of inhaled material into the GI-tract are specified. The data are presented in four columns; the first column gives the rate constants $a_{i}$, the second column shows the coefficients $A_{N P_{i},}$ for deposition in the NP region, the third column gives the coefficients $A_{T B, i}$ for deposition in the $T B$ region, and the final column presents the coefficients $A_{P, i}$ for deposition in the $P$ region. The function representing the rate of translocation of inhaled material to blood from the lung is $f_{\text {lung } \rightarrow \text { GI }}(t)$ 


$$
f_{\text {lung } \rightarrow G I}(t)=\sum_{i}\left[D_{N P} A_{N P, l}+D_{T B} A_{T B, l}+D_{P} A_{P, i}\right] e^{-a_{i} t},
$$

where $D_{N P}, D_{T B}$, and $D_{P}$ denute the deposition of the aerosol in the $N P, T B$, and $P$ regions of the lung; for an $\mathrm{AMAD}$ of 1 micron the values are $0.30,0.08$, and 0.25 , respectively.

Transfer rate per day of ingested activity to blood. For each chemical form, the parameters of the function describing the rate of translocation of ingested material to blood are given. The data are presented in two columns: the first column gives the rate constants $a_{b}$ the second column shows the coefficients $A_{i}$. The function representing the rate of translocation to blood from the GI tract $f_{G l \rightarrow \text { blood }}(t)$ is

$$
f_{G I-\text { blood }}(t)=\sum_{i} A_{i} e^{-a_{i} t} .
$$

Transfer rate per day of ingested activity to feces. For each chemical form the parameters of the function describing the rate of translocation of ingested material to feces are specified. The data are presented in two columns: the first column gives the rate constants $a_{i}$, the second column shows the coefficients $A_{l}$. The function representing the rate of translocation of ingested material to feces $f_{G l-f e c a l}(t)$ is

$$
f_{G I-f e c a l}(t)=\sum_{i} A_{i} e^{-a_{i} t}
$$

Urinary Excretion function. The nuclide file contains the parameters of the function representing the rate of urinary excretion of systemic activity following a unit input into blood at time zero. The data are presented in two columns: the first column gives the rate constants $a_{i}$, and the second column, the corresponding coefficients $A_{i}$. The function representing the urinary excretion $f_{u}(t)$ is thus

$$
f_{u}(t)=\sum_{i} A_{i} e^{-a_{i} t}
$$

For most radionuclides the urinary excretion function is that given in ICRP Publication 54 (ref. 3). 
Fecal Excretion Function. The nuclide flle contains the parameters of the function representing the rate of fecal excretion of systemic activity following a unit input into blood at time zero. The data are presented in two columns: the first column gives the rate constants $a_{i}$, and the second column the corresponding coefficients $A_{1}$. The function representing the fecal excretion $f_{f}(t)$ is thus

$$
f_{f}(t)=\sum_{l} A_{i} e^{-a_{i} t} .
$$

For most radionuclides the fecal excretion functions used are those presented in ICRP Publication 54 (ref. 3).

Retention of Inhaled Activity within the lungs. For each clearance class the parameters of the function describing the retention in the lungs of inhaled material are given. The data are presented in four columns: the first column gives the rate constants $a_{i}$, the second column shows the coefficients $A_{N P,}$ for deposition in the NP region, the third column gives the coefficients $A_{T B,}$, for deposition in the $T B$ region, and the final column presents the coefficients $A_{P, i}$ for deposition in the $P$ region. The function representing the retention in the lungs, $R_{\text {lung }}(t)$ of inhaled material is

$$
R_{\text {lung }}(t)=\sum_{i}\left[D_{N P} A_{N P, i}+D_{T B} A_{T B, i}+D_{P} A_{P, i}\right] e^{-a_{i} t}
$$

where $D_{N P}, D_{T B}$, and $D_{P}$ denote the deposition of the aerosol in the $N P, T B$, and $P$ regions of the lung; for an $\mathrm{AMAD}$ of 1 micron the values are $0.30,0.08$, and 0.25 , respectively.

Retention of Ingested activity within the GI tract. The nuclide file contains the parameters of the function representing the retention of ingested activity in the tract following a unit input at time zero. The data are presented in two columns: the first column gives the rate constants $a_{i}$, and the second column the corresponding coefficients $A_{i}$. The retention function $R_{G l}(t)$ is

$$
R_{G I}(t)=\sum_{i} A_{i} e^{-a_{i} t} .
$$

The functions are derived from the GI-Tract model of ICRP Publication 30 (ref. 4).

Retention of Systemic Activity. The nuclide file contains the parameters of the function representing the retention of a unit input into the systemic pool at time zero. The data are presented in two columns: the first column gives the rate constants $a_{i}$, and the secend column the corresponding coefficients $A_{i}$. The function representing the systemic retention $R(t)$ is thus

$$
R(t)=\sum_{i} A_{i} e^{-a_{i} t}
$$


The retention functions are derived from the metabolic models of ICRP Publications 30 (ref. 4) and 54 (ref. 3).

H/D Dose per unit deposition $(\mathrm{Sv} / \mathrm{Bq})$ for inhaled activity. For each clearance class the nuclide file contains the committed dose equivalent in tissue $T$ per unit deposition in the three regions of the respiratory tract. The data are presented in three columns: the first column gives the coefficients $H_{N P, T}$ for deposition in the NP region, the second column shows the coefficients $H_{T B, T}$ for deposition in the $T B$ region, and the third column presents the coefficients $H_{P, T}$ for deposition in the $P$ region. The committed dose equivalent per unit intake $H_{T}$ for tissue $T$ is given as

$$
H_{T}=D_{N P} H_{N P, T}+D_{T B} H_{T B, T}+D_{P} H_{H, T},
$$

where $D_{N P}, D_{T B}$, and $D_{P}$ denote the deposition of the aerosol in the $N P, T B$, and $P$ regions of the lung. For an AMAD of 1 micron the depositions are $0.30,0.08$, and 0.25 for these regions.

The dosimetric data in the nuclide files were compiled from NUREG/CR-1962 (ref. 14), which is an unabridged compilation of selected data developed during completion of ICRP Publication 30 (see also Federal Guidance Report 11 (ref. 9). In that report values of $H_{T}$ were tabulated for a AMAD of 1 micron with a triplet of numbers $\left(F_{N P}, F_{T B}, F_{P}\right)$ representing the fraction of $H_{T}$ due to deposition in the three regions of the lung. Values of $H_{N P, T}, H_{T B, T}$, and $H_{P, T}$ were computed for the nuclide files as

$$
H_{r, T}=\frac{F_{r}}{D_{r}} H_{T}, \quad r=N P, T B, P
$$

where $D_{r}$ is the deposition of a 1-micron aerosol in the various regions of the lung model; the values of $D_{r}$ are $0.30,0.08$, and 0.25 for depositions in the $N P, T B$, and $P$ regions, respectively.

H/D Dose per unit intake (Sv/Bq) for ingested activity. For each ingestion class the committed dose equivalent per unit intake is tabulated. The data are from NUREG/CR-1962 (ref. 14); see also Federal Guidance Report 11 (ref. 9).

ALI (Bq) from ICRP-30. For each inhalation and ingestion class the Annual Limit on Intake is tabulated from ICRP Publication 30. 


\section{REFERENCES}

1. International Commission on Radiological Protection, Evaluation of Radiation Dose to Body Tissues from Internal Contamination Due to Occupational Exposure, ICRP Publication 10, Pergammon Press, Oxford, 1968.

2. International Commission on Radiological Protection, The Assessment of Internal Contamination Resulting from Recurrent or Prolonged Uptakes, ICRP Publication 10A, Pergammon Press, Oxford, 1971.

3. International Commission on Radiological Protection, "Individual Monitoring for Intakes of Radionuclides by Workers: Design and Interpretation," Publication 54, Annals of the ICRP, Vol. 19, 1988.

4. International Commission on Radiological Protection, "Limits for Intakes of Radionuclides by Workers," Publication 30, Annals of the ICRP, Vol. 2, 1979.

5. National Council on Radiation Protection and Measurement, Use of Bioassay Procedures for Assessment of Internal Radionuclide Deposition, NCRP Report No. 87, 1987.

6. Radiation Protection for Occupational Workers, Department of Energy Order 5480.11, 1988.

7. K. F. Eckerman, R. C. Ward, and L. B. Maddox, U.S. Army Radiological Bioassay and Dosimetry: The RBD Software Package, ORNL/TM-11858, in preparation.

8. L. A. Currie, "Limits for Qualitative Detection and Quantitative Determination: Application to Radio Chemistry," Anal. Chem. 40, 586-593 (1968).

9. K. F. Eckerman, A. B. Wolbarst, and A. C. B. Richardson, Limiting Values of Radionuclide Intake and Air Concentration and Dose Conversion Factors for Inhalation, Submersion, and Ingestion - Federal Guidance Report No. 11, EPA-520/1-88-020, 1988.

10. International Commission on Radiological Protection, "Age-dependent Doses to Members of the Public from Intake of Radionuclides: Part 1," Publication 56, Annals of the ICRP, Vol. 20, No. 2, 1989.

11. G. G. Killough and K. F. Eckerman, "A Conversational Eigenanalysis Program for Solving Differential Equations," In Computer Applications in Health Physics (Ed. R. L. Kathren, D. P. Hicgby, and M. A. McKinney) Proceedings of the 17th Midyear Topical Symposium of the Health Physics Society, 1984. 
12. A. H. Wapstra and G. Audi, "The 1983 Atomic Mass Evaluation," Nucl. Phy. A432, 1985. International Commission on Radiological Protection, Publication 38, "Radionuclide Transformations - Energy and Intensity of Emission," Annals of the ICRP, Vol. 11-13, 1983.

13. International Commission on Radiological Protection, Publication 38, "Radionuclide Transformations - Energy and Intensity of Emission," Annals of the ICRP, Vol. 11-13, 1983.

14. K. F. Eckerman, M. R. Ford, and S. B. Watson, "Internal Dosimetry Data and Methods of ICRP - Part 2," Vol. 1: Committed Dose Equivalent and Secondary Limits, ORNL/NUREG-1962/TM-433/V1, 1981.

15. W. Snyder et al., "Urinary Excretion of Tritium Following Exposure to Man to HTO a Two Exponential Model," Phys. Med. Biol. 13, $547-559$ (1968).

16. E. T. Lessard et al., Interpretation of Bioassay Measurements, NUREG/CR-4884, 1987.

17. T. M. Beasley et al., "Distribution and Excretion of Technetium in Humans," Health Physics 12, 1425-1435 (1966).

18. I. A. Likhtarev et al., "A Study of Certain Characteristics of Strontium Metabolism in a Homogeneous Group of Human Subjects," Health Physics, 28, 49-60 (1975).

19. R. W. Leggett and K. F. Eckerman, "A Method for Estimating the Systemic Burden of Pu from Urinalysis," Health Physics, 52, 337-346 (1987). 


\section{Appendix A}

\section{DOSEXPRT BIOASSAY RECORDS FORMAT}

This section describes the format for the bioassay recurds files or input files to DOSEXPRT. The input files are ASCII files containing records with a length of 125 characters (bytes). The following information is common to both in vivo and in vitro records files:

REASON code indicates incident ( $1 \mathrm{~S}$, the $S$ standing for special) or routine ( 3 or $1 \mathrm{R}$, the $R$ standing for regular) exposure.

Note that the bioassay RESULT and MDA along with their units codes are in different columns for in vitro [breath (BRE), urine (U), and fecal $(F)$ ] and in vivo [whole body count (WBC), lung count (LUN), and thyroid count (THY)] measurements. The pathways are inhalation $(H)$, ingestion $(G)$, or injection $(J)$. Only weighted intake is computed for the injection pathway as dose-per-unit-intake conversion factors do not exist for most nuclides for this pathway.

The classes allowed for inhalation are day (D), week (W), year (Y), vapor (V) [e.g., Tritium], and labeled compound (L) [e.g., C-11 and C-14]. The classes allowed for ingestion are: very insoluble (V), insoluble (I) and soluble (S).

The social security number (SSN) is in columns 106-114 on the records. Mixed inhalation class information follows the SSN in columns 116-125.

Dates are in the form YYYYMMDD, where, YYYY is the year, MM is the month, and DD is the day. Times are in the form HHMM, where HH is the hour in 24-hour time and $\mathrm{MM}$ is the minutes. For example, if a measurement was made on April 10, 1991 at 3:45 PM, the DATE and TIME would be: 199104101545.

Units for in vivo records are: $\mathrm{M}-\mu \mathrm{Ci}, \mathrm{N}-\mathrm{nCi}, \mathrm{P}-\mathrm{pCi}, \mathrm{D}-\mathrm{dpm}, \mathrm{B}-\mathrm{Bq}$ and $\mathrm{U}-\mu \mathrm{g}$. Units for urinalysis records are: $1-\mathrm{dpm} / \mathrm{ml}, 2-\mathrm{dpm} / \mathrm{d}, 3-\mathrm{dpm} / \mathrm{sample}, 4-\mathrm{dpm} / \mathrm{l}, 5-\mathrm{ug} / \mathrm{ml}$, $6-\mathrm{Bq} / \mathrm{l}$, and $7-\mathrm{Bq} / \mathrm{d}$. Units for fecal analysis records are: 3 - dpm/sample and $7-\mathrm{Bq} / \mathrm{day}$. Units for breath analysis records are: 2 - dpm/d, $3-\mathrm{dpm} / \mathrm{sample}, 4-\mathrm{dpm} / 1,6-\mathrm{Bq} / \mathrm{l}, 7-\mathrm{Bq} / \mathrm{d}$.

On the following page is an example of a DOSEXPRT input file using BADGE $=-20$ from DOSEXPRT example input INCIDENT.DAT. 


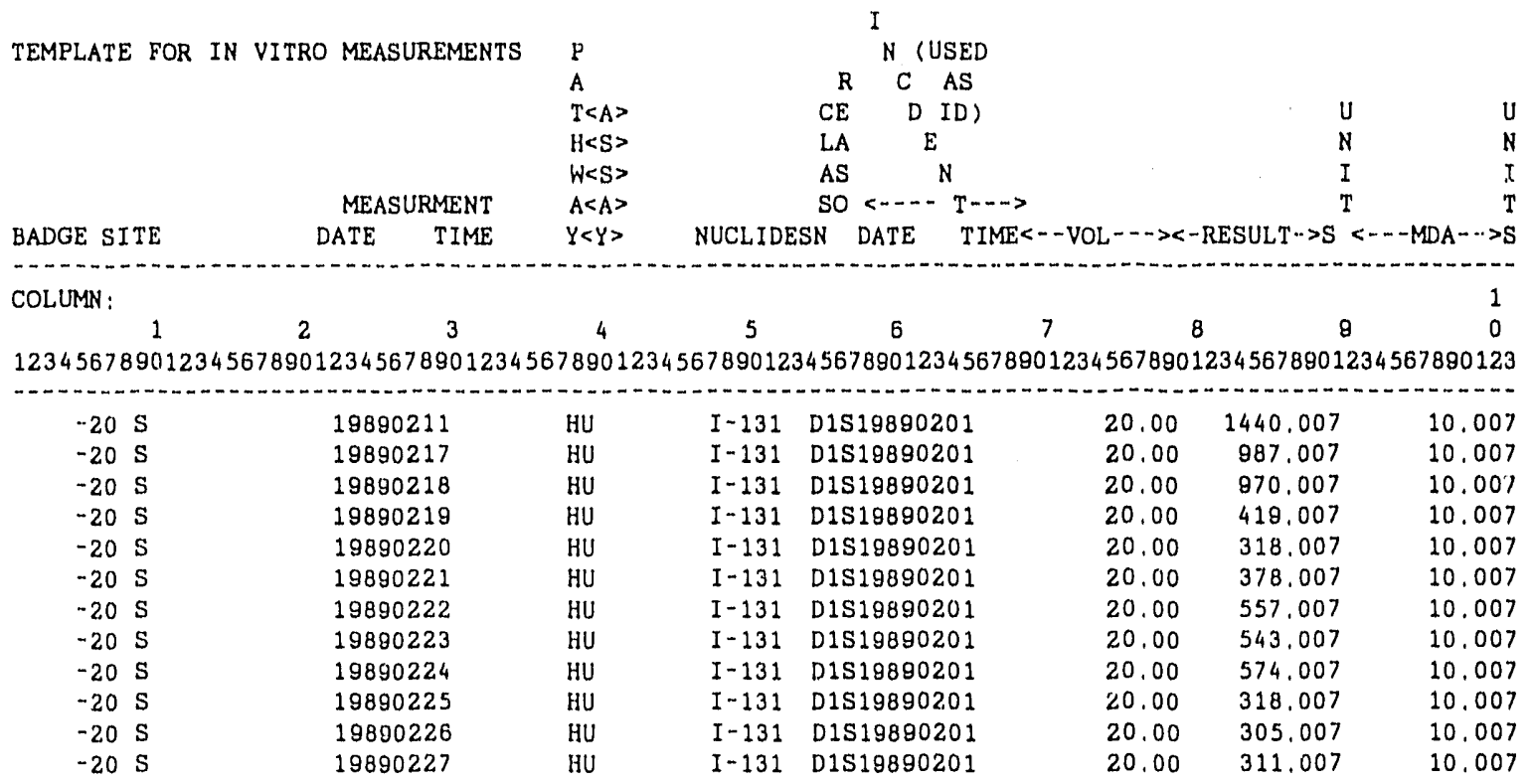

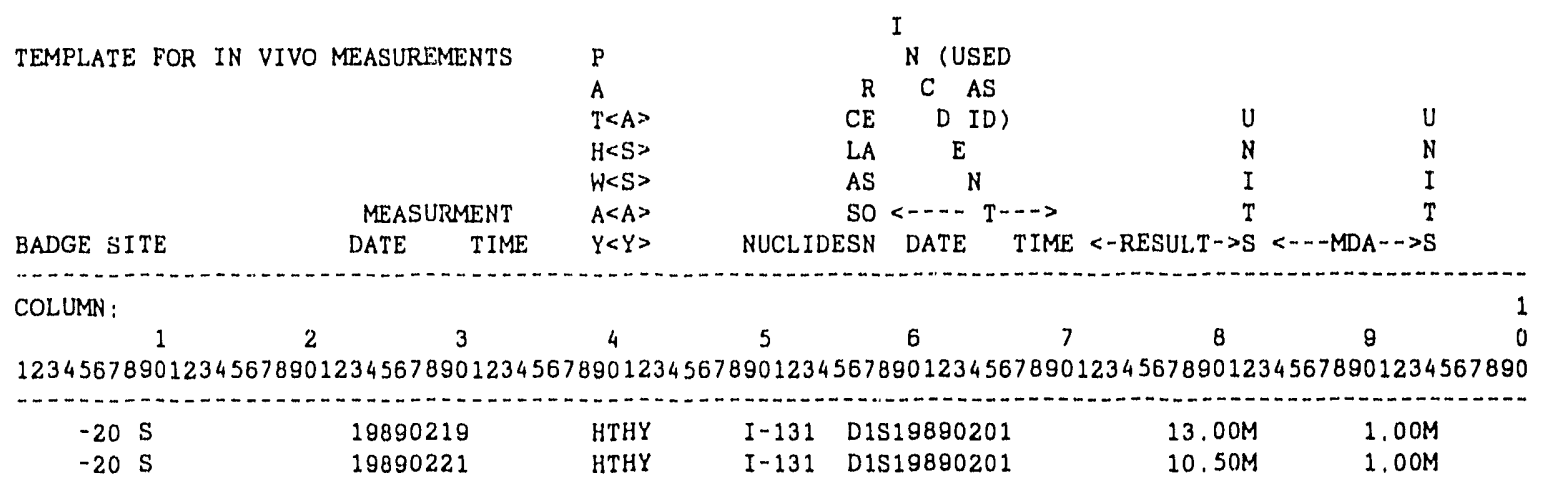


The following is the format for the bioassay records files used with DOSEXPRT. The bioassay records files are created using the FLOW GEMINI data base program from the OHIS bioassay data base. Generally two files are created: S26.DAT, which contains in vitro (urinalysis) records, and S27.DAT, which contains in vivo records. DOSEXPRT concatenates these into a single file: DOSEXPRT.DAT.

\begin{tabular}{|c|c|c|c|}
\hline ELEMENT & COLUMNS & LENGTH & DESCRIPTION \\
\hline \multicolumn{4}{|c|}{ COMMN TO IN VIVO AND IN VITRO RECORDS: } \\
\hline BADGE NUMBER & $2-7$ & 6 & \\
\hline PLANT & g & 1 & \\
\hline COUNT-DATE * & $23-30$ & 8 & Date and time that sample was taken \\
\hline COUNT -TIMI: * & $31-34$ & 4 & or count was made. \\
\hline PATHWAY & 39 & 1 & 'H'-Inhalation, 'G'-ingestion \\
\hline TYPE & $40-42$ & 3 & Type of count (WBC, eto.) \\
\hline ANALYSIS & $43-48$ & 6 & \\
\hline ISOTOPE & $49-55$ & 7 & \\
\hline CLASS & $56-56$ & 1 & Lung retention or solublifty olass \\
\hline REASON & $57-58$ & 2 & $1,1 S, 2 S-i n c 1 d e n t, 1 R, 2 R$-follow up, 3-routine \\
\hline INCIDENT-DATE* & $59-66$ & 8 & If reason $1 \mathrm{~s} 2$ (follow up of inoldent) \\
\hline INC IDENT - TIME * & $67-70$ & 4 & $\begin{array}{l}\text { date must be present to be considered part } \\
\text { of that incident }\end{array}$ \\
\hline \multicolumn{4}{|l|}{ IN VIVO RECORDS: } \\
\hline RESULT & $72-81$ & 10 & Numerio value of result \\
\hline UNITS $^{+}$ & 82 & 1 & Units of result \\
\hline MDA & $84-93$ & 10 & Minimum detectablo activity \\
\hline M-UNITS ${ }^{+}$ & 94 & 1 & Units of MDA value \\
\hline SSN & $106-114$ & 9 & Soclal Security Number \\
\hline MIXED CLASS IDENTIFIER & 116 & 1 & Sirigle Diglt (0-9) Identifier for mixed class. \\
\hline MIXED CLASS LABEL & 117 & 1 & "D" \\
\hline PERCENTAGE OF CLASS D & $118-119$ & 2 & PERCENT $(0-99)$ \\
\hline MIXED CLASS LABEL & 120 & 1 & "W" \\
\hline PERCENTAGE OF CLASS $\mathrm{W}$ & $121-122$ & 2 & PERCENT $(0-99)$ \\
\hline MIXED CLASS LABEL & 123 & 1 & "Y" \\
\hline PERCENTAGE OF CLASS $Y$ & $124-125$ & 2 & PERCENT $(0-99)$ \\
\hline \multicolumn{4}{|l|}{ IN VITRO RECORDS: } \\
\hline Vol. & $71-80$ & 10 & $\begin{array}{l}\text { Volume ( } \mathrm{ml} \text { ) of sumple (allquot) for urinalysis } \\
\text { Mass (B) of sample analyzed for fooal anaylsis } \\
\text { Volume (1) of sample analyzed for breath analys } 18 .\end{array}$ \\
\hline RESUL'T & $81-30$ & 10 & Numeric value of result \\
\hline UNITS ${ }^{++}$ & 91 & 1 & Units of result \\
\hline$M D A$ & $93-102$ & 10 & Minimum detectable activity \\
\hline M-UNITS ${ }^{++}$ & 1.03 & 1 & Units of MDA value \\
\hline SSN & $106-114$ & 9 & Social Security Number \\
\hline MIXED CLASS IDENTIFIER & 116 & 1 & Single Digit $(0-9)$ tdentifier for mixed class. \\
\hline MIXED CLASS LABEL & 117 & 1 & "D" \\
\hline PERCENTAGE OF CLASS D & $118-119$ & 2 & PERCENT $(0-99)$ \\
\hline MIXED CLASS LABEL & 120 & 1 & "W" \\
\hline PERCENTAGE OF CLASS $W$ & $121-122$ & 2 & PERCENT $(0-99)$ \\
\hline MIXED CLASS LABEL & 123 & 1 & "Y" \\
\hline PERCENTAGE OF CLASS $Y$ & $124-125$ & 2 & PERCENT $(0-99)$ \\
\hline
\end{tabular}

*DATES are in the form YYYYMMDD and TIMES are in the form HHMM. For example if a measurement was mado on Jan 5, 1989 at $3: 45$ PM, the DATE and TIME would be: 198901051545.

tunits for in vivo records:

'M' $\mu \mathrm{Cl}$, ' $N$ ' $\mathrm{nCl}$, ' $\mathrm{F}$ ' $\mathrm{pCl}$, 'D' dpm (d/min), 'B' $\mathrm{Bq}$ and ' $U$ ' $\mu \mathrm{g}$.

t+untes for in vitro records:

Urine: $1 \mathrm{dpm} / \mathrm{ml}, 2 \mathrm{dpm} / \mathrm{d}, 3 \mathrm{dpm}, 4 \mathrm{dpm} / 1,5 \mathrm{ug} / \mathrm{ml}, 6 \mathrm{~Bq} / 1,7 \mathrm{~Bq} / \mathrm{d}$.

Fecal: $3 \mathrm{dpm} / \mathrm{sample}$ and $7 \mathrm{Bcj} / \mathrm{day}$.

Breath: $2 \mathrm{dpm} / \mathrm{d}, 3 \mathrm{dpm}, 4 \mathrm{dpm} / 1,6 \mathrm{~Bq} / 1,7 \mathrm{~Bq} / \mathrm{d}$. 


\section{Appendix B}

\section{DOSEXPRT OUT'PUT FILE FORMAT}

This is the format for the DOSEXPRT output file with extension S28. Each record of the output file contains a single result for each badge, plant, nuclide, class, and reason code. Each output record will be read, and the results inserted into Segment 28 of the OHIS data base. In addition, a DOSEXPRT report file (with extension OUT) can be created from the S28 file. The S28 file is an ASCII file containing records with a length of 435 characters (bytes). The format is as follows:

\begin{tabular}{|c|c|c|}
\hline Column & Length & Description \\
\hline$-\ldots .$. & 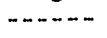 & $\cdots-\cdots-\cdots$ \\
\hline $1-6$ & 6 & Badge number \\
\hline 7 & 1 & blank \\
\hline 8 & 1 & Plant $(K, P, X, Y)$ - FINDER FIELD - \\
\hline 9 & 1 & Reason code (1-acute incldent, 3-routine \\
\hline 10 & 1 & Nuollde Class \\
\hline $11-17$ & 7 & Nuolido \\
\hline $18-23$ & 6 & DOSEXPRT Computational DATE (yymandd) \\
\hline $24-27$ & 4 & DOSEXPRT Computational TIME [hhm] \\
\hline 28 & 1 & - FINDER FIELD $\cdots$ \\
\hline 29 & 1 & Plant ( $K, P, X, Y$ or $S$ for TEST RUNS) \\
\hline $30-36$ & 7 & Nuolide \\
\hline 37 & 1 & Nuolido Class \\
\hline 38 & 1 & $\begin{array}{c}\text { Assimilation Pathway ('H'-inhalation, ' } G \text { '-ingestion, } \\
\text { ' } J \text { '-injection) }\end{array}$ \\
\hline 39 & 1 & Reason code (1-acute incident, 3-routine \\
\hline 40 & 1 & (a) \\
\hline $41-46$ & 6 & $\begin{array}{l}\text { INCIDEN'T DATE (If REASON CODE is ' } 1 \text { ') (mnddyy) } \\
\text { blank (If REASON CODE is ' } 1 \text { ' or ' } S \text { ') }\end{array}$ \\
\hline $47-50$ & 4 & $\begin{array}{l}\text { INCIDEN' IIME (If REASON CODE is ' } 1 \text { ') (hhmm] } \\
\text { blank (If REASON CODE is ' } 3 \text { ' or 'S') }\end{array}$ \\
\hline 51 & 1 & blank \\
\hline $52-57$ & 6 & START DATE for ROUTINE calculations (mmddyy) \\
\hline 58 & 1 & blank \\
\hline $59-64$ & 6 & END DATE for ROUTINE caloulations [mmddyy] \\
\hline $65-69$ & 5 & DOSEXPRT VERSION $(X X, X a)$ \\
\hline $70-75$ & 6 & DATE OF DOSEXPRT VERSION (mmildyY) \\
\hline $76-81$ & 6 & DATE OF NUCLIDE FILE USED [mmddyy] \\
\hline $82-87$ & 6 & DATE OF CONPUTATION [mmaldyy] \\
\hline $88-96$ & 9 & INTAKE (micro Curies) \\
\hline 97 & 1 & UNITS OF INTAKE (M=micro curles) \\
\hline $98 \cdots 106$ & 9 & COMMTTED DOSE EQUIVALENT to GONADS (mrem) \\
\hline $107-115$ & 9 & COMMITTED DOSE EQUIVALENT to BREAST (mrem) \\
\hline $116-124$ & 9 & COMMITTED DOSE EQLIVALENT to LUNGS (mrem) \\
\hline $125-133$ & 9 & COMMITTED DOSE EQUIVALENT to R, MARROW (mrem) \\
\hline $134-142$ & 9 & COMMITTED DOSE EQUIVALENT to BONE SURFACE (mrem) \\
\hline $143-151$ & 9 & COMMITED DOSE EQUIVALENT to THYROID (mrem) \\
\hline $151-160$ & 9 & COMMITTED DOSE EQUIVALENT to REMAINDER (mrem) \\
\hline $161-169$ & 9 & COMMITTED EFFECTIVE DOSE (mrem) \\
\hline $170-178$ & 9 & ANNUAL DOSE to GONADS (mrem) \\
\hline $178-187$ & 9 & ANNUAL DOSE to BREAST (mram) \\
\hline $188-196$ & 9 & ANNUAL DOSE to LUNGS (mrem) \\
\hline $197-205$ & 9 & ANNUAL DOSE to $R$. MARROW (mrem) \\
\hline $206-214$ & 9 & ANNUAL DOSE to BONE SURFACE (mrem) \\
\hline $215-223$ & 9 & ANNUAL DOSE to THYROID (mrem) \\
\hline $224-232$ & 9 & ANNUAL DOSE to REMAINDER (mrem) \\
\hline $233-241$ & 9 & ANNUAL, EFFECTIVE DOSE (mrem) \\
\hline $242-245$ & 4 & $\begin{array}{l}\text { YEAR PRIOR TO YEAR IN WHICH ANNUAL DOSE DROPS } \\
\text { BELOW TRESHOLD VALUE ( } 1 \mathrm{mrem} \text { ) (yYyY) }\end{array}$ \\
\hline
\end{tabular}




\begin{tabular}{|c|c|c|}
\hline Column & Length & Desor1ption \\
\hline 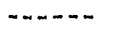 & $-\cdots--$ & $-\cdots+-\cdots-n-n$ \\
\hline $246-254$ & $\theta$ & AMAD used in oaloulation (miorons) \\
\hline $255-263$ & 8 & Volume of urtne per day used in oaloulation (m1) \\
\hline $264-272$ & 8 & Value of volume of urine per sample (ml) \\
\hline $273-281$ & 8 & Mass of fooal exoretion por day used in oaloulation (grams) \\
\hline $282-280$ & g & Value of nass of feoal samplo analyzed (8rams) \\
\hline $291-301$ & 11 & $\begin{array}{l}\text { Number of days between flrst measurement and INCIDENT DATE - } \\
\text { used only if INCIDENT DATE is mlssing from ACUTE INCIDENT } \\
\text { RECORDS. }\end{array}$ \\
\hline 302 & 1 & blank \\
\hline $303-311$ & 8 & $\begin{array}{l}\text { Threshold value for intake } \\
\text { - if intake to }>0.01 \text { * THRESHI * ALI, a flas is set. }\end{array}$ \\
\hline $312-320$ & $\theta$ & $\begin{array}{l}\text { Threshold value for annual dose } \\
\text { - if effeotive annual dose > THRESHAD (in mrem), a flag } \\
\text { is set. }\end{array}$ \\
\hline $321-329$ & 9 & $\begin{array}{l}\text { Ratio of MDA to Lower Critioal Limit (LC). This is used } \\
\text { to determine LC. Results below LC are set to zero. }\end{array}$ \\
\hline $330-338$ & 8 & ASSAY NAME AND WEIGHT \#1(oombined fleld) (example: BRE0,300) \\
\hline $339-347$ & 8 & ASSAY NAME AND WEIGHT \#2(combined fleld) (example: $U \quad 0,300$ ) \\
\hline $348-356$ & 8 & ASSAY NAME AND WEIGHT \#3(oombined fleld) (exarnple: F 0.300 ) \\
\hline $357-365$ & 9 & ASSAY NAME AND WEIGHT \#4(oombined fleld) (example: WBLO 300 ) \\
\hline $366-374$ & 9 & ASSAY NAME AND WEIGHT \#5(oombined field) (example: LUNO.300) \\
\hline $\begin{array}{l}375-383 \\
384\end{array}$ & $\begin{array}{l}9 \\
1\end{array}$ & $\begin{array}{l}\text { ASSAY NAME AND WEIGHT \#6(oombined fleld) (example: THYO.300) } \\
\text { blank }\end{array}$ \\
\hline 385 & 1 & MIXED CLASS IDENTIFIER \\
\hline 386 & 1 & MIXED CLASS LABEL "D" \\
\hline $387-388$ & 2 & PERCENTAGE OF CLASS "D" IN MIXED CLASS" \\
\hline 389 & 1 & MIXED CLASS LABEL "W" \\
\hline $390-391$ & 2 & PERCENTAGE OF CLASS "W" IN MIXED CLASS \\
\hline 392 & 1 & MIXED CLASS LABEL "Y" \\
\hline $\begin{array}{l}393-394 \\
395\end{array}$ & $\begin{array}{l}2 \\
1\end{array}$ & $\begin{array}{l}\text { PERCENTAGE OF CLASS "Y" IN MIXED CLASS } \\
\text { blank }\end{array}$ \\
\hline $\begin{array}{l}396-404 \\
405\end{array}$ & $\begin{array}{l}\theta \\
1\end{array}$ & $\begin{array}{l}\text { SOCIAL SECURITY NUMBER (SSN) } \\
\text { blank }\end{array}$ \\
\hline $406-414$ & 9 & $\begin{array}{l}100 * \text { SUM OF COMMIT'TED DOSES (SUM OVER NUCLIDE, CLASS, REASON) } \\
\text { THIS NUMBER IS USED TO SORT THE OUTPUT FOR THE DOSEXPRT REPORI' FILE. }\end{array}$ \\
\hline 415 & 1 & blank \\
\hline $416-421$ & 6 & START DATE for INTAKE calculation [mmddyy] \\
\hline 422 & 1 & blank \\
\hline $423-428$ & 6 & END DATE for INTAKE caloulation [mmddyy] \\
\hline 429 & 1 & blank \\
\hline 430 & 1 & $\begin{array}{l}\text { IASWCH is } 0 \text { if there are no cases with positive annual dose } \\
\text { for an individual and } 1 \text { if there is any case with positive } \\
\text { annual dose. (DOSEXPRT } 4,2 \text { ) }\end{array}$ \\
\hline 431 & 1 & 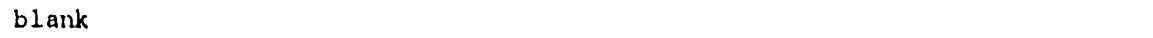 \\
\hline $432-435$ & 4 & IKYEAR is year of computation of intake, (DOSEXPRT 4,2) \\
\hline
\end{tabular}

Columns 39-50 will indicate errors if they have occurred. There are three types of errors noted: NO NUC FILE, RECORD ERROR, and WINDOW ERROR. NO NUC FILE indicates no nuclide data file for the specified nuclide and that bioassay results are greater than LC. RECORD ERROR indicates that information critical to the calculation, such as nuclide class, is missing from the bioassay record. Some missing information such as sample volume for urinalysis units dpm/sample, is replaced by default values from the SITE.DFT file. WINDOW ERROR occurs when an incident date is outside the intake window or when there are no measurements for a routine case inside the measurement window. 


\section{Appendix C}

\section{SITE-SPECIFIC FILE (SITE.DFT)}

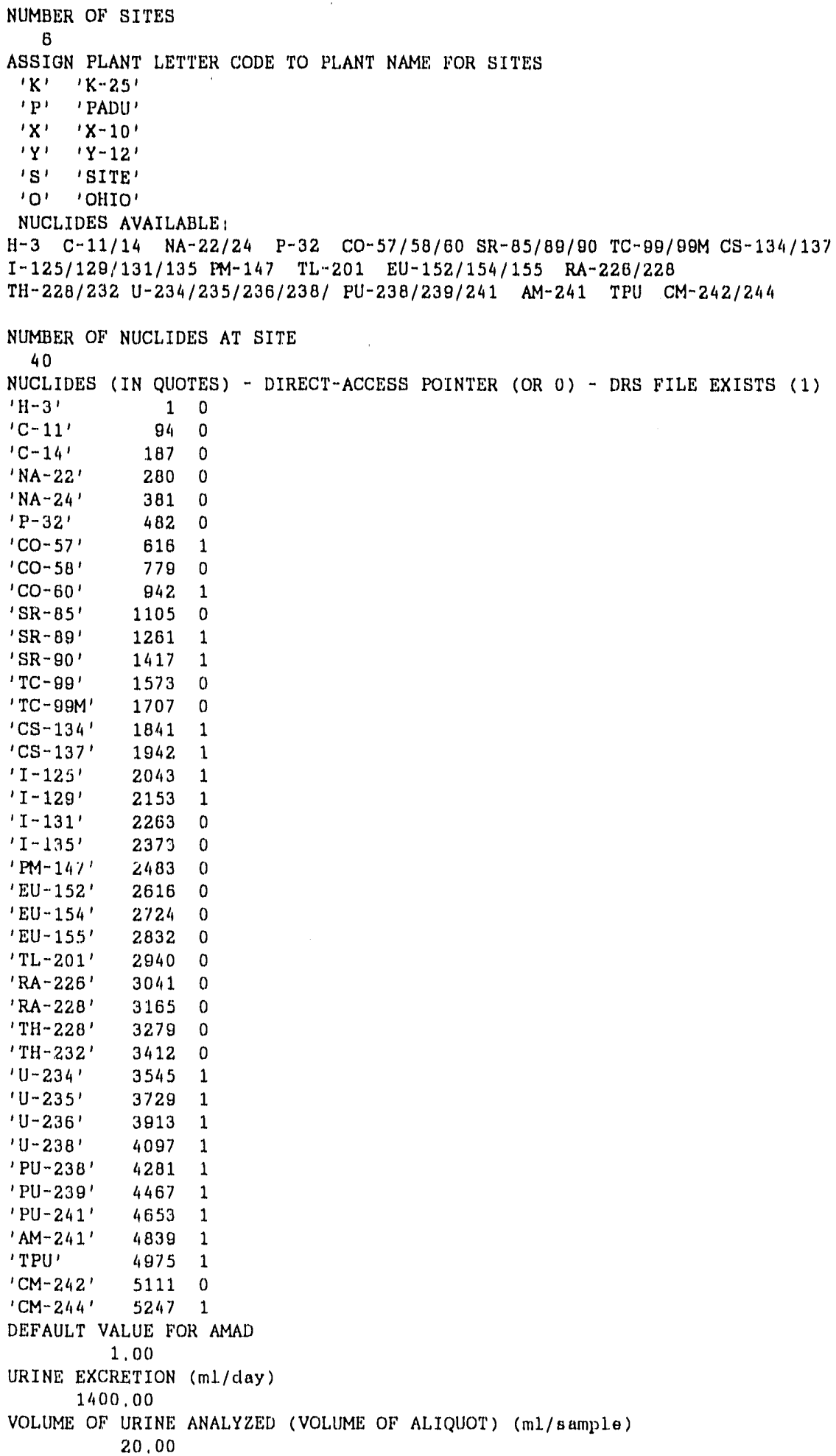


FECAL EXCRETION (grams/day)

135,00

MASS OF FECAL SAMPLE ANALYZED ( $8 \mathrm{ram} / \mathrm{sample}$ )

20,00

BREATH EXCRETION ( $L /$ day)

20000,00

VOLUME OF BREATH SAMPLE ANALYZED ( $L / 8$ aMple)

20.00

IF INCIDENT DATE (AND TIME) MISSING, INT'EGER NUMBER OF DAYS SINCE INCIDENT

RMDALC - RATTO OF MDA TO LC (LOWER CRITICAL LIMIT)

$$
1.0
$$

TRESHOLD FOR INTAKE - IF INTAKE IS > 0.01 * TRESHI * ALI, SET FLAG

2, 00

TRESHOLD FOR AEDE - IF AEDE IS > TRESHAD (mrom), SET FLAG

1.00

ANNUAL DOSE: NONE(-1), EFFECTIVE DOSE ONLY (0), EFFECTIVE/ORGAN DOSES (1) 


\section{Appendix D}

\section{DOSE-RATE FILE CONTROL TABLE (DRS.TAB)}

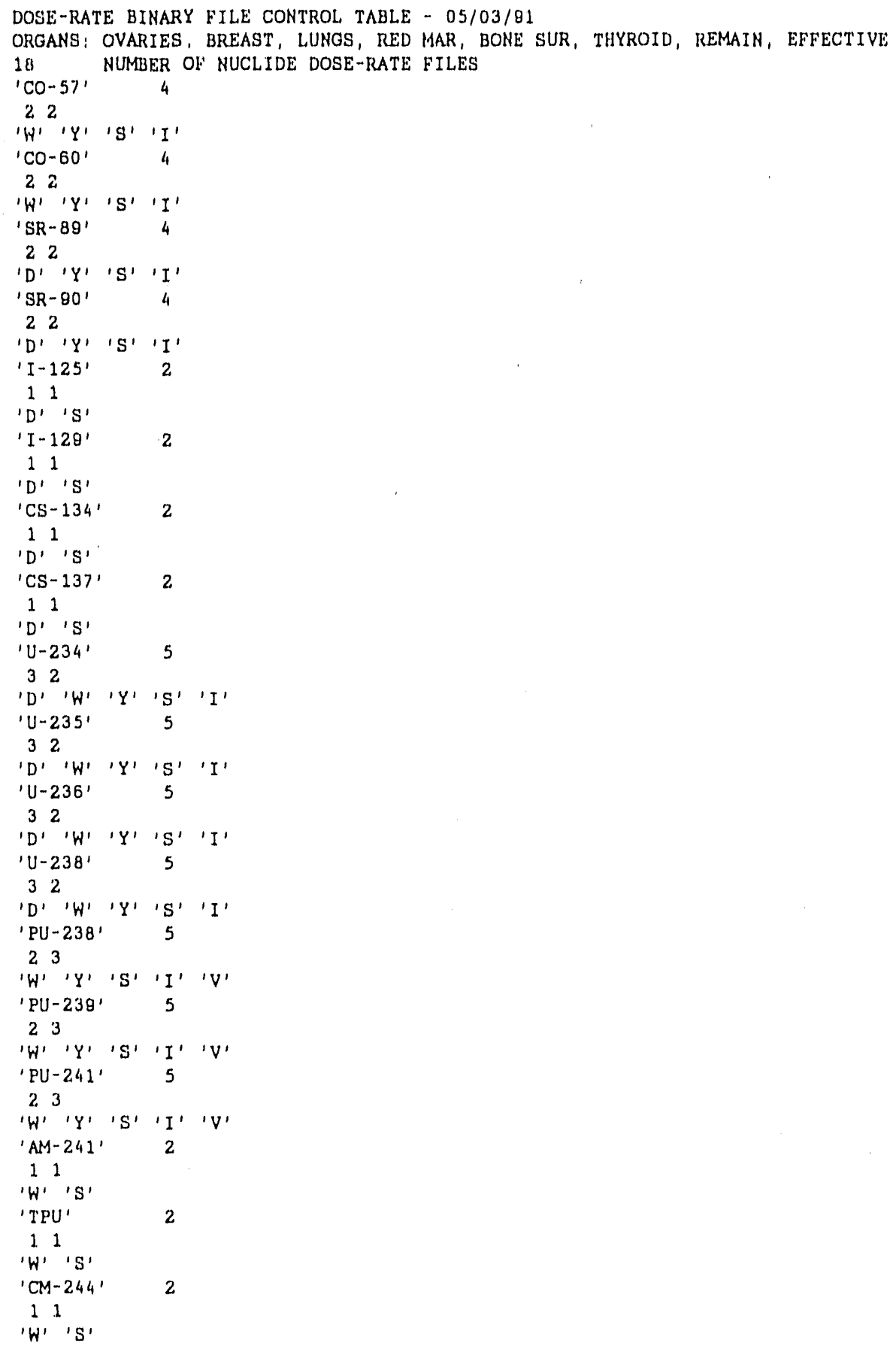




\section{Appendix E}

\section{DOSEXPRT EXAMPLES-INCIDENT EXPOSURE}

The input file (INCIDENT.DAT) for the incident exposure examples is given in Appendix I. To run all these example problems, use the SITE.DFT file shown in Appendix $C$, but set NDAYS to 10 and set annual dose calculation parameter to -1 . In all cases the incidents occurred in 1989. The user should use a measurement window and an intake window starting in 1989 with a duration of 1 year. The example output is listed in Appendices $\mathrm{J}$ and $\mathrm{K}$.

The first example is inhalation exposure to tritium, taken from a publication of Snyder et al. ${ }^{15}$ Note that only the first 119 days of incident data are used in this example. The additional excretion data should increase the result by only a few percent.

Example $1($ BADGE $=-10)$ Nuclide H-3 Literature DOSEXPRT Results
Urinalysis
$86 \mathrm{mCl}$
$70 \mathrm{mCi}$

The next three incident exposure examples are taken from NUREG/CR-4884 (ref. 16). The intakes given for the examples in NUREG/CR-4884 are compared with our results in this table:

NUREG/CR-4884 DOSEXPRT Results

Example $2($ BADGE $=-20)$ Nuclide $I-131$

Urinalysis

In vivo assay
$4.99 \times 10^{6} \mathrm{~Bq}$

$1.34 \times 10^{7} \mathrm{~Bq}$
$5.15 \times 10^{6} \mathrm{~Bq}$

$1.37 \times 10^{7} \mathrm{~Bq}$

Example 3 (BADGE $=-31,-32,-33$ ) Nuclide U-238

Individual 1 (Urinalysis)

Individual 2 (Urinalysis)

Individual 3 (Urinalysis)

$136 \mathrm{~Bq}$

$260 \mathrm{~Bq}$

$21 \mathrm{~Bq}$
$175 \mathrm{~Bq}$

$289 \mathrm{~Bq}$

$18 \mathrm{~Bq}$

Example 4 (BADGE $=-41, .42$ ) Nuclide Cs-137

Individual 1 (WBL assay)

Individual 2 (WBL assay)

$878 \mathrm{~Bq}$

$2240 \mathrm{~Bq}$

$939 \mathrm{~Bq}$

$2400 \mathrm{~Bq}$

(The results for Example 3 were converted from $\mu \mathrm{g}$ to $\mathrm{Bq}$. Example 4 was also run as a routine case to compare the routine results with those obtained for the incident case above. For routine, we obtain $238 \mathrm{~Bq}$ for Individual 1 and $608 \mathrm{~Bq}$ for Individual 2. We would expect that the routine results would be less than the incident results and of the order of those obtained here.)

Differences between the DOSEXPRT results and those in NUREG/CR-4884 are probably because of weighting of the individual measurements in NUREG/CR-4884. 
DOSEXPRT uses uniform weighting of the bloassay measurements.

EXAMPLE $5($ BADGE $=-50)$ is the same as EXAMPLE 1 (an I-131 incident) except that some of the information is missing on the records. DOSEXPRT uses default values from the SITE.DFT file and from the nuclide files to fill in the missing information. Note that the time between the first measurement and the incident date (in the SITE.DFT file) must be set to 10 days to execute this example.

EXAMPLE 6 (BADGE $=-60)$ is a Tc-99 ingestion incident (urinalysis) from ref. 17 (Table 2, page 1433). Because the table gives percent administered dose excreted per day, we assign units of $\mathrm{Bq} / \mathrm{day}$ to percent values and obtain an estimated intake of $100 \mathrm{~Bq}$.

\section{Literature $\quad$ DOSEXPRT Results}

Estimated intake: $\quad 100 \mathrm{~Bq} \quad 130 \mathrm{~Bq}$

EXAMPLE 7 (BADGE $=-70$ ) is a Tc-99 injection incident (fecal) from ref. 17 (Fig 10, page 1433). Because the figure shows percent injected dose excreted per day, we assign units of $\mathrm{Bq} /$ day to percent values and obtain an estimated intake of $100 \mathrm{~Bq}$.

\section{Literature $\quad$ DOSEXPRT Results}

Estimated intake: $\quad 100 \mathrm{~Bq} \quad 82 \mathrm{~Bq}$

EXAMPLE $8($ BADGE $=-90)$ is a Sr-90 injection incident (urinalysis and fecal assay) from ref. 18 (individual SSL, Table 3, page 53). Because results are expressed in percent injected activity excreted per day, we assign units of $\mathrm{Bg} /$ day to the values and obtain an estimated intake of $100 \mathrm{~Bq}$ in each case.

\section{Literature $\quad$ DOSEXPRT Results}

$\begin{array}{lll}\text { Estimated intake (urinalysis): } & 100 \mathrm{~Bq} & 41 \mathrm{~Bq} \\ \text { Estimated intake (fecal assay): } & 100 \mathrm{~Bq} & 66 \mathrm{~Bq}\end{array}$

EXAMPLE 9 (BADGE $=-100$ ) is a Pu-241 injection incident (urinalysis) from ref. 19 (interval 5-19 of Table 2, page 343). In DOSEXPRT we treated this as a class W inhalation incident. Because results are expressed as percent of injected amount excreted per day, we assign units of $\mathrm{Bq} / \mathrm{day}$ and have an estimated intake of $100 \mathrm{~Bq}$ if uptake had been by injection as shown in the reference. The transfer of material from the lungs to the blood is $12 \%$ for class $\mathrm{W}$ inhalation of $\mathrm{Pu}-241$. Thus, we would expect a result of $12 \mathrm{~Bq}$ for class $\mathrm{W}$ inhalation, which is what we oblained.

Literature $\quad$ DOSEXPRT Results

Estimated intake (injection): $\quad 100 \mathrm{~Bq}$

Estimated intake (inhalation): $\quad 12 \mathrm{~Bq} \quad 12 \mathrm{~Bq}$ class W 
EXAMPLE $10($ BADGE $=-110)$ is a Pu-238 Inhalation (class $W$ ) Incident, fecal bioassay. The hand calculation, which was done by ORNL internal dosimetrist E. Brackett, assumed that the two fecal samples contained the total activity excreted for the first 3 days post intake. The retention function from NUREG/CR-4884 was used.

Hand Calculation DOSEXPRT Results

Estimated intake:

$20 \mathrm{~Bq}$

$18 \mathrm{~Bq}$

Committed effective dose:

$200 \mathrm{mrem}$

194 mrem 


\section{Appendix F}

\section{DOSEXPRT EXAMPLES-ROUTINE EXPOSURE}

The input file (ROUTINE.DAT) for the routine exposure examples is given in Appendix I. The output is listed in Appendices $\mathrm{J}$ and $\mathrm{K}$. The routine examples were generated using an IBM PC-AT BASIC routine, PANELS. PANELS uses the same algorithuns as DOSEXPRT but was coded independently of DOSEXPRT by Keith Eckerman. To run this example, use the SITE.DFT file in Appendix $C$ with the annual dose calculations parameter set to 1 . The user should enter a starting date of 1989 and duration of 1 year for both the measurement and intake winduss.

The first of the routine examples $(\mathrm{BADGE}=-120)$ is exposure to $\mathrm{I}-131$ at a uniform rate of $2000 \mathrm{~Bq} / \mathrm{day}$. Since the duration of the intake wintow is 1 year, the total intake should be $2000 \mathrm{~Bq} / \mathrm{day} * 365$ days or $7.3 \times 10^{5} \mathrm{~Bq}$. This example assumes that the assay is thyroid count (THY) to test the thyroid retention algorithms in the code. In the tables shown here, the EXACT result is the total intake used in the PANELS program to generate the measurement values.

EXAMPLE 11 Nuclide: I-131 RESULTS

DOSEXPRT

Estimated intake:

$7.3 \times 10^{5} \mathrm{~Bq}$

$7.29 \times 10^{5} \mathrm{~Bq}$

The rest of the routine examples are in sets, one for each inhalation class, and are routine exposure to either uniform or nonuniform intake rate of U-238. For all of these examples, the user is asked the starting date (1989) and duration (1 ycar) for both the measurement and intake windows. Each example assumes that the assay is lung count (LUN) to test the lung retention algorithms in the code.

The first of these (BADGE $=-131,-132,-133$ ) is routine exposure to $\mathrm{U}-238$ at a uniform rate of $100 \mathrm{~Bq} / \mathrm{day}$. The total intake for a period of 1 year will be $100 \mathrm{~Bq} /$ day $* 365$ days or $3.65 \times 10^{4}$.

EXAMPLE 12 Nuclide: U-238

Time Intake Rate(Bq/day)

$\begin{array}{ll}100 & 100 \\ 200 & 100 \\ 300 & 100 \\ 365 & 100\end{array}$

RESULTS

\begin{tabular}{lcl}
\multicolumn{3}{c}{ Lung Burden (Bq) } \\
Class D & Class W & Class Y \\
22.35 & 884.7 & 1462 \\
22.35 & 1121 & 2649 \\
22.35 & 1186 & 3911 \\
22.35 & 1200 & 4607
\end{tabular}

Estimated intake (for all classes): $3.65 \times 10^{4} \mathrm{~Bq} \quad 3.65 \times 10^{4} \mathrm{~Bq}$ 
The second set of routine examples (BADGE $=-141,-142,-143$ ) was developed by assigning constant but differing intake rates in four panels through the year.

EXAMPLE 13 Nuclide: U-238 Total Intake: $1.52 \times 10^{4} \mathrm{~Bq}$

Time Intake Rate(Bq/day)

100

200

100

300

1

365

50

1

Lung Burden (Bq)

$\begin{array}{ccc}\text { Class D } & \text { Class W } & \text { Class Y } \\ 22.35 & 884.7 & 1462 \\ 0.22 & 245.3 & 1301 \\ 11.17 & 509.8 & 1907 \\ 0.22 & 221.3 & 1778\end{array}$

RESULTS

Exact

DOSEXPRT

Estimated intake (for all classes): $1.52 \times 10^{4} \mathrm{~Bq} \quad 1.51 \times 10^{4} \mathrm{~Bq}$

The last routine example (BADGE $=-150$ ) is exposure to $U-238$ with both a lung and whole body count. This example is provided to exhibit the assay averaging used to obtain the committed and annual effective dose (see report output listing). 
Appendix G

\section{FLOWCHART OF DOSEXPRT}

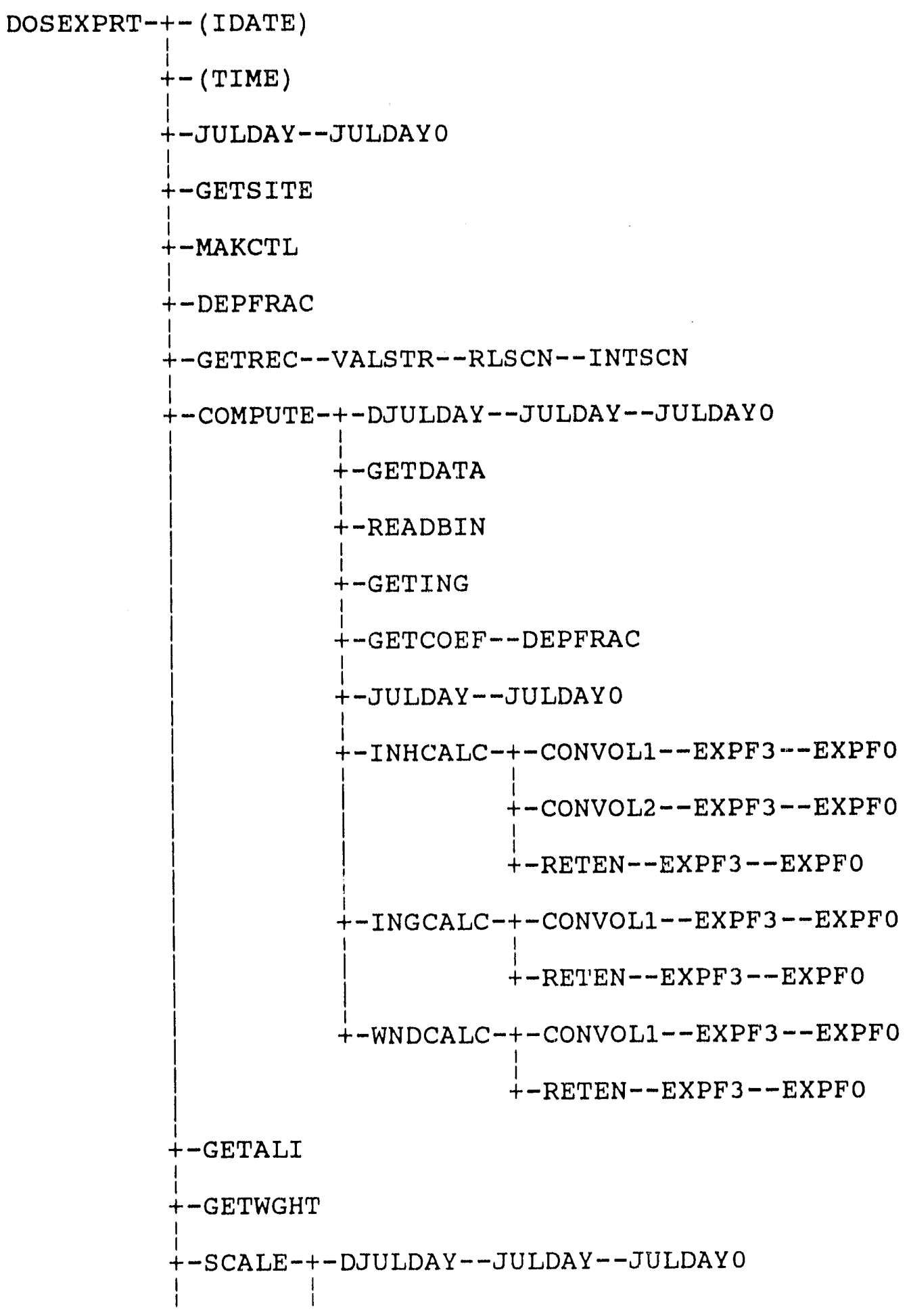


79

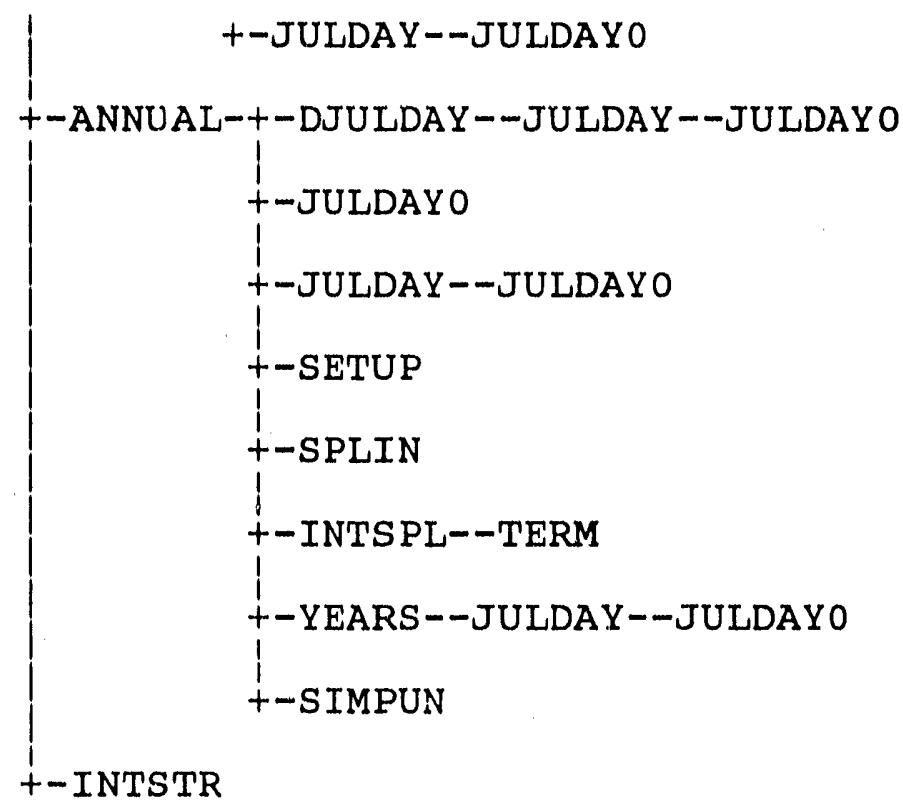




\section{Appendix H}

\section{LISTINGS OF NUCLIDE FILES}

This appendix contains listings of the DOSEXPRT nuclide files. For evaluating 1990 and 1991 bioassay data, a total of 40 nuclide data files were used, which included the file TPU. The latter file was identical to the Am-241 nuclide data file. The nuclide data files all

have extension NUC. The nuclide files are combined into the binary, direct-access file NUCLIDE.BIN. 


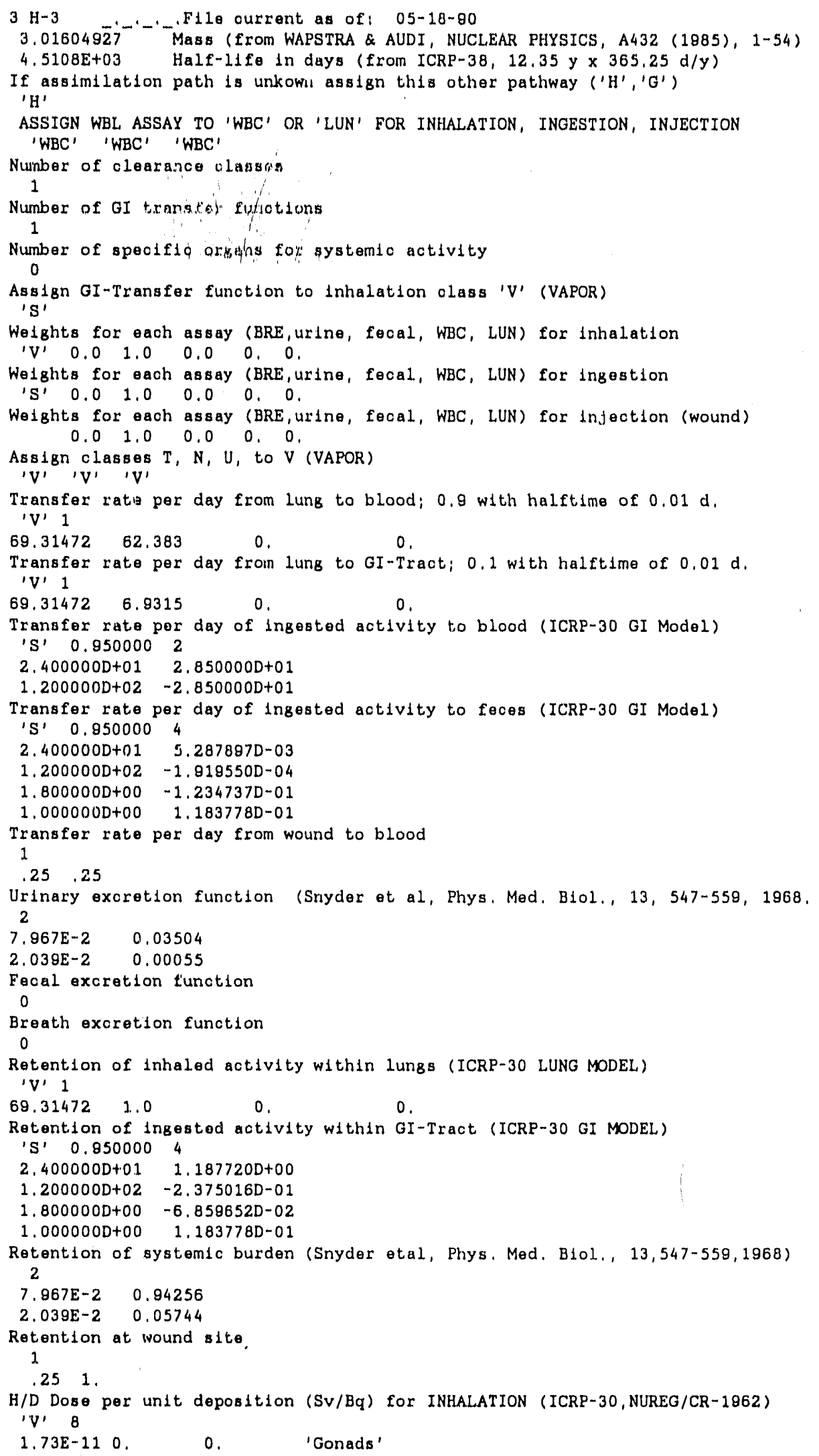




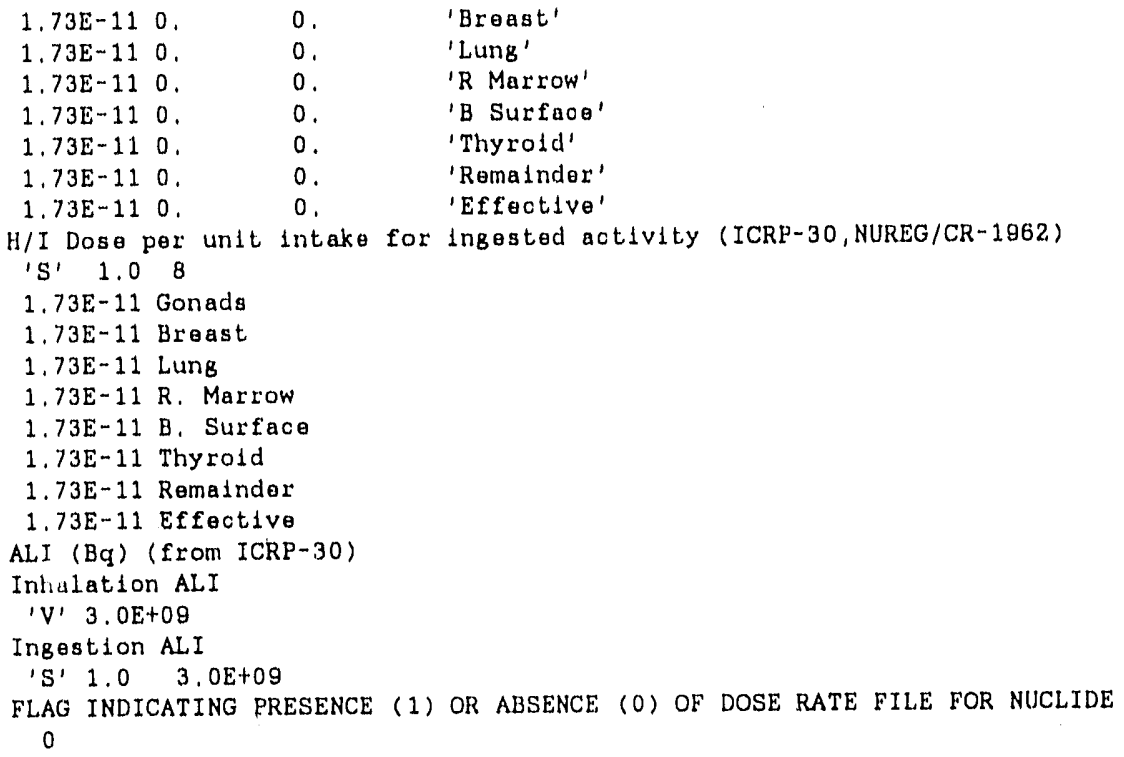


C-11 --D-D.F1le ourrent as of: 01-22-911

$11.01143 \overline{3} 3^{-1}-1$ Mass (from WAPSTRA \& AUDI, NUCLEAR PHYSICS, A432 (1985), 1-54)

0.01415278 Half-11fe in days (from ICRP $-38,20.38 \mathrm{~m} \star \mathrm{d} / 1440 \mathrm{~m}$ )

If assimilation path is unkown assign this other pathway $\left(H^{\prime},{ }^{\prime} G\right.$ ')

' $\mathrm{H}$ '

ASSIGN WBL ASSAY TO 'WBC' OR 'LUN' FOR INHALATION, INGESTION, INJECTION

'WBC' 'WBC' 'WBC'

Number of olearance olasses

1

Number of GI transfer functions

1

Number of speolfio organs for systemio aotivity

0

Asslgn GI-Transfor function to inhalation olass ' $L$ ' (Labolited oompounds)

'S'

Weights for each assay (BRE, urine, fecal, WBC, LUN) for inhalation

'L' $0.1 \quad 0.45 \quad 0.0 \quad 0.45 \quad 0.0$

Welghts for each assay (BRE, urine, feoal, WBC, LUN) for ingestion

'S' $0.10 .450 .0 \quad 0.45 \quad 0.0$

Welghts for each assay (BRE, urine, fecal, WBC, LUN) for injection (wound) $\begin{array}{llllll}0.1 & 0.45 & 0.0 & 0.45 & 0.0\end{array}$

Assign classes $T, N, U$, to $L$ (Labelled compounds)

'L' 'L' 'L'

Transfer rate per day from lung to blood; 0.9 with halftime of $0.01 \mathrm{~d}$.

'L' 1

69.3147262 .383
Transfer rate per day from lung to GI-Tr

Transfer rate per day from lung to GI-Tract; 0.1 with halftime of $0.01 \mathrm{~d}$.

'L' 1

$69.31472 \quad 6.9315 \quad 0$ ingested aotivitty

Transfer rate per day of ingested aotivity to blood (ICR!-30 GI Model)

'S' $0.850000 \quad 2$

$2.400000 D+01 \quad 2,850000 D+01$

$1,200000 \mathrm{D}+02-2,850000 \mathrm{D}+01$

Transfer rate per day of ingested activity to feoes (ICRP-30 GI Mode1)

'S' $0.850000 \quad 4$

$2.400000 D+01 \quad 5.287897 D-03$

$1.200000 \mathrm{D}+02-1.919550 \mathrm{D}-04$

$1.800000 D+00-1.234737 D-01$

$1.000000 \mathrm{D}+00 \quad 1.183778 \mathrm{D}-01$

Transfer rate per day from wound to blood

1

.25 .25

Urinary excretion funotion $E u(t)=-0.45 d R(t) / d t ; R(t)=\exp (-0.693 t / 40)$

1

$1.732868 E-02 \quad 7.797906 E-03$

Fecal excretion function

1

$1.732868 \mathrm{E}-02 \quad 1.732868 \mathrm{E}-03$

Breath excretion function $E b(t)=-0.45 d R(t) / d t ; R(t)=\exp (-0.693 t / 40)$

1

$1.732868 \mathrm{E}-02 \quad 7.797906 \mathrm{E}-03$

Retention of Inhaled activity within lungs (ICRPי30 LUNG MODEL)

'L' 1

69. $31472 \quad 1.0 \quad 0$

Retention of ingested activity within GI-Tract (ICRP-30 GI MODEL)

'S' 0.8500004

$2.400000 D+01 \quad 1.187720 D+00$

$1.200000 D+02-2.375016 D-01$

$1.800000 \mathrm{D}+00-6.859652 \mathrm{D}-02$

$1.000000 \mathrm{D}+00 \quad 1.183778 \mathrm{D}-01$

Retention of systemlc burden: $R(t)=\exp (-0.693 t / 40)$

1

$1.732868 \mathrm{E}-02 \quad 1.0$

Retention al wound site

1

.251.

H/D Dose per unit deposition (Sv/Bq) for INHALATION (ICRP-30,NUREG/CR-1962) ' $L$ ' 8

3.41E-12 0. $0 . \quad$ 'Gonads' 


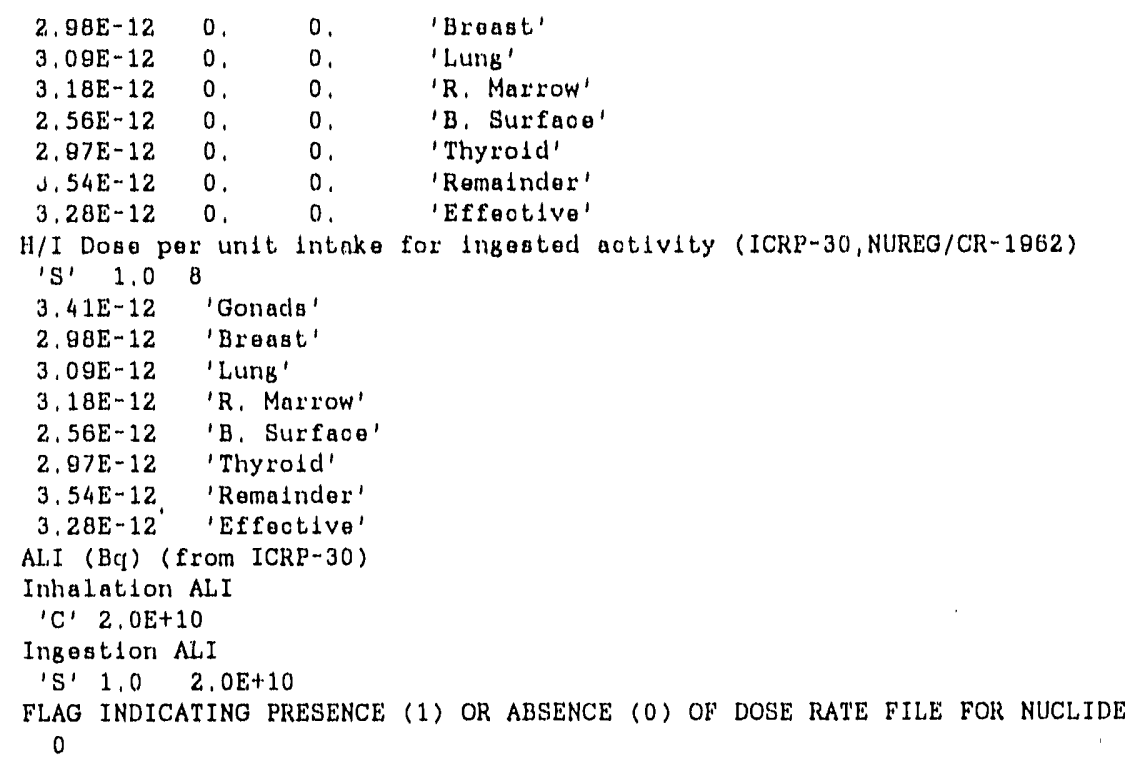




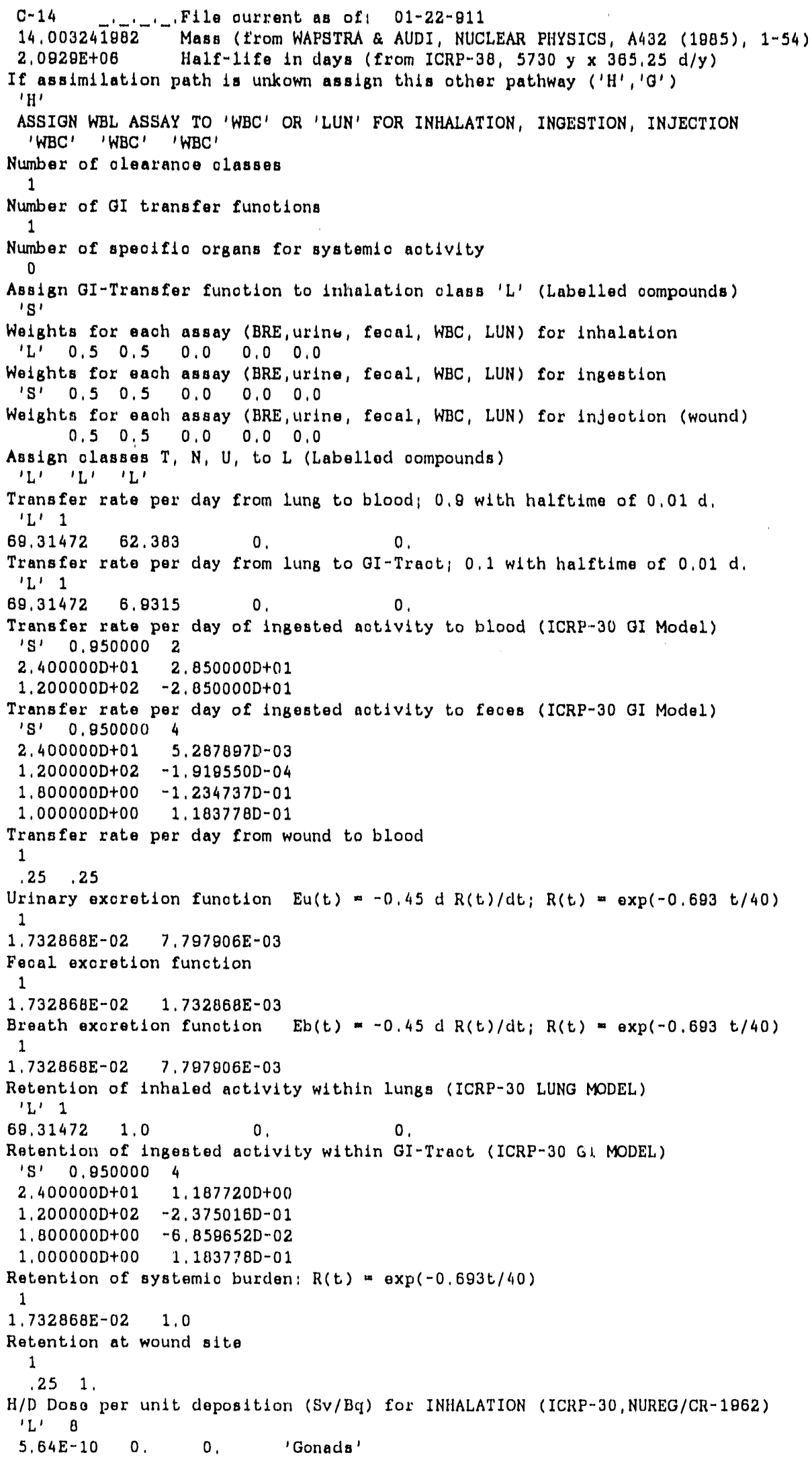




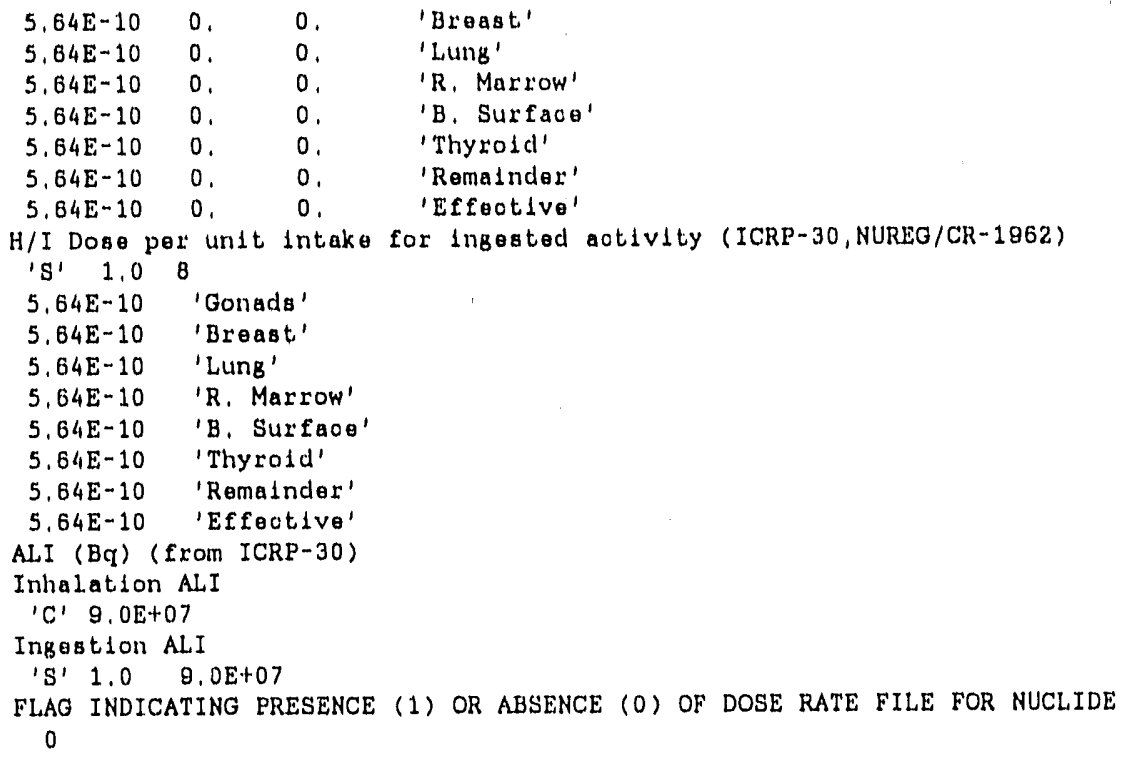


Na-22 $-1-\bar{B}^{-}-\mathrm{F}_{10}$ ourrent as of $01-04-01$

21. $9944 \overrightarrow{3} 4 \overline{1}-$ Mas\& (from WAPSTRA \& AUDI, NUCLEAR PHYSICS, A432 (1985), 1-45)

950.30 Half-11fe in days (ICRP-38, 2.602 y *365.25 d/y)

If assimilation path is unkown assign this other pathway ('H', ' $O$ ')

'H'

ASSIGN WBL ASSAY TO 'WBC' O'R 'LUN' FOR INHALATION, INGESTION, INJEC'ION

'WBC' 'WBC' 'WBC'

Number of olearanoe olassos

1

Number of GI transfor funotions

1

Number of spoolfio organs for systemlo autivity

0

Asslgn GI-transfer funotion to inhalation olass ' $D$ '

' $\mathrm{S}$ '

Wolghts for eaoh assay (BRE, urine, feoal, WBC, LUN) for olearanoe class

'D' $0.0 \quad 0.3 \quad 0.1 \quad 0.6 \quad 0$.

Wolghts for each assay (BRE, urine, fecal, WBC, LUN) for ingestion

' $\mathrm{S}$ ' $0.0 \quad 0.3 \quad 0.1 \quad 0.6 \quad 0$.

Wolghts for eaoh assay (BRE, urine, feoal, WBC, LUN) for injeotion (wound) $\begin{array}{lllll}0.0 & 0.3 & 0.1 & 0.6 & 0 .\end{array}$

Assign olasses T, N, U, to D

'D' $D$ ' $D$ '

Transfor rate per day from lung to blood olass D (ICRP-30 LUNG MODEL)

'D' 3

$6.9315 D+01 \quad 3,46573590+01 \quad 6.5848982 D+01 \quad 0,0000000 D+00$

$1.3863 D+00 \quad 0.0000000 D+00 \quad 0.0000000 D+00-1.3752040 D+02$

$\begin{array}{llll}1,3835 \mathrm{D}+00 & 0,0000000 \mathrm{D}+00 & 0.0000000 \mathrm{D}+00 & 1,3862944 \mathrm{D}+02\end{array}$

Transfer rate per day from lung into GI-Traot Class D. (ICRP-30 LUNG MODEL)

'D' 2

$6.9315 D+01 \quad 3.4657359 D+01 \quad 0.0000000 D+00 \quad 0.0000000 D+00$

$3.4657 D+00 \quad 0.0000000 D+00 \quad 1.7328680 D \cdots 01 \quad 0.0000000 D+00$

Transfer rate pel day of ingested aotivity to blood (ICRP-30 GI MODEL)

'S' $0.950000 \quad 2$

2. $4000000+01 \quad 2.850000 D+01$

$1,200000 D+02-2,850000 D+01$

Transfer rate per day of ingested aotivity to feoes (ICRP-30 GI MODEL)

's' $0.950000 \quad 4$

$2.400000 D+01 \quad 5.2878970-03$

$1,200000 D+02-1.9195500-04$

$1,800000 D+00-1.234737 D-01$

$1,000000 D+00 \quad 1,183778 D-01$

Transfer rate per day from wound to blood

1

$.25 \quad .25$

Urinary excretion funotion $=.75 *-d R(t) / d t$

2

$6,83147 E-02 \quad 5,18301 E-02$

$1,38629 \mathrm{E}-03 \quad 3,11916 \mathrm{E}-06$

Feoal excretion funotion $=.02 *-d R(t) / d t$

2

$6.93147 \mathrm{E}-02 \quad 1,38214 \mathrm{E}-03$

1.38628E-03 8.31777E-08

Breath excretion funotion

0

Retention of Inhaled aotivity within lungs (ICRP-30 LUNG MODEL)

'D' 4

$6.9315 D+01 \quad 1.0000000 D+00 \quad 8,5000000 D-01 \quad 0.0000000 D+00$

$3,46,57 D+00 \quad 0,0000000 D+00 \quad 5,0000000 D-02 \quad 0,0000000 D+00$

$1.3863 D+00 \quad 0,0000000 D+00 \quad 0,0000000 D+00-9,9200000 D+01$

$\begin{array}{lllll}1.3835 D+00 & 0.0000000 D+00 & 0.0000000 D+00 & 1.0020000 D+02\end{array}$

Retention of ingested activity within GI-Tract (ICRP-30 GI MODEL)

's' 0.8500004

$2.4000000+01 \quad 1.1877200+00$

$1.200000 D+02-2.375016 D-01$

$1.800000 D+00 \quad-6.859652 D-02$

$1.000000 D+00 \quad 1.183778 D-01$

Retention of systemlo activity (ICRP-30

2 


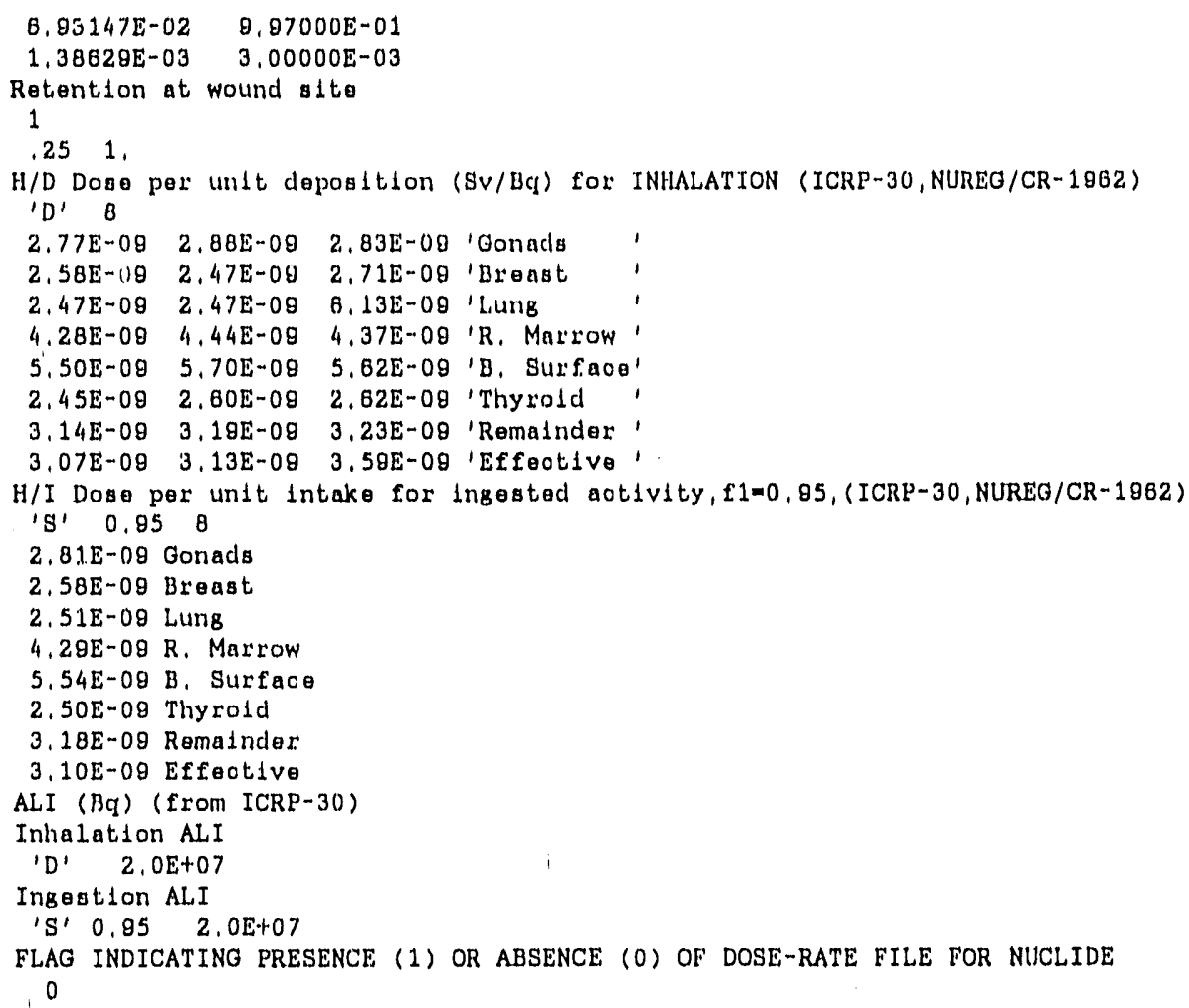


$\mathrm{Na}-24 \quad-1 \ldots+$ F1le ourrent as of $01-04-91$

23, $9909 \overline{6} 1 \overline{4}^{\prime} \cdots+$ Mass (from WAPSTRA \& AUDI, NUCLEAR PHYSICS, A432 (1985), 1-45)

0.625 Ilate-11fo in days (ICRP-38, $15 \mathrm{~h} * \mathrm{~d} / 24 \mathrm{~h}$ )

If assimllation patli 18 unkown assign this othor pathway $\left(' H^{\prime}, \mathrm{C}^{\prime}\right)$

'H'

ASSIGN WBL ASSAY TO "WDC' OR 'LUN' FOR INHALATION, INGESTION, INJECTION

'WBC' 'WBC' 'WBC'

Number of olearanoe 0 ) asses

1

Number of $G I$ transfer funotiona

1

Number of spoolfio orbans fol systemlo aotivity

Assign GI-transfer funotion to Inhalation olass ' $D$ '

' $\mathrm{S}$ '

Welght, for oach assay (BRE, urino, fooal, WBC, LUN) for oloaranco olass

'D' $0.0 \quad 0.3 \quad 0.1 \quad 0.6 \quad 0$.

Wolghts for oach assay (BRE, urine, fooal, WBC, LUN) for ingestion

'S' $0.0 \quad 0.3 \quad 0.1 \quad 0.6 \quad 0$.

Welghts for each assay (BRE, urino, feoal, WBC, LUN) for injection (wound),

$\begin{array}{llllll}0.0 & 0.3 & 0.1 & 0.6 & 0 .\end{array}$

Assign olasegs $T, N, U$, to $D$

'D' 'D' 'D'

Transfer rate per day from lung to blood olase D (ICRP-30 LUNG MODEL)

' $D$ ' 3

$6.9315 D+01 \quad 3,46573590+01 \quad 6,5848982 D+01 \quad 0.0000000 D+00$

$1.3863 D+00 \quad 0,0000000 D+00 \quad 0,0000000 D+00-1.3752040 D+02$

$1.3835 D+00 \quad 0.0000000 D+00 \quad 0.0000000 D+00 \quad 1.3862944 D+02$

Transfer rate per day from lung into GI-Tract Class D, (ICRP-30 LUNG MODEL)

'D' 2.

$6.9315 D+01 \quad 3,4657359 D+01 \quad 0,0000000 D+00 \quad 0.0000000 D+00$

$3.4657 D+00 \quad 0,0000000 D+00 \quad 1,7328680 D-01 \quad 0.0000000 D+00$

Transfer rate per day of ingested activity to blood (ICRP-30 GI MODEL)

'S' $0.950000 \quad 2$

$2.4000000+01 \quad 2.8500000+01$

$1,2000000+02-2,8500000+01$

Transfer rate per day of ingestud activity to feces (ICRP-30 GI MODEL)

's' $0.950000 \quad 4$

$2.400000 D+01 \quad 5.287887 D-03$

$1.200000 D+02-1.919550 D \cdot 04$

$1.800000 D+00-1.234737 D-01$

$1.0000000+00 \quad 1.1837780-01$

Transfer rate per day from wound to blood

$.25 \quad .25$

Urinary excretion function $=.75 *-\mathrm{dR}(\mathrm{t}) / \mathrm{dt}$

2

$6.93147 E-02 \quad 5.18301 E-02$

1.38629E-03 3.11916E-06

Fooal excrotion iunotion $=.02 *-\mathrm{dR}(t) / \mathrm{dt}$

2

$6.93147 E-02 \quad 1.38214 E-03$

$1.38629 \mathrm{E}-03 \quad 8.31777 \mathrm{E}-08$

Breath exoretion function

n

Retention of inhalod activity within Lungs (ICRP-30 LUNG MODEL)

'D' 4

$6.931 .5 D+01 \quad 1.0000000 D+00 \quad 9.5000000 D-01 \quad 0.0000000 D+00$

3.4657D+00 $0.0000000 D+00 \quad 5.0000000 D-02 \quad 0.0000000 D+00$

$1.3863 \mathrm{D}+00 \quad 0.0000000 \mathrm{D}+00 \quad 0.0000000 \mathrm{D}+00-9.9200000 \mathrm{D}+01$

$1.3835 D+00 \quad 0.00000000+00 \quad 0.0000000 D+00 \quad 1.0020000 D+02$

Retention of ingestod activity within GI-Trant (ICRP-30 GI MODEL)

'S' 0.9500004

$2.4000000+01 \quad 1,1877200+00$

$1,200000 D+02-2.375016 D-01$

$1,800000 D+00-6,859652 D \cdots 02$

$1.000000 D+00 \quad 1.183778 D-01$

Retention of systemlo activity (ICRP-30

2 


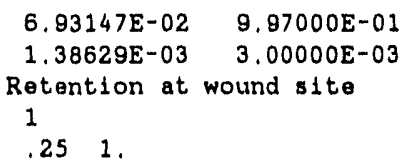




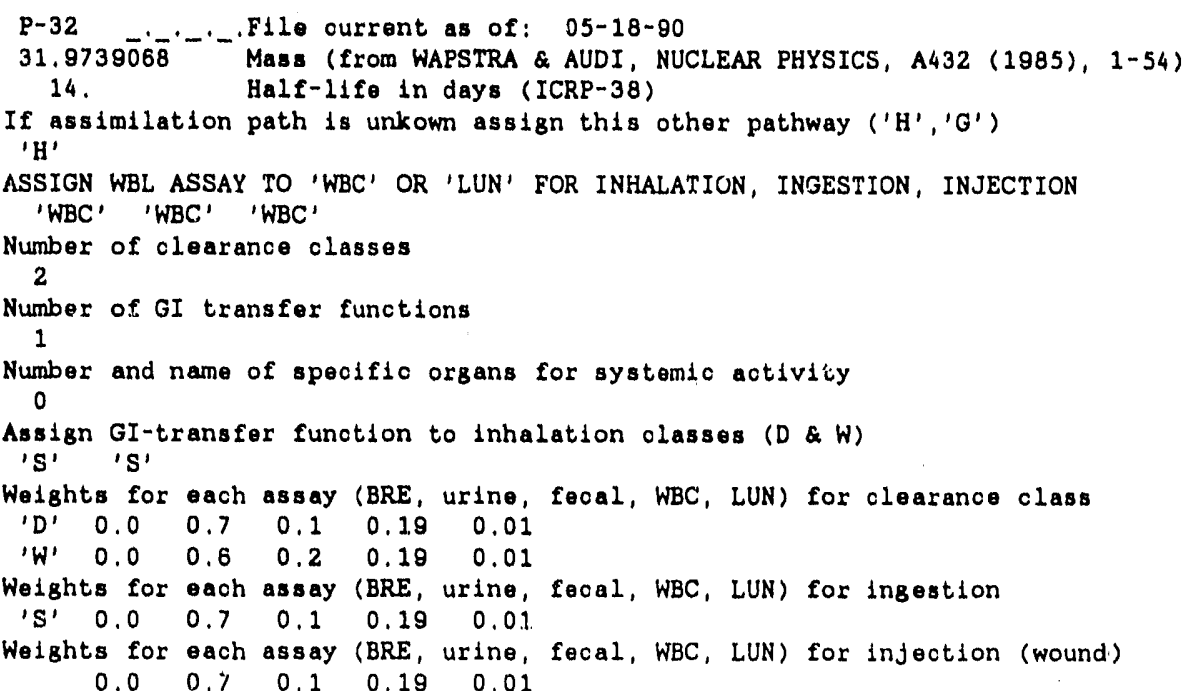

Assign classes $T, N, U$, to $D$

'D' ' $W$ ' ' $D$ '

Transfer rate per day from lung to blood (ICRP-30 LUNG MODEL)

'D' 3

$6.9315 D+01 \quad 3.4657359 D+01 \quad 6.5848982 D+01 \quad 0.0000000 D+00$

$\begin{array}{llll}1.3863 D+00 & 0.0000000 D+00 & 0.0000000 D+00 & -1.3752040 D+02\end{array}$

$1.3835 \mathrm{D}+00 \quad 0.0000000 \mathrm{D}+00 \quad 0.0000000 \mathrm{D}+00 \quad 1.3862944 \mathrm{D}+02$

' $W$ ' 3

$6.9315 D+01 \quad 6.9314718 D+00 \quad 3.4657358 D+01 \quad 0.0000000 D+00$

$1.3863 D-02 \quad 0.0000000 D+00 \quad 0.0000000 D+00-3.4449415 D-01$

$\begin{array}{lllll}1.3835 D-02 & 0.0000000 D+00 & 0.0000000 D+00 & 3.4657359 D-01\end{array}$

Transfer rate per day from lung into GI-Tract (ICRP-30 LUNG MODEL)

' $D$ ' 2

6. $9315 \mathrm{D}+01 \quad 3.46573590+01 \quad 0.006,0000 D+00 \quad 0.0000000 D+00$

$3.4657 \mathrm{D}+00 \quad 0.0000000 \mathrm{D}+00 \quad 1.7328680 \mathrm{D}-01 \quad 0.0000000 \mathrm{D}+00$

'W' 4

$3.4657 \mathrm{D}+00 \quad 0.0000000 \mathrm{D}+00 \quad 1.7328680 \mathrm{D}+00-3.5214104 \mathrm{D}-01$

$\begin{array}{lllll}1.7329 D+00 & 1.5595812 D+00 & 0.0000000 D+00 & 0.0000000 D+00\end{array}$

$\begin{array}{llll}6.9315 \mathrm{D}-01 & 0.0000700 \mathrm{D}+00 & 0.0000000 \mathrm{D}+00 & 3.4657359 \mathrm{D}-01\end{array}$

$\begin{array}{lllll}1.3863 D-02 & 0.0000000 D+00 & 0.0000000 D+02 & 5.5674472 D-03\end{array}$

Transfer rate per day of ingestied activity to blood. (ICRP-30 GI Model)

'S' 0.8000002

2.400000D+01 $9.6000000+01$

$3.000000 D+01-9.600000 D+01$

Transfer rate per day of ingested activity to feces. (ICRP-30 GI Model) 'S' $0.800000 \quad 4$

2. $400000 D+01 \quad 8.460635 D-02$

3. $000000 D+01-5.282465 D-02$

i. $8000000+00-5.175388 D-01$

1. $000000 D+00 \quad 4.8575710 .01$

Transfer rate per day from wound to blood 1

.25 .25

Urinary excretion function (f_umo.9 0 Differential of $R(t)$ of ICRP-30) 4

1.386294D+00 1.871497E-01

3. $465736 \mathrm{E}-01 \quad 4.678744 \mathrm{E}-02$

3. $648143 E-02 \quad 1,313331 E-02$

$6.931472 \mathrm{E}-01 \quad 1.882750 \mathrm{E}-07$

Fecal excretion function ( $f f=0.1 \times$ Differential of $R(t)$ of ICRP 30 )

$1.386294 D+00 \quad 2.079441 E-02$

$3.465736 \mathrm{E}-01 \quad 5,198604 \mathrm{E}-03$

$3.648143 \mathrm{E}-02 \quad 1.459257 \mathrm{E}-03$

$6.931472 E \cdot 07 \quad 2.079442 E-08$

Breath 11mination 


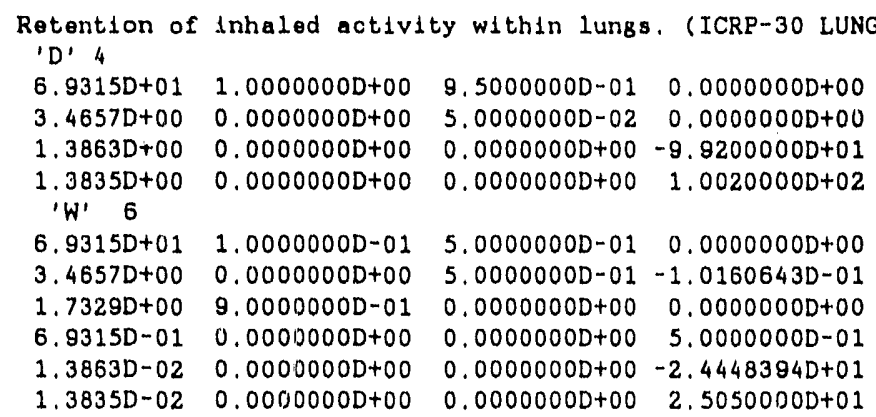

Retention of ingested activoty within GI-Tract (ICRP-30 GI Model) 'S' 0.8000004

2. $4000000+01 \quad 4.0035250+00$

$3.000000 D+01-3.201761 D+00$

1.800000D+00 $-2.875216 \mathrm{D}-01$

1. $0000000+00 \quad 4.8575710-01$

Retention of systemic activity (R(t) from ICRP-30, Part 2) 4

$1.386294 D+00 \quad 0.15$

$3.465736 E-01 \quad 0.15$

$3.648143 \mathrm{E}-02 \quad 0.40$

$6.931472 \mathrm{E}-07 \quad 0.30$

Retention at wound site

1

.251.

H/D DOSE per unit deposition (Sv/Bq) FOR INHALATION (ICRP-30, EPA-520/1-88-020) 'D' 8

7.41E-10 7.85E-10 7.92E-10 'Gonads'

$7.41 \mathrm{E}-10 \quad 7.85 \mathrm{E}-10 \quad 7.92 \mathrm{E}-10$ 'Breast'

7. $50 \mathrm{E}-10 \quad 9.37 \mathrm{E}-10 \quad$ 8.80E-09 'Lung'

9.15E-09 9.70E-09 9.79E-09 'll Marrow'

8.91E-09 9.44E-09 9.53E-09 'B Surface'

$7.41 E-10 \quad 7.85 E-10 \quad 7.9,2 E-10$ 'Thyrold'

1.75E-09 9.0OE-10 7.92E-10 'Remainder'

2.30E-09 2.17E-09 3.09E-09 'Effect1ve'

' $W$ ' 8

6. $63 \mathrm{E}-10 \quad 7.16 \mathrm{E}-10 \quad 3.24 \mathrm{E}-10$ 'Gonads'

$6.63 \mathrm{E}-10 \quad 7.16 \mathrm{E}-10 \quad 3.24 \mathrm{E}-10$ 'Breast'

8. 53E-10 3.20E-09 1.00E-07 'Lung'

8.20E-09 8.86E-09 4.00E-09 'R Marrow'

7.96E-09 8.61E-09 3.89E-09 'B Surface'

$6.63 E-10 \quad 7.16 E-10 \quad 3.24 E-10$ 'Thyrold'

2. 42E-09 1.71E-09 1.25E-09 'Remalnder'

2.34E-09 2.53E-09 1.32E-08 'Effect1ve'

H/I DOSE/INTAKE (SV/BQ) FOR INGESTION, F1=0.8 (ICRP-30, EPA-520/1-88-020)

'S' 0.8

$6.55 E-10$ Gonads

$6.55 E-10$ Areast

6. $55 \mathrm{E}-10$ Luns

8.09E-09 R. Marrow

7.87E-09 B. Surface

6. 55E-10 Thyroid

2. 67E-09 Remainder

2. 37E-09 Effective

ALI (Bq) (from ICRP 30, Part 2)

Inhalation

'D' $3.0 \mathrm{E}+7$

' $W$ ' $1.0 \mathrm{E}+7$

Ingestion

'S' $0.80 \quad 2.0 \mathrm{E}+7$

FLAG INDICATING PRESENCE (1) OR ABSENCE (0) OF DOSE-RATE FILE FOR NUCLIDE 0 


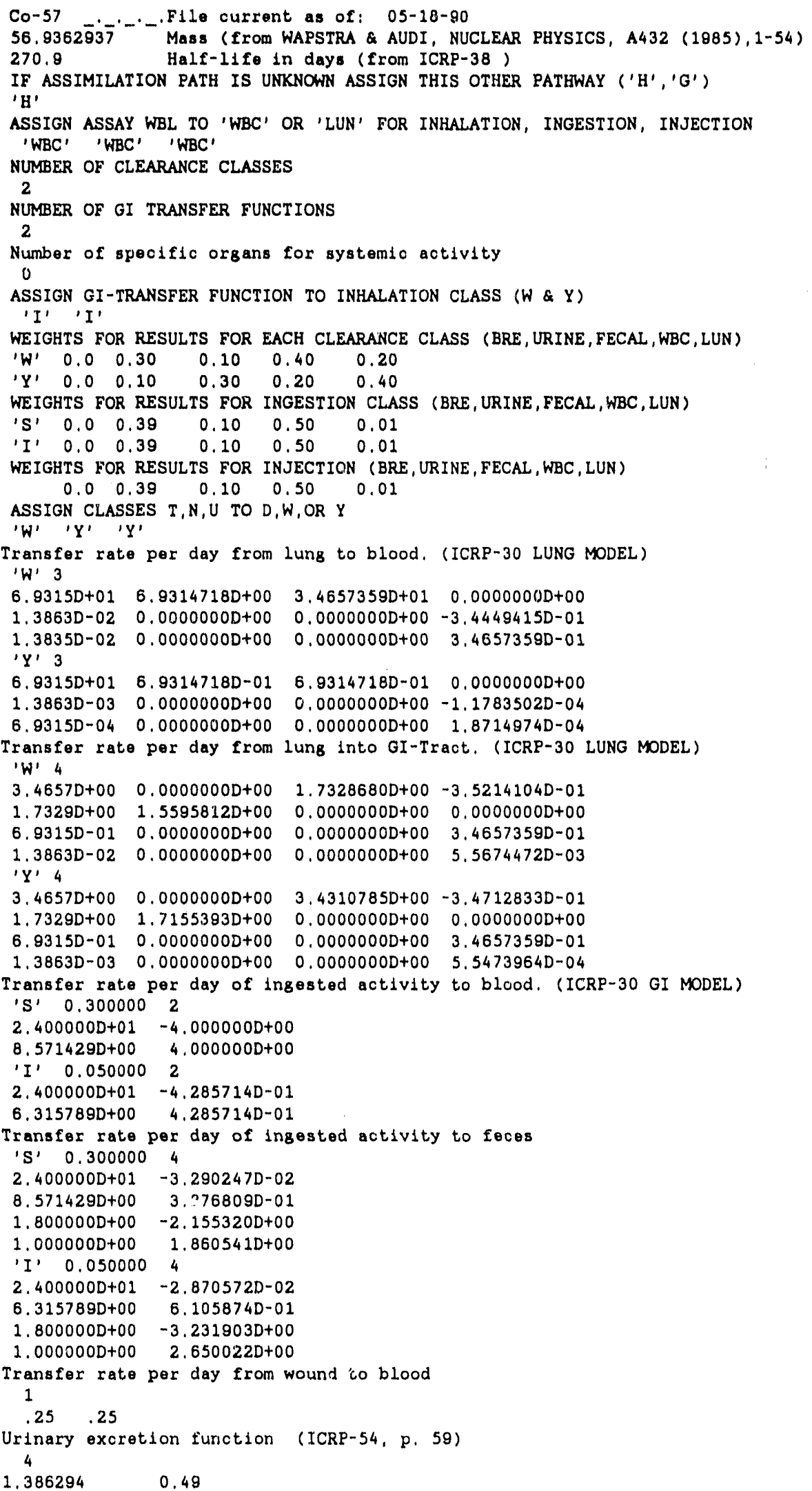




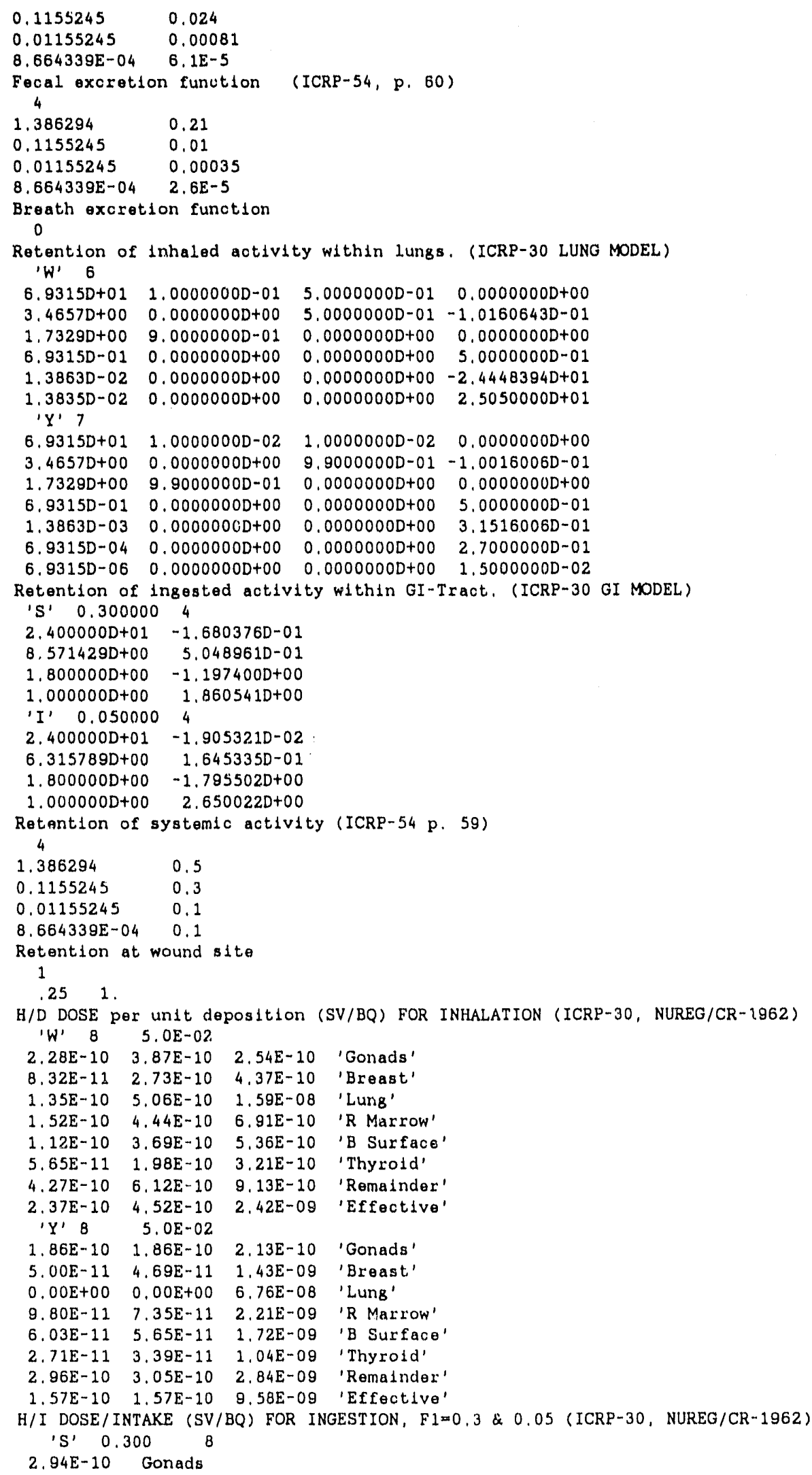




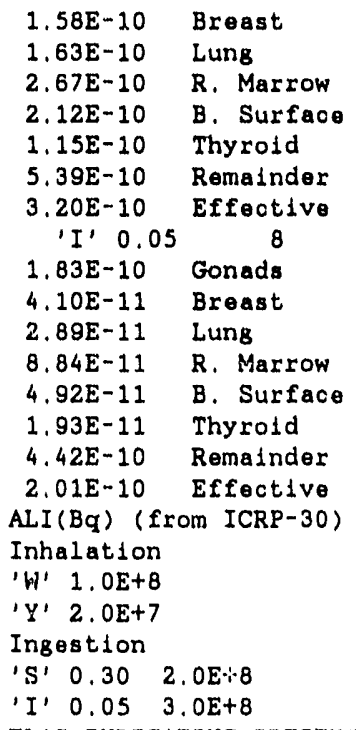

FLAG INDICATING PRESENCE (1) OR ABSENCE (0) OF DOSE-RATE FILE FOR NUCLIDE 1 


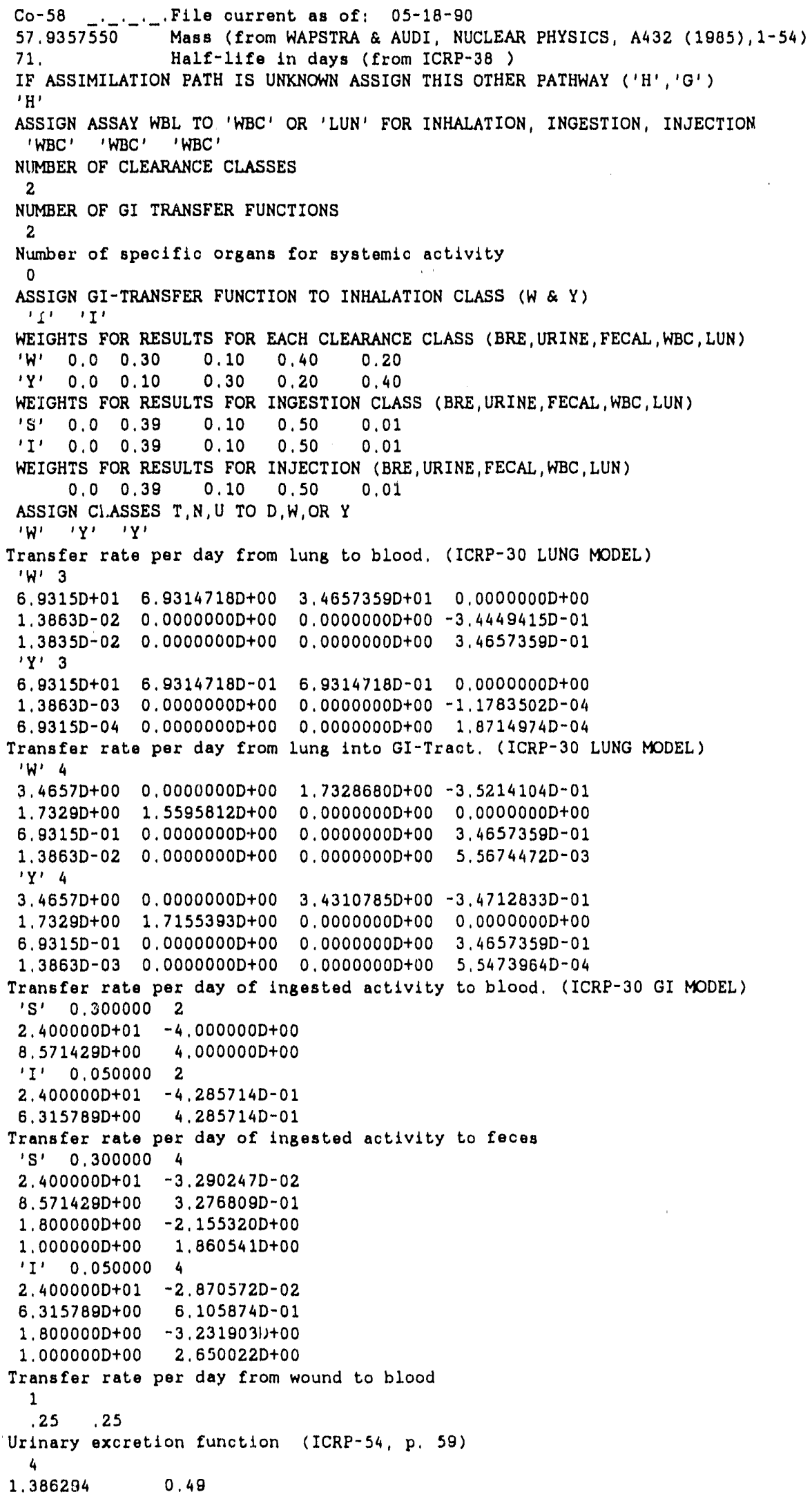




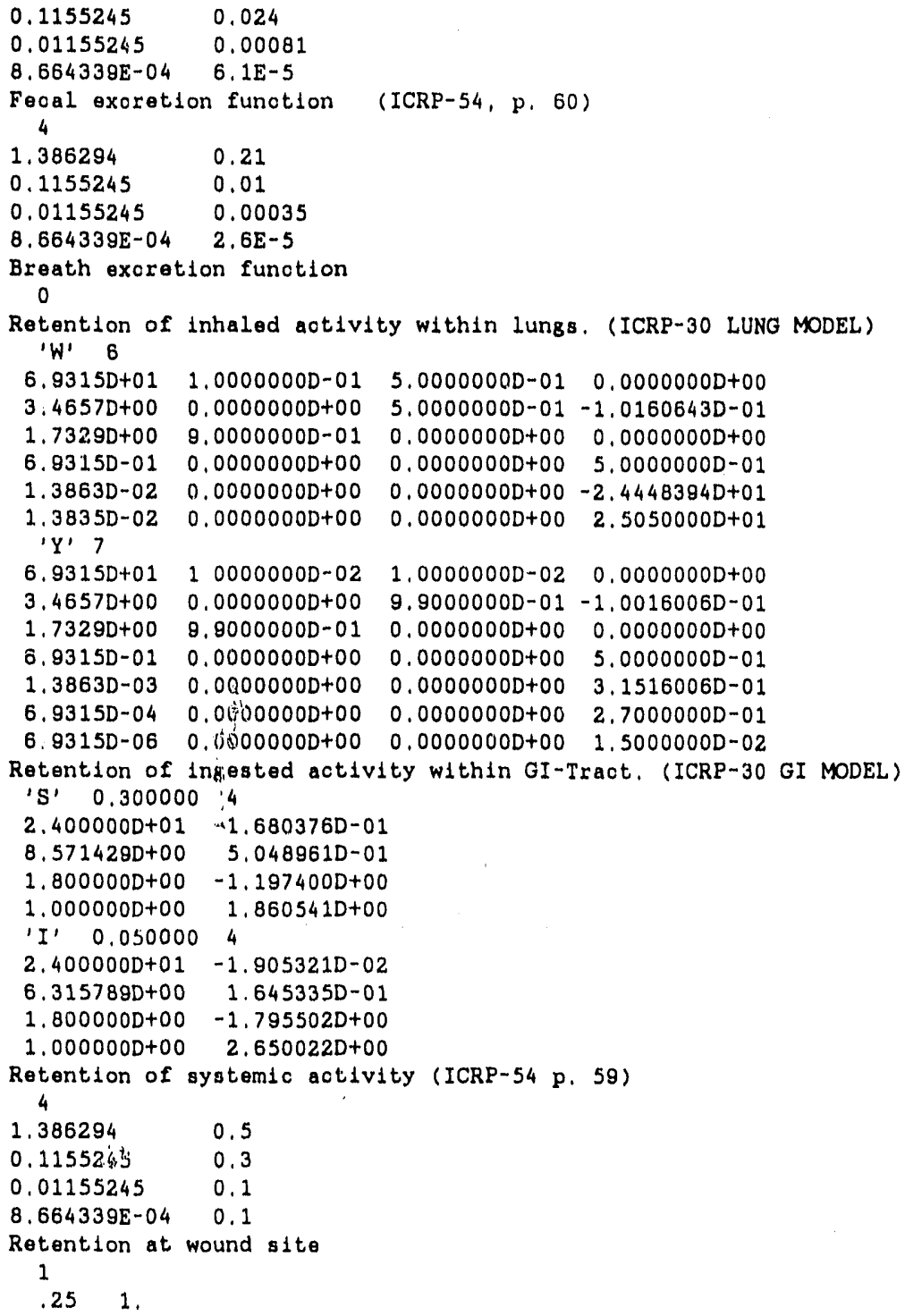




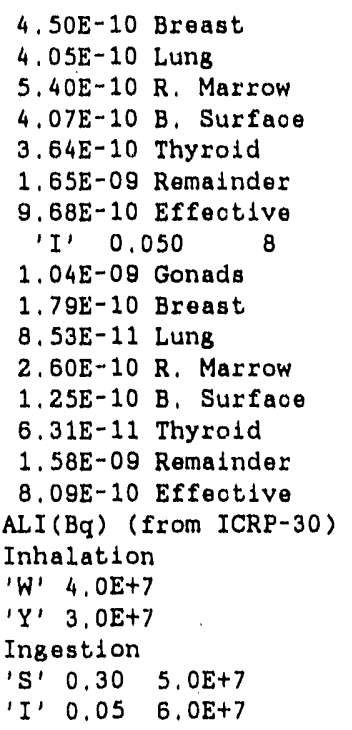

FLAG INDICATING PRESENCE ( 1 ) OR ABSENCE ( 0 ) OF DOSE-RATE FILE FOR NUCLIDE 0 


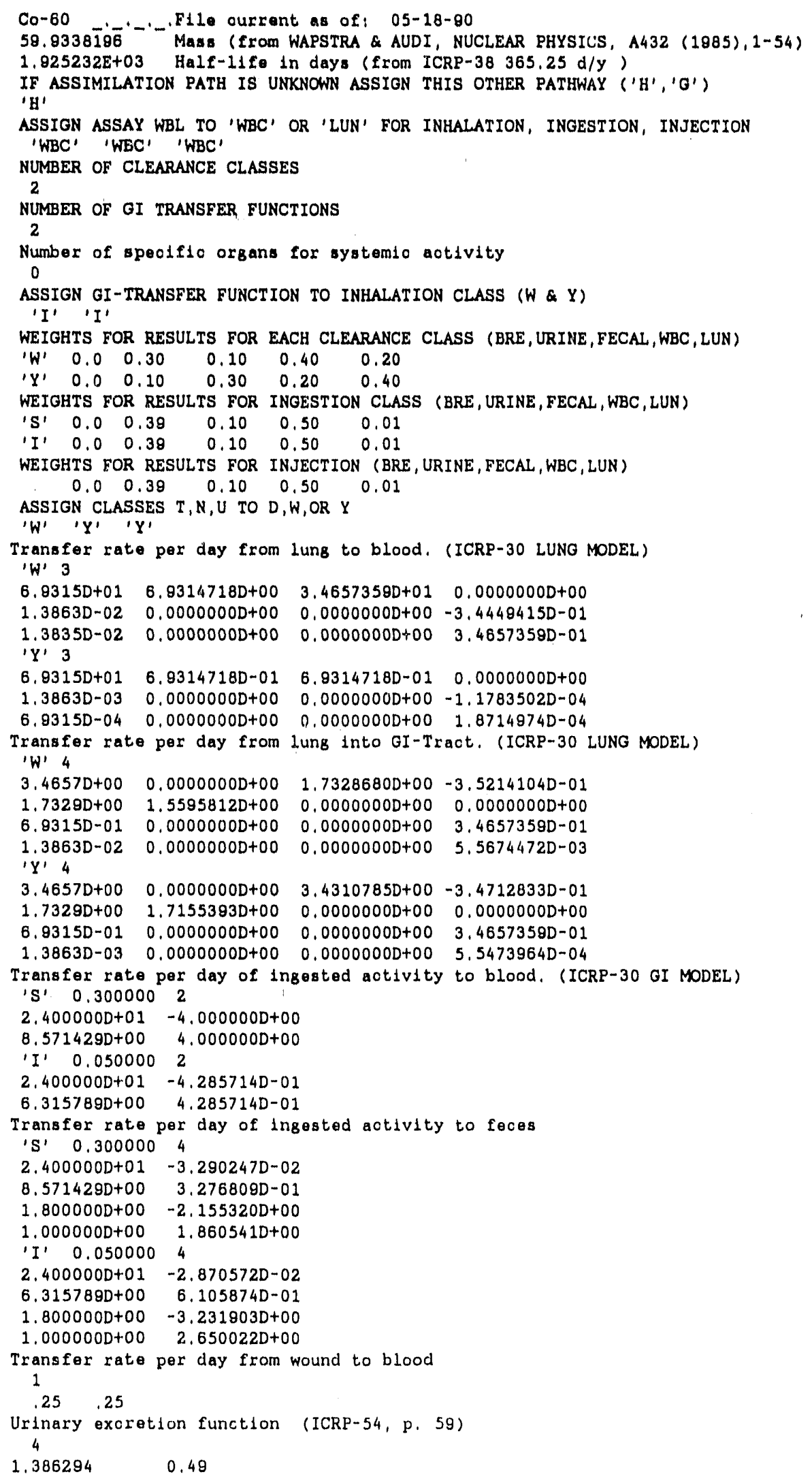




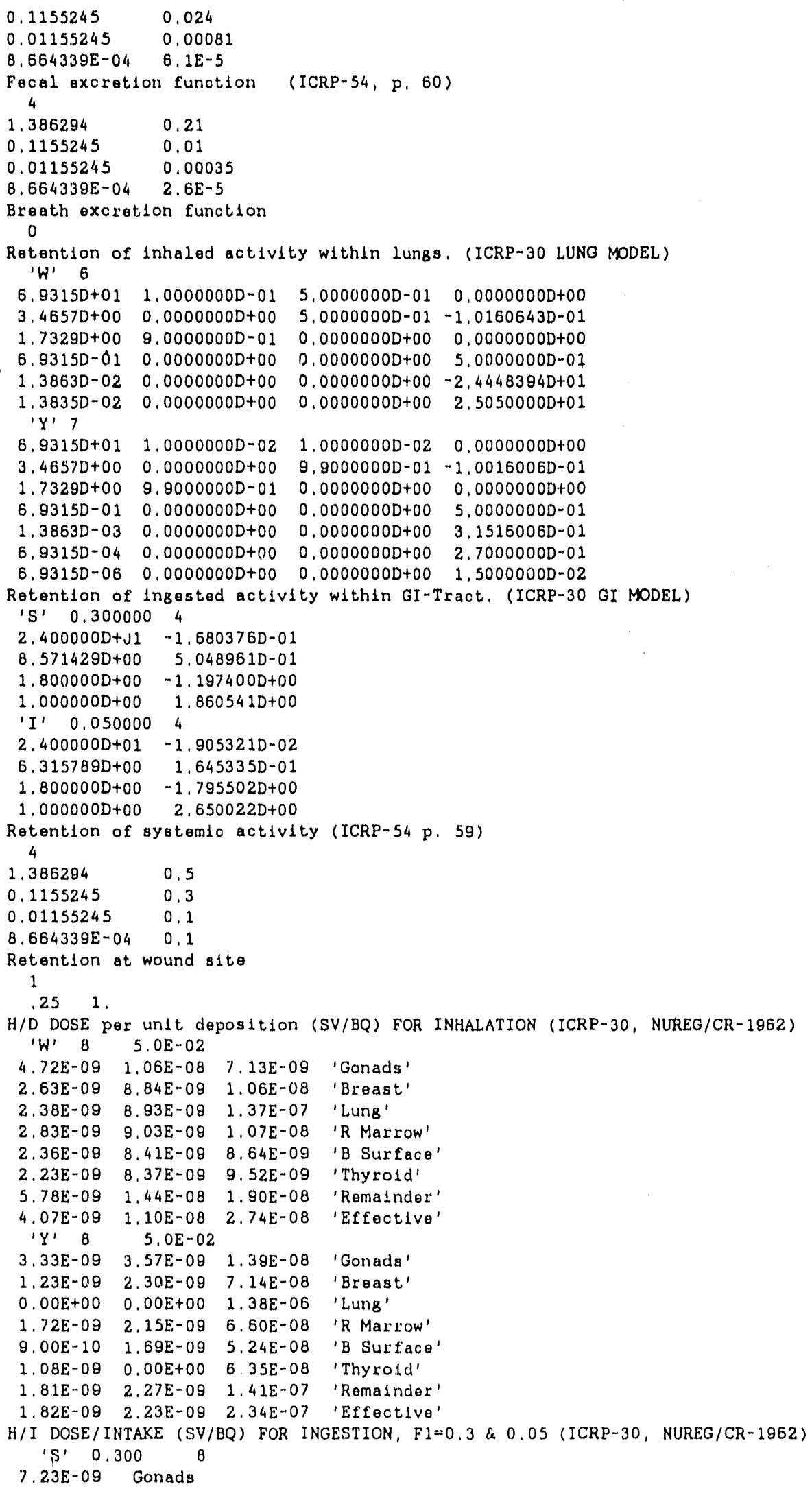




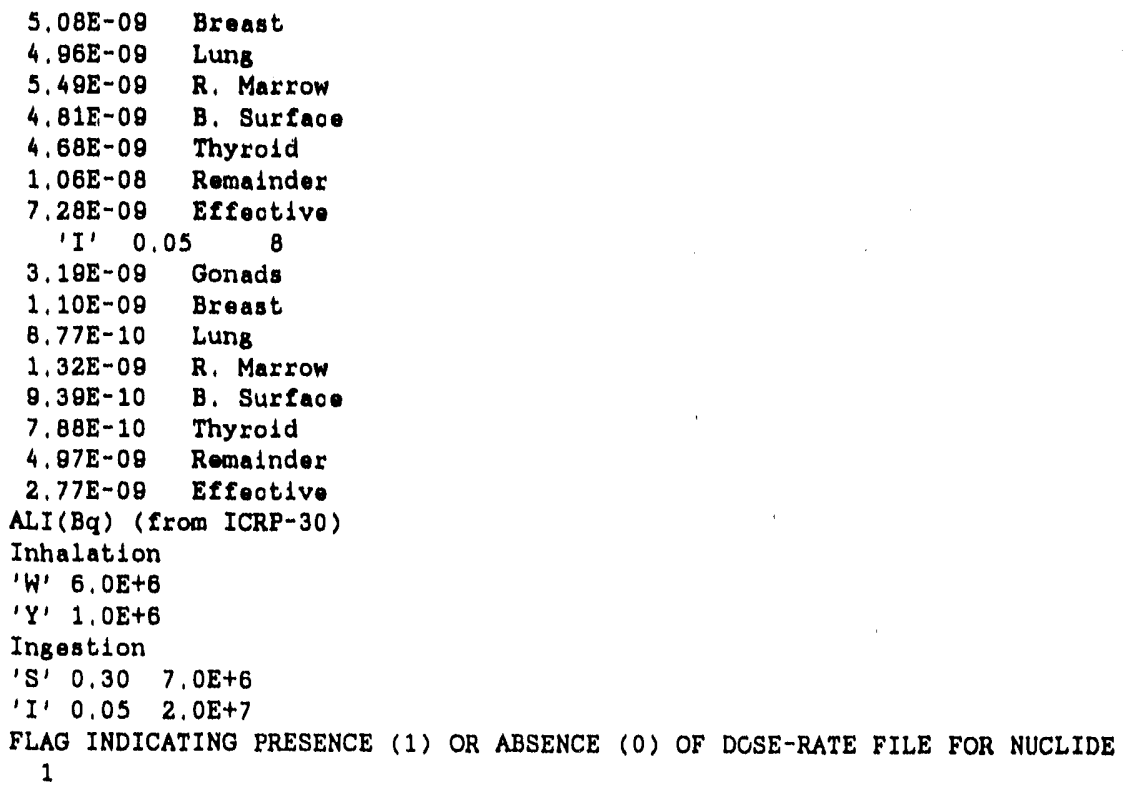




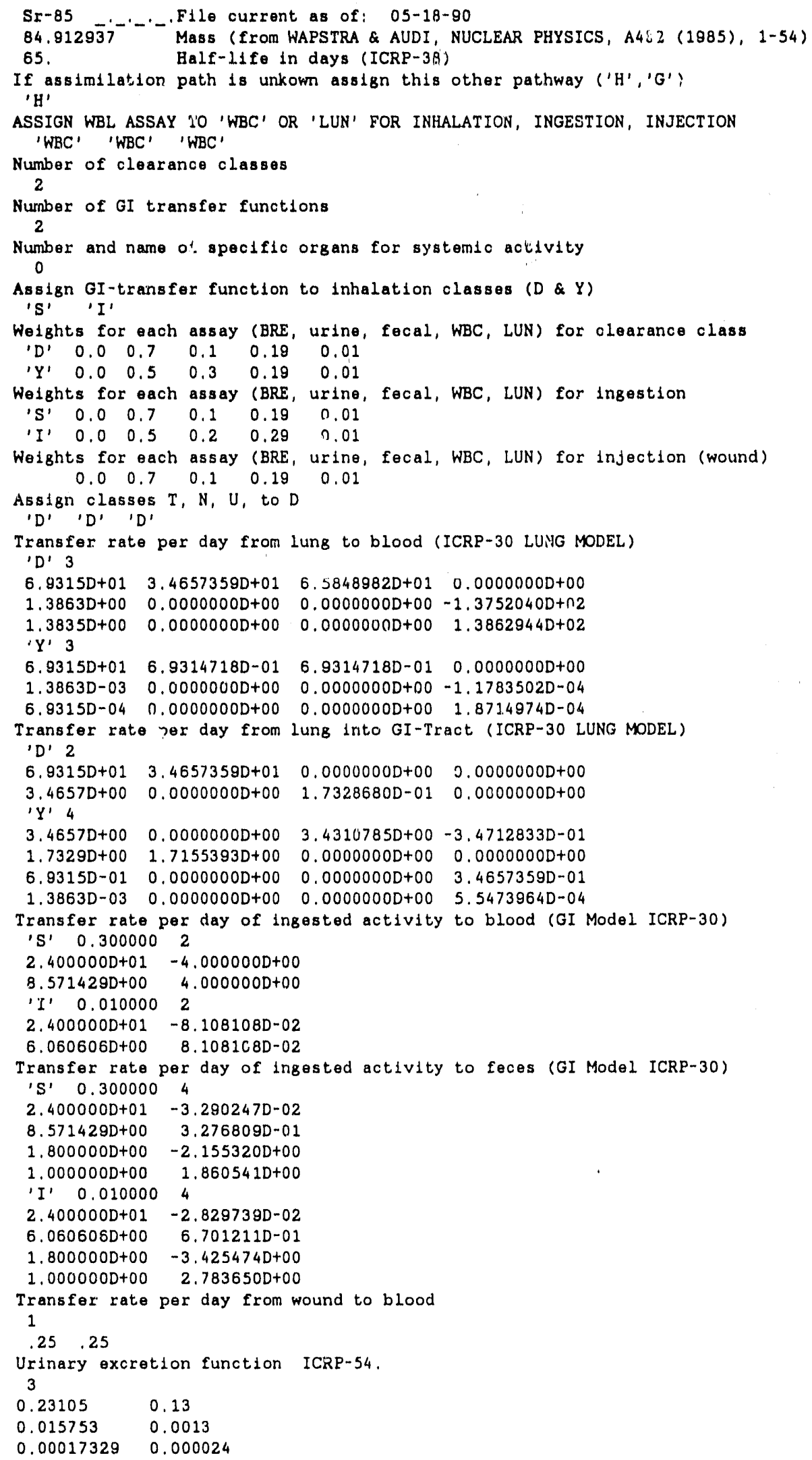




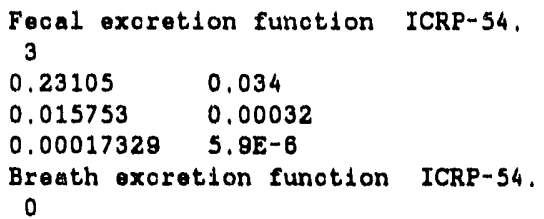

0

Reterition of inhaled activity within lungs (ICRP-30 LUNG MODEL)

'D' 4

$6.9315 D+01 \quad 1.0000000 D+00 \quad 9.5000000 D-01 \quad 0.0000000 D+00$

$3.4657 D+00 \quad 0.0000000 D+00 \quad 5,0000000 D-02 \quad 0.0000000 D+00$

$1.3863 D+00 \quad 0.0000000 D+00 \quad 0.0000000 D+00-8.9200000 D+01$

$1.3835 \mathrm{D}+00 \quad 0.0000000 \mathrm{D}+00 \quad 0,0000000 \mathrm{D}+00 \quad 1.0020000 \mathrm{D}+02$

' $Y$ ' 7

6.9315D+01 1,0000000D-02 1.0000000D-02 $0.0000000 D+00$

$3.4657 D+00 \quad 0.0000000 D+00 \quad 9.9000000 D-01-1.0016006 D-01$

$\begin{array}{lllll}1.7329 D+00 & 9.9000000 D-01 & 0.0000000 D+00 & 0.0000000 D+00\end{array}$

$\begin{array}{lllll}6.8315 D-01 & 0.0000000 D+00 & 0.0000000 D+00 & 5.0000000 D-01\end{array}$

$\begin{array}{llll}1.3863 D-03 & 0.0000000 D+00 & 0.0000000 D+00 & 3.1516006 D-01\end{array}$

$\begin{array}{lllll}6.9315 D-04 & 0.0000000 D+00 & 0.0000000 D+00 & 2.7000000 D-01\end{array}$

$\begin{array}{lllll}6.9315 D-06 & 0.0000000 D+00 & 0.0000000 D+00 & 1.5000000 D-02\end{array}$

Retention of ingested activity within GI-Tract (ICRP-30 GI Model)

's' 0.300000

$2.400000 D+01-1.680376 D-01$

8.571429D+00 5.048961D-01

$1.800000 D+00-1.197400 D+00$

$1.000000 D+00 \quad 1.860541 D+00$

'I' $0.010000 \quad 4$

$2.400000 D+01-4.557436 D-03$

6. $060606 \mathrm{D}+00 \quad 1.239484 \mathrm{D}-01$

$1.800000 D+00-1.903041 D+00$

$1.0000000+00 \quad 2.783650 D+00$

Retention of systemic activity (ICRP-30/54)

3

$0.23105 \quad 0.73$

$0.015753 \quad 0.10$

$0.000173 \quad 0.17$

Retention at wound site

.251 .

H/D Dose per unit, deposition (Sv/Bq) for INHALATION (ICRP-30, NUREG/CR-1962)

'D' 8

6. $81 \mathrm{E}-10 \quad 7.22 \mathrm{E}-10 \quad 7.28 \mathrm{E}-10$ 'Gonads'

4.71E-10 6.51E-10 7.14E-10 'Breast'

4.35E-10 6.41E-10 1.14E-09 'Lung'

1.17E-09 1.73E-09 1.73E-09 'R Marrow'

1.29E-09 1.81E-09 1.92E-09 'B Surface'

$4.48 \mathrm{E}-10 \quad 6.81 \mathrm{E}-10 \quad 6.97 \mathrm{E}-10$ 'Thyroid'

7.35E-10 7.58E-10 7.81E-10 'Remainder'

7.06E-10 8.67E-10 $8.46 \mathrm{E}-10$ 'Effective'

'Y' 8

5.79E-10 5.85E-10 4.54E-10 'Gonads'

$7.75 \mathrm{E}-11 \quad 1.16 \mathrm{E}-10 \quad 1.73 \mathrm{E}-00$ 'Breast'

$0.00 E+00 \quad 0.00 E+00 \quad 2.86 E-08$ 'Lung'

1.39E-10 1.74E-10 1.64E-09 'R Marrow'

7.00E-11 8.75E-11 1.29E-09 'B Surface'

1.2.8E-11 $0.00 E+00 \quad 1.52 E-09$ 'Thyrotd'

3. $98 \mathrm{E}-10 \quad 4.26 \mathrm{E}-10$ 3.00E-09 'Remalnder'

2. $95 \mathrm{E}-10$ 3.15E-10 4.98E-09 'Effective'

H/I Dose per unit intake for ingested activity (ICRP-30, NUREG/CR-1962)

'S' $0.3^{8} 8$

6. 25E-10 Gonads

2. 53E-10 Breast

2. 06E-10 Lung

5.97E-10 R. Marrow

6.06E-10 B. Surface

2.05E-10 Thyroid

7. 31E-10 Remainder

5. 34E-10 Effectve 
'I' 0.018

5. 82E-10 Gonads

7. 34E-11 Breast

1. $67 \mathrm{E}-11$ Lung

1. 30E-10 R, Marrow

5.69E-11 B. Surfaco

8. 1.4E-12 Thyrold

7. 56E-10 Remalnder

4. 03E-10 Effeotive

ALI (Bg) (from ICRP-30)

Inhalation ALI

'D' 1.0E+08

' $Y$ ' $6.0 E+07$

Ingestion ALI

'S' $0.3 \quad 9.0 E+07$

'I' $0.01 \quad 1.0 E+08$

FLAG INDICATING PRESENCE (1) OR ABSENCE (0) OF DOSE-RATE FILE FOR NUCLIDE 


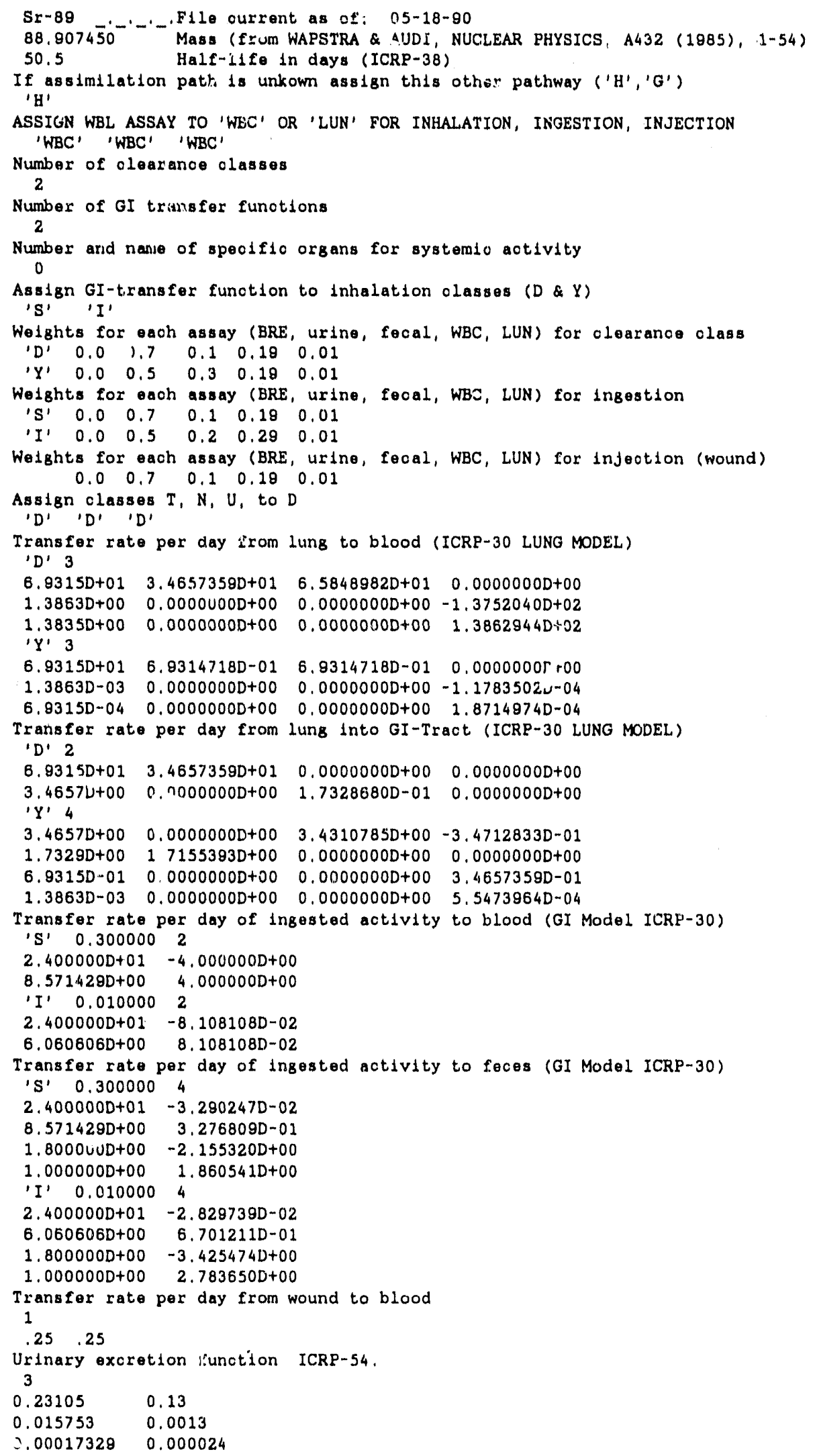




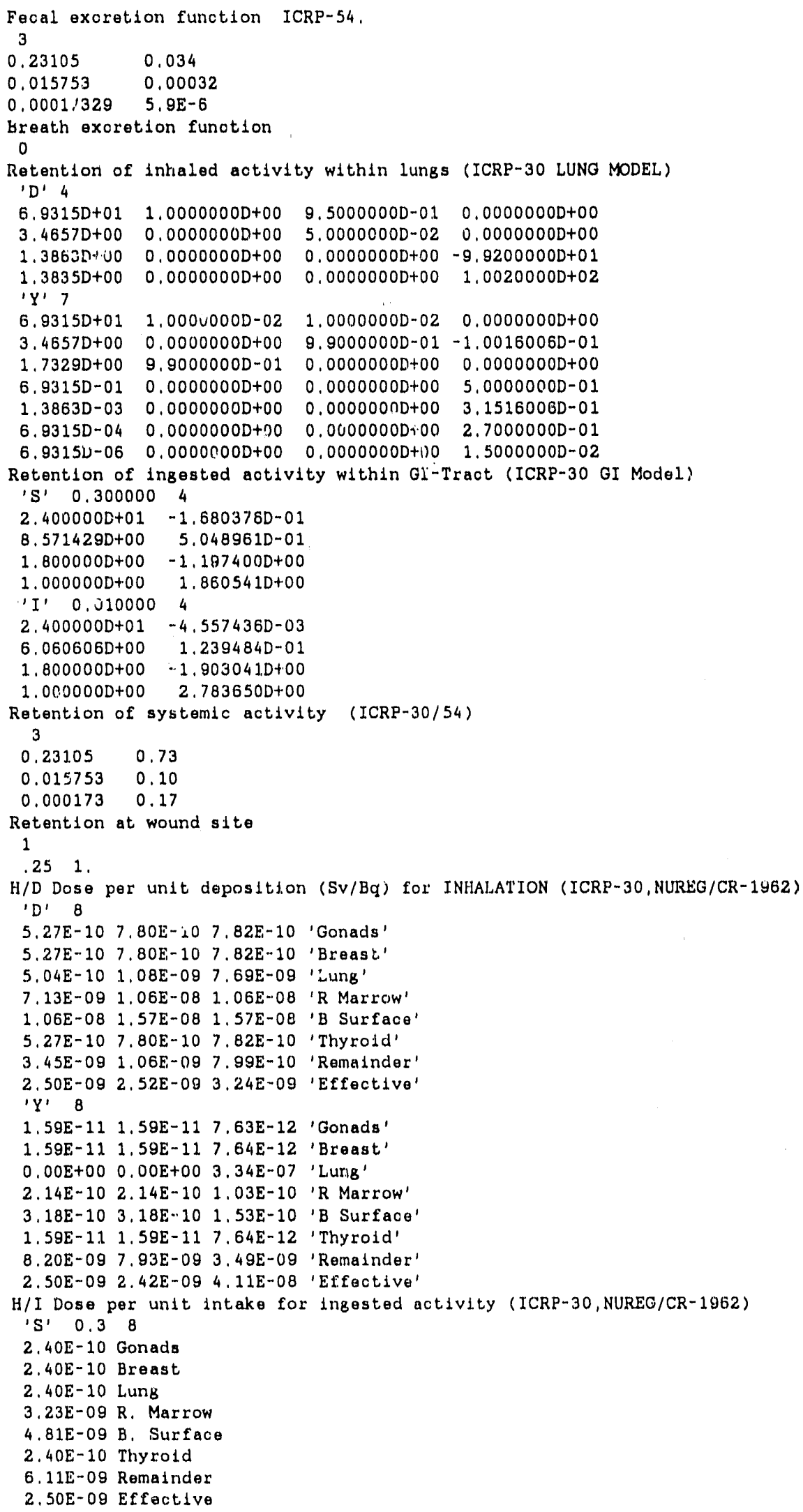




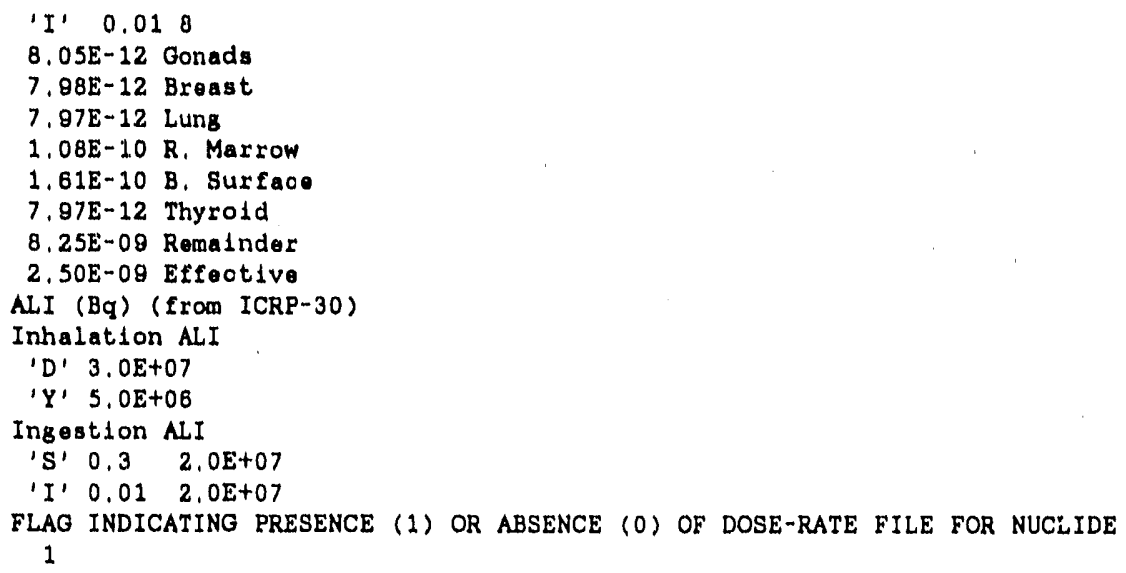

FLAG INDICATING PRESENCE ( 1 ) OR ABSENCE (0) OF DOSE-RATE FILE FOR NUCLIDE 


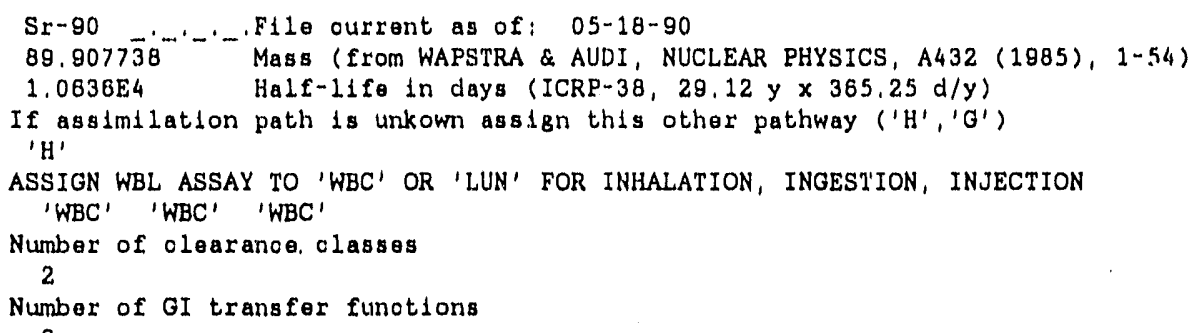


Fooal excretion funotion ICRP-54.

3

$0.23105 \quad 0.034$

$0.015753 \quad 0,00032$

$0,00017329 \quad 5,9 E-6$

Breath exoretion funotion ICRP- 54 .

0

Retention of inhaled aotivity within lungs (ICRP-30 LUNG MODEL)

'D' 4

6.9315D+01 $1.0000000 D+00 \quad 9,5000000 D-01 \quad 0,0000000 D+00$

$\begin{array}{llll}3.4657 D+00 & 0.0000000 D+00 & 5.0000000 D-02 & 0,0000000 D+00\end{array}$

$1.3863 D+00 \quad 0,0000000 D+00 \quad 0.0000000 D+00-9.9200000 D+01$

$1.3835 D+00 \quad 0,0000000 D+00 \quad 0,0000000 D+00 \quad 1,0020000 D+02$

'Y' 7

$6.9315 D+01 \quad 1,0000000 D-02 \quad 1,0000000 D-02 \quad 0,0000000 D+00$

3.4657D+00 $0.0000000 D+00 \quad 8.9000000 D-01-1.0016006 D-01$

$1.7329 D+00 \quad 9.8000000 D-01 \quad 0.0000000 D+00 \quad 0.0000000 D+00$

$6.9315 D-01 \quad 0.0000000 D+00 \quad 0,0000000 D+00 \quad 5,0000000 D-01$

$\begin{array}{llll}1,3863 D-03 & 0,0000000 D+00 & 0.0000000 D+00 & 3,1516006 D-01\end{array}$

$6,9315 D-04 \quad 0,0000000 D+00 \quad 0,0000000 D+00 \quad 2,7000000 D-01$

$\begin{array}{lllll}6,9315 D-06 & 0,0000000 D+00 & 0,0000000 D+00 & 1,5000000 D-02\end{array}$

Retention of ingested aotivity within GI-Tract (ICRP-30 GI Model)

' $\mathrm{S}$ ' 0,3000004

$2.400000 D+01-1.680376 D-01$

$8.5714290+00 \quad 5.0489610-01$

$1.800000 D+00-1.187400 D+00$

$1.000000 D+00 \quad 1.860541 D+00$

'I' 0.0100004

$2,400000 D+01-4,557436 D-03$

$6.060606 \mathrm{D}+00 \quad 1,239484 \mathrm{D}-01$

$1.800000 D+00-1.903041 D+00$

$1.000000 D+00 \quad 2.7836500+00$

Retention of systemio activity (ICRP-30/54)

$0.23105 \quad 0.73$

$0.015753 \quad 0.10$

$0.000173 \quad 0.17$

Retention at wound site

.251.

B/D Dose per untt deposition (Sv/Bq) for INHALATION (ICRP-30, NUREG/CR-1962)

'D' $B$

3.26E-09 4.85E-09 5,07E-09 'Gonads'

$3.26 \mathrm{E}-09$ 4.85E-09 5.07E-09 'Breast'

3. 23E-09 5, 13E-09 9, 40E-09 'Lung'

4. 14E-07 6.30E-07 6.45E-07 'R Marrow'

8.97E-07 1.36E-06 1.40E-06 'B Surfaco'

3. ڤOOE-09 4.95E-09 5.07E-09 'Thyrold'

5.59E-09 5.09E-09 5.10E-09 'Remainder'

8.01E-08 1.21E-07 1,24E-07 'Effective'

' $Y$ ' 8

9.86E-11 1.01E-10 8,25E-10 'Gonads'

8. 86E-11 1.01E-10 $8.25 E-10$ 'Broast

$0.00 \mathrm{E}+00 \quad 0.00 \mathrm{E}+00 \quad 1,14 \mathrm{E}-05$ 'Jung'

1.31E-08 1.23E-08 1.12E-07 'R Marrow'

2.84E-08 2.66E-08 2.41E-07 'B Surfaoe'

9.86E-11 1.01E-10 9.25E-10 'Thyrotd'

7.95E-09 7.33E-09 1.10E-08 'Remainder'

4.85E-09 4.52E-09 1,40E-06 'Effeotive'

H/I Dose per undt intake for ingested activity (ICRP-30, NUREG/CR-1962)

'S' $0.3 \quad 8$

$1,51 \mathrm{E}-09$ Gonads

1. $51 \mathrm{E}-09$ Breast

1. 51E-09 Lung

1.84E-07 R. Marrow

4. $19 E-07$ B. Surface

1. 51E-09 Thyrotd

6. 14E-09 Remalnder

3. BSE 0 B Effeotive 


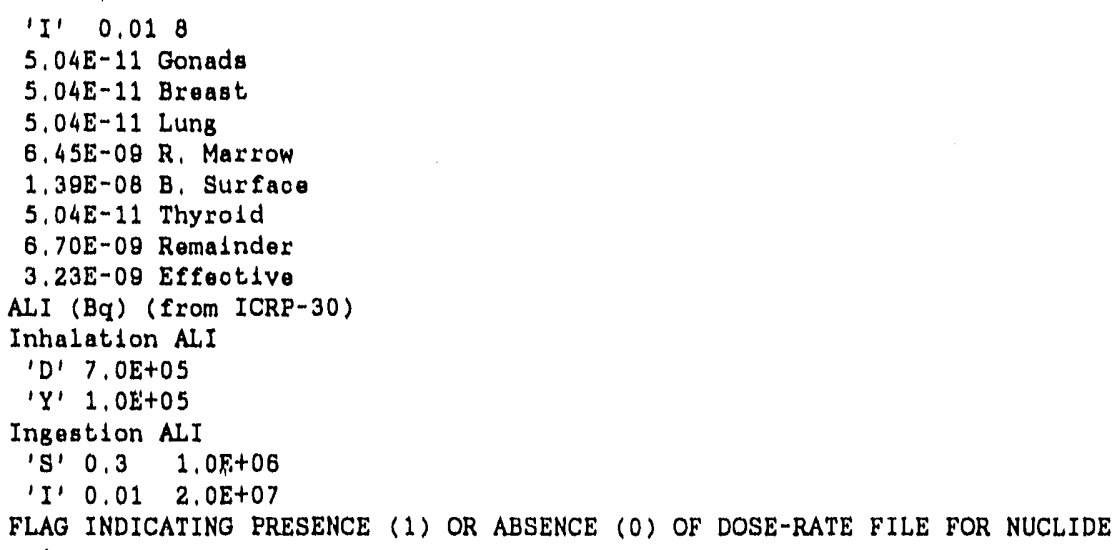




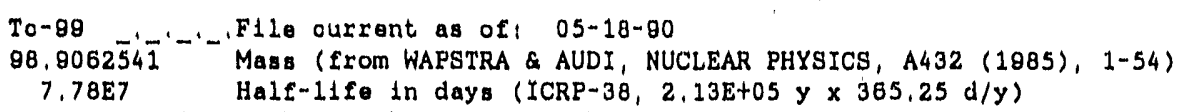




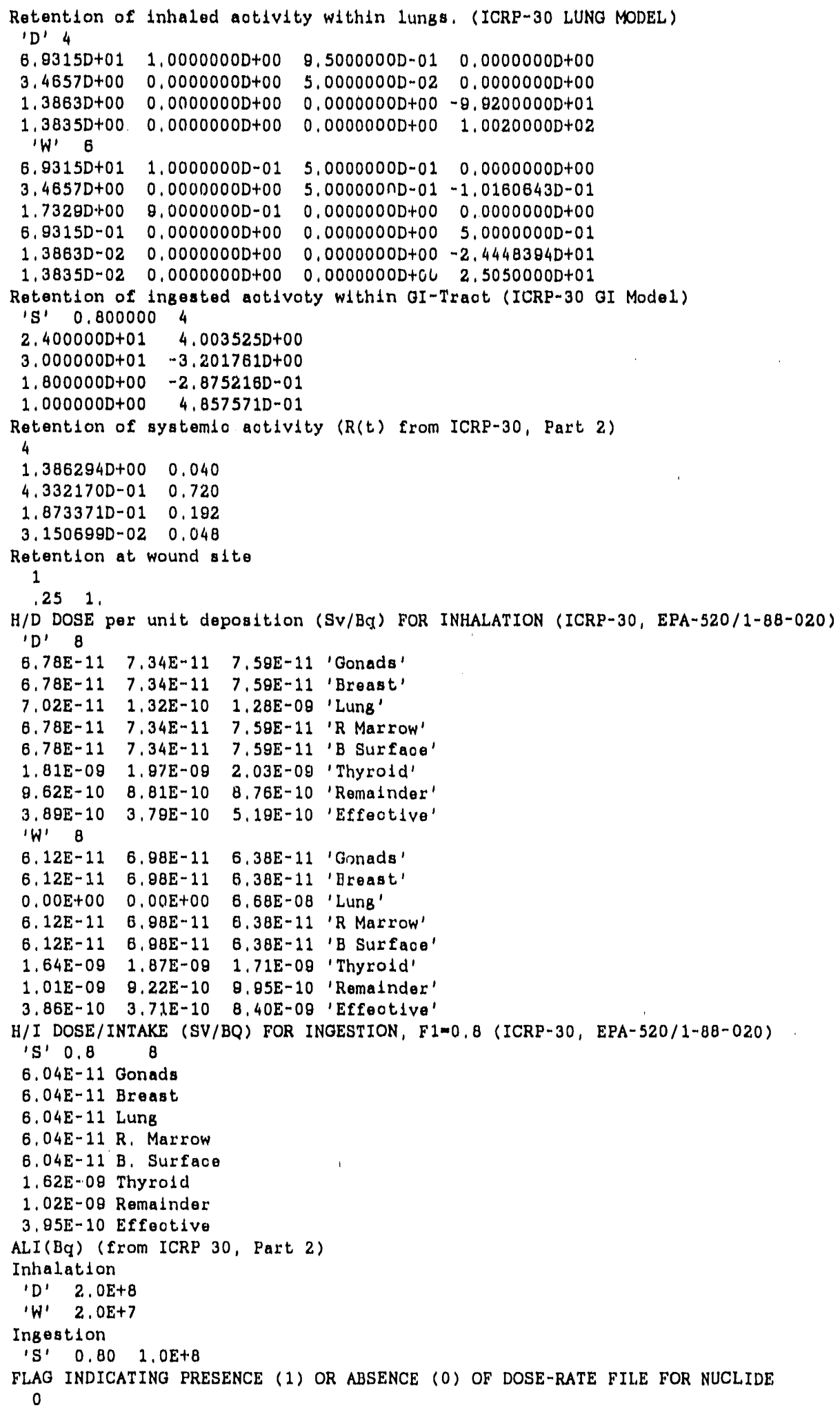




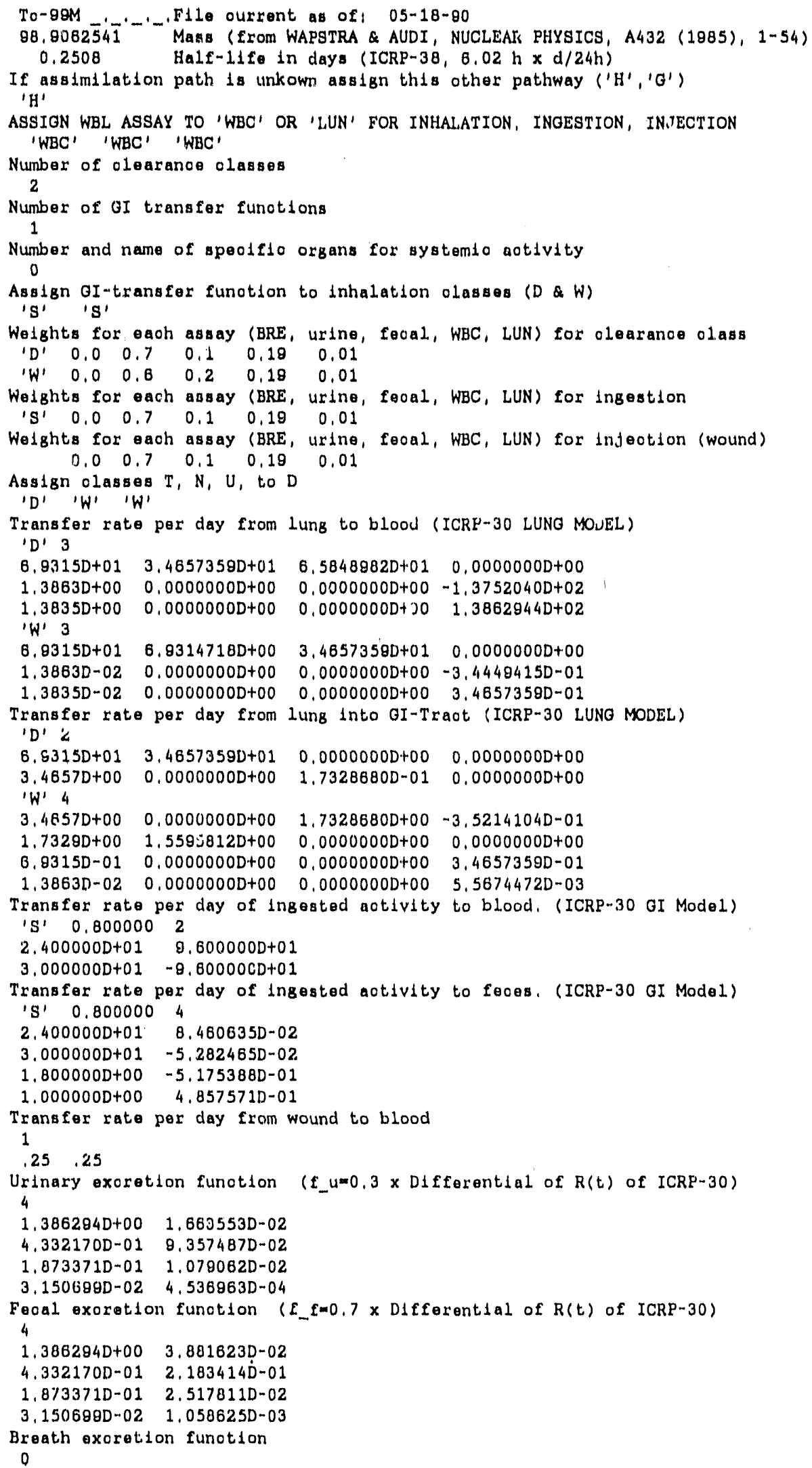




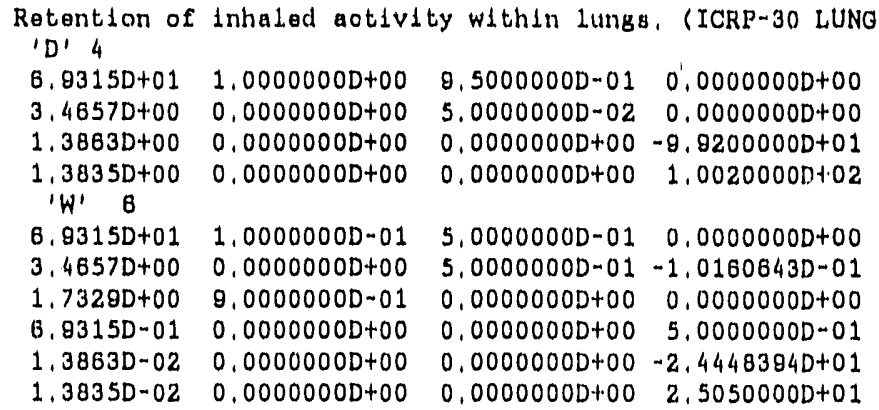

Retention of ingested aotivoty within GI-Traot (ICRP-30 GI Mode1)

's' 0,8000004

2.400000D+01 4,003525D+00

3,000000D+01 $-3,2017610+00$

$1.800000 D+00-2.8752160-01$

$1.000000 D+00 \quad 4.857571 D-01$

Retention of systemio aotivity (R(t) from ICRP-30, Part 2)

$1.3862940+00 \quad 0.040$

$4.3321700-01 \quad 0,720$

$1,8733710-01 \quad 0,192$

$3.1506990-02 \quad 0.048$

Retention at wound site

1

251.

H/D DOSE per unit deposition (SV/Bq) FOR INHALATION (ICRP-30, EPA-520!1-88-020)

'D' 0

6. 83E-12 4.50E-12 $1.44 E-12$ 'Gonads'

$3.44 E-12 \quad 3,76 E-12 \quad 3,27 E-12$ 'Breast'

3.04E-12 1.14E-11 8.30E-11 'Lung'

$5.71 \mathrm{E}-12 \quad 5.46 \mathrm{E}-12 \quad 4.84 \mathrm{E}-12$ ' $R$ Marrow'

4.28E-12 4.58E-12 3.88E-12 'B Surfaoo'

$1,0 ' E-10 \quad 1,18 E-10 \quad 3,81 E-11$ 'Thyrold'

2.42E-11 1,65E-11 6.54E-12 'Remalnder'

1.38E-11 1.24E-11 1,47E-11 'Effeotive'

' $W$ ' 8

3, 80E-12 4, 89E-12 6, 80E-13 'Gonads'

1.57E-12 3.42E-12 3.10E-12 'Broast'

$1.02 E-12 \quad 3.07 E-11 \quad 1,12 E-10$ 'Lung'

2. 71E-12 5.38E-12 4, 58E-12 'R Marrow'

1.84E-12 4.23E-12 3.56E-12 'B Surfaoo'

$4,18 E-11 \quad 8,62 E-11 \quad 5,85 E-12$ 'Thyrotd'

1.32E-11 1,80E-11 3,76E-12 'Remalnder'

6.91E-12 1,42E-11 1,60E-11 'Effeot1ve'

H/I DOSE/INTAKE (SV/BQ) FOR INGESTION, F1=0,8 (ICRP-30, EPA-520/1-88-020)

'S' $0, \theta$ 8

9.75E-12 Gonads

3. 57E-12 Breast

3. 14E-12 Lung

6. 20E-12 R. Marrow

4. 06E-12 B. Surface

8.46E-11 Thyroid

3. 34E-11 Remalnder

1,68E-11 Effeotive

$A L I(B q)$ (from ICRP 30, Part 2)

Inhalation

'D' $6,0 E+8$

'W' $9,0 \mathrm{E}+9$

Ingestion

'S' $0,80 \quad 3,0 E+8$

FLAG INDICATING PRESENCE (1) OR ABSENCE (0) OF DOSE-RATE FIIE FOR NUCLIDE 


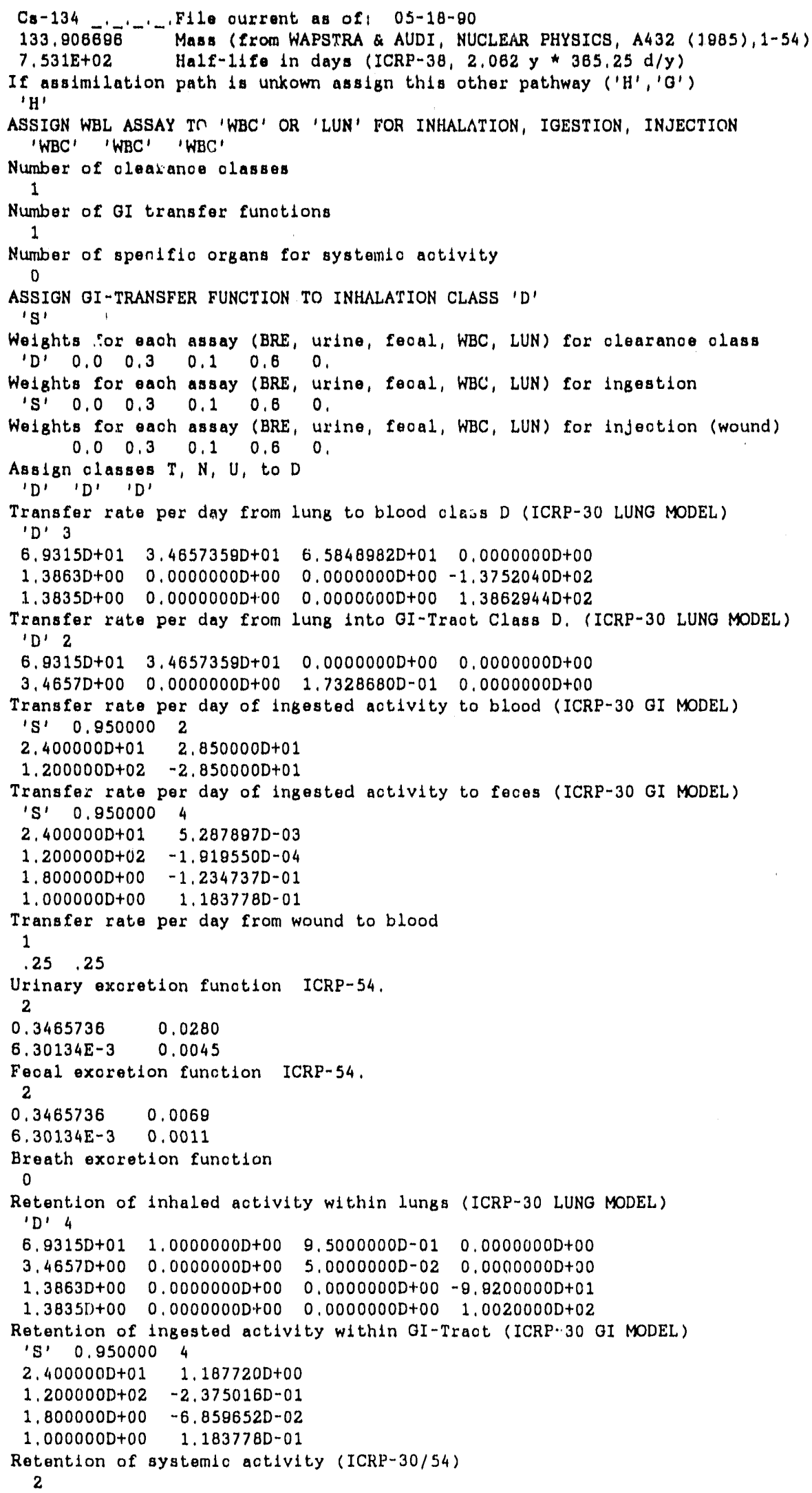




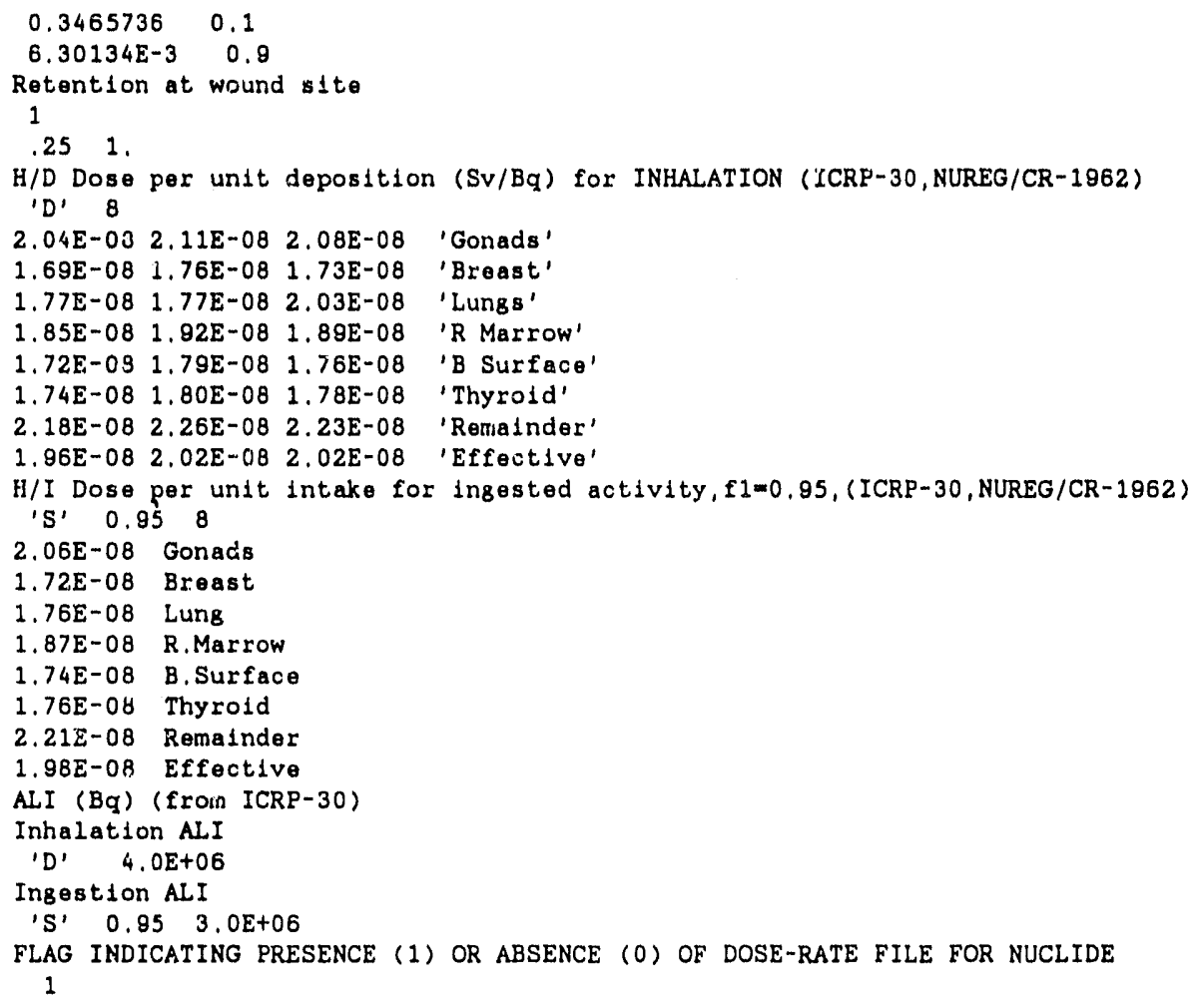




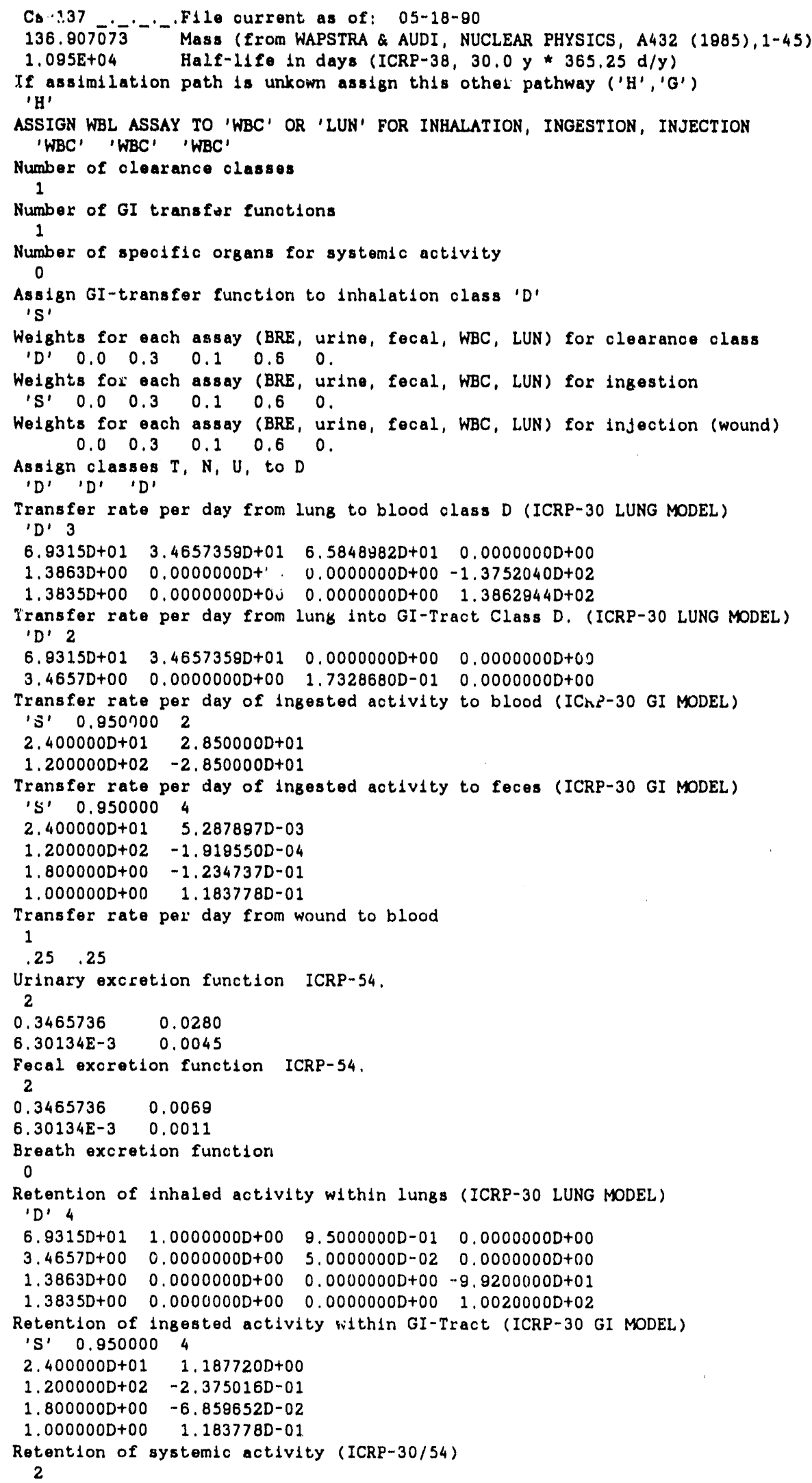




$$
0.3465736 \quad 0.1
$$




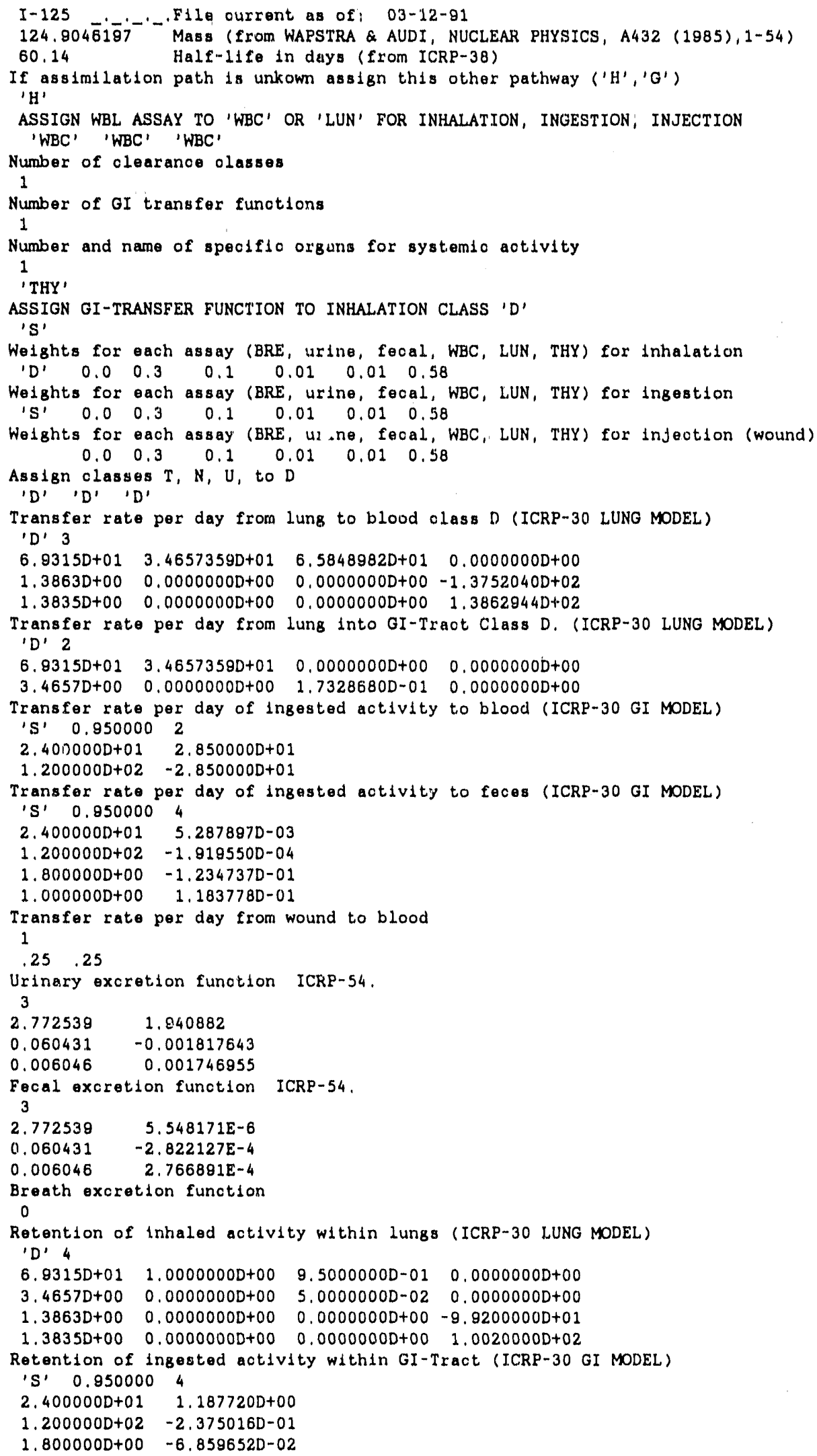




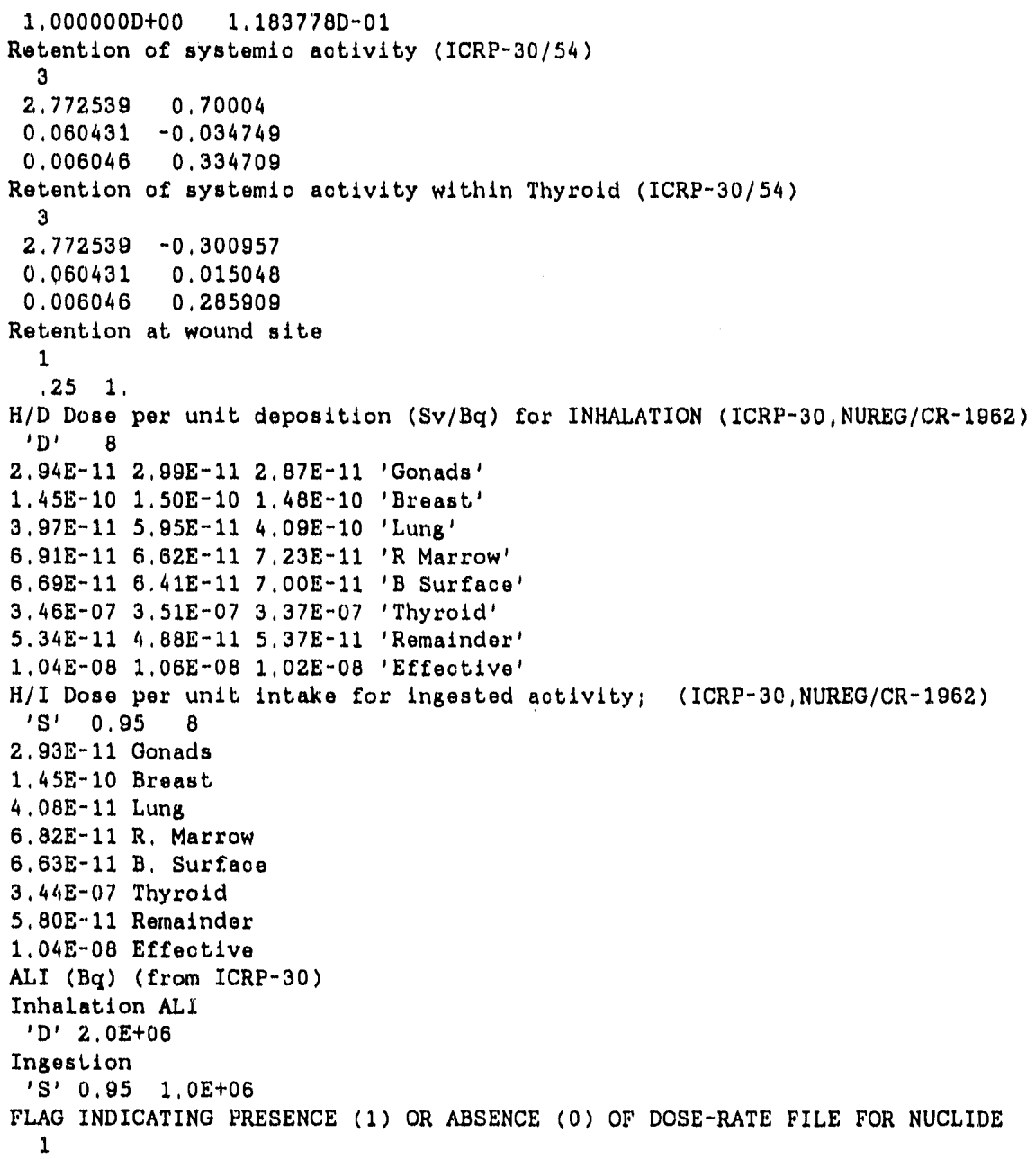




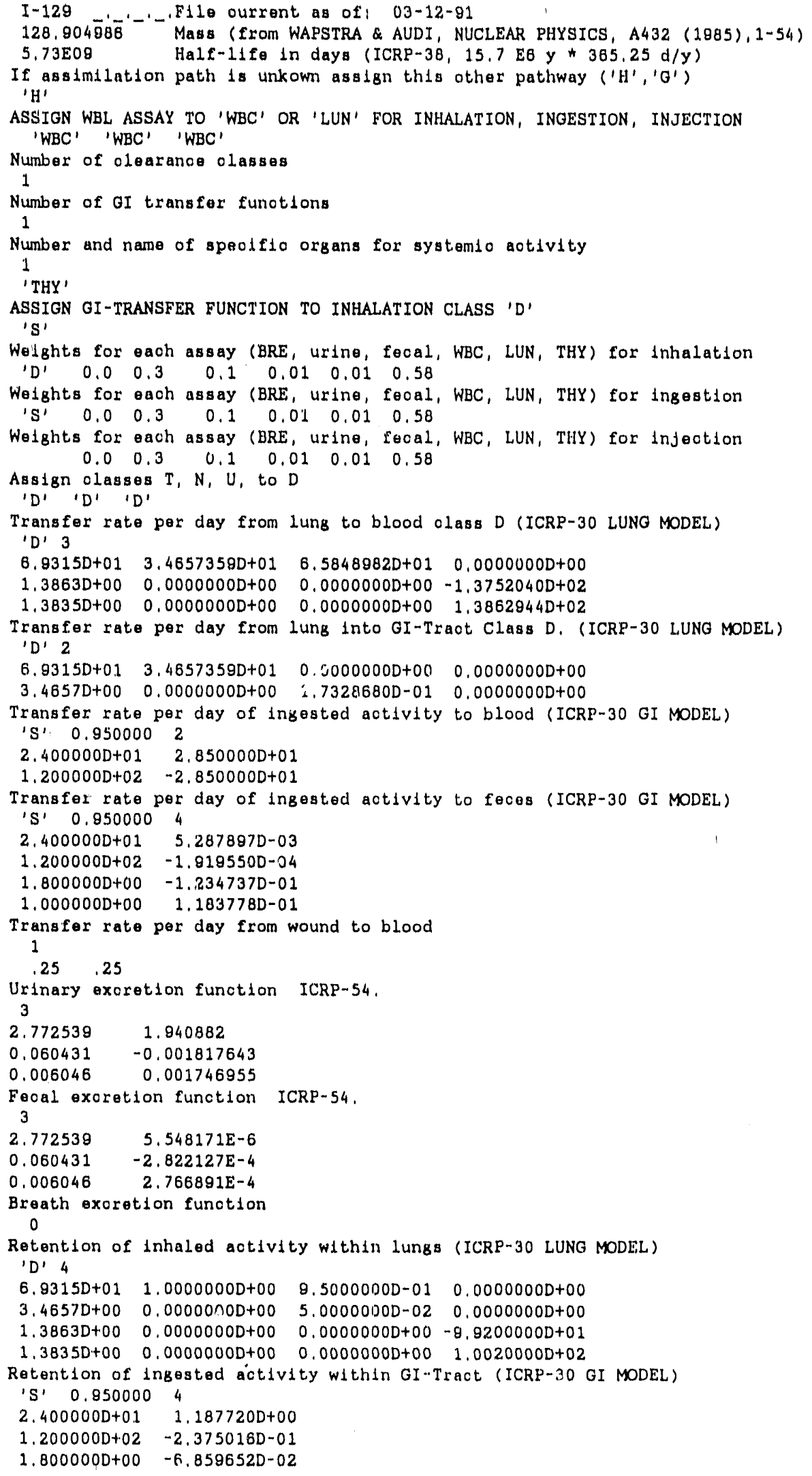




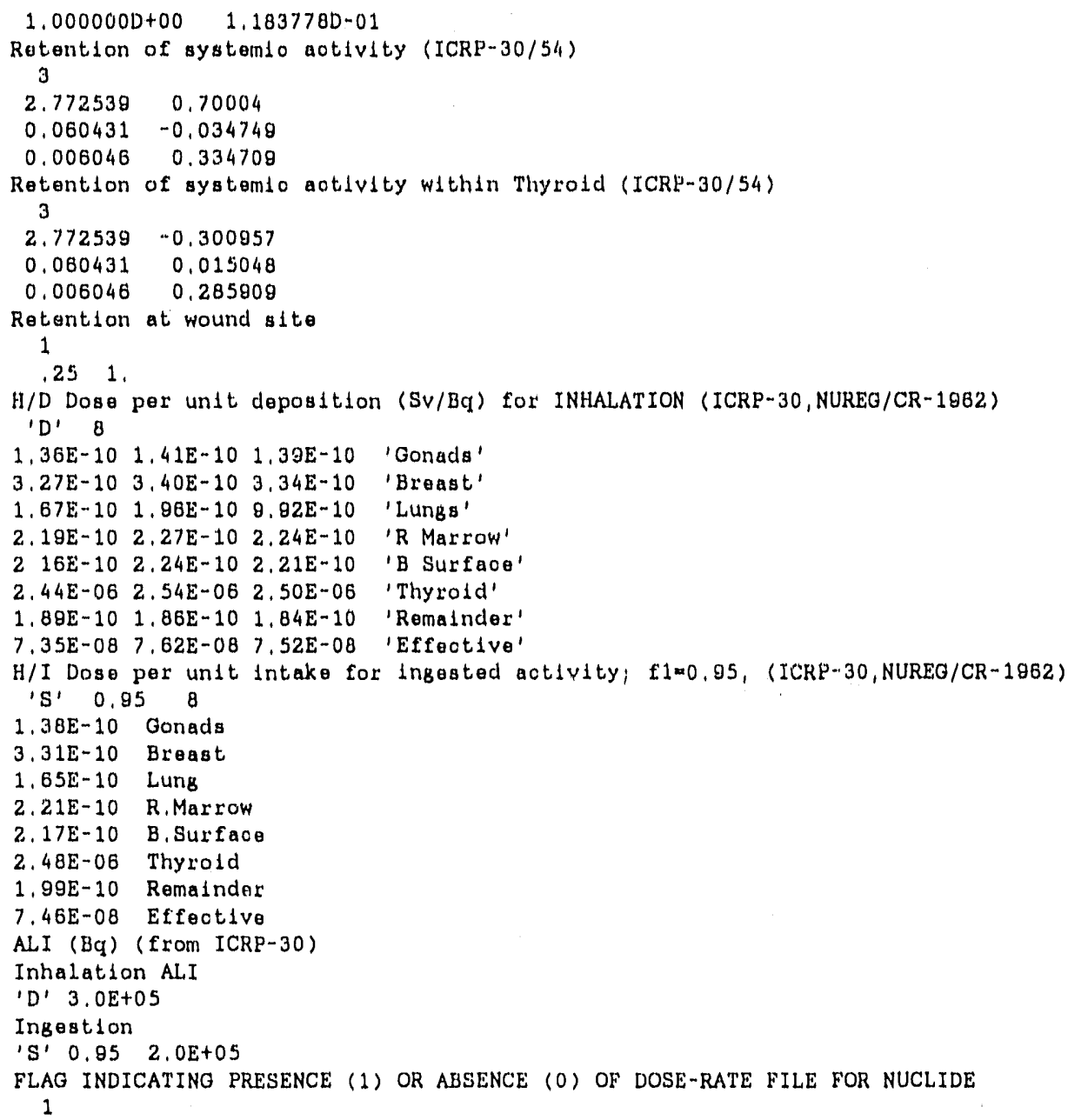




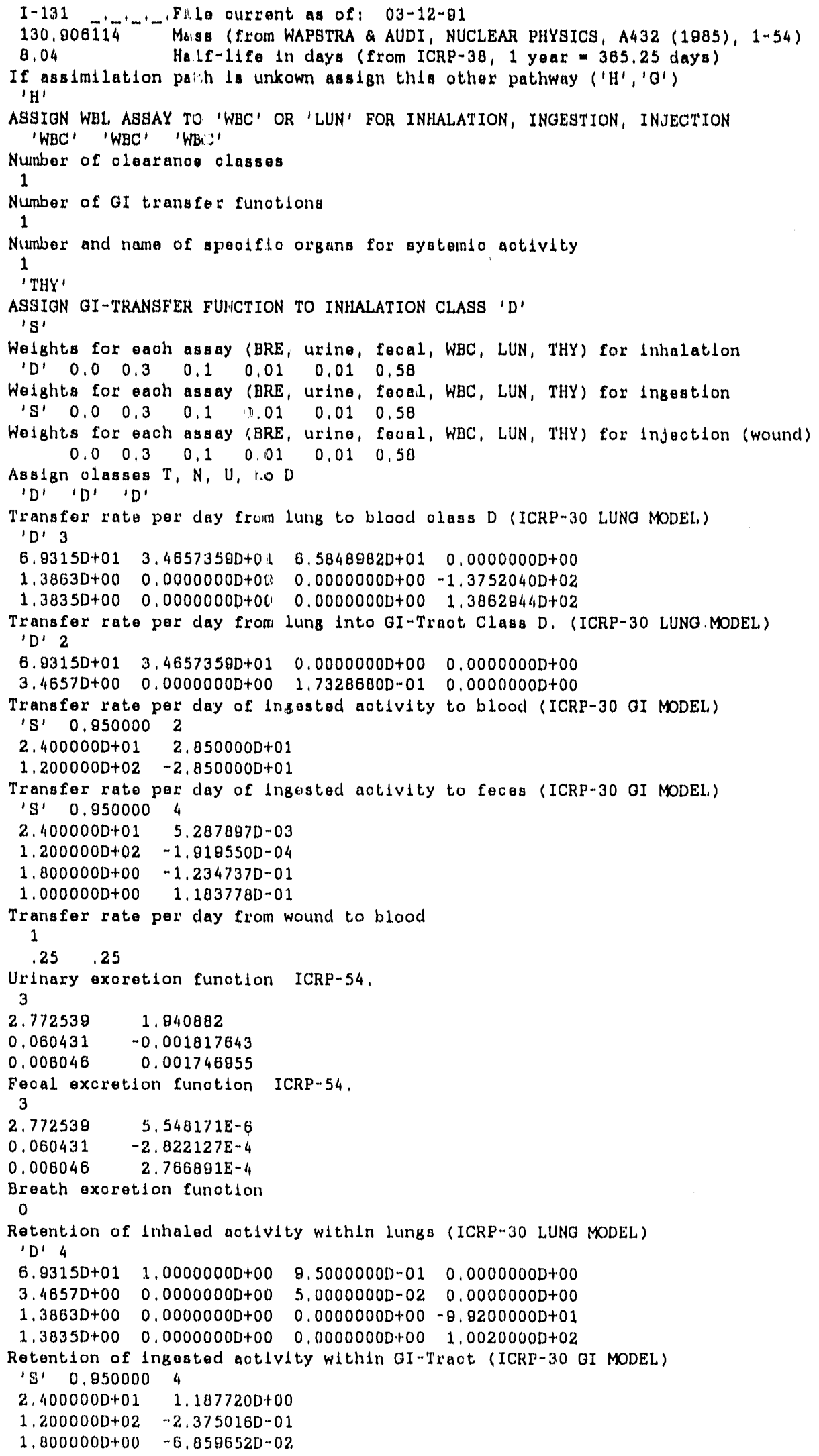




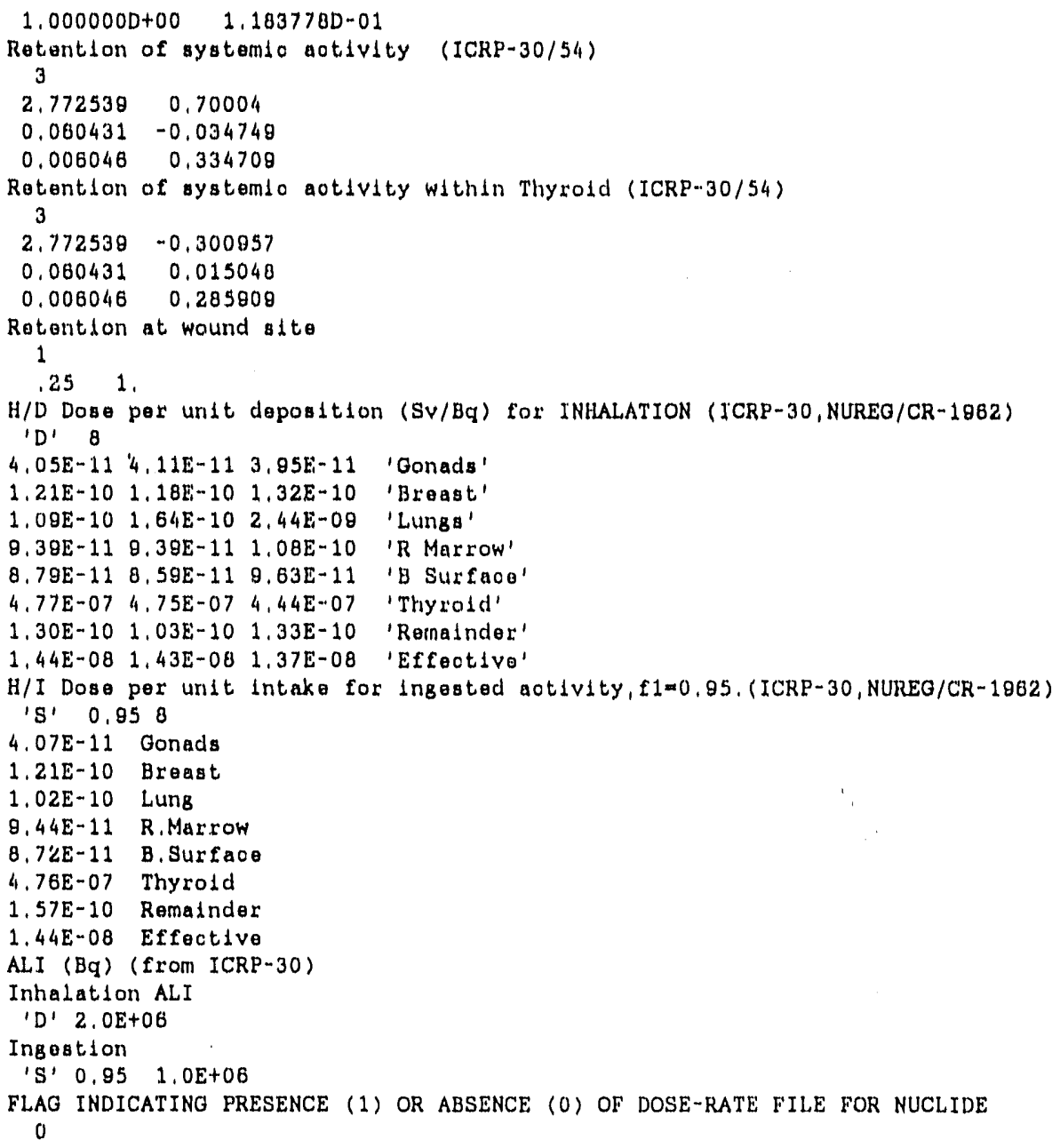

FLAG INDICATING PRESENCE (1) OR ABSENCE (0) OF DOSE-RATE FILE FOR NUCLIDE 0 


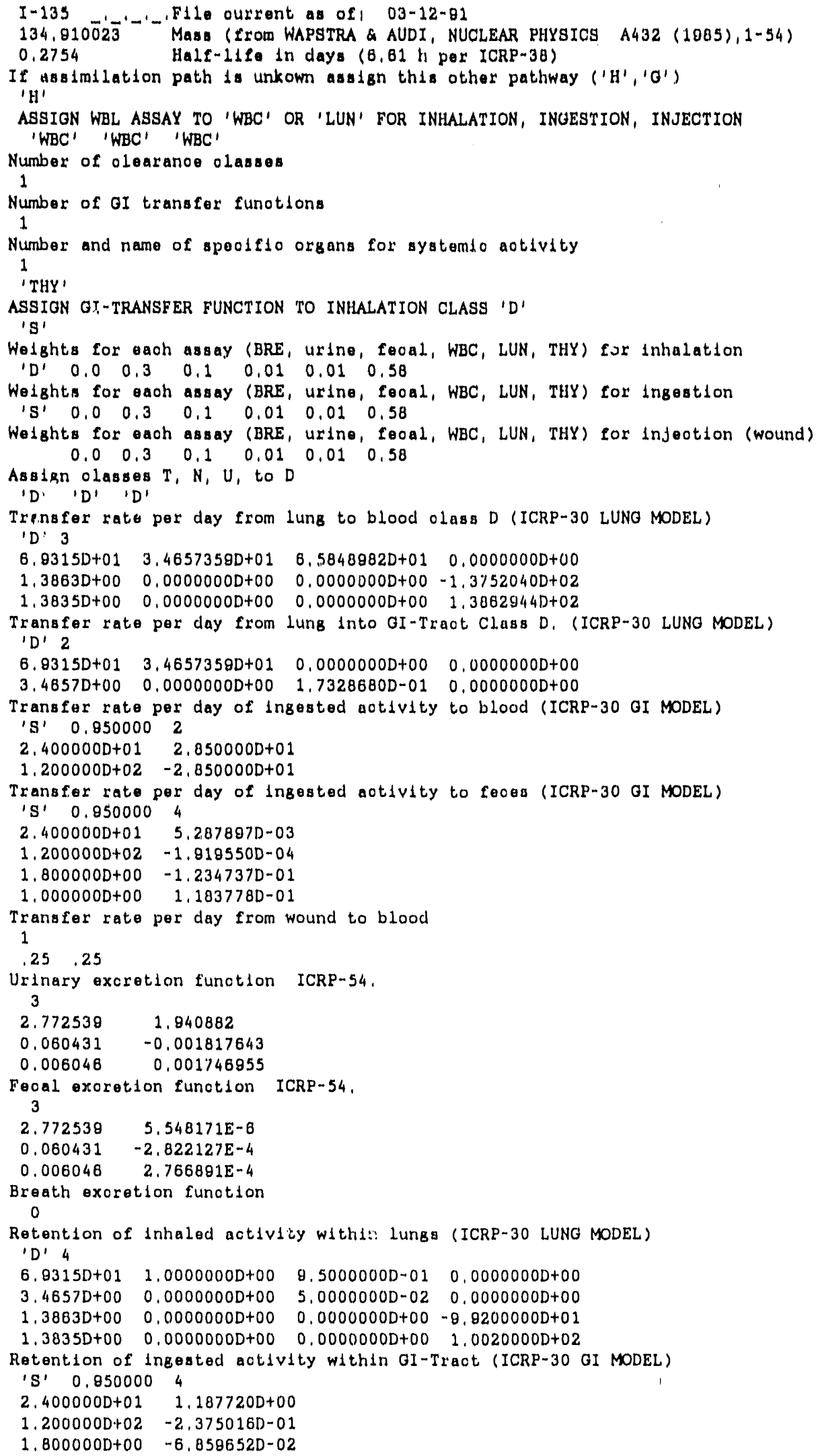




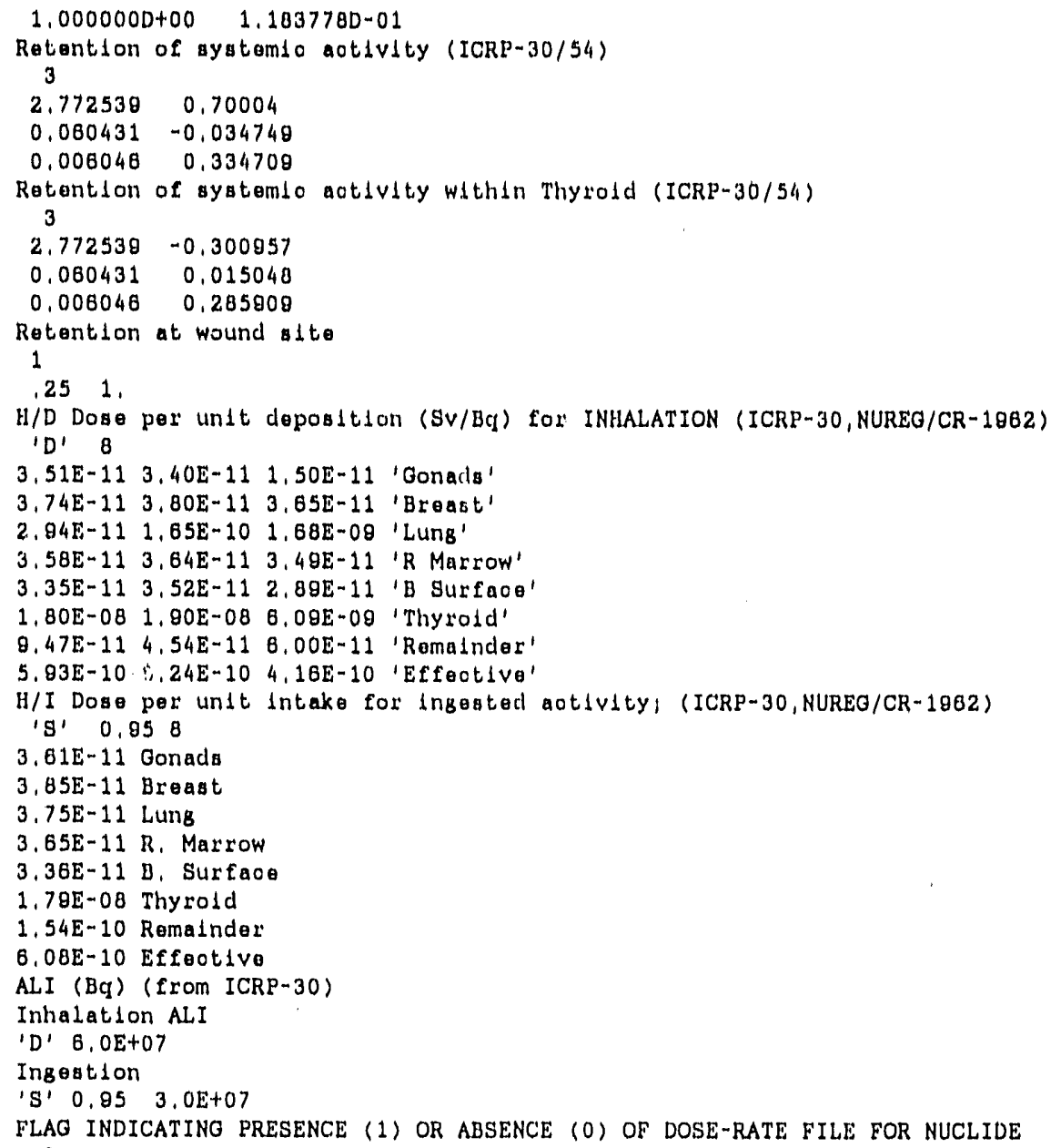




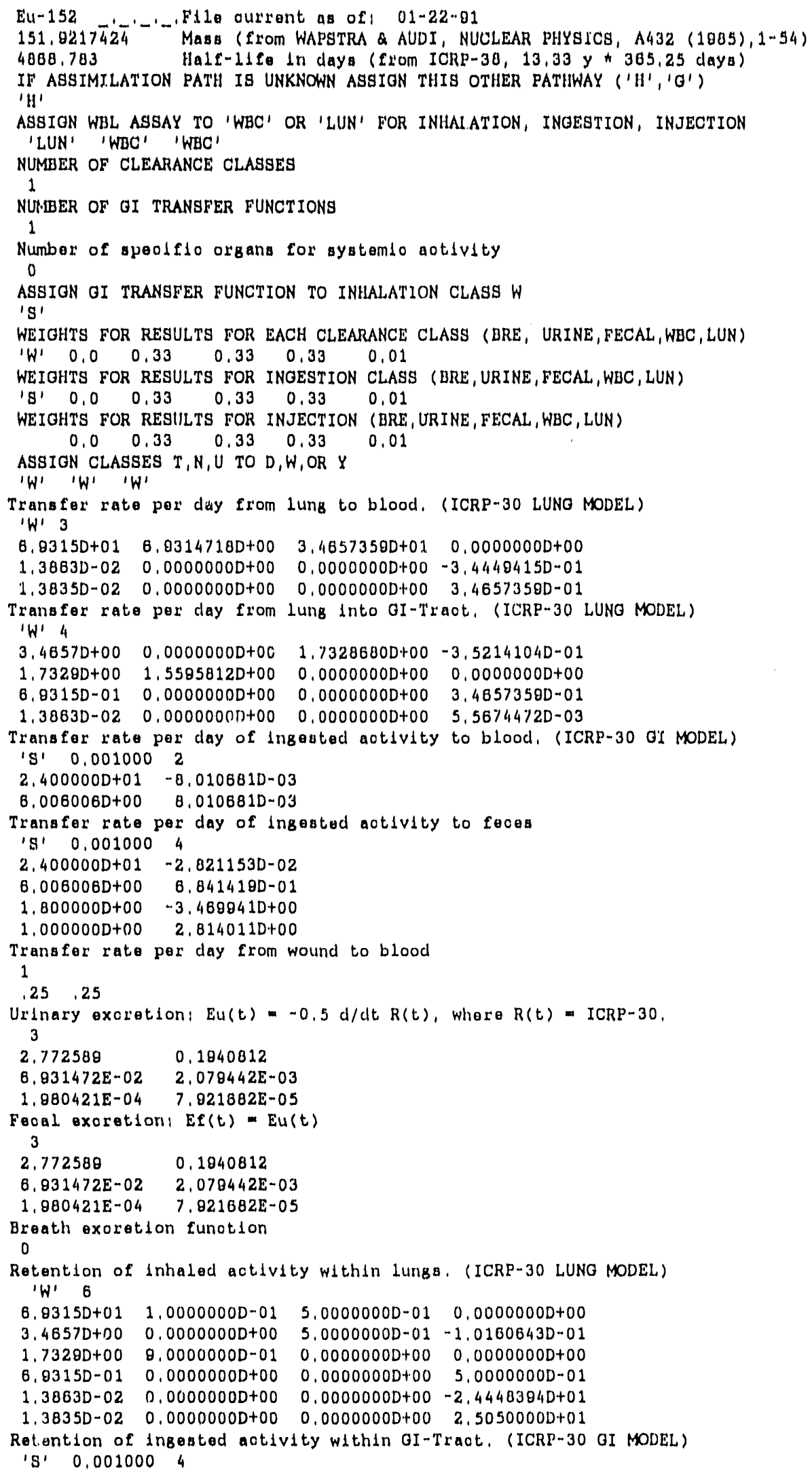




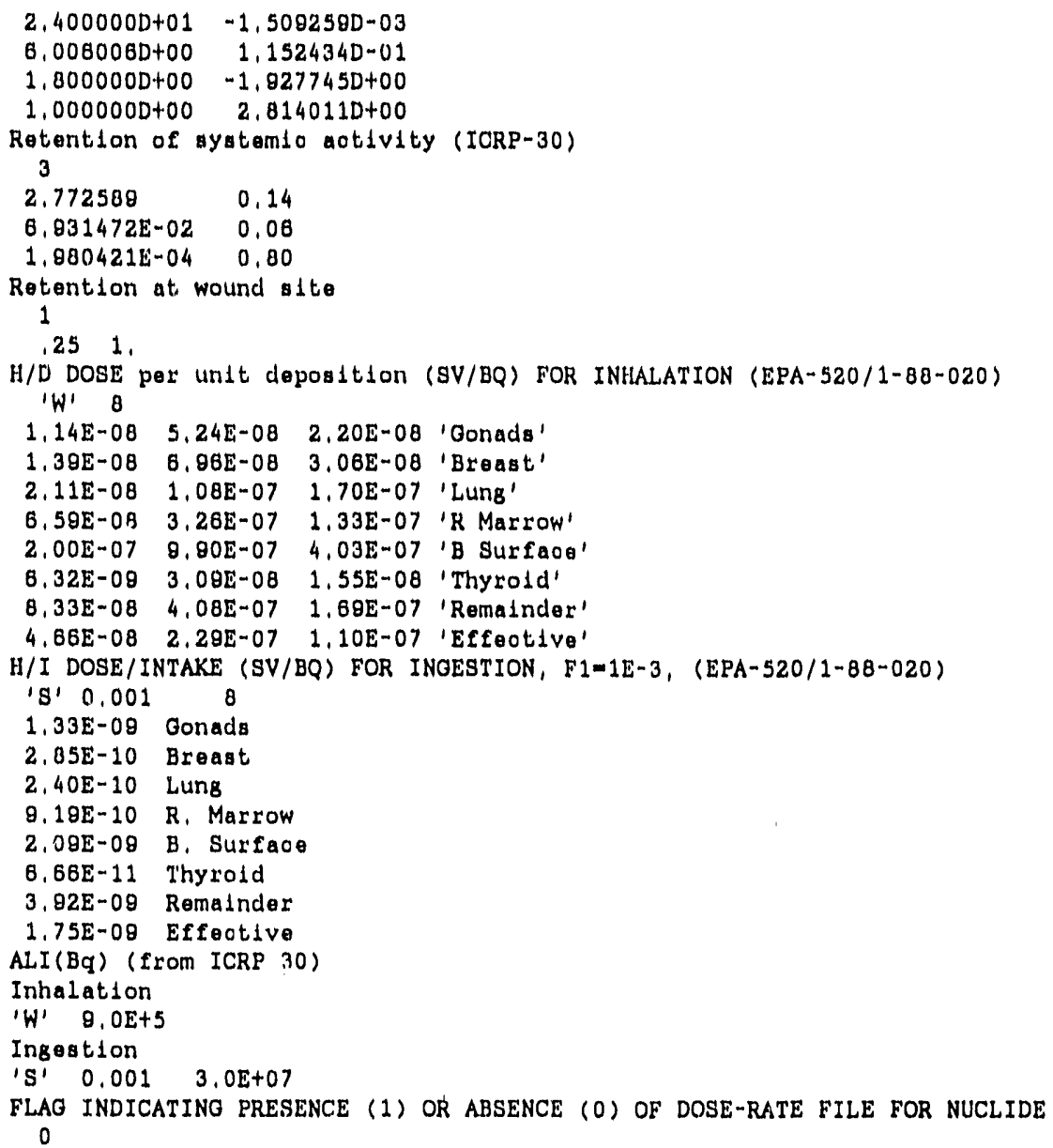




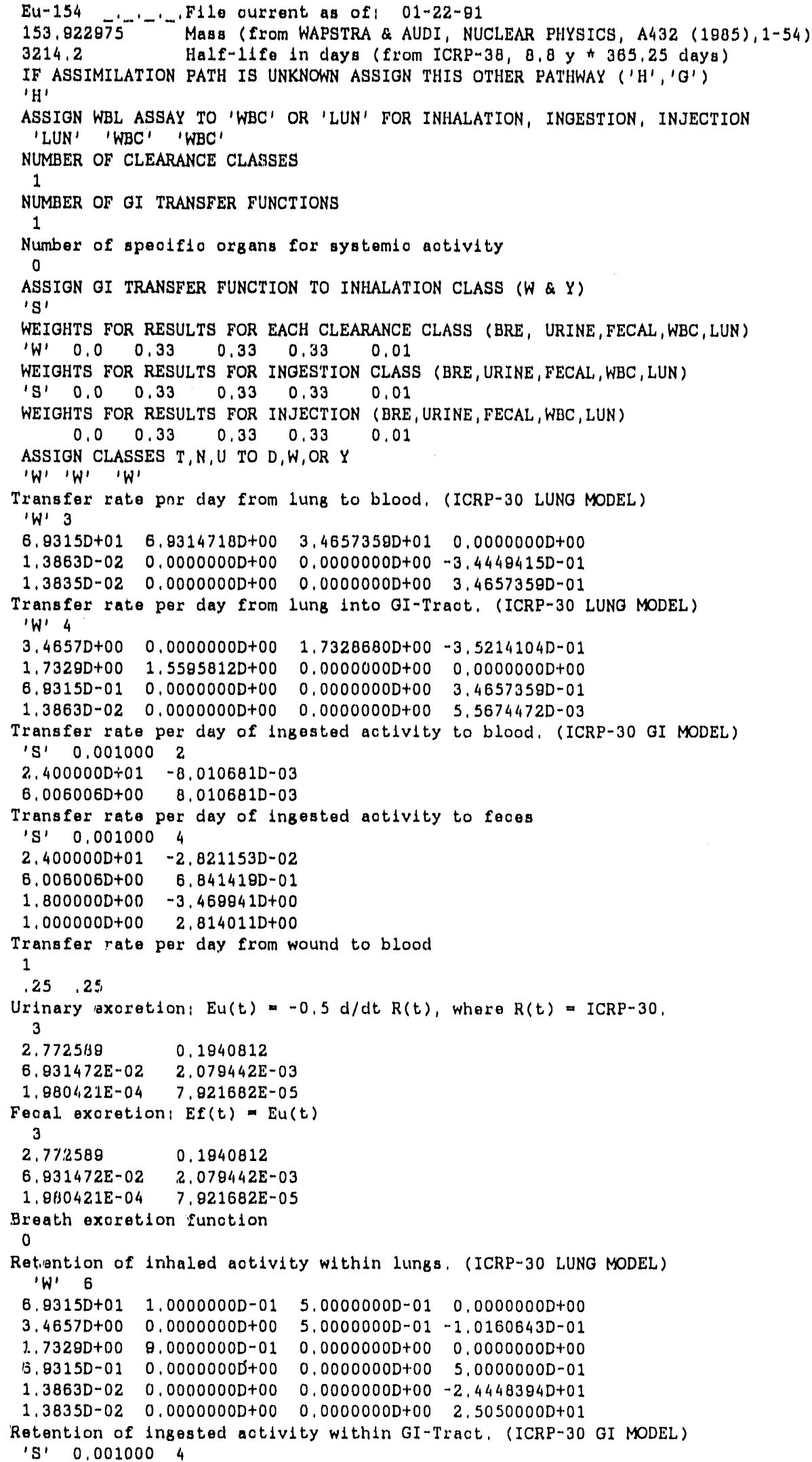




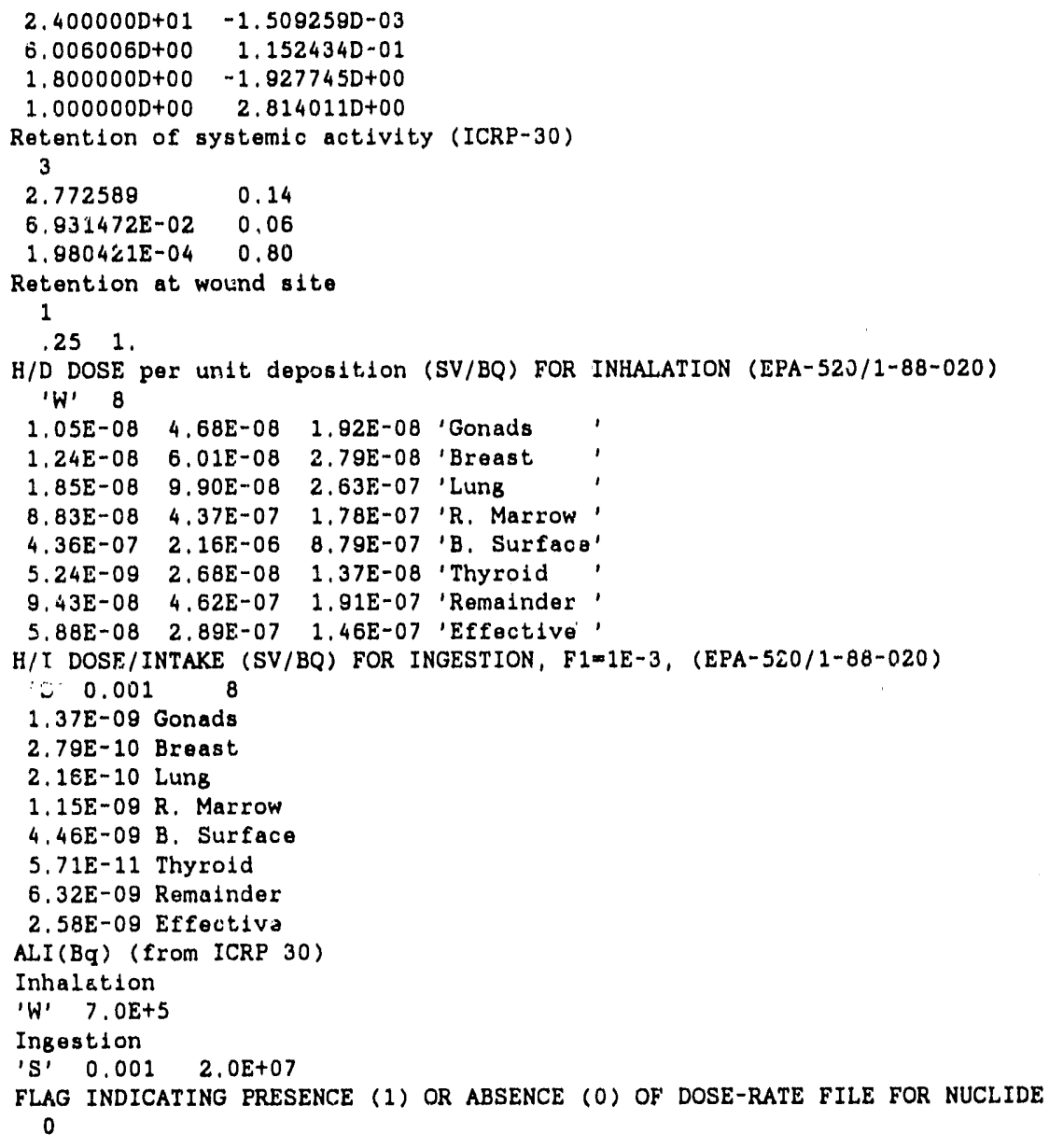




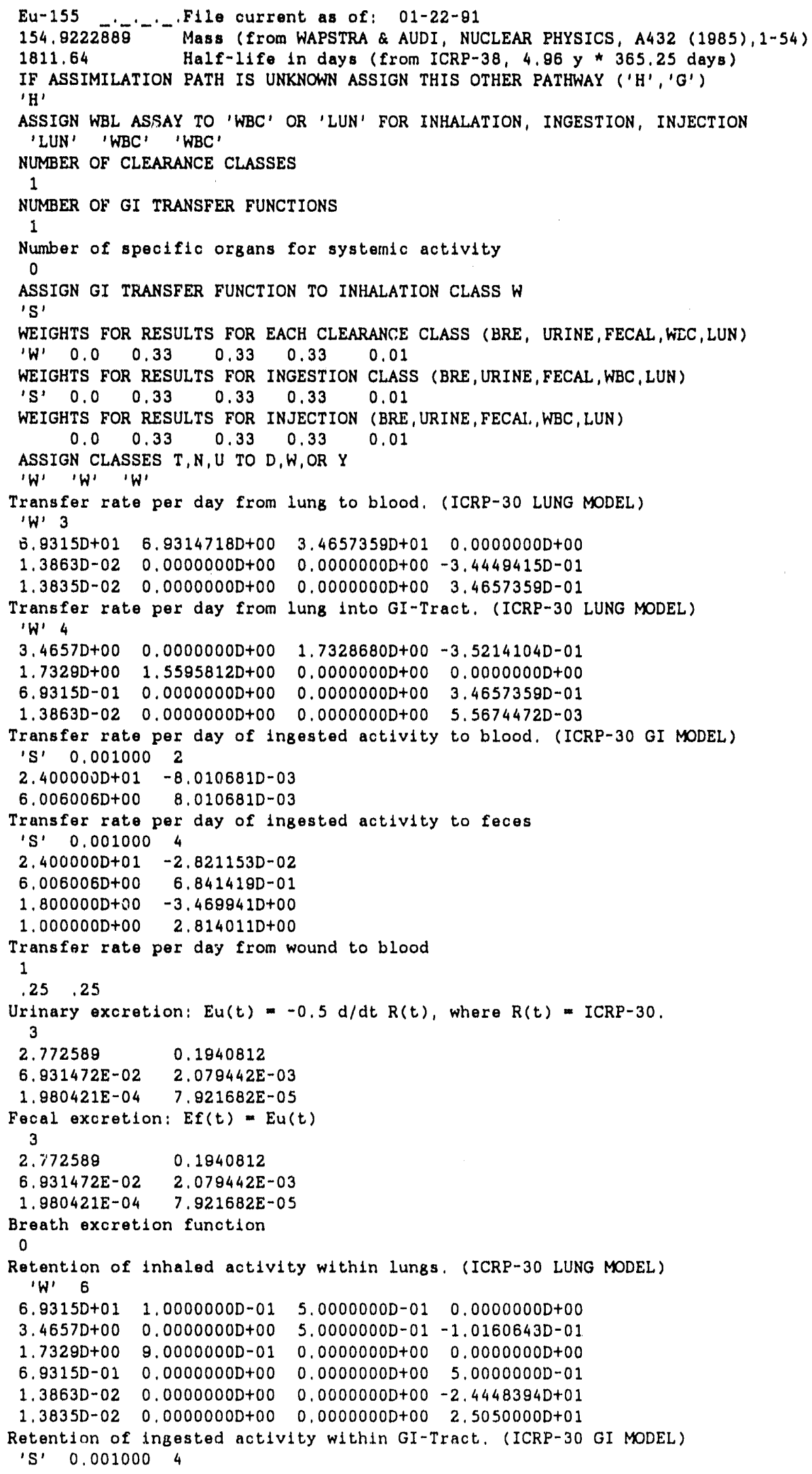




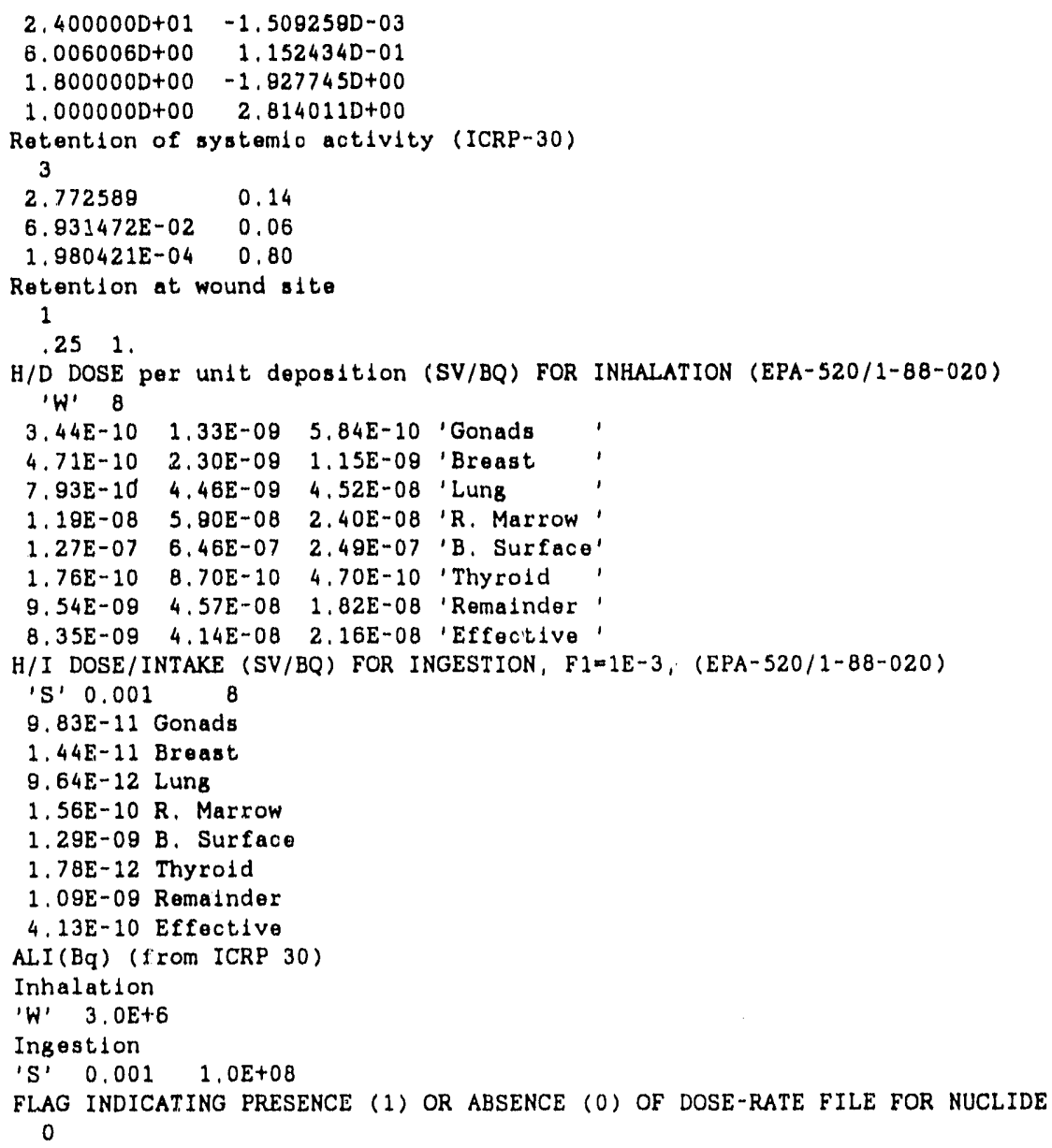




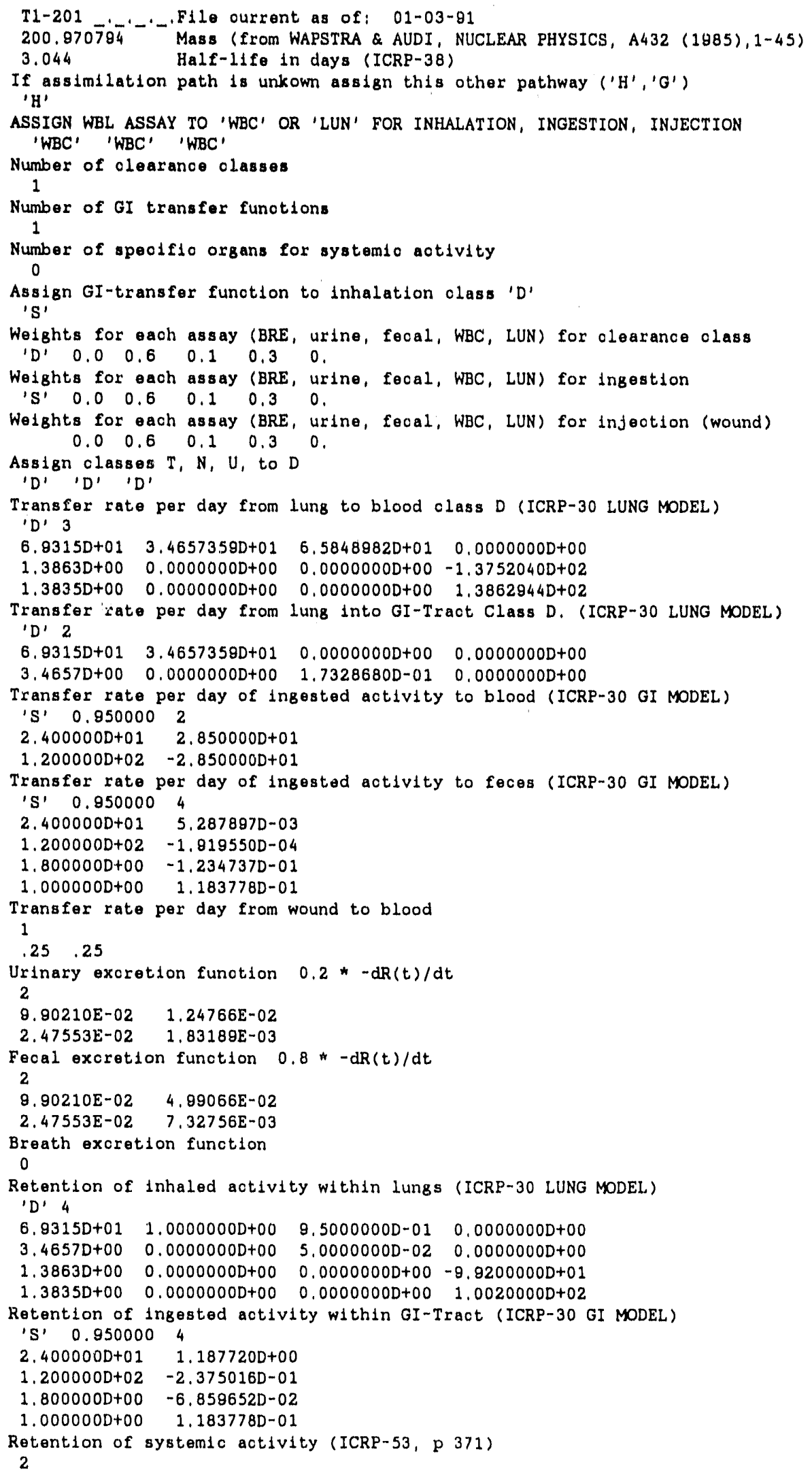




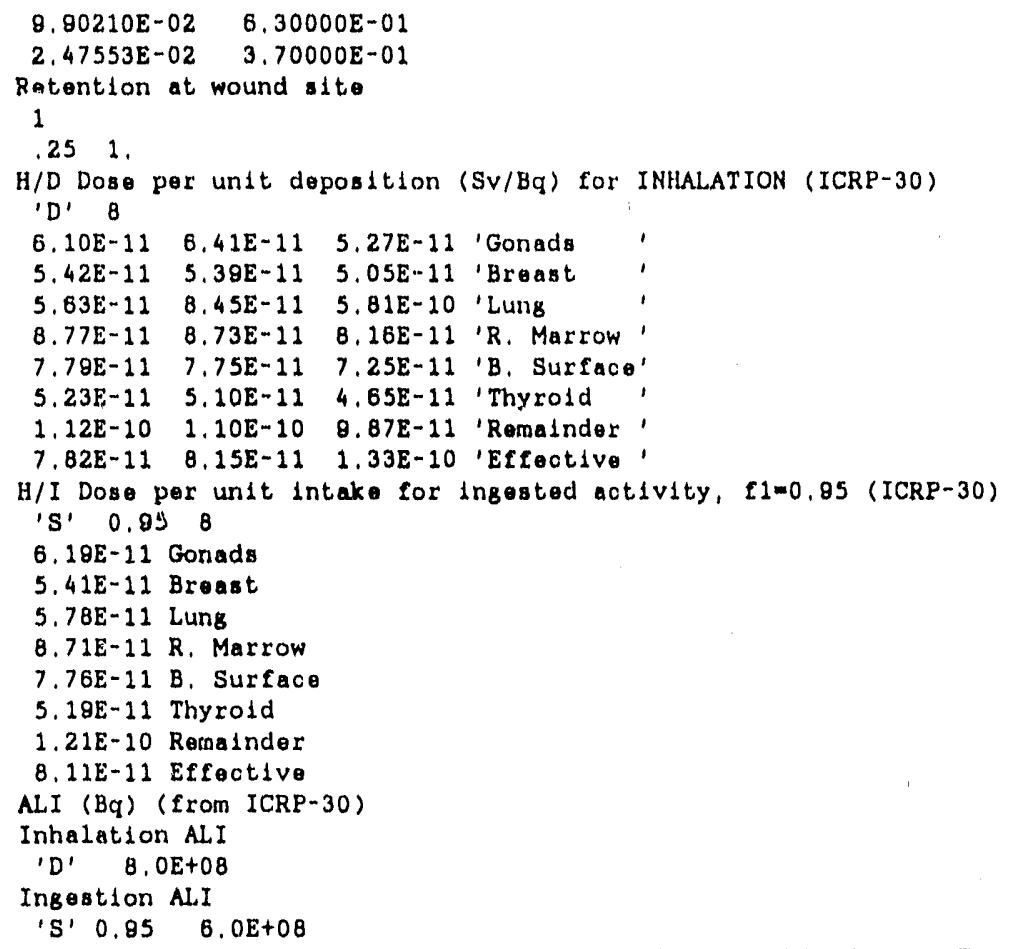




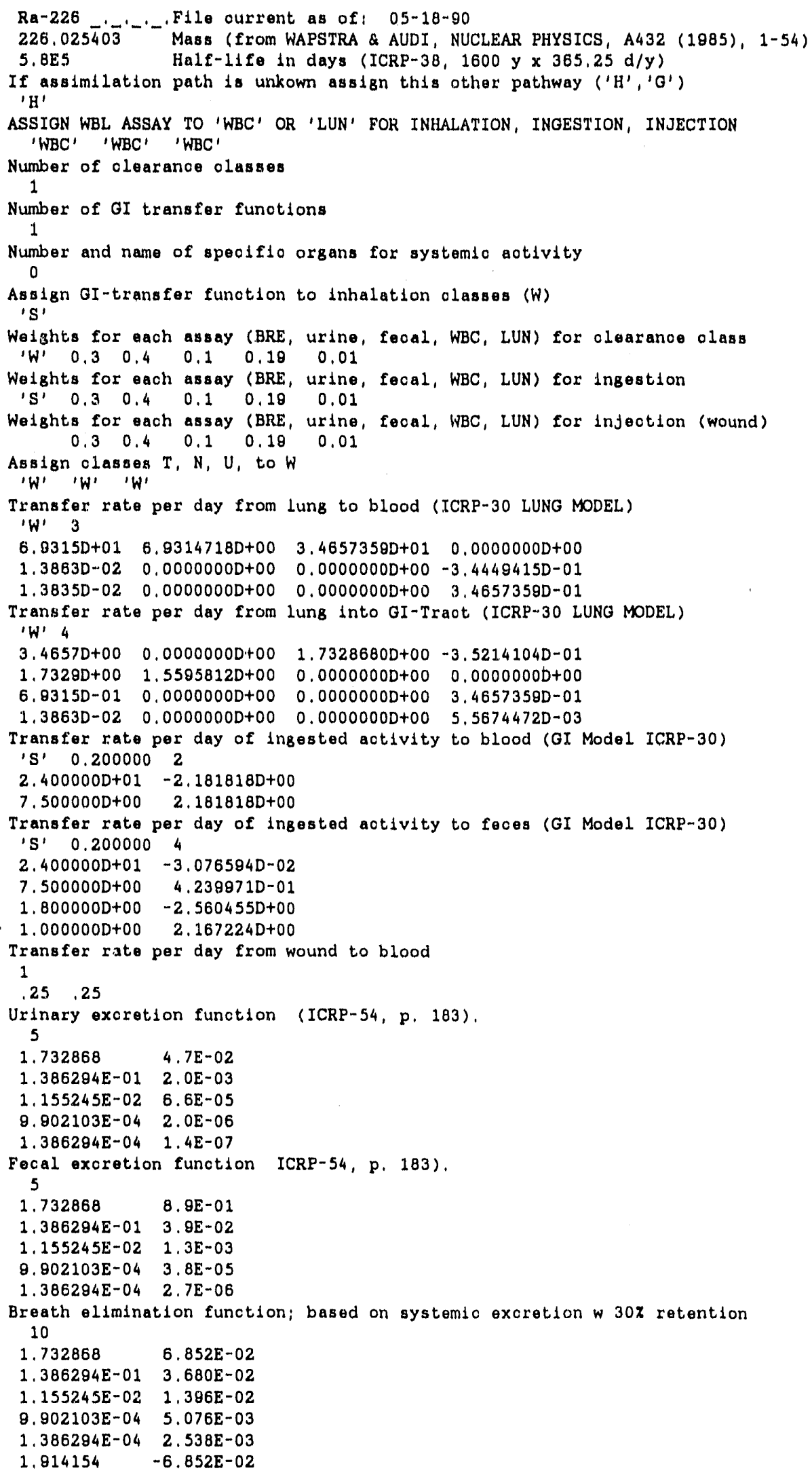




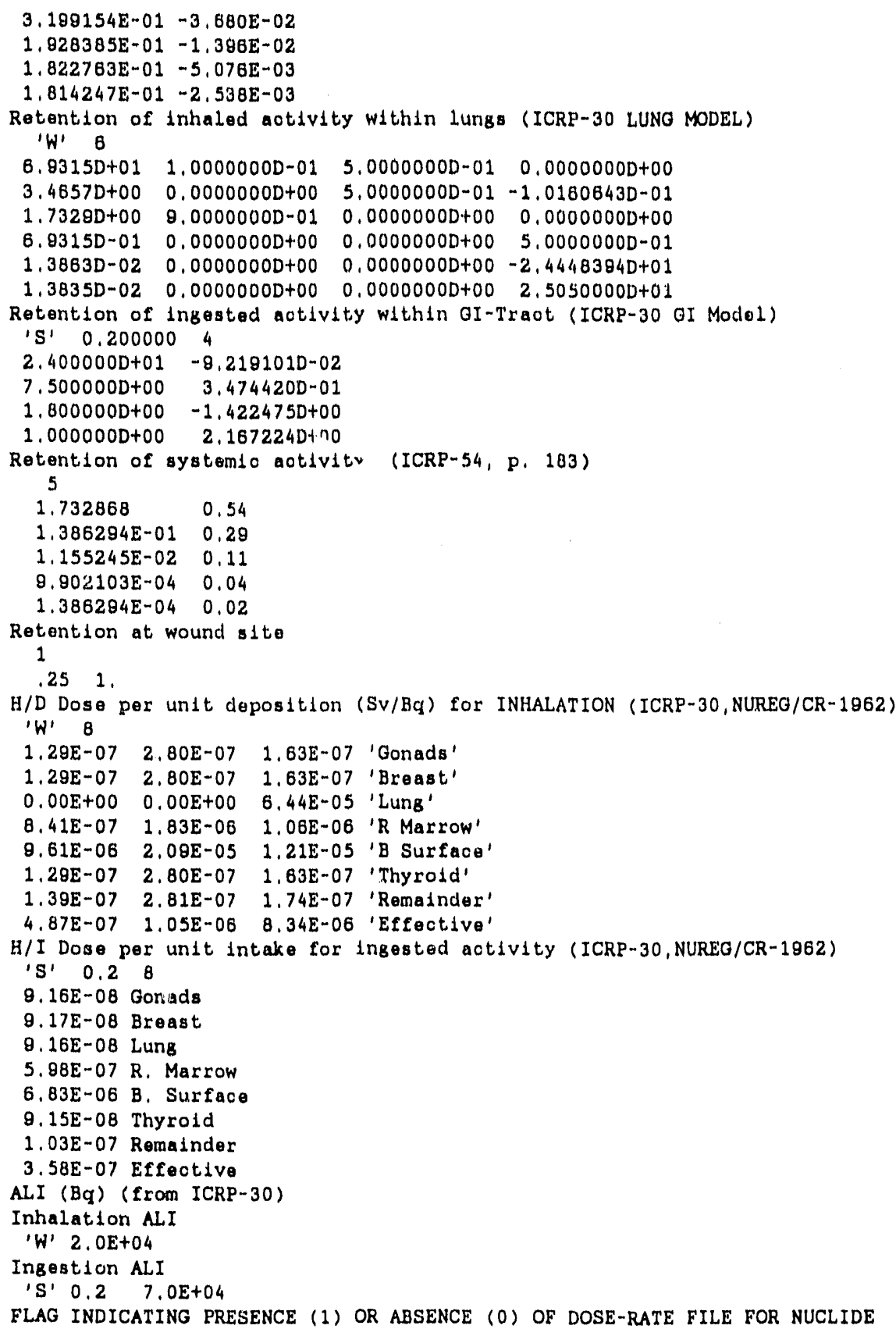




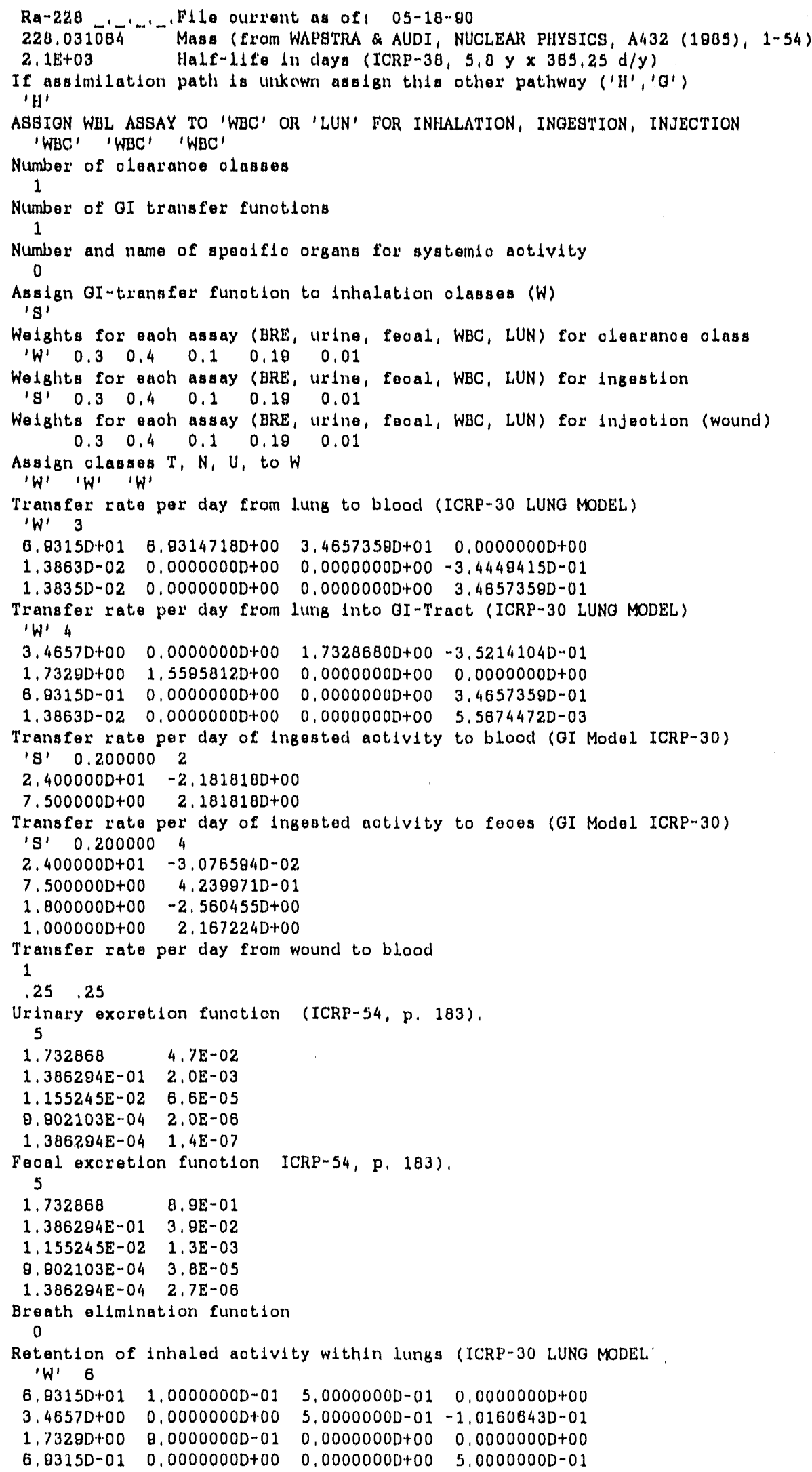




\section{8}

1.3863D-02 $\quad 0,0000000 D+00 \quad 0,0000000 D+00-2,4448394 D+01$

$\begin{array}{lllll}1.3835 D-02 & 0,0000000 D+00 & 0.0000000 D+00 & 2.5050000 D+01\end{array}$

Retention of ingested aotivity within GI-Traot (ICRP-30 OI Model)

's' $0.200000 \quad 4$

$2,4000000+01-9,2191010-02$

$7,500000 D+00 \quad 3.4744200-01$

$1,8000000+00-1,4224750+00$

1. $0000000+00 \quad 2,167224 D+00$

Retention of systemio aotivity (ICRP-54, p. 183)

$1.732868 \quad 0.54$

$1.386294 E-01 \quad 0,29$

$1,155245 \mathrm{E}-02 \quad 0,11$

$9,902103 \mathrm{E}-04 \quad 0,04$

$1.386294 \mathrm{E}-04 \quad 0.02$

Retention at wound site

1

.251.

H/D Dose per unit deposition (Sv/Bq) for INHALATION (ICRP-30, NUREG/CR-1962)

'W' 8

2.20E-07 4.80E-07 3,15E-07 'Gonads'

2.21E-07 4.83E-07 3.16E-07 'Breast'

2.41E-07 9.02E-07 2.83E-05 'Lung'

8.10E-07 1.94E-06 1.24E-06 'R Marrow'

8.25E-06 1.71E-05 1.,07E-05 'B Surface

2.20E-07 4,80E-07 3,15E-07 'Thyrold'

2.26E-07 4.73E-07 3.27E-07 'Remalnder'

5.48E-07 1.20E-06 4.10E-06 'Effective'

H/I Dose per undt intake for ingested activity (ICRP-30, NUREG/CR-1962)

'S' 0.28

1.58E- 07 Gonads

1. $57 \mathrm{E}-07$ Breast

1.57E-07 Luns

6. 53E-07 R. Marrow

5.82E-06 B. Surfaco

1.57E-07 Thyrold

1.63E-07 Rernainder

3. 88E-07 Effoot1ve

ALI (Bq) (from ICRP-30)

Inhalation ALI

' $W$ ' $4.0 E+04$

Ingestion ALI

'S' $0.2 \quad 9.0 E+04$

FLAG INDICATING PRESENCE (1) OR ABSENCE ( 0 ) OF DOSE-RATE FILE FOR NUCLIDE 


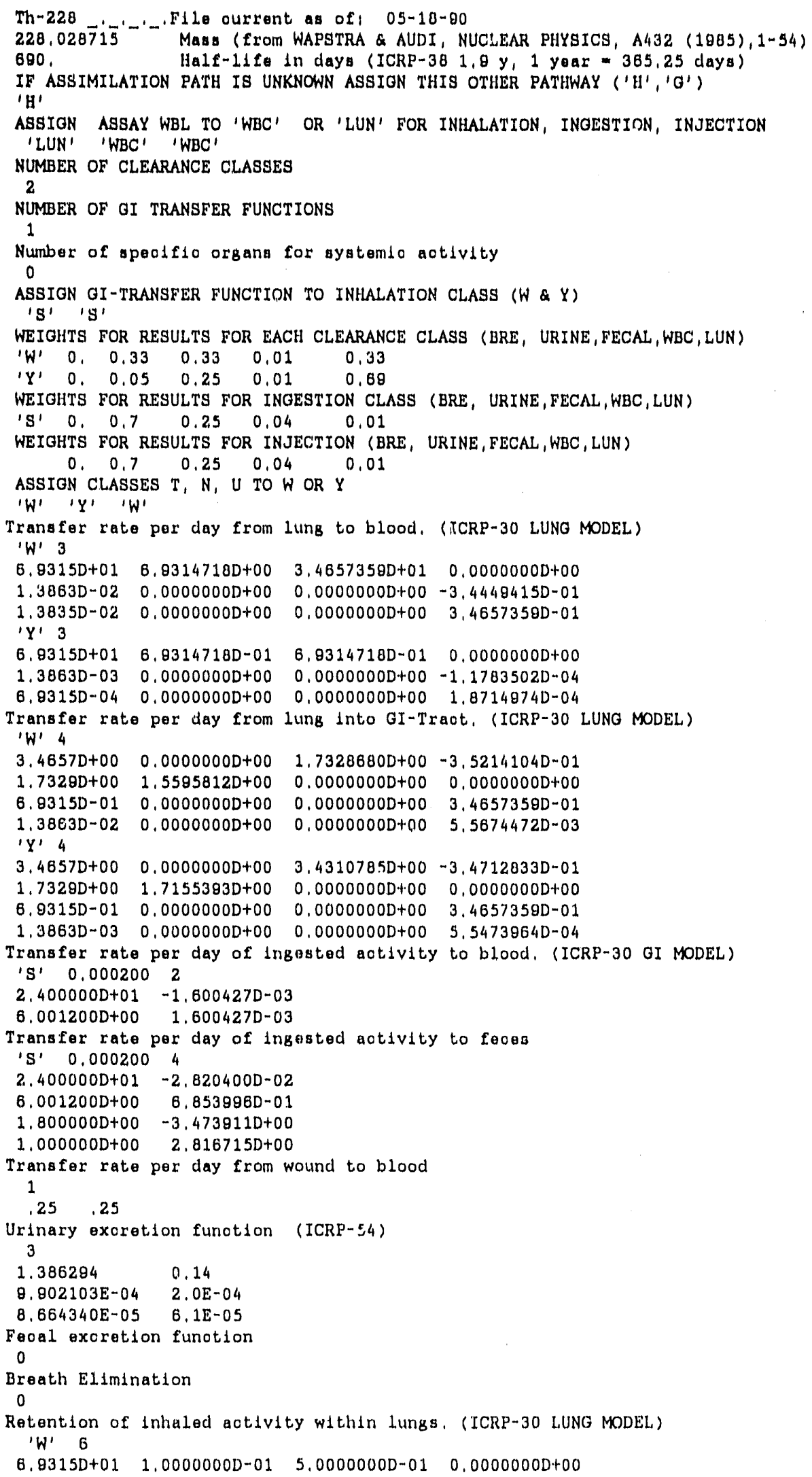




\begin{tabular}{|c|c|c|c|}
\hline $3,46570+00$ & $0,0000000 D+00$ & $5,0000000 D-01$ & $-1,01000430-01$ \\
\hline $1,73200+00$ & $0,00000000-01$ & $0,0000000 D+00$ & $0,00000000+00$ \\
\hline $6.93150-01$ & $0,00000000+00$ & $0,00000000+00$ & $5,00000000-01$ \\
\hline $1,38030-02$ & $0.00000000+00$ & $0,00000000+00$ & $-2,4448394 D+01$ \\
\hline $\begin{array}{l}1.3835 D-02 \\
1 Y 17\end{array}$ & $0,0000000 D+00$ & & \\
\hline $6.931 .5 \mathrm{D}+01$ & & & \\
\hline & & & -1. \\
\hline $1.73290+00$ & $O D=01$ & 0,0 & $000 D+00$ \\
\hline $0,9315 D-01$ & $10 D+00$ & 0.0 & $0000-01$ \\
\hline $1,38830-03$ & $0,0000000 D+00$ & $0,0000000 D+00$ & $3,1518000 D-01$ \\
\hline & $0.0000000 D+00$ & $0,0000000 D+00$ & $2,70000000-01$ \\
\hline $6.93150 \cdots 00$ & $0,00000000+00$ & $0,0000000 \mathrm{D}+00$ & $1,5000000 D-02$ \\
\hline
\end{tabular}

's' 0.0002004

$2.400000 p+01-1.2418510-03$

$0,0012000+00 \quad 1.1447710-01$

$1.8000000+00-1.8299500+00$

$1.0000000+00 \quad 2.8167150+00$

Retention of systemlo activity (ICRP-30/34)

3

1. 386294

0.1

$0.902103 \mathrm{E}-04 \quad 0.2$

$8,664340 \mathrm{E}-0.5 \quad 0.7$

Rotention at wound site 1

251 .

$H / D$ DOSE por untt doposition (SV/BQ) FOR INHALATION (ICRPr30, NUREG/CR-1962) 'W' 8

1.17E-08 5.74E-08 2.16E-06 'Gonads'

1.17E-06 5.74E-08 2,16E-06 'Breast'

$0.00 E+00 \quad 1.19 E-05 \quad 3.75 E-04$ 'Lung'

9.71E-0S 4,76E-04 1.79E-04 'R Marrow'

1.18E-03 5.82E-03 2.19E-03 'B Surfaoo'

1.16E-06 5,70E-06 2.14E-06 'Thyrold'

2.99E-06 1.46E-05 5.52E-06 'Remainder'

4.87E-05 2.40E-04 1.35E-04 'Effeot1vo'

'Y' 8

1.21E-07 1.13E-07 7.23E-07 'Gonads'

1.16E-07 1.16E-07 7.52E-07 'BLeast'

$0.00 E+00 \quad 0.00 E+00 \quad 2.76 E-03$ 'Luns'

9.97E-06 0.35E-06 5.98E-05 'R Marrow'

1.22E-04 1.14E-04 7.33E-04 'B Surface'

1.15E-07 1.15E-07 7.45E-07 'Thyrold'

3.41E-07 3.25E-07 1,91E-06 'Remainder'

5.01E-06 4.70E-06 3.62E-04 'Effective'

H/I DOSE/INTAKE (SV/BQ) FOR INGESTION, FI=0.0002 (ICRP-30, NUREG/CR-1962)

'S' 2,E-04 8

2. $53 \mathrm{E}-08$ Gonads

2. 33E-09 Braast

2. 31E-09 Lung

1.93E-07 R. Marrow

2. 37E-06 B, Surface

2. 30E-00 Thyroid

3. 86E-08 Remainder

1.07E-07 Effeotive

ALI (Bq) (from ICRP-30)

Inhalation

' $W$ ' $4,0 \mathrm{E}+2$

' $Y$ ' $6,0 E+2$

Ingestion

'S' $0.0002 \quad 2,0 E+5$

FLAG INDICATING PRESENCE (1) OR ABSENCE (0) OF DOSE-RATE FILE FOR NUCLIDE

0 


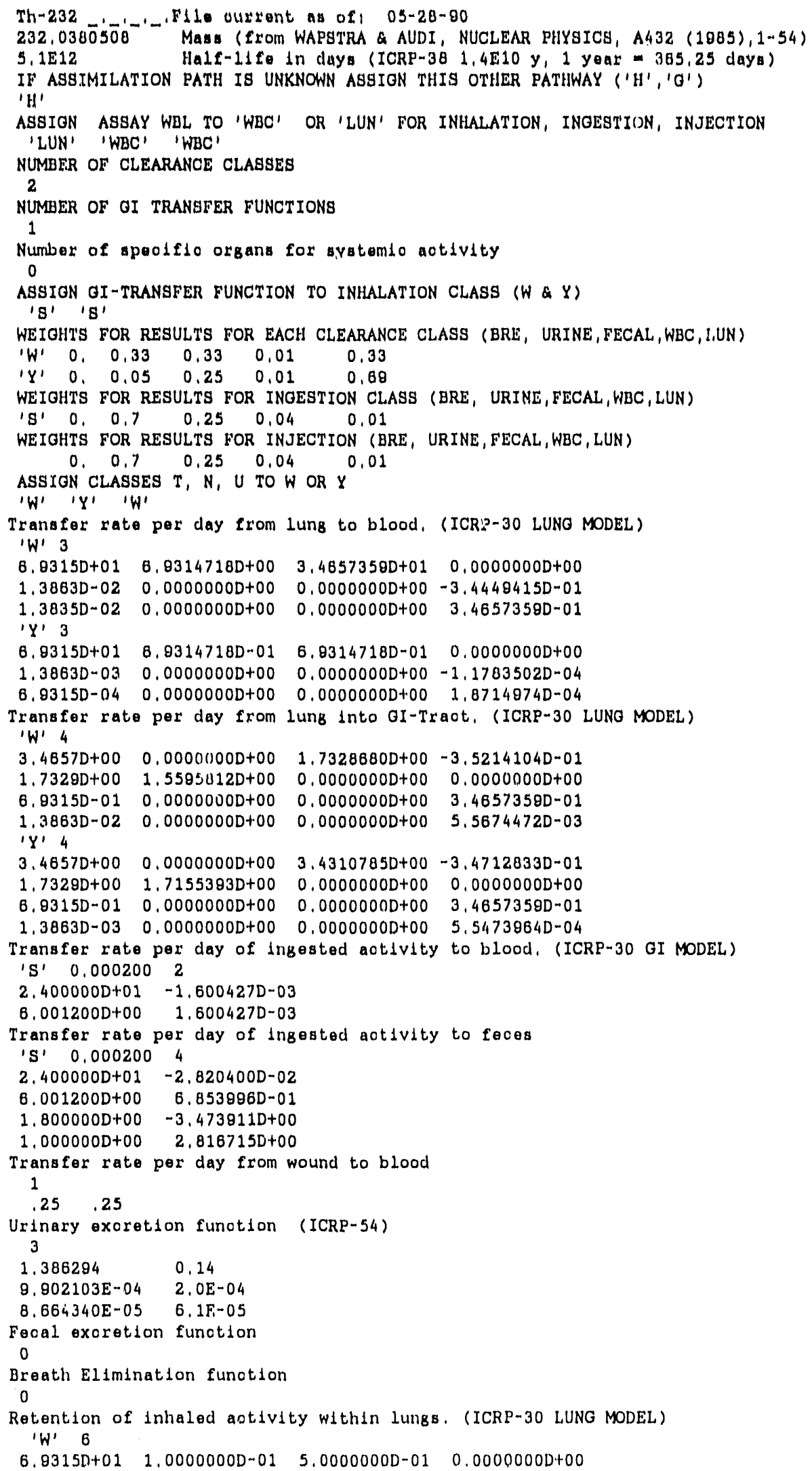




\section{2}

\begin{tabular}{|c|c|c|c|}
\hline $3,4657 D+00$ & $0,0000000 D+00$ & $5.00000000 \times 01$ & $-1,01600430-01$ \\
\hline $1.73280+00$ & $9,00000000-01$ & $0.0000000 D+00$ & $0,00000000+00$ \\
\hline, $9315 D=01$ & $0,0000000 D+00$ & $0,00000000+00$ & $5.00000000-01$ \\
\hline $1,306,30-02$ & $0,0000000 D+00$ & $0.00000000+00$ & $-2.4448384 D+01$ \\
\hline $\begin{array}{l}1,38350-02 \\
1 Y^{\prime} 7\end{array}$ & $0,0000000 D+00$ & $0.00000000+00$ & $2.5050000 D+01$ \\
\hline 8. 8315D+01 & $1,00000000-02$ & 1.000 & $0,0000000 D+00$ \\
\hline $3,46570+00$ & $100 D+00$ & $O D-01$ & $-1,0016006 D-01$ \\
\hline $1.73280+00$ & $9,9000000 D-01$ & $0,0000000 D+00$ & $0,0000000 D+00$ \\
\hline 6. $9315 D-01$ & $0.0000000 D+00$ & $0.00000000+00$ & $5,00000000-01$ \\
\hline & $0,0000000 \mathrm{D}+00$ & $0,00000000+00$ & $3,1516006 \mathrm{D}-01$ \\
\hline $6.9315 D-04$ & $0,0000000 D+00$ & $0.00000000+00$ & $2,70000000-01$ \\
\hline
\end{tabular}

$\begin{array}{llll}6.9315 D-06 & 0.0000000 D+00 & 0.0000000 D+00 & 1.5000000 D-02\end{array}$

Retention of ingested aotivity within Gl.Traot, (ICRP-30 GI MODEI,

' $S$ ' 0.0002004

$2.4000000+01-1.2418510-03$

$6,0012000+00 \quad 1.1447710-01$

$1.800000 D+00-1.929950 D+00$

$1,000000 D+00 \quad 2.816715 \mathrm{D}+00$

Retention of systemio activity (ICRP-30/54)

3

$\begin{array}{ll}1.386294 & 0.1 \\ 9.902103 E-04 & 0.2\end{array}$

$\begin{array}{ll}9.902103 E-04 & 0.2 \\ 8.664340 E-0.5 & 0.7\end{array}$

Retention at wound site

1

251

H/D DOSE per unit deposition (SV/BQ) FOR INHALATION (ICRP-30, NUREG/CR-1862) 'W' 8

6.35E-07 3,14E-06 1.28E-06 'Gonads'

6. 43E-07 3,18E-06 1,30E-06 'Breast'

4.80E-07 3.60E-06 5.59E-05 'Lung'

$7.44 \mathrm{E}-04$ 3,68E-03' 1.50E-03 'R Marrow'

9.25E-03 4,58E-02 1,86E-02 'B Surfaod'

6.20E-07 3.07E-06 1.25E-06 'Thyrold'

1.56E-06 7,68E-06 3.15E-06 'Remainder'

3.68E-04 1.82E-03 7.48E-04 'Effeot1vo'

' $\mathrm{X}$ ' 8

5.98E-08 7.47E-08 2.30E-06 'Gonads'

6.14E-08 7.67E-08 2,36E-06 'Breast'

$0,00 \mathrm{E}+00 \quad 0,00 \mathrm{E}+00 \quad 3,76 \mathrm{E}-03$ 'Lung'

8.02E-05 1,00E-04 1.48E-03 'R Marrow'

8.98E-04 1.25E-03 1.84E-02 'B Surfaoo'

5.89E-08 7.48E-08 2,30E-06 'Thyrotd'

1.59E-07 1.89E-07 5.79E-06 'Remainder'

3.,86E-05 4.95E-05 1.18E-03 'Effeot1ve'

H/I DOSE/INTAKE (SV/BQ) FOR INGESTION, F1=0.0002 (ICRP-30, NUREG/CR-1862) 'S' 2,E-04,8

1.25E-09 Gonads

1. 26E-08 Breast

1. 25E-00 Luns

1. $48 \mathrm{EE}-06 \mathrm{R}$. Marrow

1.85E-05 B. Surface

1. 21E-09 Thyroid

1,47E-08 Remainder

7.38E-07 Effeotive

ALI (Bq) (from ICRP-30)

Inhalation

' $W$ ' $4, O E+1$

'Y' $1.0 \mathrm{E}+2$

Ingestion

'S' $0.0002 \quad 3,0 E+4$

FLAG INDICATING PRESENCE (1) OR ABSENCE (0) OF DOSE-RATE FILE FOR NUCLIDE 


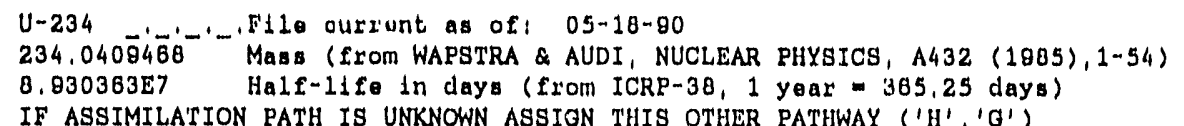
IF ASSIMILA'TION PATH IS UNKNOWN ASSION THIS OTHER PATHWAY ('H', 'G')

' $\mathrm{H}$ '

ASSION WBL ASSAY TO 'WBC' OR 'LUN' FOR INHALATION, INGESTION, INJECTION

'LUN' 'WBC' 'WBC'

NUMBER OF CLEARANCE CLASSES

3

NUMBER OF GI TRANSFER FUNCTIONS

2

Numbor of speolflo organs for systemio aotivity

0

ASSION GI TRANSFER FUNCTION TO INHALATION CLASS $(D, W, Y)$

'S' 'S' 'I'

WEIGHTS FOR RESULTS FOR EACH CLEARANCE CLASS (BRE, URINE, FECAL, WBC, LUN)

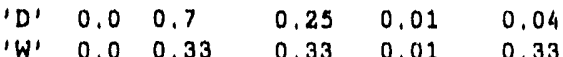

$\begin{array}{llllll}\prime Y & 0.0 & 0.33 & 0.33 & 0.01 & 0.33\end{array}$

WEIGHTS FOR RESULTS FOR INGESTION CLASS (BRE, URINE, FECAL, WBC, LUN)

'S' $0.0 \quad 0.7 \quad 0.25 \quad 0.04 \quad 0.01$

'I' $\begin{array}{lllll}0.0 & 0.05 & 0.25 & 0.69 & 0.01\end{array}$

WEIGHTS FOR RESULTS FOR INJECTION (BRE, URINE, FECAL, WBC, LUN)

$$
\begin{array}{lllll}
0.0 & 0.7 & 0.25 & 0.04 & 0.01
\end{array}
$$

ASSIGN CLASSES $T, N, U$ TO $D, W, O R$ Y

'D' ' $Y$ ' ' $Y$ '

Transfer rate per day from lung to blood. (ICRP-30 LUNG MODEL)

' $D$ ' 3

$6.9315 D+01 \quad 3,4657359 D+01 \quad 6,5848982 D+01 \quad 0,0000000 D+00$

$1.3863 D+00 \quad 0.0000000 D+00 \quad 0,0000000 D+00-1,3752040 D+02$

$\begin{array}{llll}1.3835 D+00 & 0,0000000 D+00 & 0.0000000 D+00 & 1,3882844 D+02\end{array}$

' $W$ ' 3

$6.8315 D+01 \quad 6,9314718 D+00 \quad 3,4657359 D+01 \quad 0,0000000 D+00$

$\begin{array}{llll}1.3863 D-02 & 0.0000000 D+00 & 0.0000000 D+00 & -3.4449415 D-01\end{array}$

$\begin{array}{llll}1.3835 D-02 & 0,0000000 D+00 & 0,0000000 D+00 & 3,4657359 D-01\end{array}$

' $\mathrm{Y}$ ' 3

6. $9315 D+01 \quad 6,9314718 D-01 \quad 6,9314718 D-01 \quad 0.0000000 D+00$

$1.3863 D-03 \quad 0,0000000 D+00 \quad 0.0000000 D+00-1.1783502 D-04$

$6.9315 D-04 \quad 0.0000000 D+00 \quad 0.0000000 D+00 \quad 1.8714974 D-04$

Transfer rate per day from lung Into GI-Traot. (ICRP-30 LUNG MODEL)

'D' 2

$6.9315 D+01 \quad 3,4657359 D+01 \quad 0,0000000 D+00 \quad 0,0000000 D+00$

$3.4657 D+00 \quad 0.0000000 D+00 \quad 1.7328680 D-01 \quad 0.0000000 D+00$

' $W$ ' 4

$3,4657 D+00 \quad 0,0000000 D+00 \quad 1,7328680 D+00-3,5214104 D-01$

$\begin{array}{llll}1.7329 D+00 & 1.5585812 D+00 & 0,0000000 D+00 & 0,0000000 D+00\end{array}$

$6.8315 D \cdot 01 \quad 0,0000000 D+00 \quad 0,0000000 D+00 \quad 3,4657350 D-01$

1.3863D-02 $0,0000000 D+00 \quad 0,0000000 D+00 \quad 5,5674472 D-03$

'Y' 4

$3.4657 D+00 \quad 0.0000000 D+00 \quad 3.4310785 D+00 \quad-3,4712833 D-01$

$\begin{array}{llll}1.7328 D+00 & 1.7155393 \mathrm{D}+00 & 0.0000000 D+00 & 0.0000000 D+00\end{array}$

6. 9315D-01 $0.0000000 D+00 \quad 0.0000000 D+00 \quad 3.4657359 D-01$

$1.3863 \mathrm{D}-03 \quad 0,0000000 \mathrm{D}+00 \quad 0.0000000 \mathrm{D}+00 \quad 5,5473964 \mathrm{D}-04$

Transfer rate per day of ingested aotivity to blood. (ICRP-30 GI MODEL)

's' 0.0500002

$2.400000 D+01-4,285714 D-01$

$6.3157880+00 \quad 4.2857140-01$

'I' 0.0020002

$2.4000000+01-1.604278 D-02$

6.012024D+00 1.604278D-02

Transfer rate per day of Ingested activity to feces

's' $0.050000 \quad 4$

$2.400000 D+01-2.870572 D-02$

$6.315789 D+00 \quad 6.105874 D-01$

$1.800000 D+00-3,231903 D+00$

$1.000000 D+00 \quad 2.650022 D+00$

'I' $0.002000 \quad 1$

$2,4000000+01-2,822097 D-02$

$6.012024 D+00 \quad 6.825724 D-01$ 


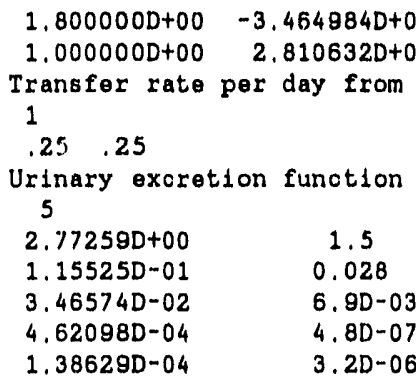

Fecal excretion function

0

Breath excretion function

0

Retention of inhaled activity within lungs. (ICRP-30 LUNG MODEL)

'D' 4

$6.9315 D+01 \quad 1.0000000 D+00 \quad 9.5000000 D-01 \quad 0.0000000 D+00$

$\begin{array}{llll}3.4657 D+00 & 0.0000000 D+00 & 5.0000000 D-02 & 0.0000000 D+00\end{array}$

$1.3863 D+00 \quad 0.0000000 D+00 \quad 0.0000000 D+00-9.9200000 D+01$

$\begin{array}{llll}1.3 P, 35 D+00 & 0,0000000 D+00 & 0.0000000 D+00 & 1.0020000 D+02\end{array}$

' $W$ ' 6

$6.9315 \mathrm{D}+01 \quad 1.0000000 \mathrm{D}-01 \quad 5.0000000 \mathrm{D}-01 \quad 0.0000000 \mathrm{D}+00$

$3.4657 D+00 \quad 0.0000000 D+00 \quad 5,0000000 D-01-1.0160643 D-01$

$\begin{array}{llll}1.7329 D+00 & 9.0000000 D-01 & 0.0000000 D+00 & 0.0000000 D+00\end{array}$

$6.9315 \mathrm{D}-01 \quad 0.0000000 \mathrm{D}+00 \quad 0,0000000 \mathrm{D}+00 \quad 5.0000000 \mathrm{D}-01$

$\begin{array}{llll}1.3863 D-02 & 0.0000000 D+00 & 0.0000000 D+00 & -2.4448394 D+01\end{array}$

$\begin{array}{llll}1.3835 D-02 & 0.0000000 D+00 & 0.0000000 D+00 & 2.5050000 D+01\end{array}$

' $Y$ ' 7

$\begin{array}{llll}6.9315 D+01 & 1.0000000 D-02 & 1.0000000 D-02 & 0.0000000 D+00\end{array}$

$3.4657 D+00 \quad 0.0000000 D+00 \quad 9.9000000 D-01-1.0016006 D-01$

$\begin{array}{llll}1.7329 D+00 & 9.8000000 D-01 & 0.0000000 D+00 & 0.0000000 D+00\end{array}$

$\begin{array}{llll}6.9315 D-01 & 0.0000000 D+00 & 0.0000000 D+00 & 5.0000000 D-01\end{array}$

$\begin{array}{llll}1.3863 D-03 & 0.0000000 D+00 & 0.0000000 D+00 & 3.1516006 D-01\end{array}$

$\begin{array}{llll}6.9315 \mathrm{D}-04 & 0.0000000 \mathrm{D}+00 & 0.0000000 \mathrm{D}+00 & 2.7000000 \mathrm{D} \cdots 01\end{array}$

6.9315D-06 $0.0000000 D+00 \quad 0.0000000 D+00 \quad 1.5000000 D-02$

Retention of ingested activity within GI-Tract. (ICRP-30 GI MODEL)

'S' 0.0500004

$2.400000 D+01-1.905321 D-02$

$6.315789 D+00 \quad 1.645335 D-01$

$1.800000 D+00-1.795502 D+00$

$1.000000 D+00 \quad 2.650022 D+00$

'I' 0.0020004

$2.400000 D+01-1.844323 D-03$

$6.012024 D+00 \quad 1.162030 D-01$

$1.800000 D+00-1.924991 D+00$

$1.000000 \mathrm{D}+00 \quad 2.810632 \mathrm{D}+00$

Retention of systemic activity (ICRP-30/54)

5

$2.77259 E+00 \quad 5.37849 E-01$

1.15525E-01 2.39044E-01

$3.46574 \mathrm{E}-02 \quad 1.99203 \mathrm{E}-01$

$4.62 C 98 E-04 \quad 9.96016 E-04$

1.3862UE-04 2.29084E-02

Retention at wound site

1

.251.

H/D DOSE per untt deposition (SV/BQ) FOR INHALATION (ICRP-30, NUREG/CR-1962) 'D' 8

$2.75 E-8 \quad 5.00 E-8 \quad 5.10 E-8$ 'Gonads'

2.75E-8 5.00E-A $\quad \therefore .10 \mathrm{E}-8$ 'Broast'

$3.18 E-8 \quad 7.95:-8$ - $1.21 E-6$ 'Lungs'

7.68E-7 1.40E-6 1.42E-6 'R Marrow'

1.20E-5 2.18E-5 2.22E-5 'B Surface'

2.75E-8 5.00E-8 5.10E-8 'Thyrold'

1.02E-6 1.85E-6 1.89E-6 'Remalnder'

$7.74 E-7 \quad 1.41 E-6 \quad 1.57 E-6$ 'Effective'

'W' 8 


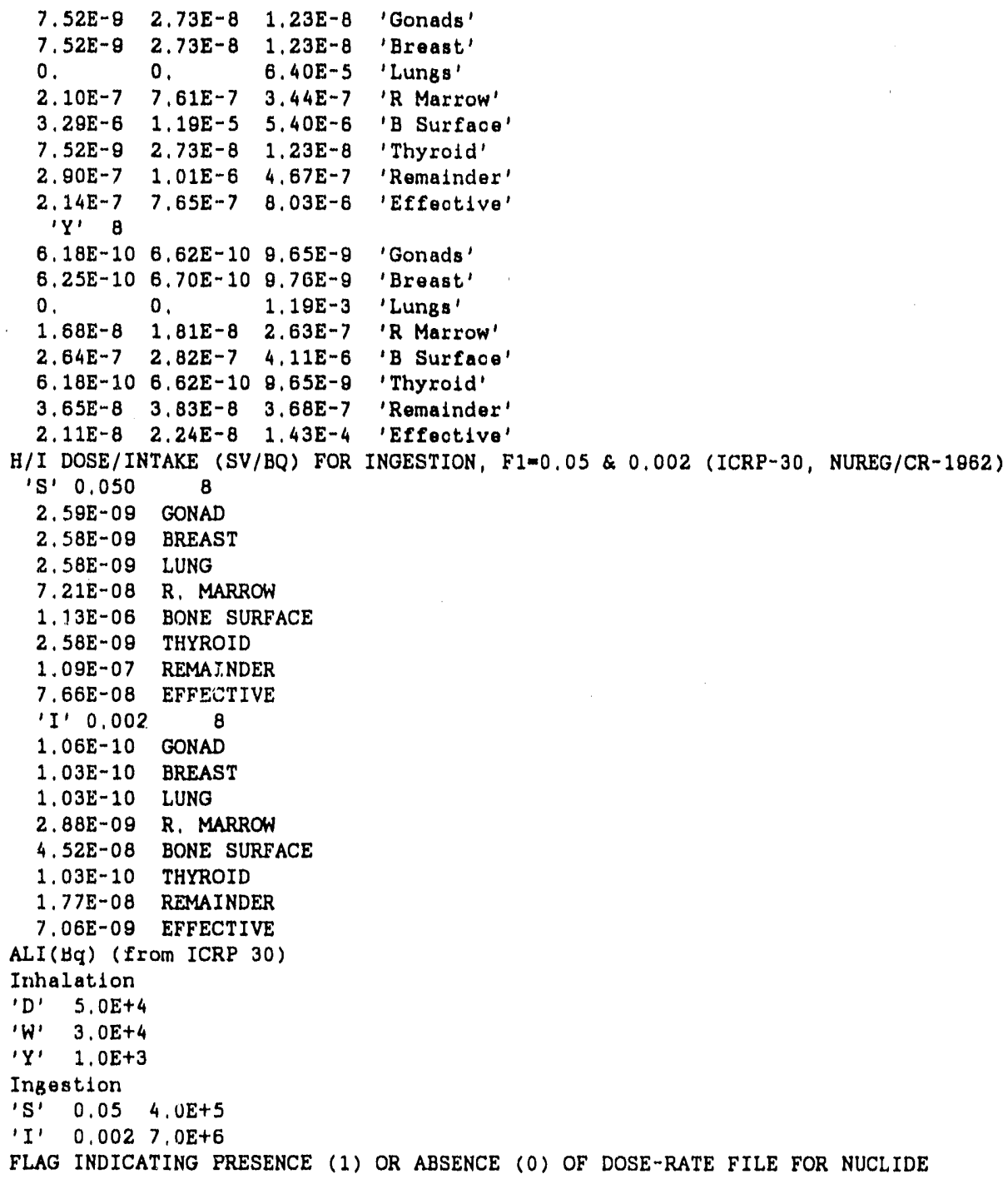




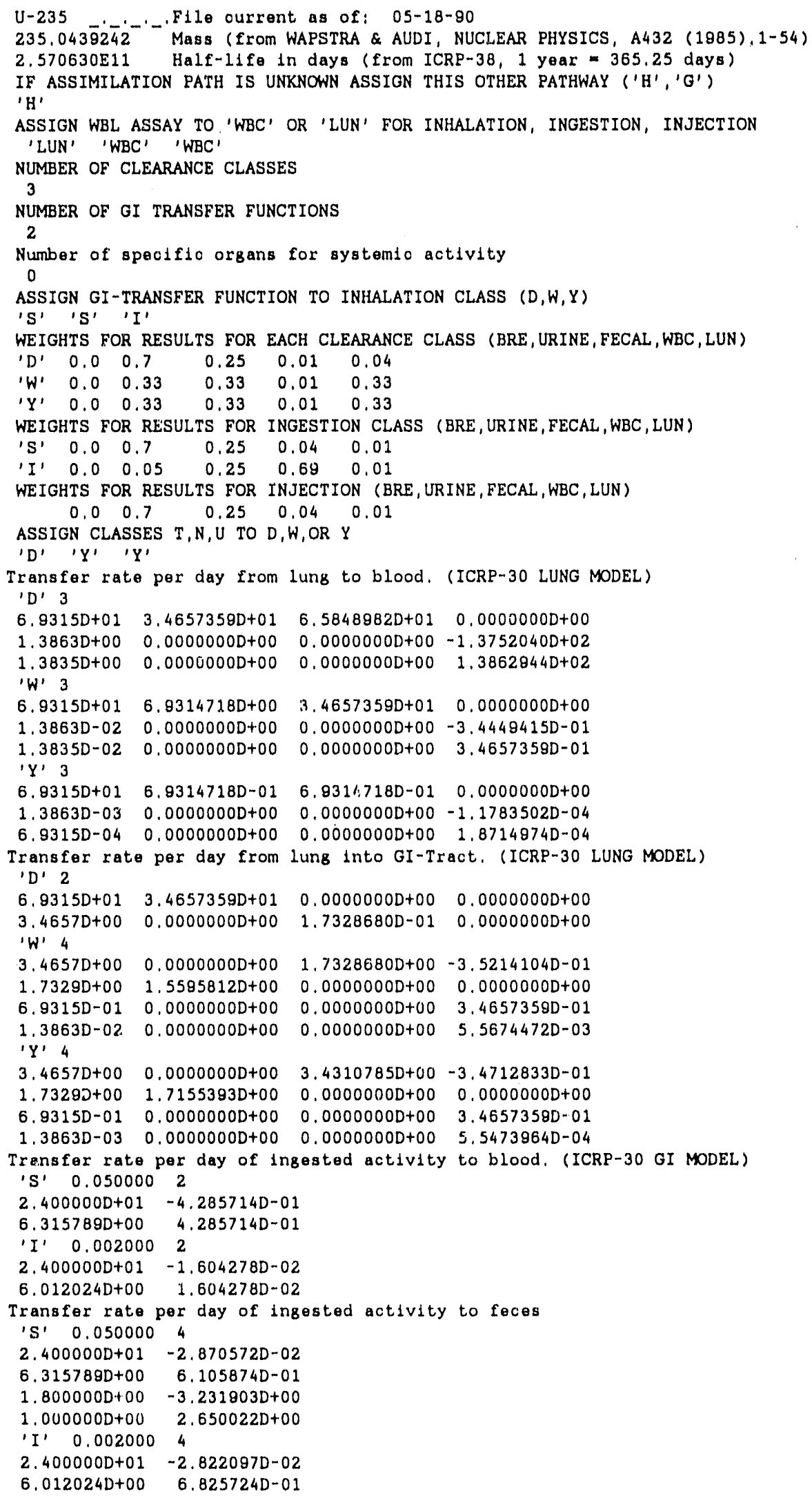




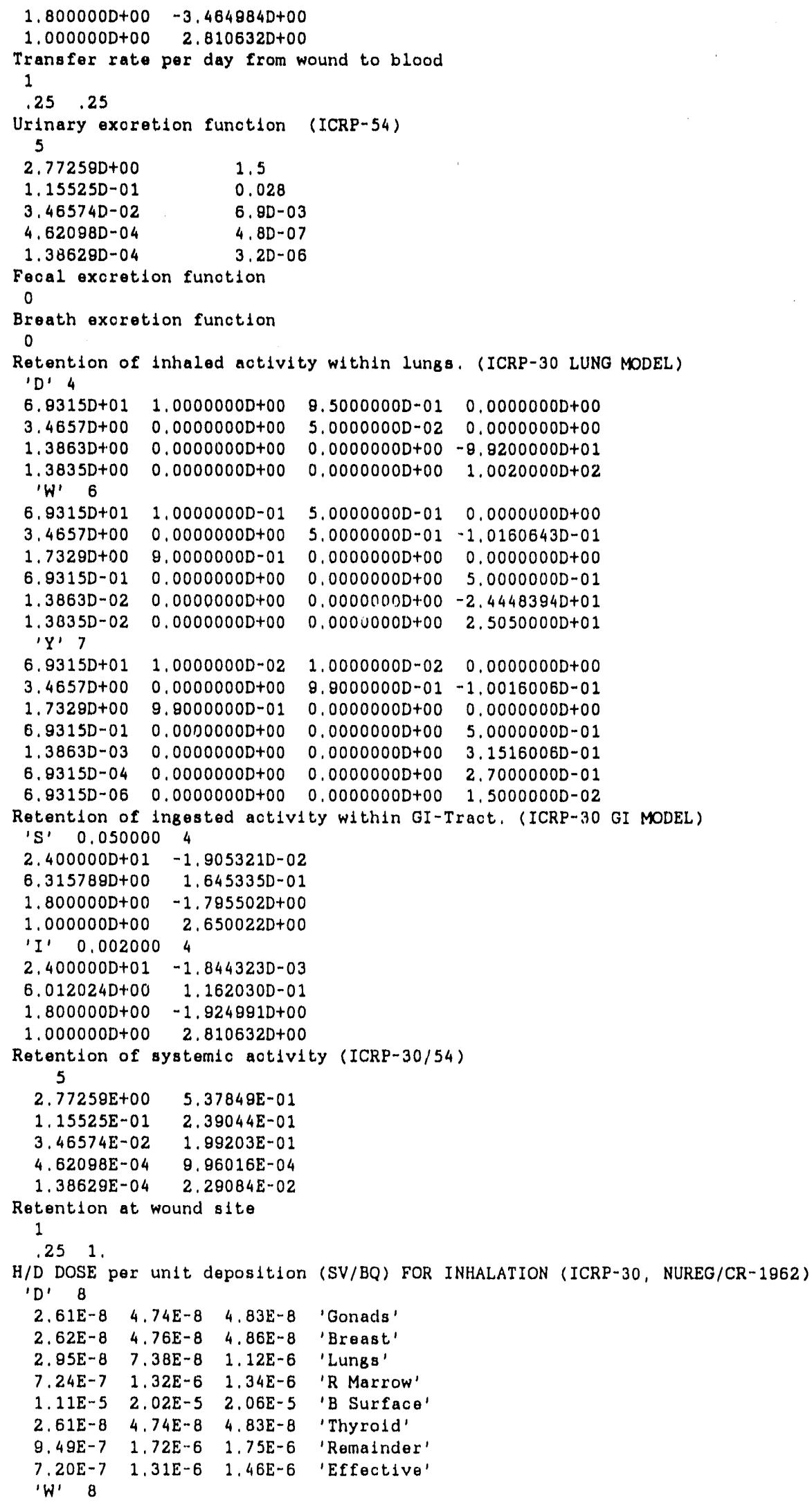




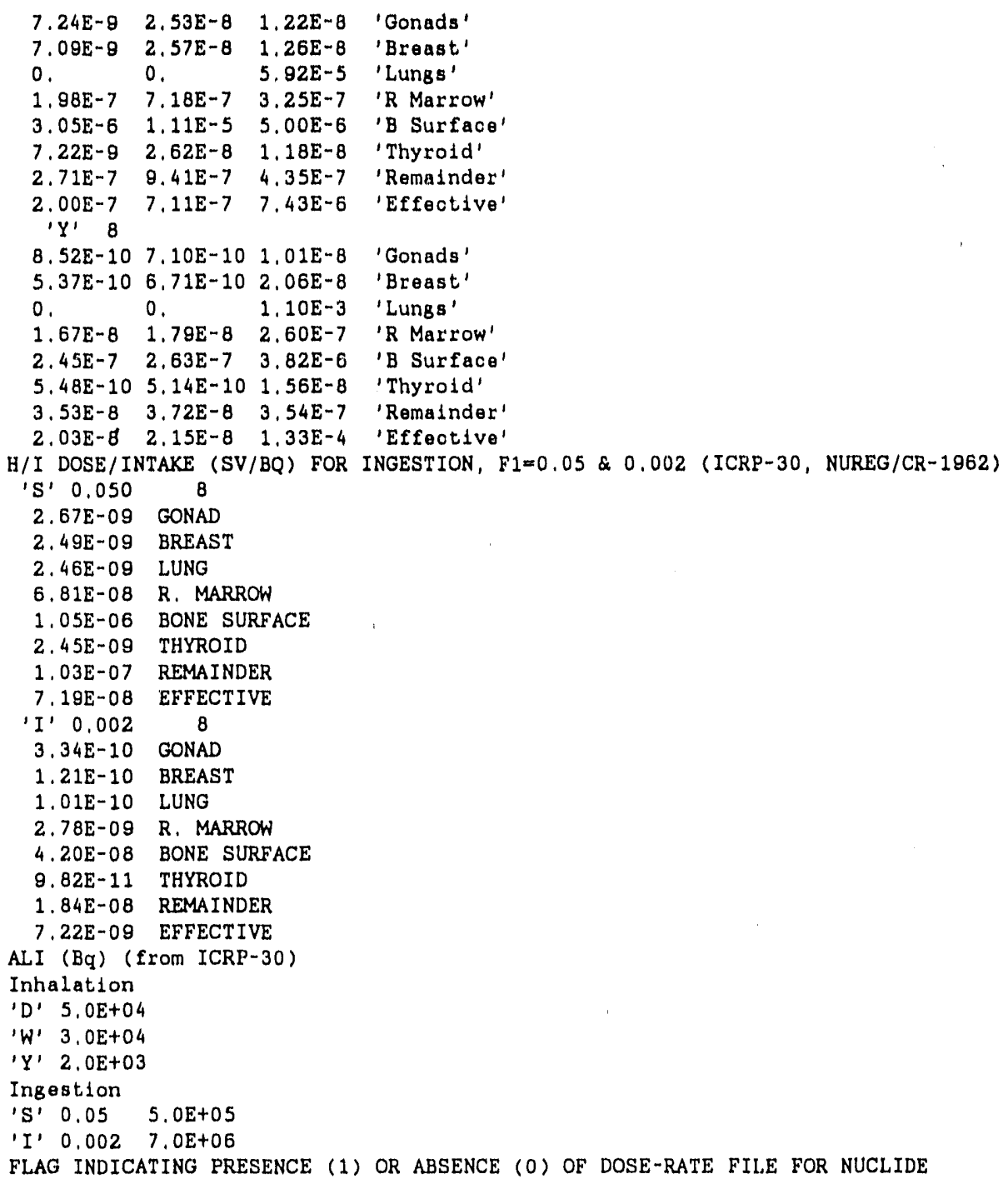




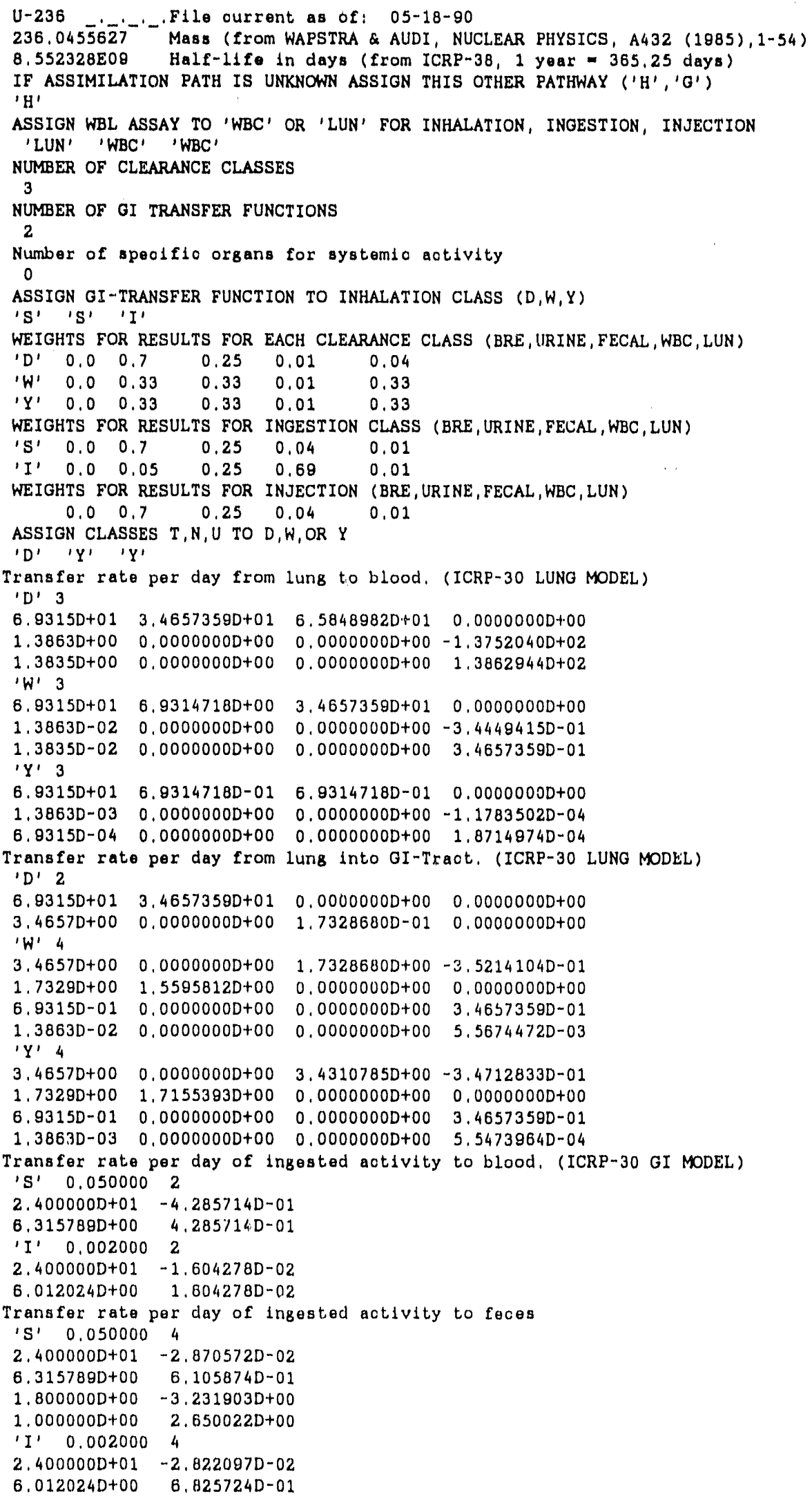




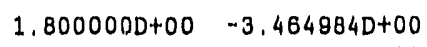




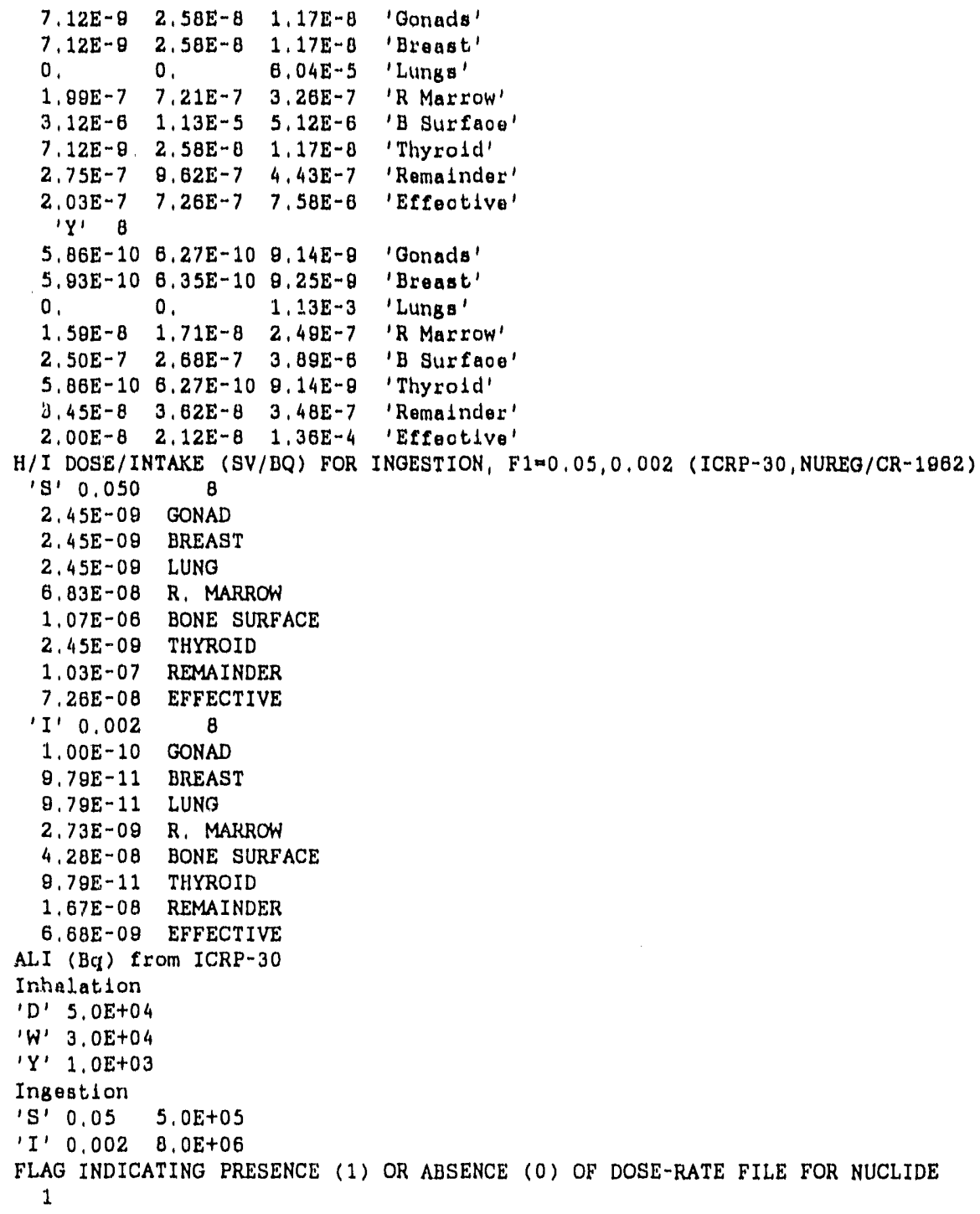




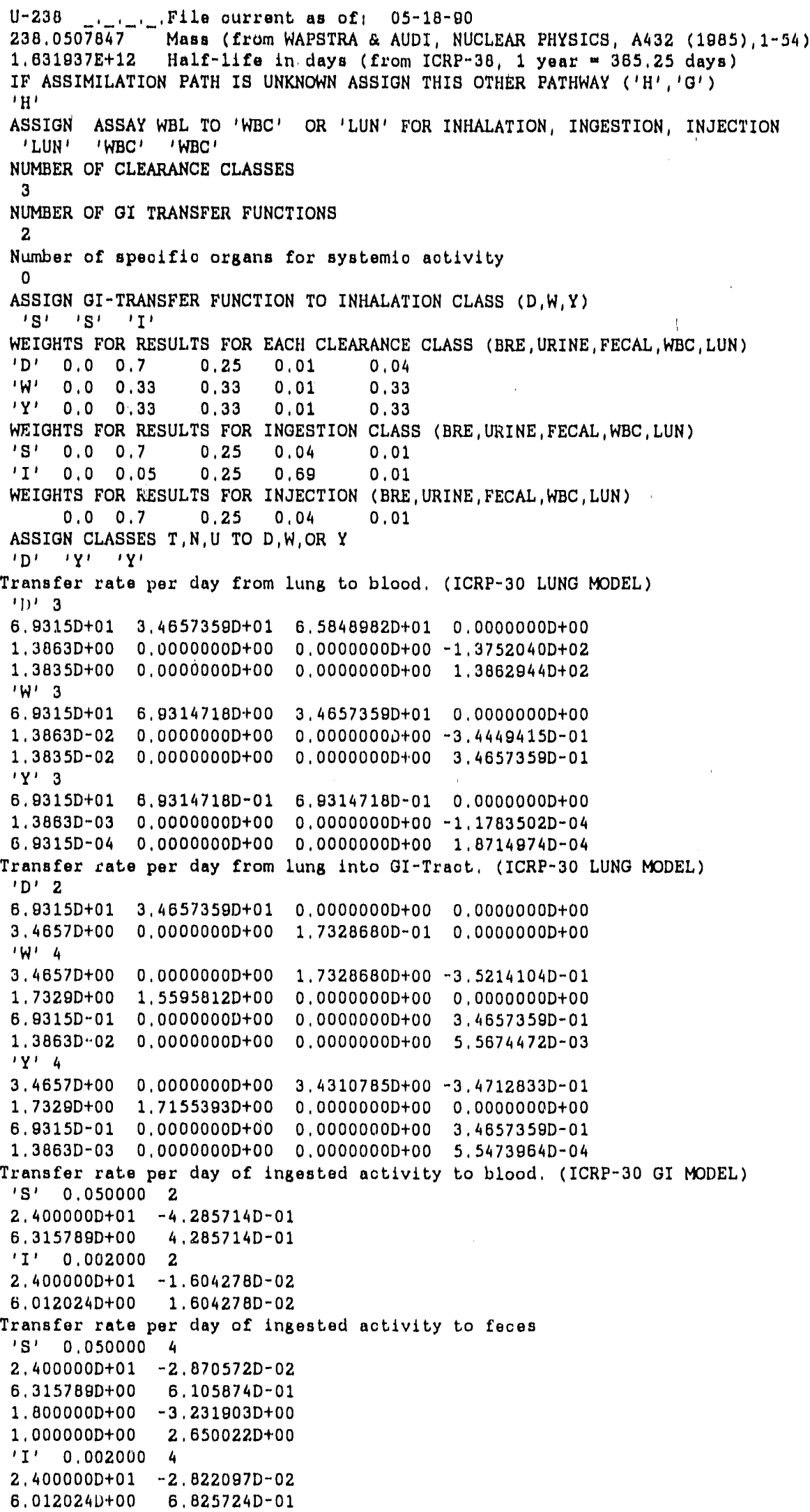




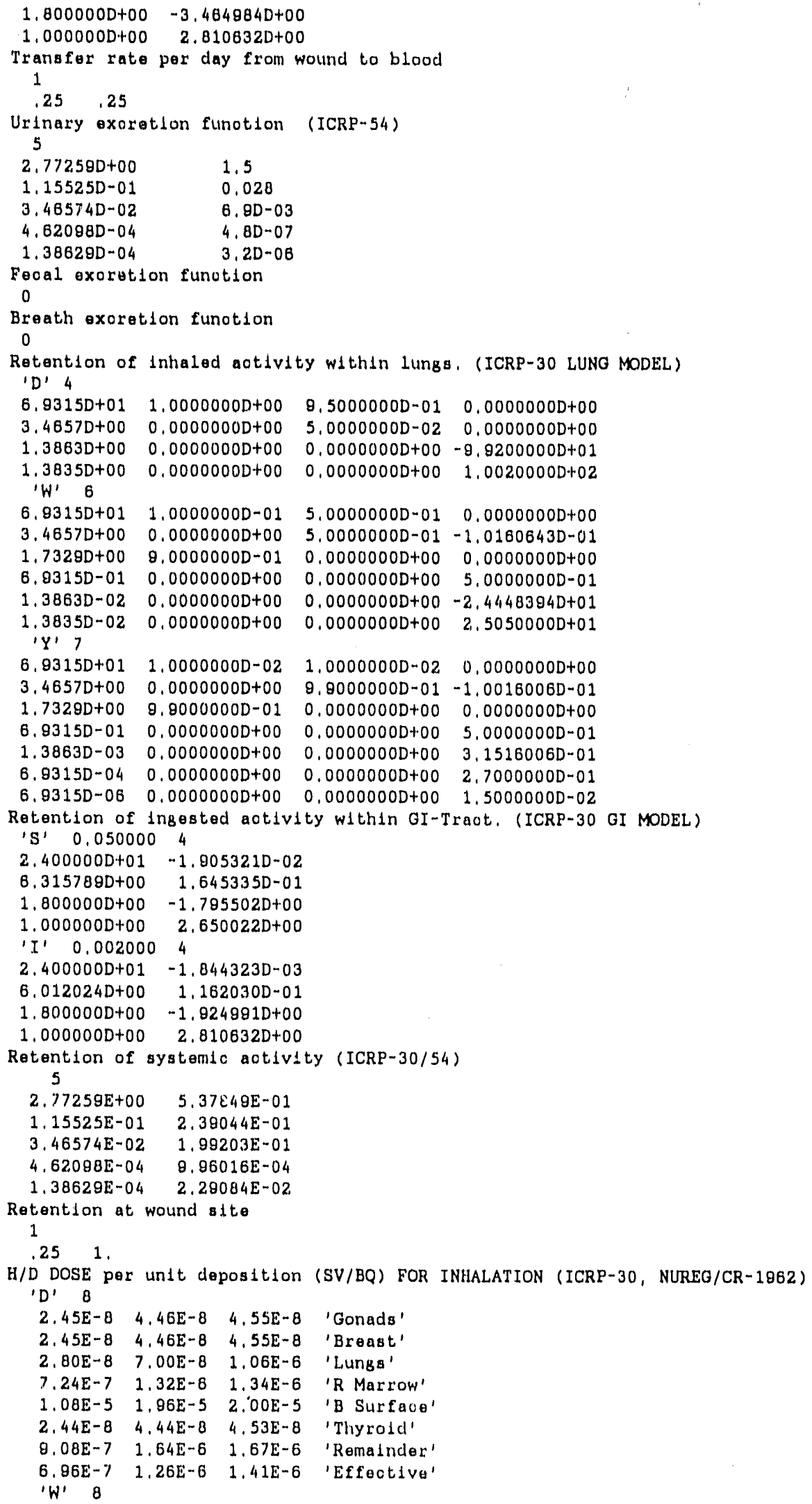




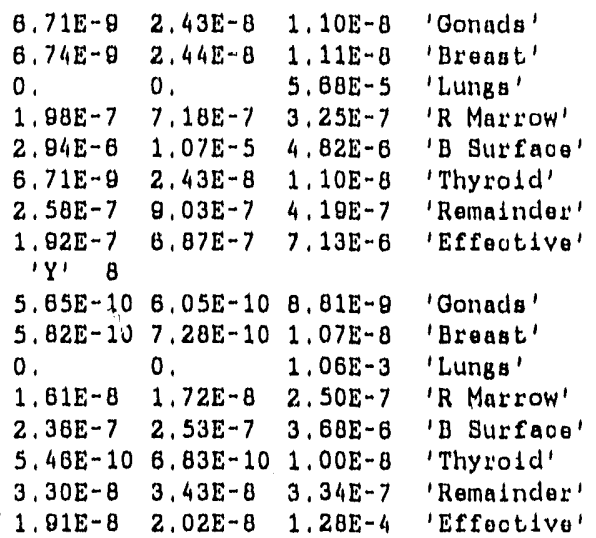




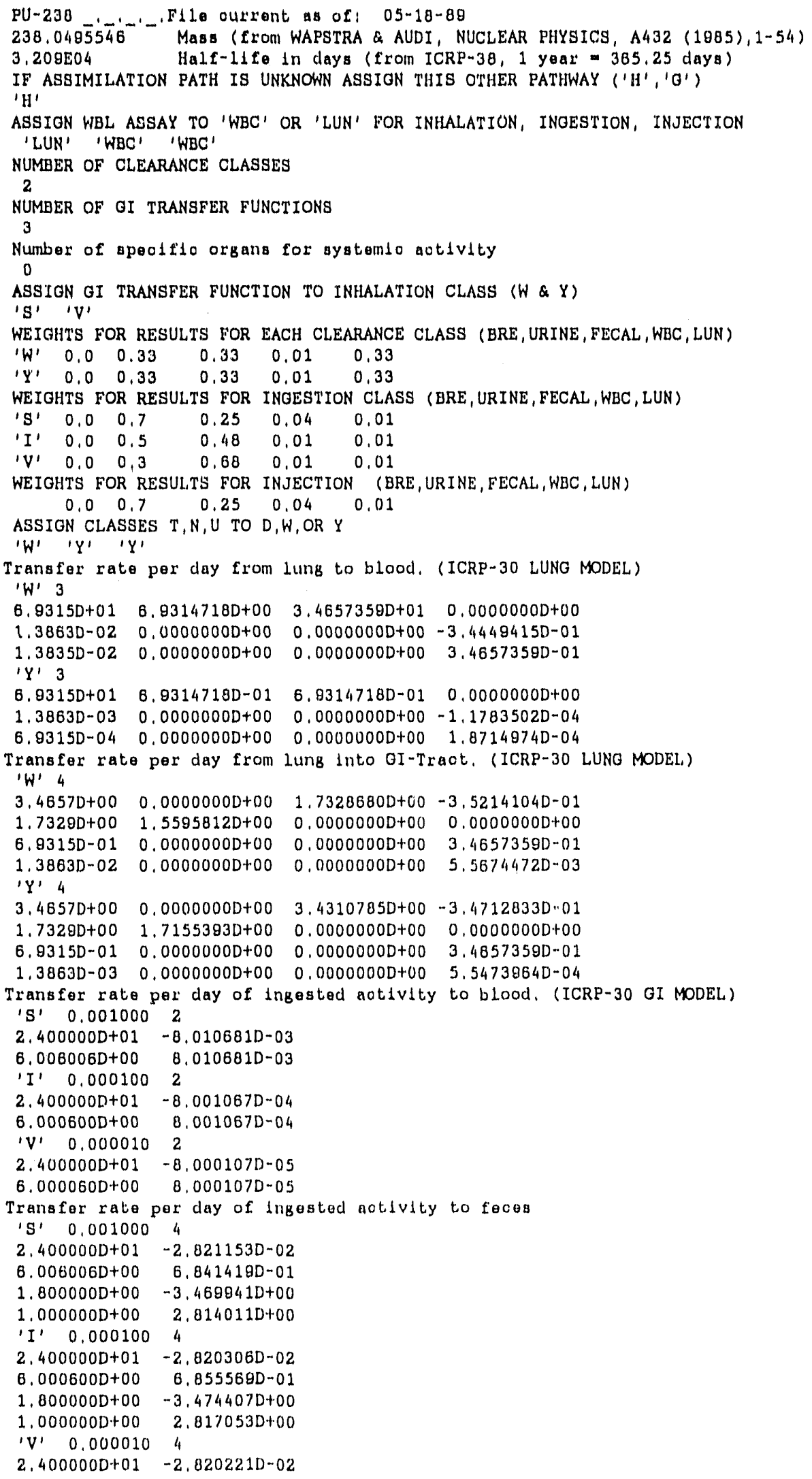




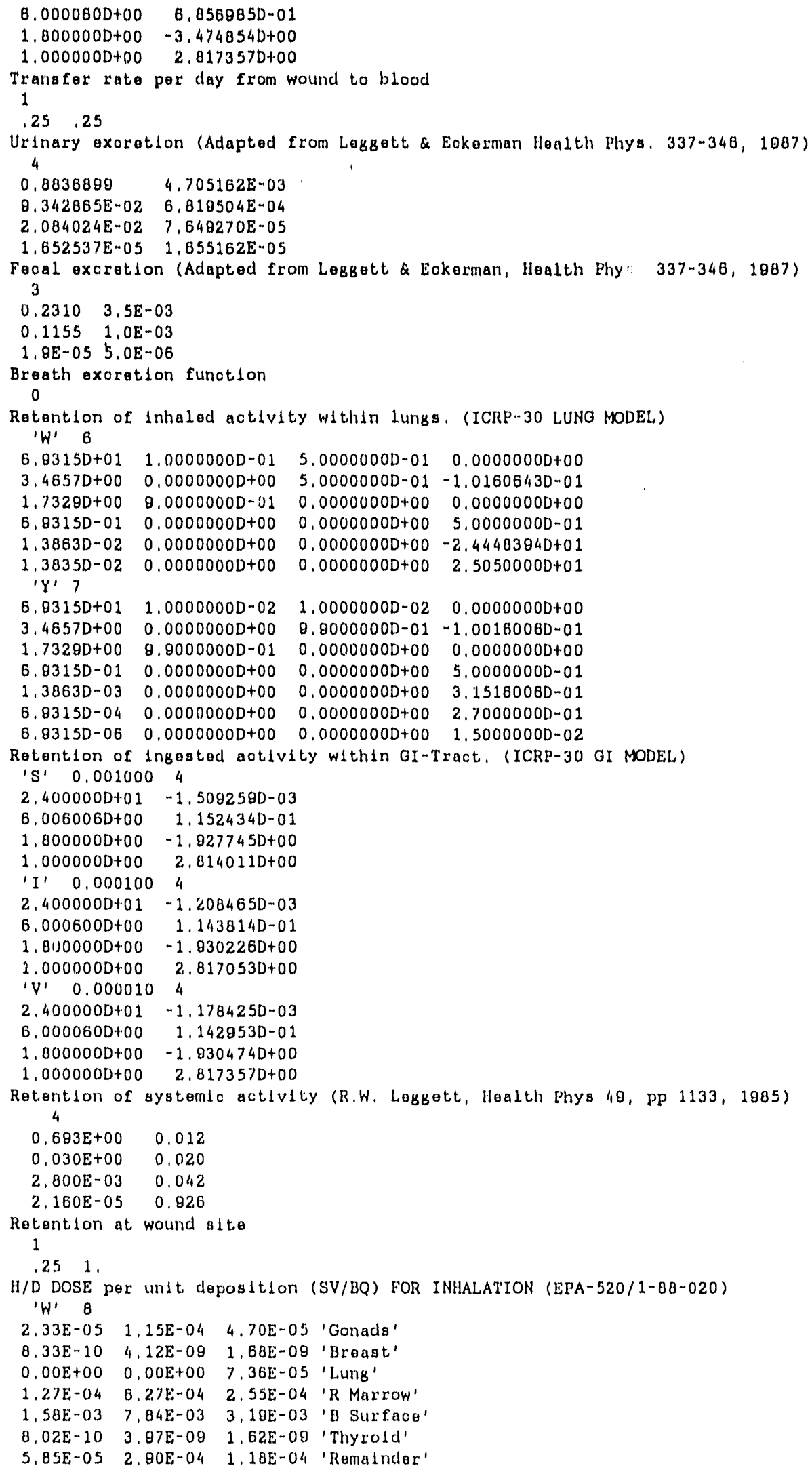




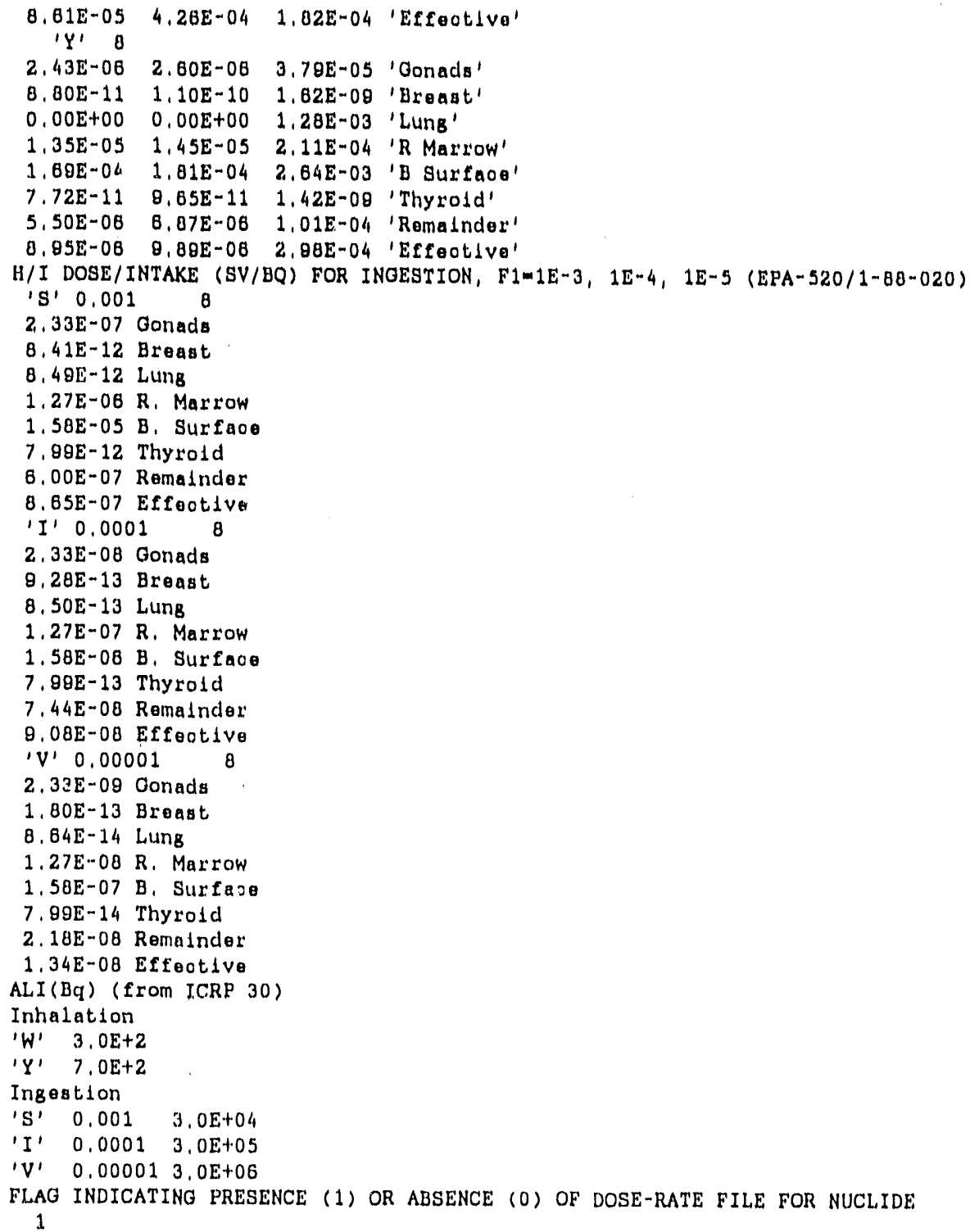




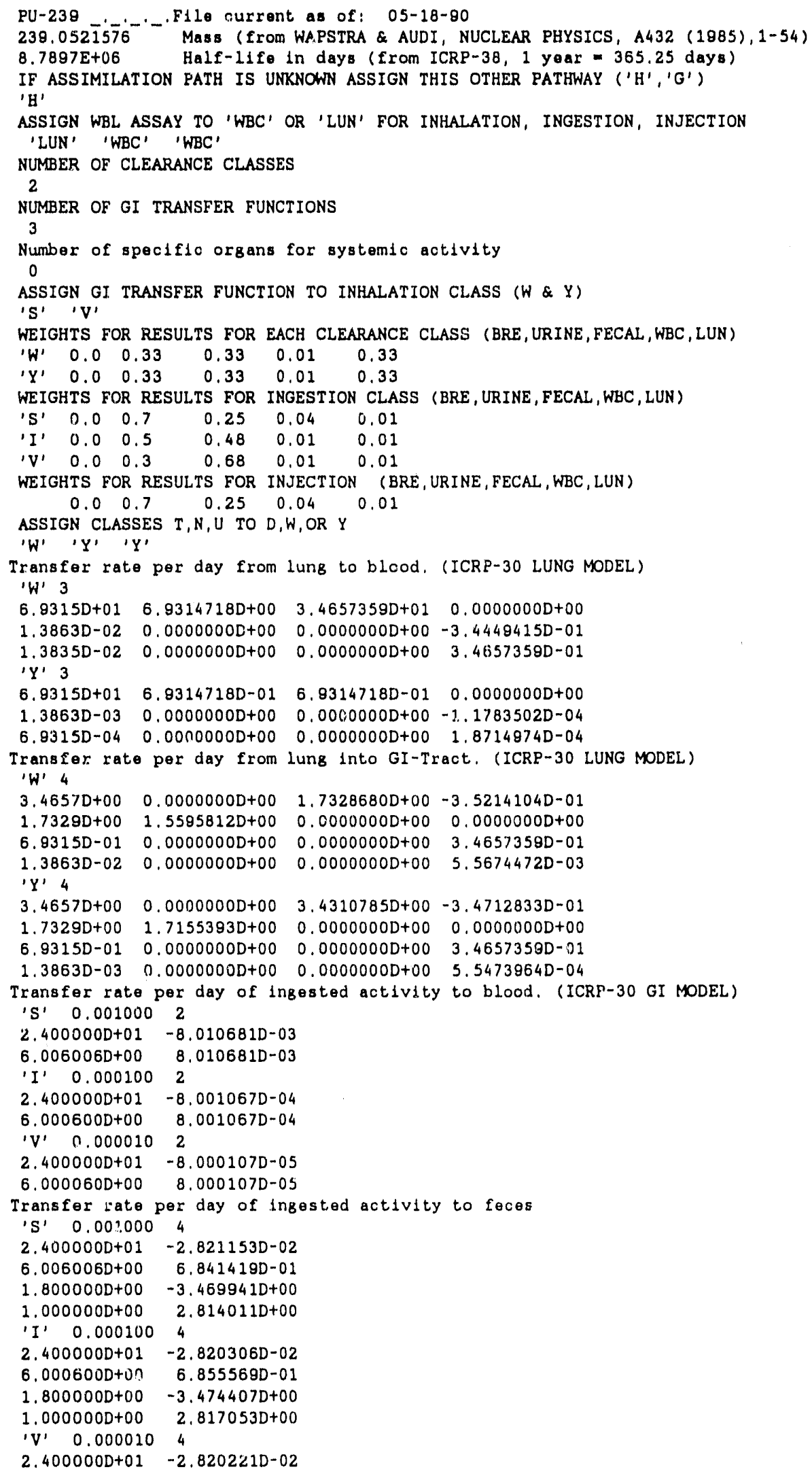




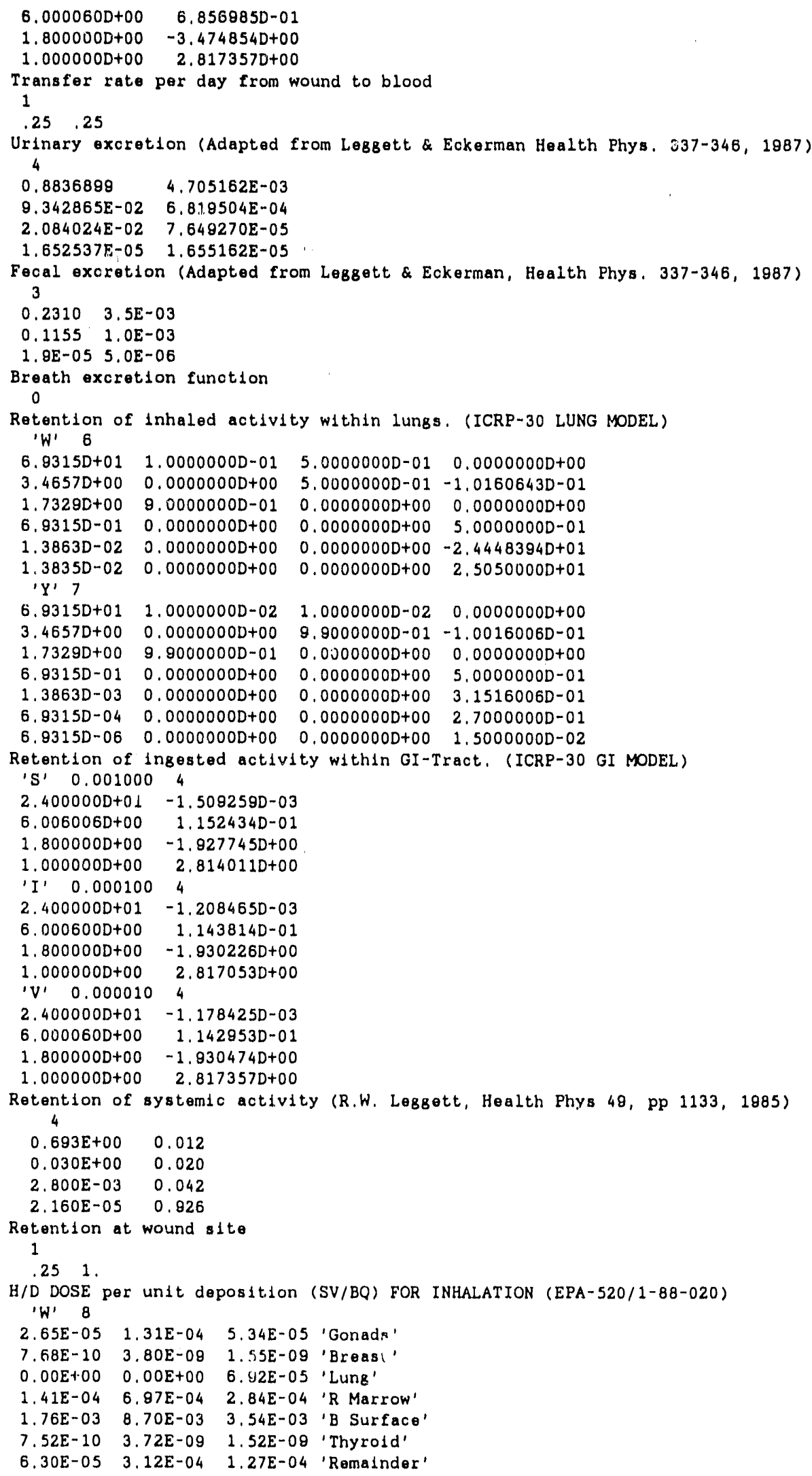




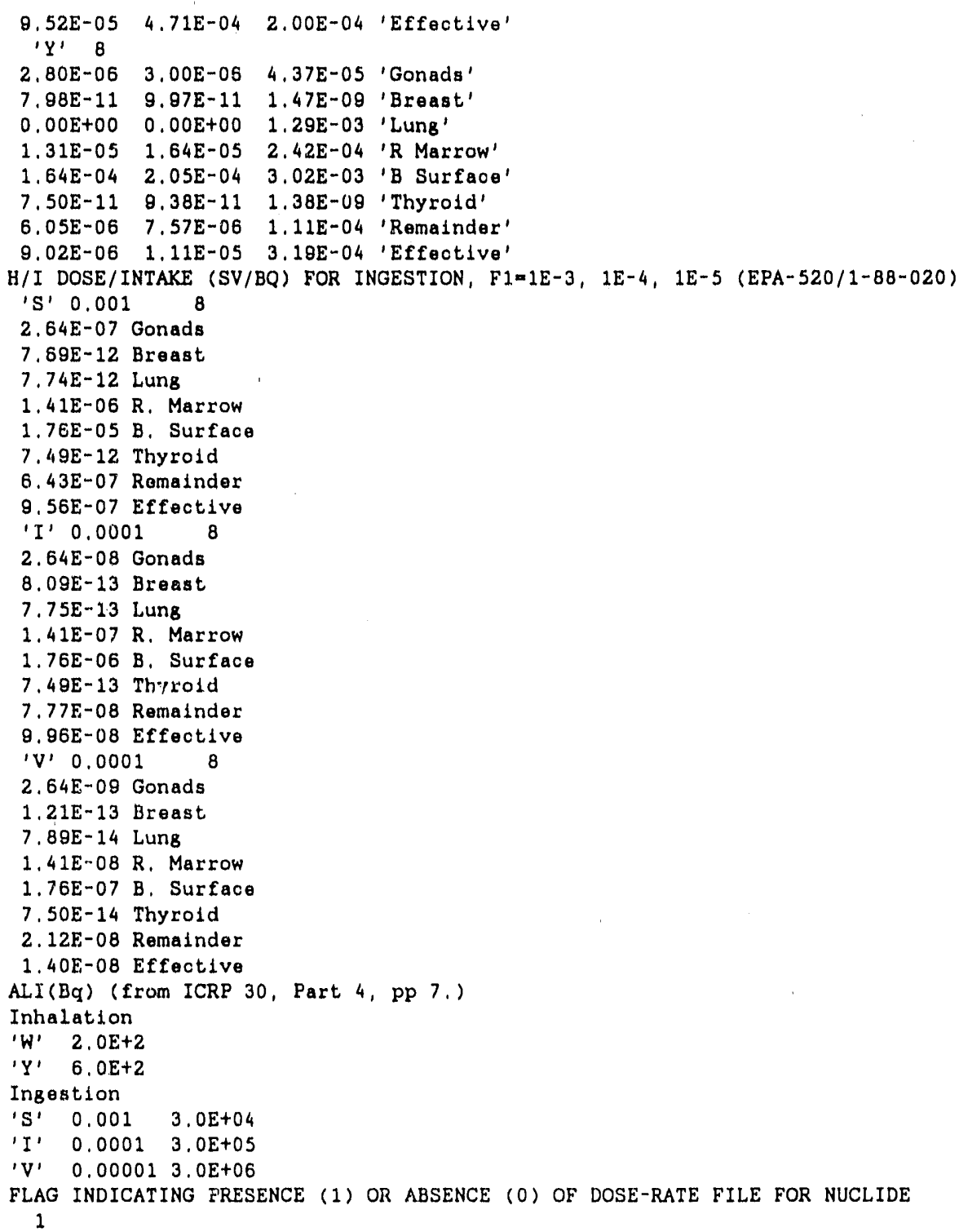




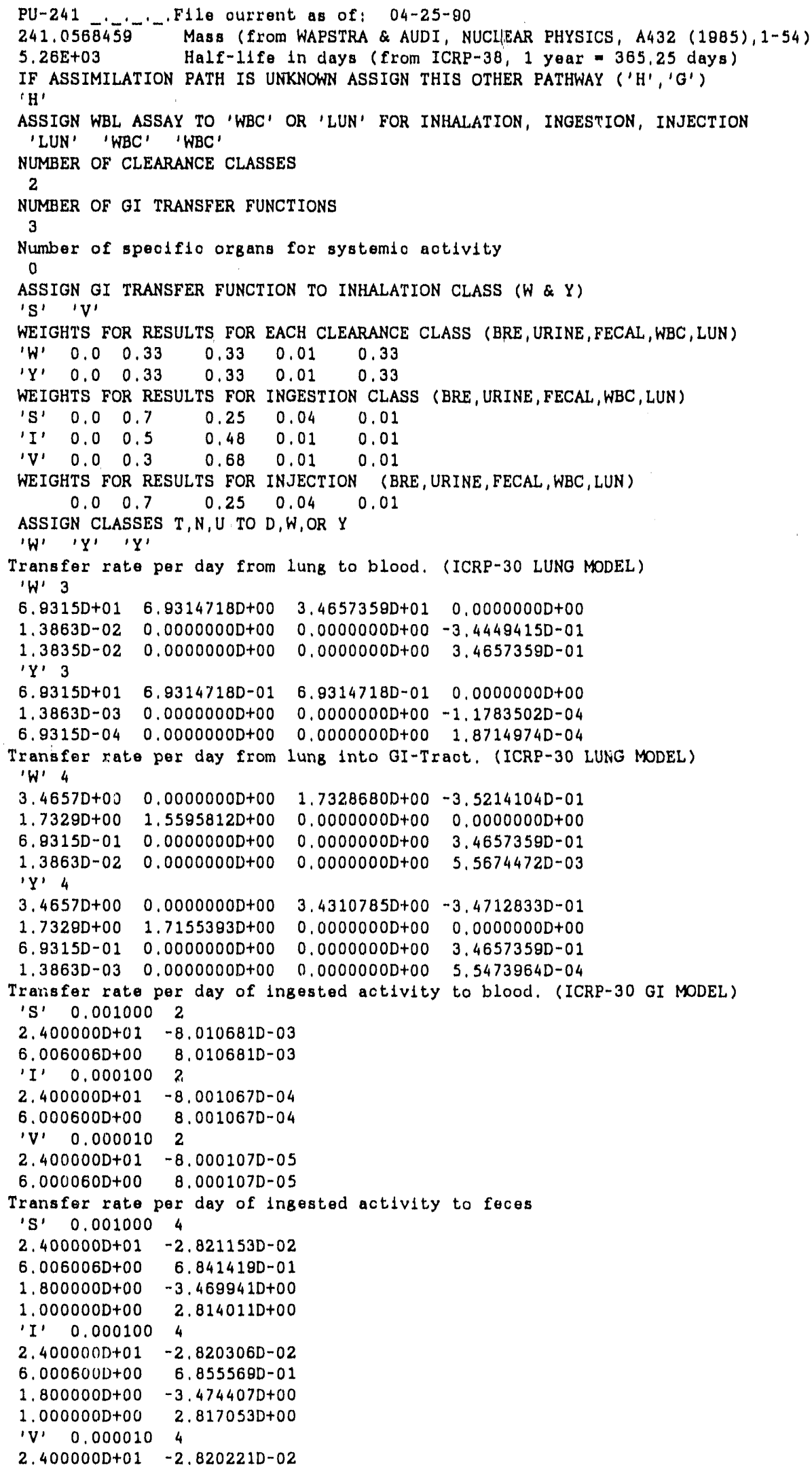




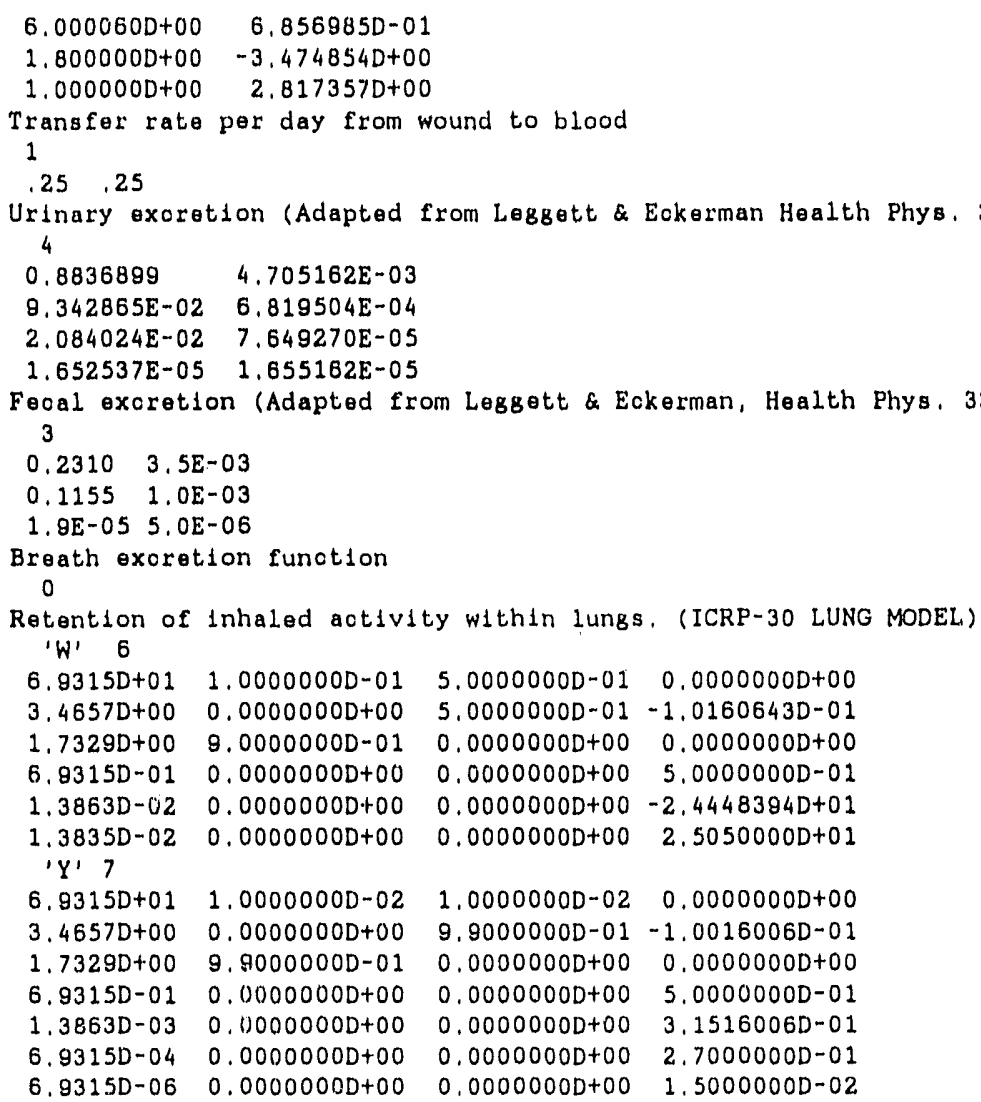




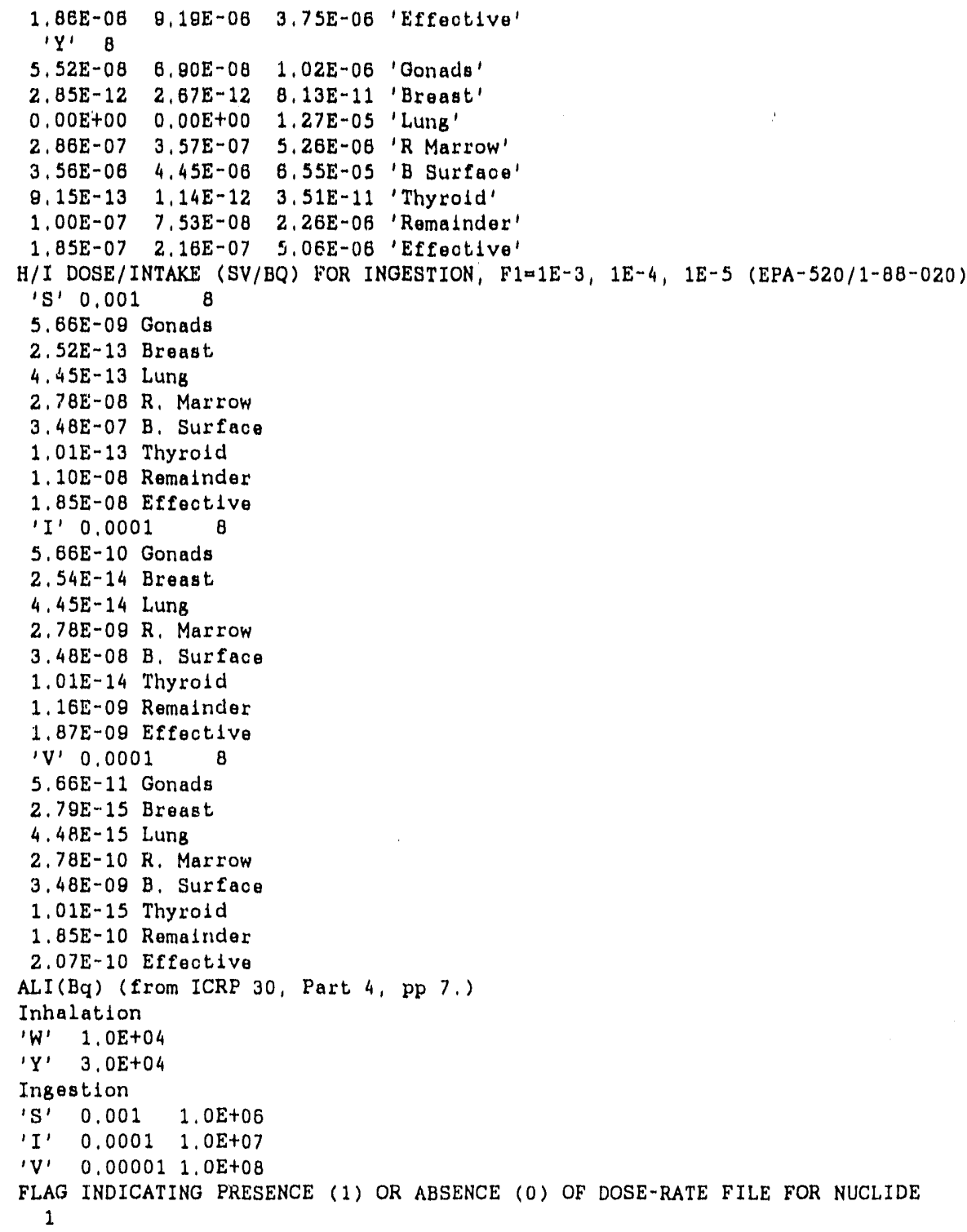




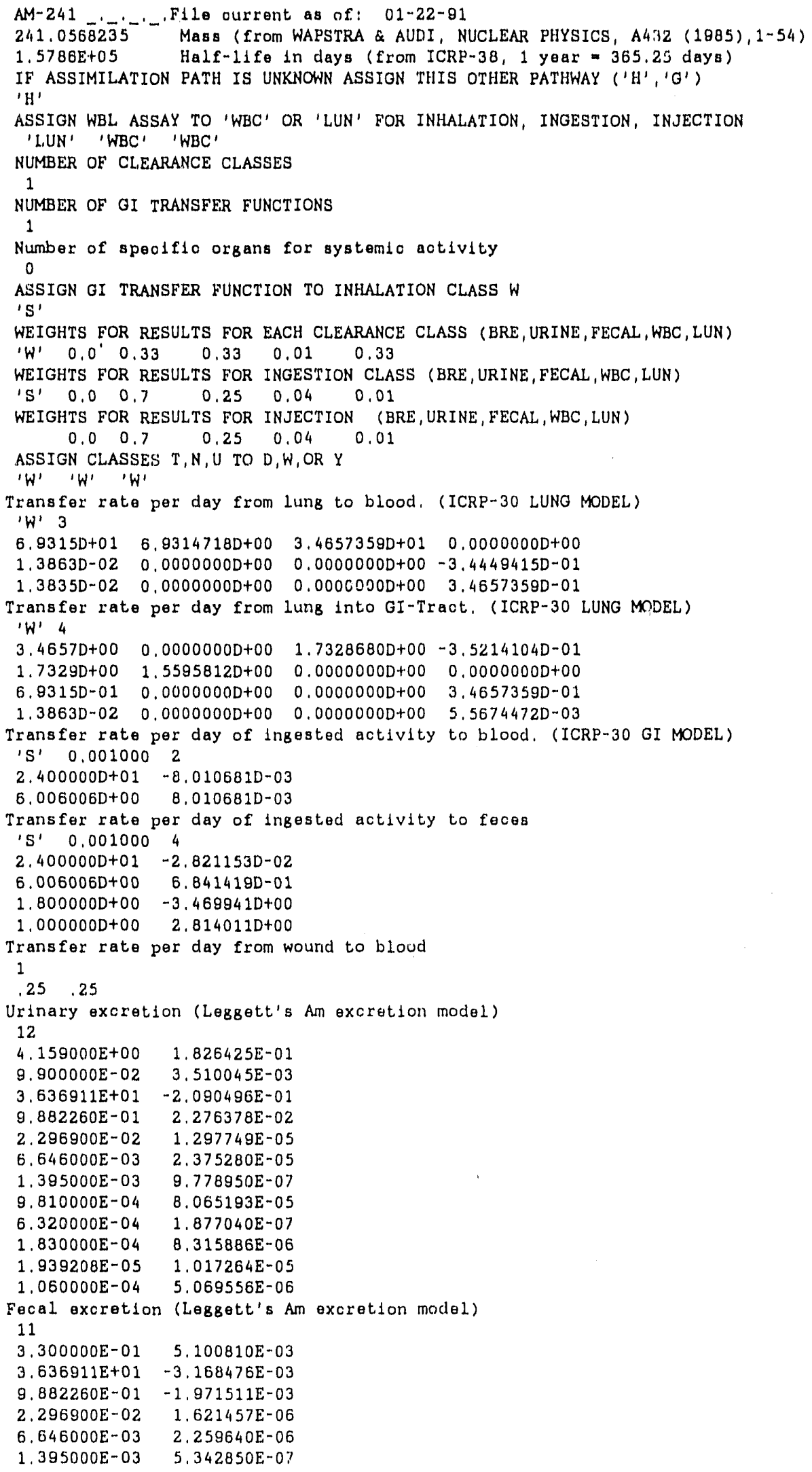




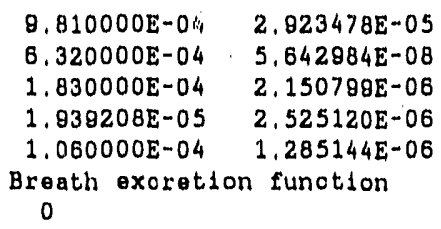




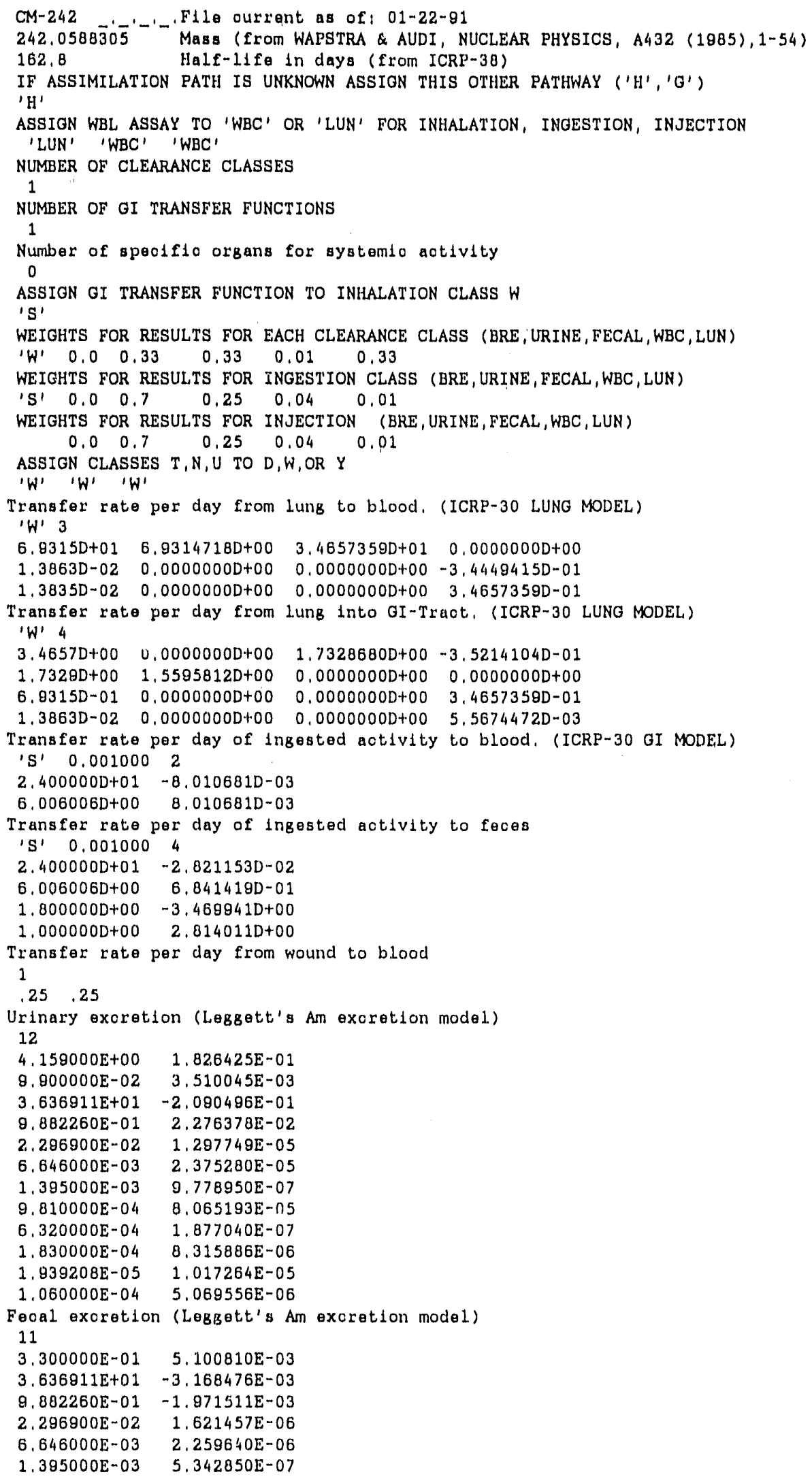




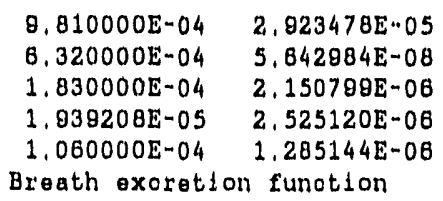




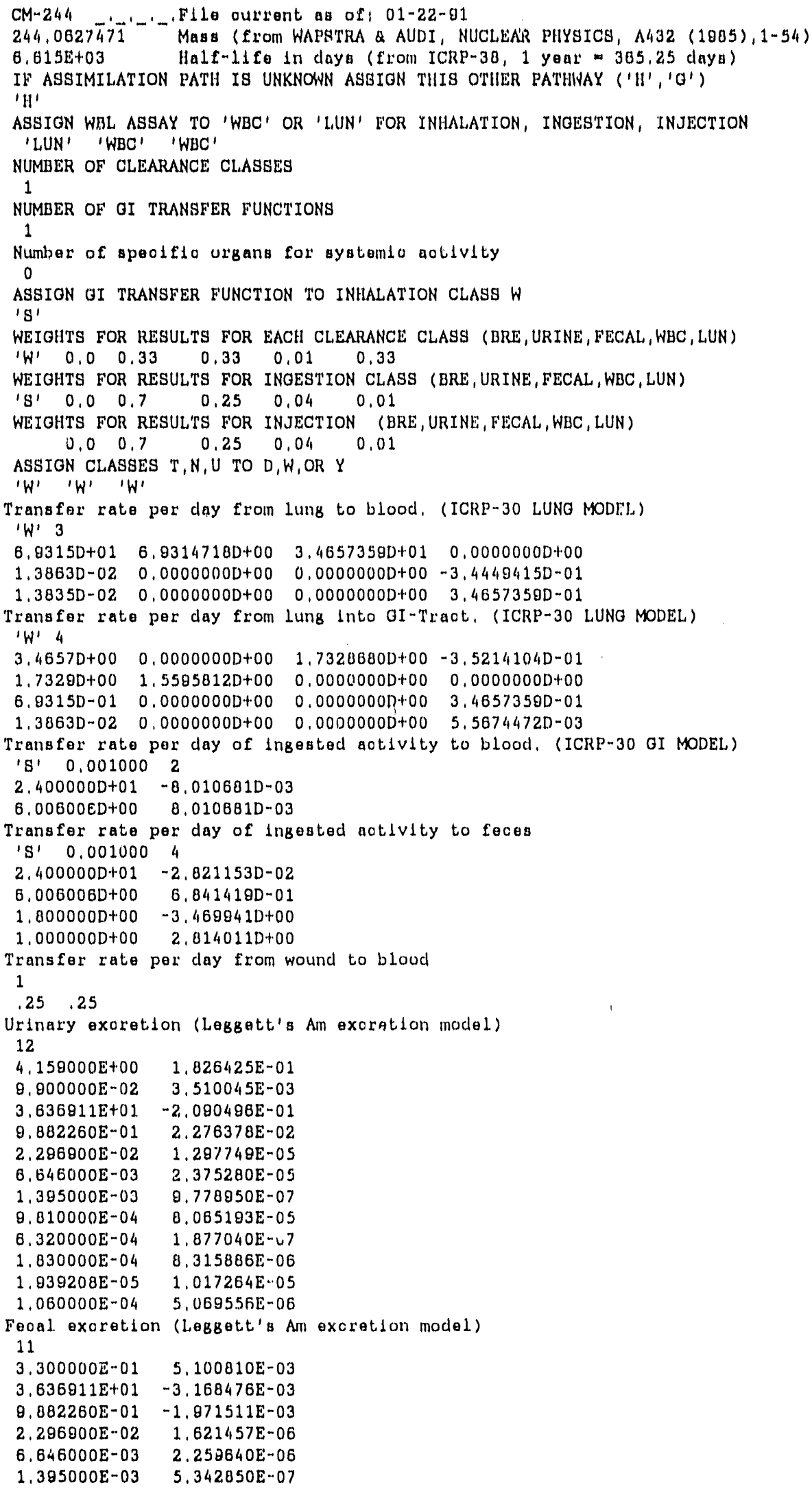




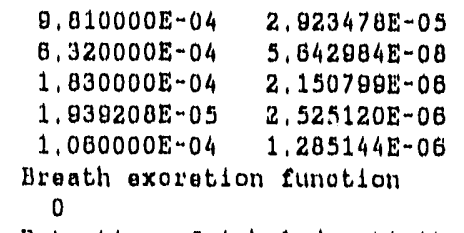

F'LAG INDICATING PRESENCE (1) OR ABSENCE (0) OF DOSE-RATE FILE FOR NUCLIDE 
Appendix I

\section{INPUT DATA FOR EXAMPLE PROBLEMS}

INCIDENT.DAT:

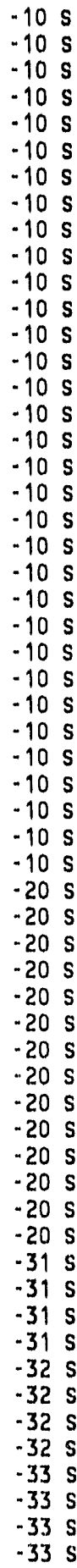

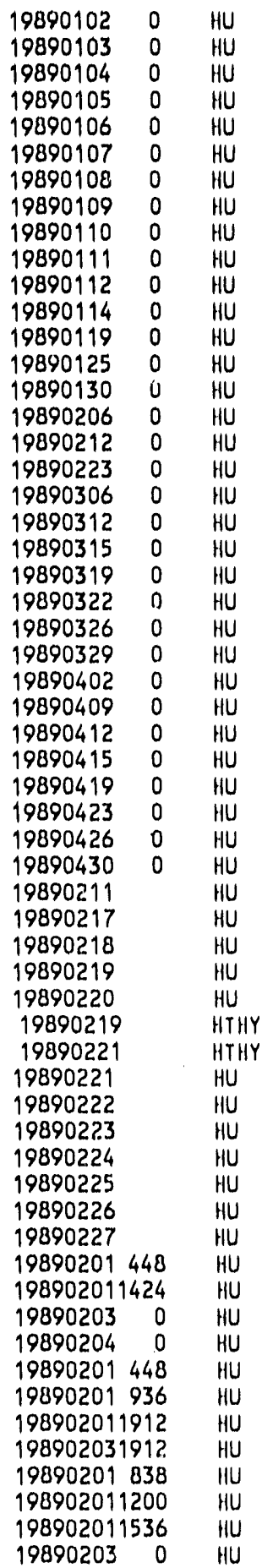

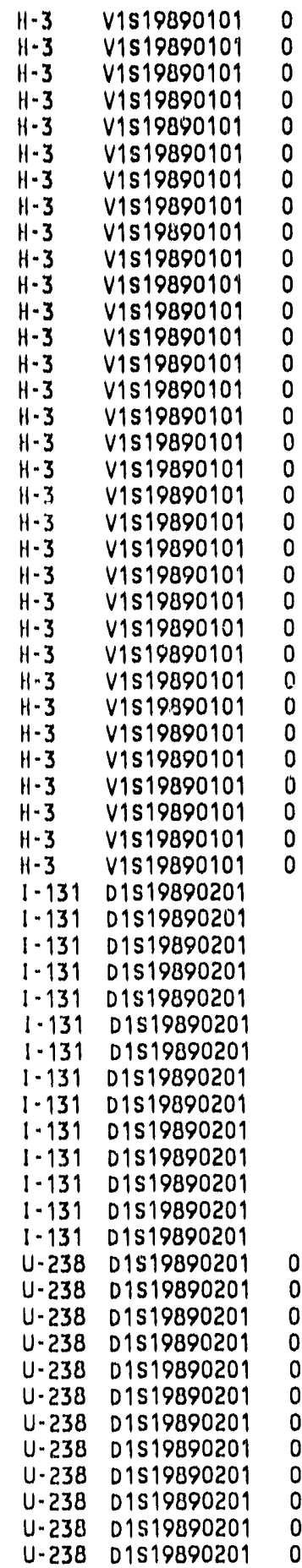

20.004900000 .001

20.004500000 .001

20.004200000 .001

20.003700000 .001

20.003800000 .001

20.003600000 .001

20.003100000 .001

20.002900000 .001

20.002600000 .001

20.002400000 .001

20.002100000 .001

20.001900000 .001

20.001000000 .001

20.00790000 .001

20.00540000 .001

20.00320000 .001

20.00190000 .001

$20.00 \quad 94000.001$

$20.00 \quad 46000.001$

$20.00 \quad 30000.001$

$20.00 \quad 23000.001$

$20.00 \quad 18000.001$

$20.00 \quad 15000.001$

$20.00 \quad 11000.001$

$20.00 \quad 9200.001$

$20.00 \quad 6700.001$

$20.00 \quad 4600.001$

$20.00 \quad 4200.001$

$20.00 \quad 3500.001$

$20.00 \quad 3000.001$

$20.00 \quad 2300.001$

$20.00 \quad 2200.001$

$20.00 \quad 2100.001$

$20.00 \quad 1440.007$

$20.00 \quad 987.007$

$20.00 \quad 970.007$

$20.00 \quad 419.007$

$20.00 \quad 318.007$

$13.00 \mathrm{M} \quad 1.00 \mathrm{M}$

$10.50 \mathrm{M} \quad 1.00 \mathrm{M}$

$20.00 \quad 378.007$

$20.00 \quad 557.007$

$20.00 \quad 543.007$

$20.00 \quad 574.007$

$20.00 \quad 318.007$

20.00

20.00

20.00

20.00

20.00

20.00

20.00

20.00

20.00

20.00

20.00

20.00

20.00

2.0 .00

4.007

311.007

6.105

.995

.095

.215
9.605

2.605

1.305

.225

.545

.315

.115

.005
1.001

1.001

1.001

1.001

1.001

1.001

1.001

1.001

1.001

1.001

1.001

1.001

1.001

1.001

1.001

1.001

1.001

1.001

1.001

1.001

1.001

1.001

1.001

1.001

1.001

1.001

1.001

1.001

1.001

1.001

1.001

1.001

1.001

10.007

10.007

10.007

10.007

10.007

10.007

10.007

10.007

10.007

10.007

10.007

10.007

.055

.055

.055

.055

.105

.105

.105

.105

.105

.105

.105

.005 


\section{1}

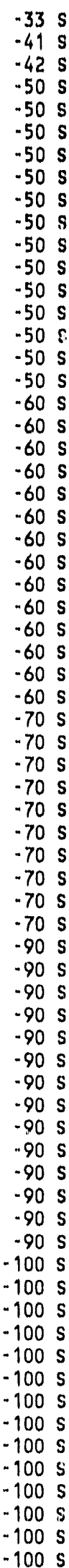

198902031912
$19891231 \quad 0$
19891231
19890211
19890217
19890218
19890219
19890220
19890219
19890221
19890221
19890222
19890223
19890224
19890225
19890226
19890227
19890105
19890106
19890107
19890108
19890109
19890110
19890111
19890112
19890115
19890117
19890119
19890121
19890123
19890126
19890102
19890103
19890105
19890107
19890109
19890110
19890111
19890113
19890114
19890125
198901012000
198901020400
198901020800
198901022000
198901030200
198901032200
198901040200
198901042200
198901020600
198901022000
198901030200
198901032200
198901040200
198901042200
19890105
19890106
19890107
19890108
19890109
19890110
19890112
19890114
19890116
19890118
19890120
19890125
19890130
19890204

U.238 D1S19890201 0

CS- 1370151989010

1.131 01S

1.131 D1S

$1 \cdot 131$ D1S

1.131 D1S

$1-131$ D1S

$\mid-131$ D1s

$1-131$ D1s

1.131 D1S

1.131 D1S

1.131 D1s

$1-131$ D1S

1.131 D1S

1.131 D1S

$1-131$ D1S

TC-99 S1S19890101

TC-99 S1s19890101

TC-99 s1s19890101

TC-99 s1s19890101

TC-99 S1S19890101

TC-99 S1S19890101

TC-99 S1S19890101

TC-99 S1S19890101

TC. 99 S1s19890101

TC-99 S1S19890101

TC-99 S1S19890101

TC-99 S1S19890101

TC-99 S1S19890101

TC. 99 s1s19890101

TC-99 1s19890101

TC-99 1S19890101

TC-99 1519890101

TC-99 1s19890101

TC-99 1s19890101

IC-99 1519890101

TC-99 1s19890101

TC. $99 \quad 1 \mathrm{~S} 19890101$

TC. $99 \quad 1 \$ 19890101$

TC.99 1S19890101

SR-90 1S19390101

SR-90 1S19890101

SR-90 1S19890101

SR-90 1S19890101

SR-90 1S19890101

$S R=90 \quad$ IS 19890101

SR-90 IS19890101

SR-90 1S19890101

SR-90 IS19890101

SR-90 1S19890101

SR-90 1S19890101

SR-90 1S19890101

SR-90 $1 \mathrm{~S} 19890101$

SR-90 1S19890101

PU-241 W1S1989J101

PU-241 W1S19890101

PU-241 W1S19890101

PU-241 W1S19890101

PU-241 W1S19890101

PU-241 W1S 19890101

PU-241 W1S19890101

PU- 241 W1S19890101

PU-241 WIS19890101

PU-241 W1S19890101

PU-241 W1S19890101

PU-241 W1S19890101

PU-241 W1S19890101

PU-241 W1S19890101

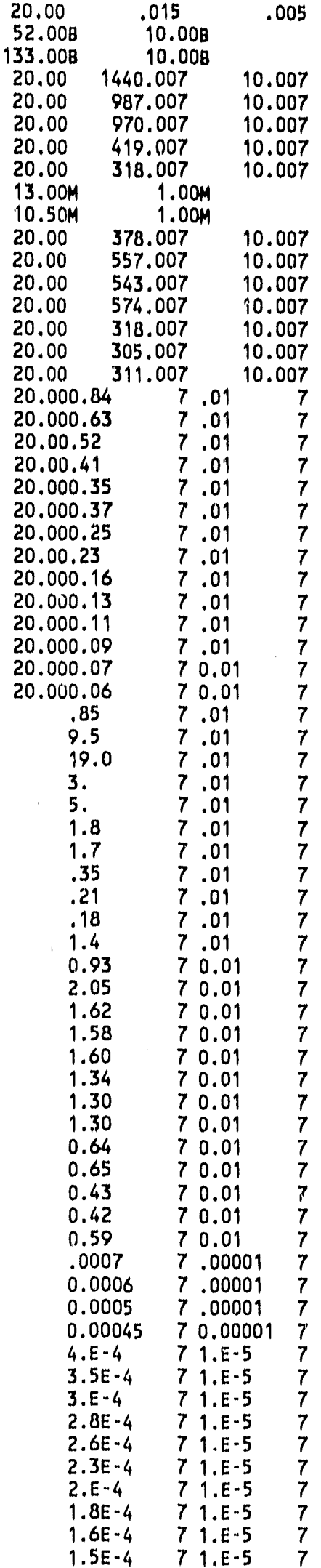




$\begin{array}{lllllll}-100 \mathrm{~S} & 19890218 & \text { HU } & \text { PU-241 W1S } 19890101 & 1.3 E-4 & 71 . E-5 & 7 \\ -110 \mathrm{~S} & 198909030900 & \text { HF } & \text { PU-238 W1S198909011100114 } & 244 . & 3 & 3 \\ -110 \mathrm{~S} & 198909041100 & \text { HF } & \text { PU-238 W1S198909011100103 } & 5.74 & 31 & 3\end{array}$

ROUTINE.DAT:

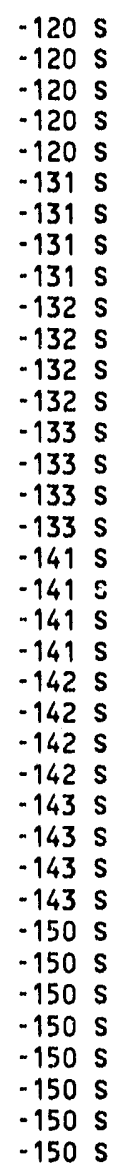

$-120 \mathrm{~s}$

$120 \mathrm{~s}$

120

$-120 \mathrm{~s}$

$131 \mathrm{~s}$

$131 \mathrm{~S}$

$.131 \mathrm{~S}$

1325

$32 \mathrm{~S}$

$132 \mathrm{~s}$

$133 \mathrm{~S}$

$133 \mathrm{~s}$

$141 \mathrm{~S}$

$141 \mathrm{~s}$

$141 \mathrm{~S}$

$142 \mathrm{~s}$

$142 \mathrm{~S}$

$143 \mathrm{~S}$

$143 \mathrm{~S}$

$-150 \mathrm{~S}$

$150 \mathrm{~s}$

$150 \mathrm{~s}$

-150 S

$-150 \mathrm{~s}$

$\begin{array}{lrl}19890102 & & \text { HTHY } \\ 19890201 & 0 & \text { HTHY } \\ 19890301 & 0 & \text { HTHY } \\ 19891124 & 0 & \text { HTHY } \\ 198912312400 & \text { HTHY } \\ 19890410 & 0 & \text { HLUN } \\ 19890719 & 0 & \text { HLUN } \\ 19891027 & 0 & \text { HLUN } \\ 198912312400 & \text { HLUN } \\ 19890410 & 0 & \text { HLUN } \\ 19890719 & 0 & \text { HLUN } \\ 19891027 & 0 & \text { HLUN } \\ 198912312400 & \text { HLUN } \\ 19890410 & 0 & \text { HLUN } \\ 19890719 & 0 & \text { HLUN } \\ 19891027 & 0 & \text { HLUN } \\ 198912312400 & \text { HLUN } \\ 19890410 & & \text { HLUN } \\ 19890719 & & \text { HLUN } \\ 19891027 & & \text { HLUN } \\ 198912312400 & \text { HLUN } \\ 19890410 & & \text { HLUN } \\ 19890719 & \text { HLUN } \\ 19891027 & \text { HLUN } \\ 198912312400 & \text { HLUN } \\ 19890410 & & \text { HLUN } \\ 19890719 & & \text { HLUN } \\ 19891027 & \text { HLUN } \\ 198912312400 & \text { HLUN } \\ 198903300000 & \text { HLUN } \\ 198903300000 & \text { HWBC } \\ 198906280000 & \text { HLUN } \\ 198906280000 & \text { HWBC } \\ 198909260000 & \text { HLUN } \\ 198909260000 & \text { HWBC } \\ 198912300000 & \text { HLUN } \\ 198912300000 & \text { HWBC }\end{array}$

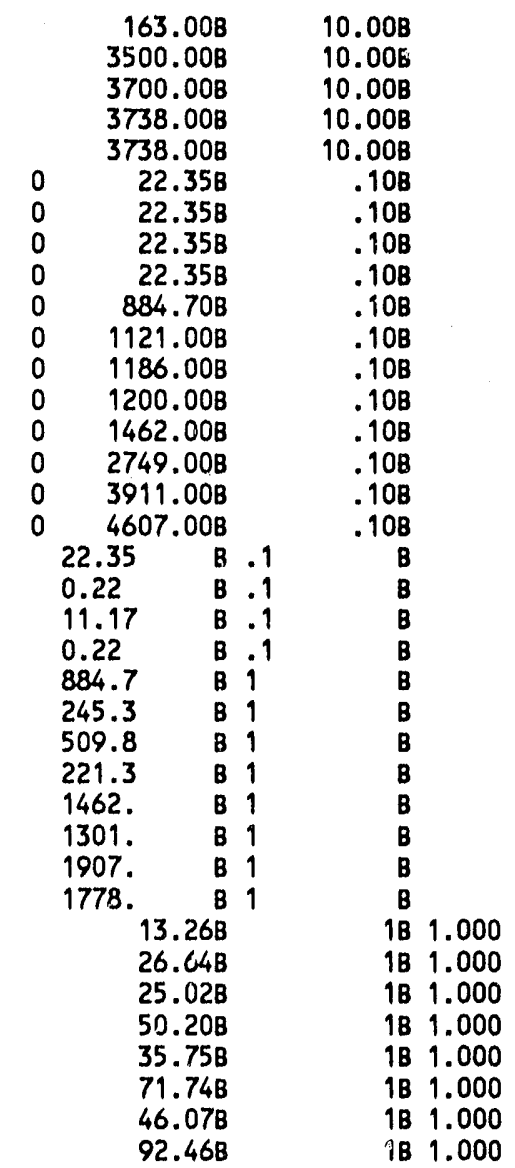




\section{Appendix J}

\section{LISTINGS OF DOSEXPRT SCREEN OUTPUT FOR EXAMPLE PROBLEMS}

INCIDENT.DAT screen output listing when DOSEXPRT is run in debug/iwst mode with long listing option:

KOHISS RUN [RWD.DOSEX41]DOSEXPRT

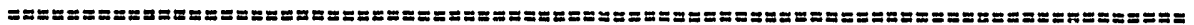
DOSEXPRT VERSION: 4.2 (DATE: 03/17/92)

Determination of Intake and Dose Using Bioassay Records

Developed for Martin Marietta Energy Systems, Inc, by

R. C. Ward and K. F. Eckerman of Oak Ridge National Laboratory

ANY PROBLEMS WITH DOSEXPRT SHOULD BE COMMUNICATED TO:

RICHARD C. WARD, ORNL (Phone: $4-5449$ e-mail: RWD)

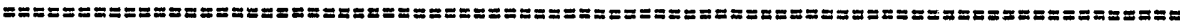

Date of Computation: $3 / 17 / 92$

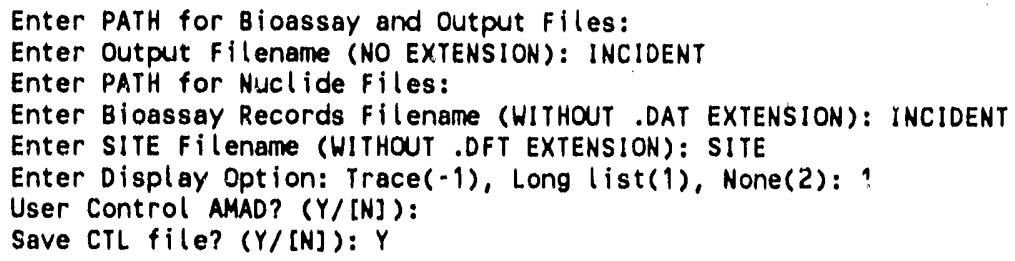




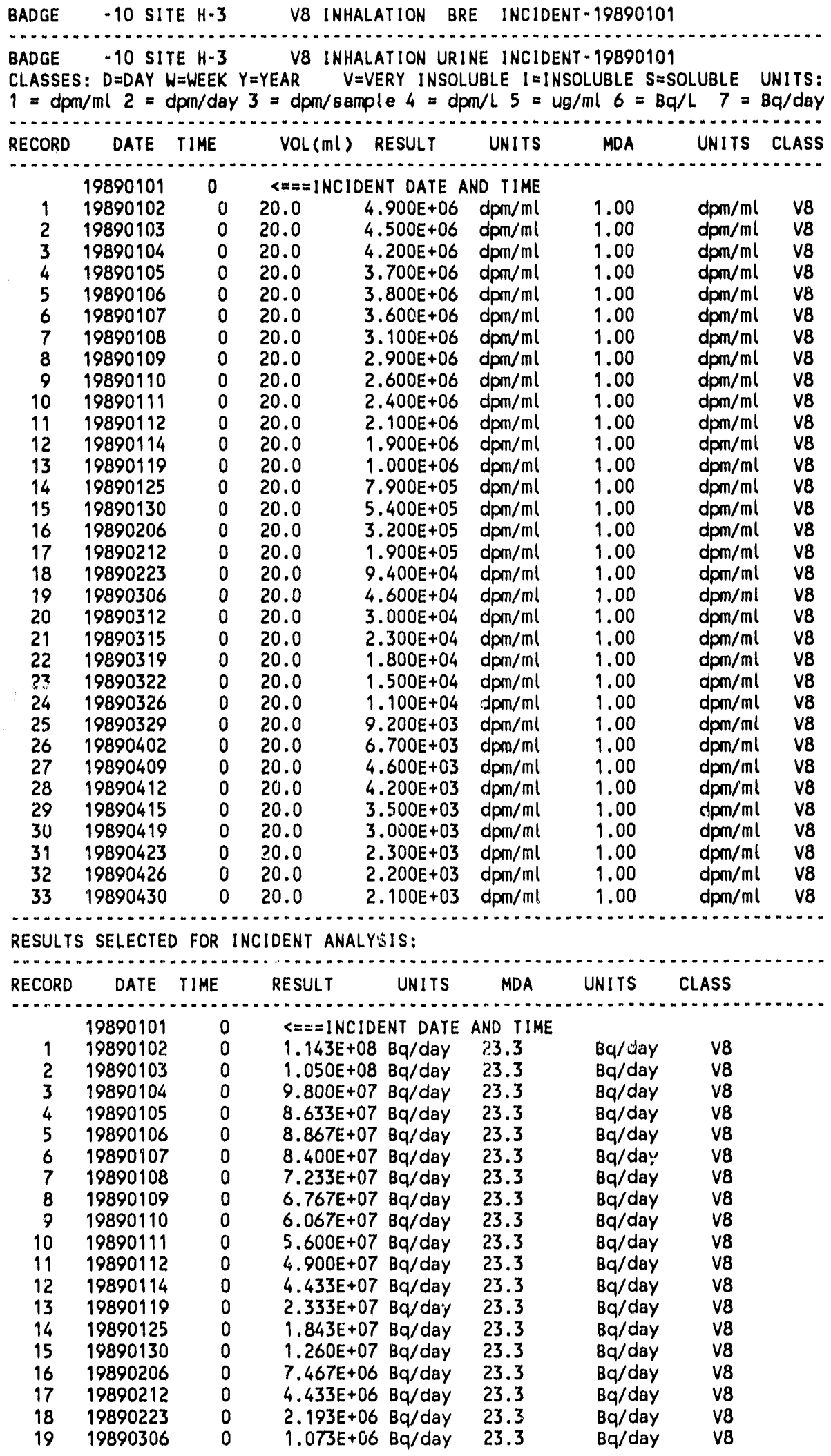


175

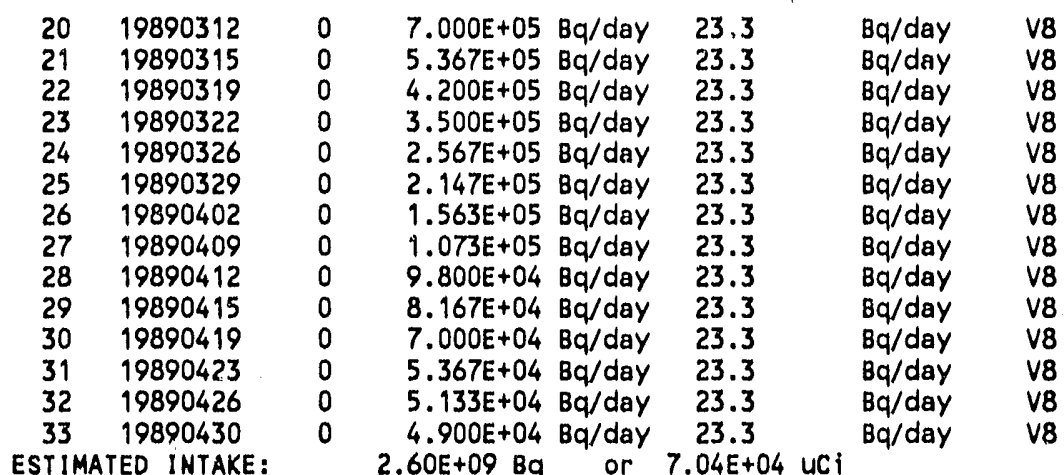

ALI: $(3.00 E+09 \mathrm{~Bq})$ or $(8.11 \mathrm{E}+04 \mathrm{UC} \mathrm{Ci})$

MEAN FRACTIONAL DEVIATION: 0.34 FOR 33 RESULTS

**** HIT RETURN TO CONTINUE $\star \star \star \star *$

\begin{tabular}{lcc} 
CRGAN & \multicolumn{2}{c}{ COMMITTED DOSE EQUIVALENT } \\
USV & Or & mrem \\
GONADS & $4.51 E+04$ & $4.51 E+03$ \\
BREAST & $4.51 E+04$ & $4.51 E+03$ \\
LUNG & $4.51 E+04$ & $4.51 E+03$ \\
R. MARRON & $4.51 E+04$ & $4.51 E+03$ \\
BONE SURFACE & $4.51 E+04$ & $4.51 E+03$ \\
THYROID & $4.51 E+04$ & $4.51 E+03$ \\
REMAINDER & $4.51 E+04$ & $4.51 E+03$ \\
EFFECTIVE & $4.51 E+04$ & $4.51 E+03$
\end{tabular}

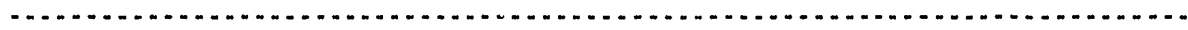

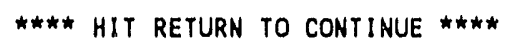

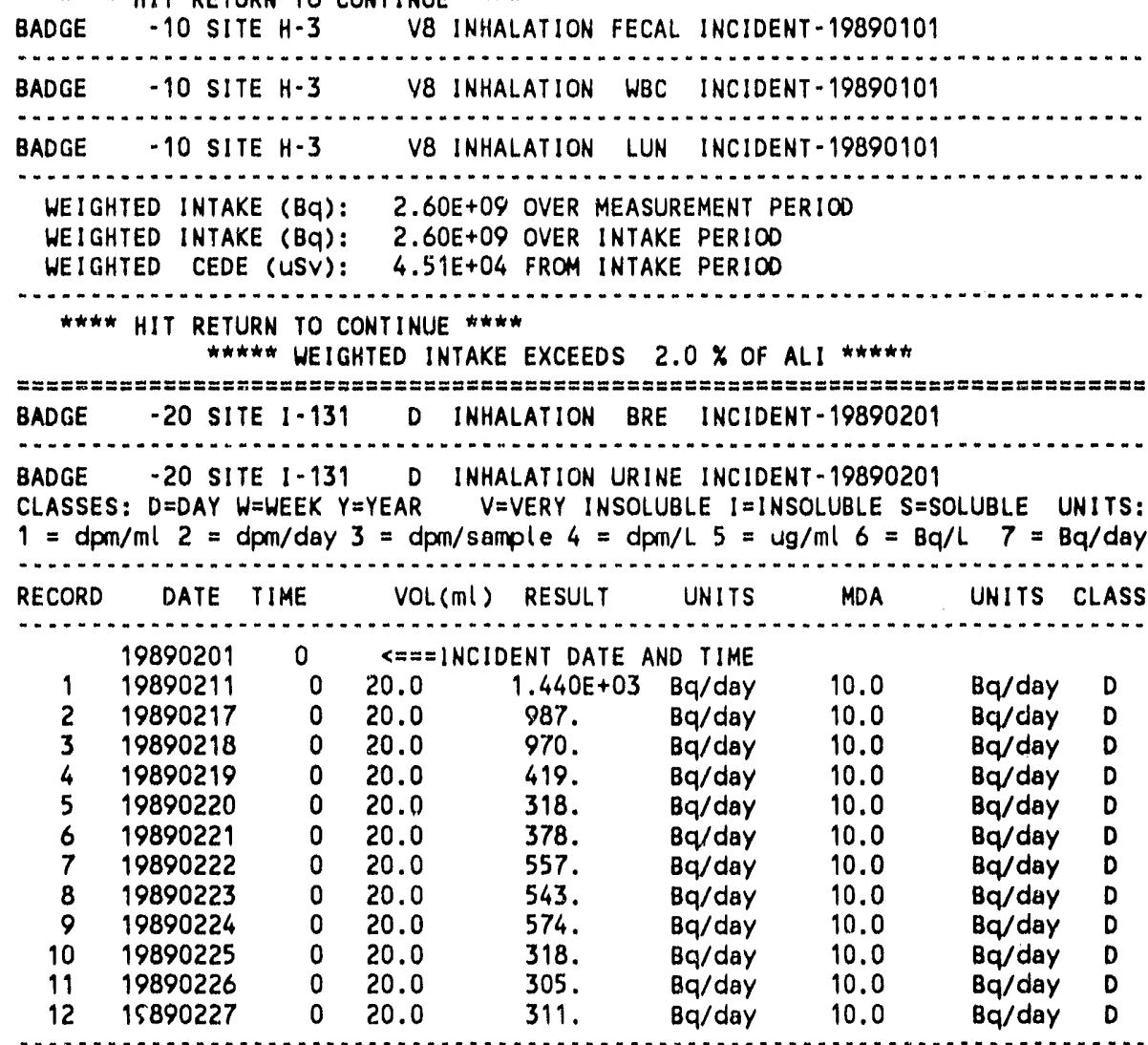

RESULTS SELECTED FOR INCIDENT ANALYSIS: 


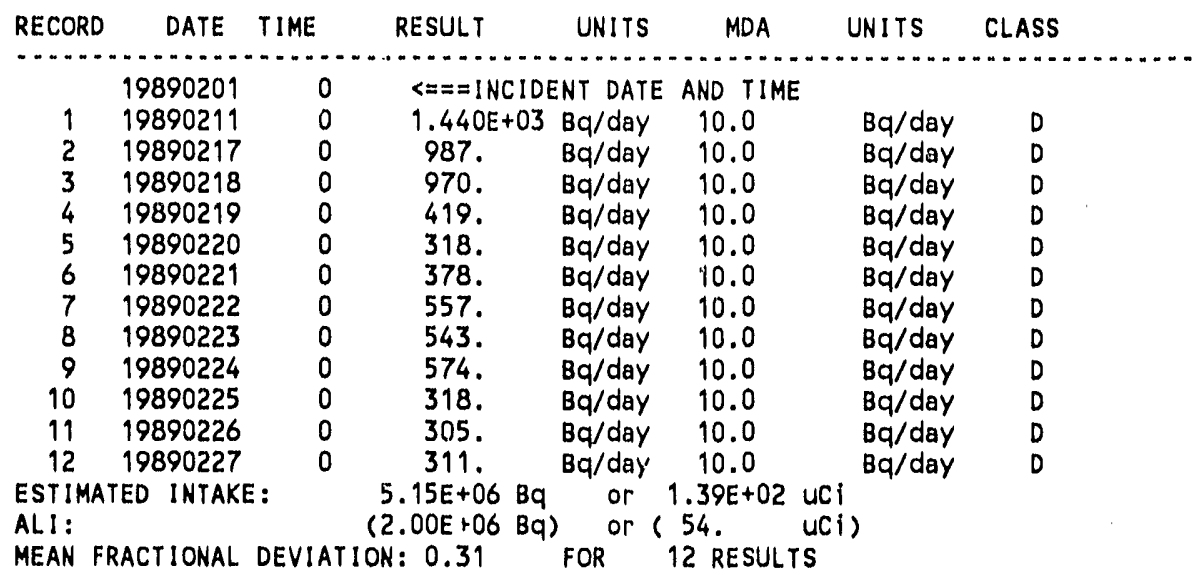

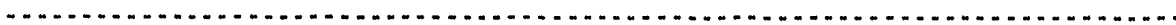

**** HIT RETURN TO CONTINUE $* * * *$

ORGAN

COMMITTED DOSE EQUIVALENT

\begin{tabular}{|c|c|c|c|}
\hline $\begin{array}{l}\text { GONADS } \\
\text { BREAST } \\
\text { LUNG } \\
\text { R. MARROW } \\
\text { BONE SURFACE } \\
\text { THYROID } \\
\text { REMAINDER } \\
\text { EFFECTIVE }\end{array}$ & $\begin{array}{c}\text { USV } \\
1.30 E+02 \\
4.05 E+02 \\
3.37 E+03 \\
3.23 E+02 \\
2.95 E+02 \\
1.50 E+06 \\
4.14 E+02 \\
4.57 E+04\end{array}$ & or & $\begin{array}{l}\text { mrem } \\
13 . \\
41 . \\
3.37 E+02 \\
32 . \\
29 . \\
1.50 E+05 \\
41 . \\
4.57 E+03\end{array}$ \\
\hline
\end{tabular}

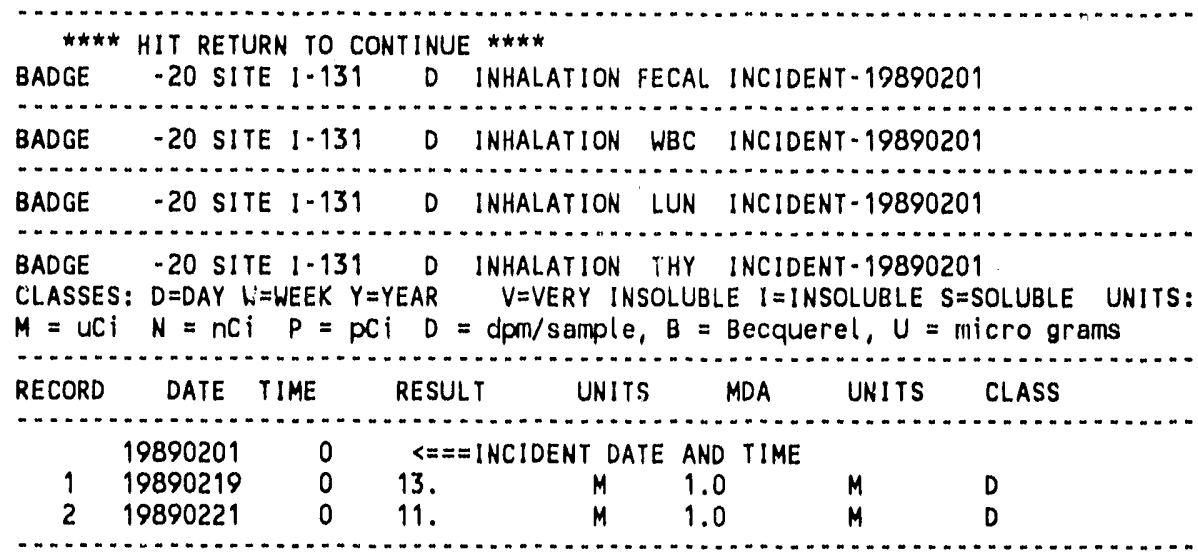

RESULTS SELECTED FOR INCIDENT ANALYSIS:

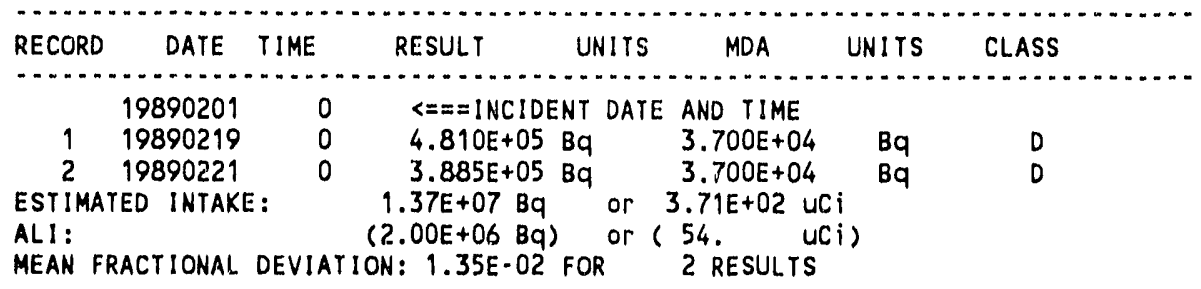

MEAN FRACTIONAL DEVIATION: $.35 E$ O2 FOR 2 RESULTS

\begin{tabular}{|c|c|c|}
\hline $\begin{array}{l}\text { ORGAN } \\
\text { GONADS } \\
\text { BREAST } \\
\text { LUNG } \\
\text { R. MARROW } \\
\text { BONE SURFACE }\end{array}$ & 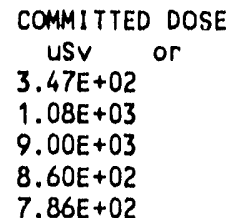 & $\begin{array}{l}\text { EQUIVALENT } \\
\text { mrem } \\
35 . \\
1.08 E+02 \\
9.00 E+02 \\
86 . \\
79 .\end{array}$ \\
\hline
\end{tabular}




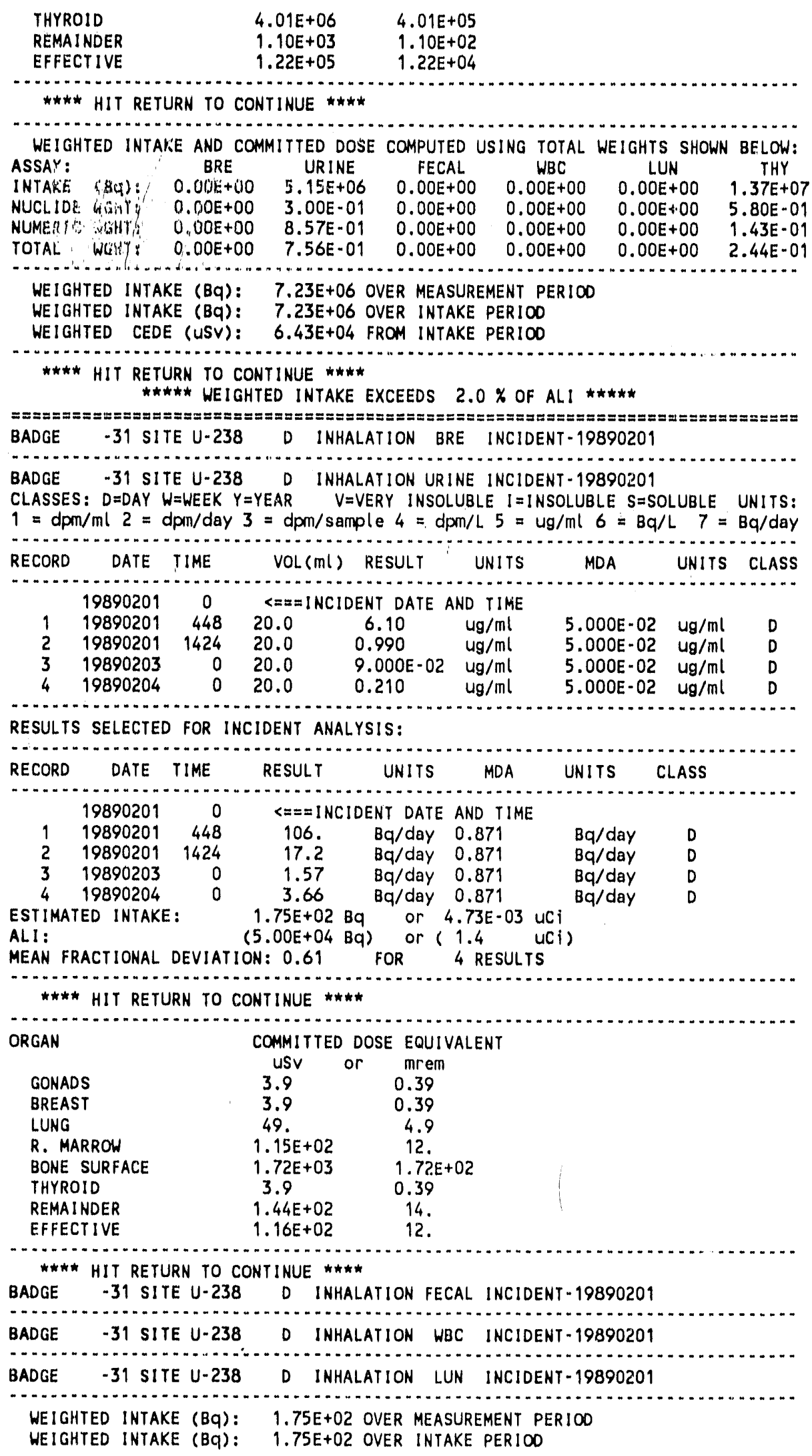


WEIGHTED CEDE (USV): 1.16E+02 FROM INTAKE PERIOD

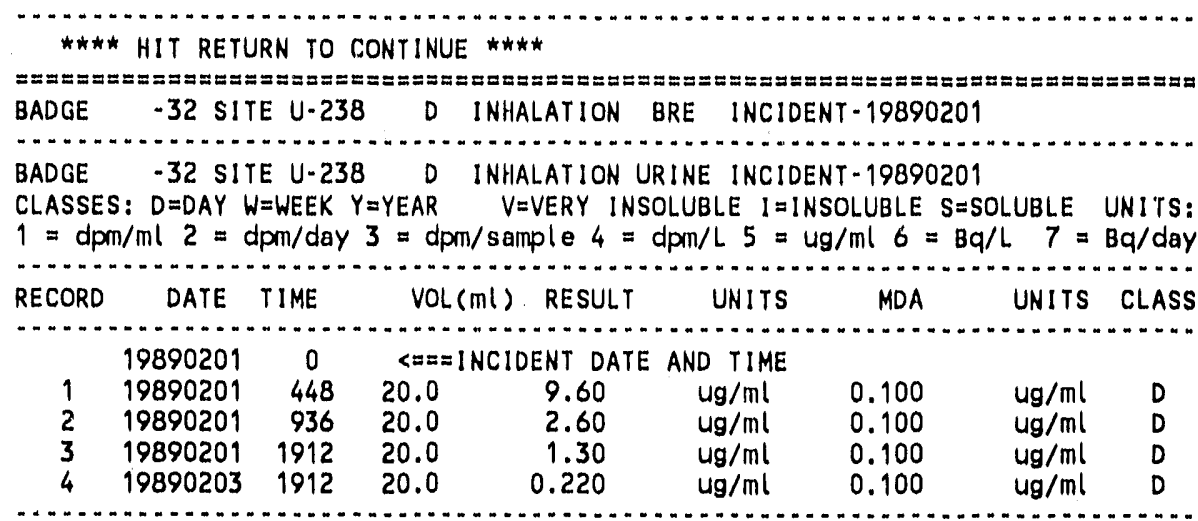

RESULTS SELECTED FOR INCIDENT ANALYSIS:

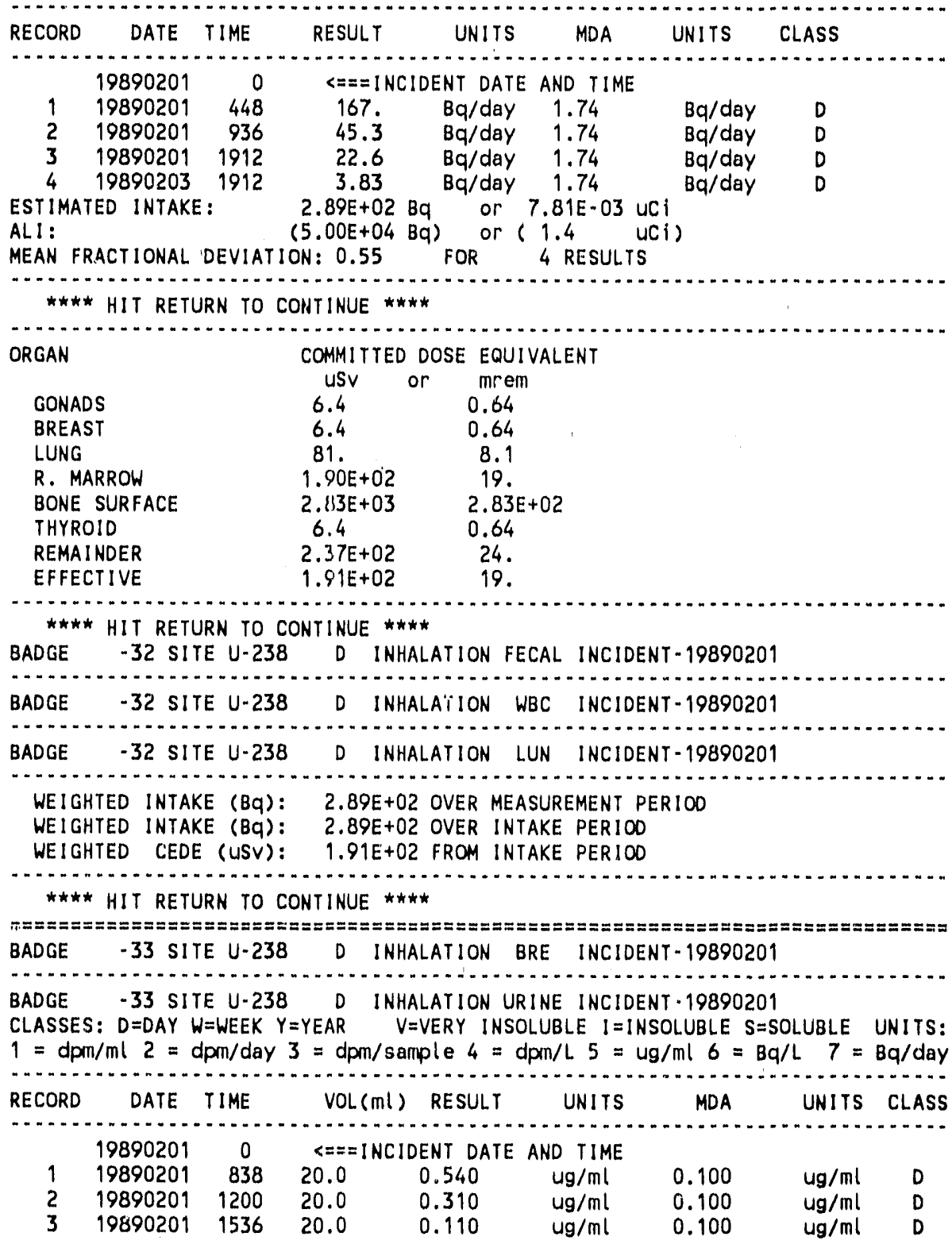




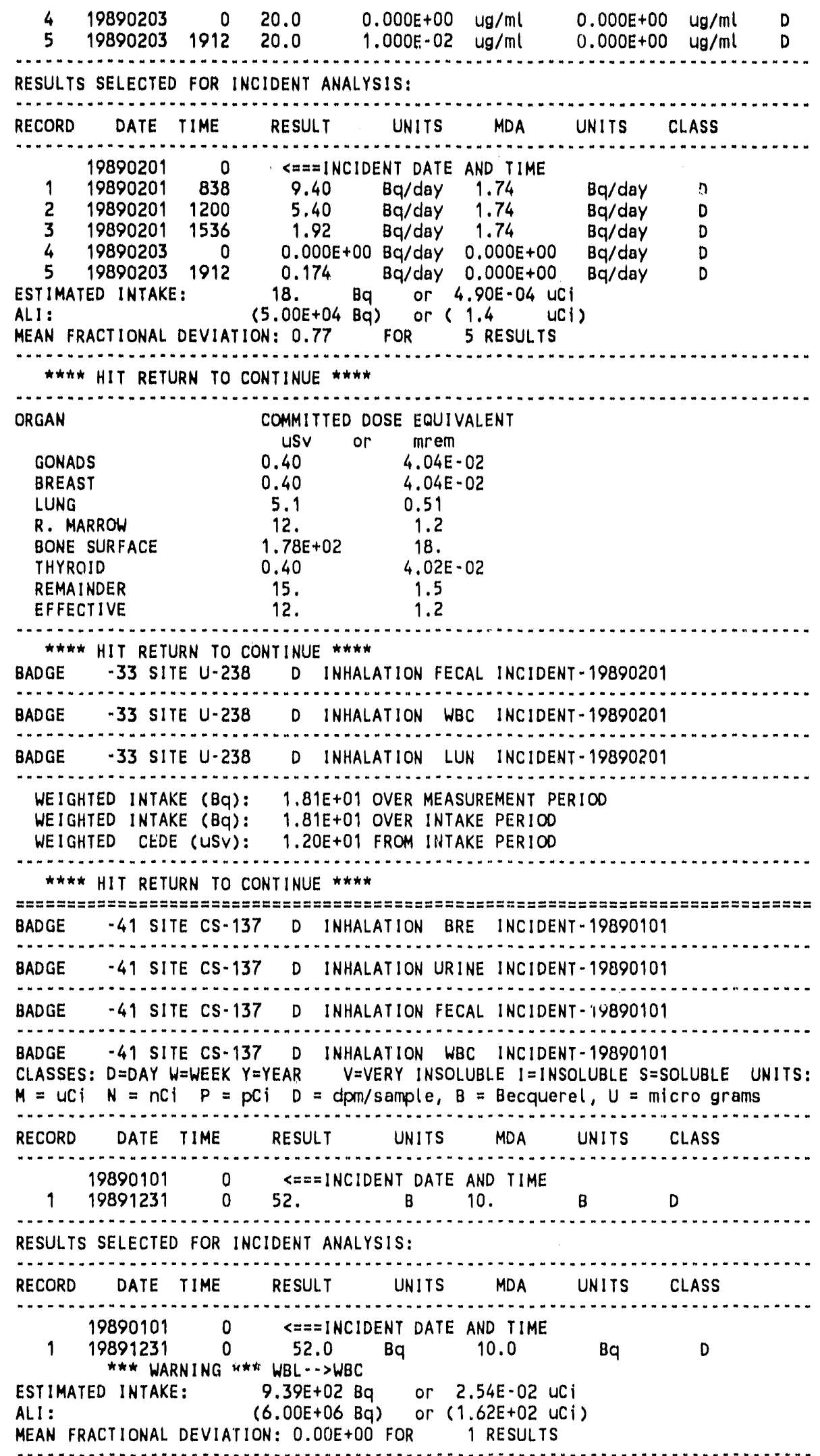


**** HIT RETURN TO CONTINUE ****

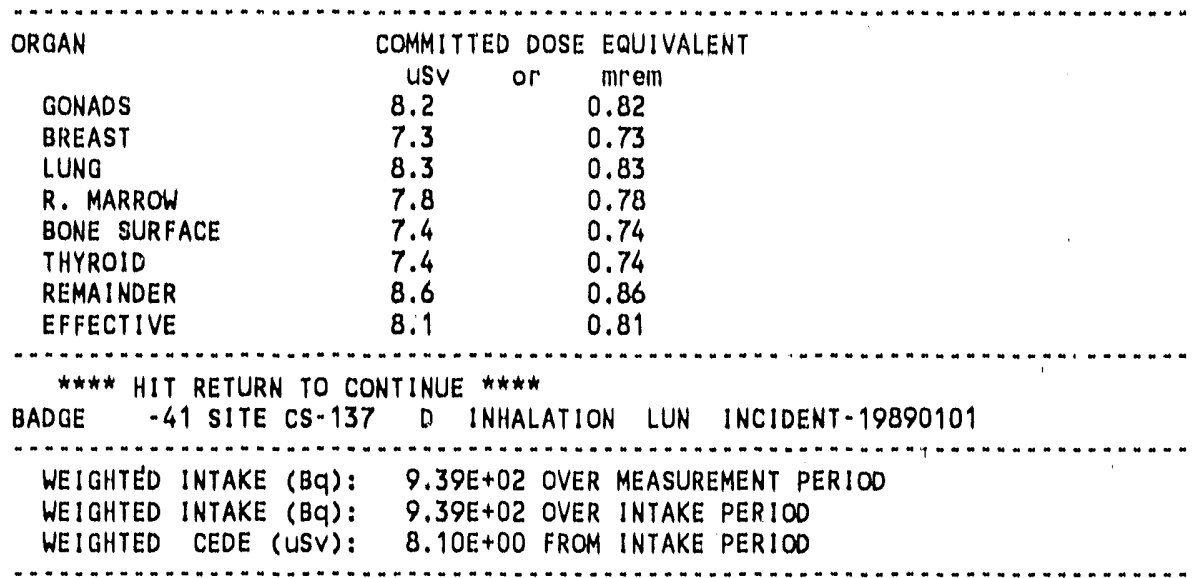

**** HIT RETURN TO CONTINUE $* * * *$

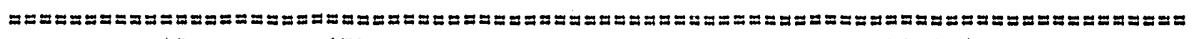
BADGE -42 SITE CS-137 D INHALATION BRE INCIDENT-19890101

BADGE 42 SITE CS. 137 D INHALATION URINE INCIDENT -19890101

BADGE -42 SITE CS-137 D INHALATION FECAL INCIDENT-19890101

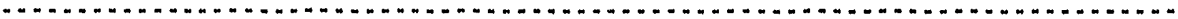

BADGE -42 SITE CS -137 D INHALATION WBC INCIDENT-19890101

CLASSES: $D=D A Y$ WVWEEK $Y=Y E A R \quad V=V E R Y$ INSOLUBLE $I=I N S O L U B L E ~ S=S O L U B L E$ UNITS: $M=u C i \quad N=n C i \quad P=p C i \quad D=d p m /$ sample, $B=$ Becquerel, $U=$ micro grams

(n)

RECORD DATE TIME RESULT UNITS MDA UNITS CLASS

$19890101 \quad 0 \quad<===I N C I D E N T$ DATE AND TIME

1
$19891231 \quad 0 \quad 1.33 E+02$

RESULTS SELECTED FOR INCIDENT ANALYSIS:

$\begin{array}{lll}\text { RECORD DATE TIME RESULT UNITS MDA UNITS CLASS } \\ 19890101 & 0 & 5==\text { INCIDENT DATE AND TIME }\end{array}$

$\begin{array}{lllllll}1 & 19891231 & 0 & 133 . & B q & 10.0 & B q\end{array}$

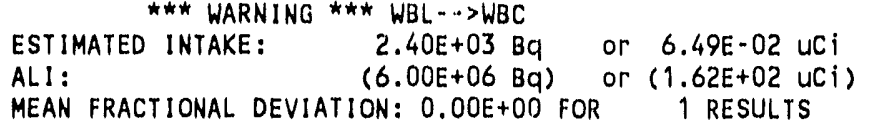

MEAN FRACTIONAL DEVIATION: $0.00 E+00$ FOR

\begin{tabular}{|c|c|c|}
\hline $\begin{array}{l}\text { ORGAN } \\
\text { GONADS } \\
\text { BREAST } \\
\text { LUNG } \\
\text { R. MARROW } \\
\text { BONE SURFACE } \\
\text { THYROID } \\
\text { REMAINDFR } \\
\text { EFFECTIVE }\end{array}$ & $\begin{array}{l}\text { COMMITTED DOSE } \\
\text { USV ON } \\
21 . \\
19 . \\
21 . \\
20 . \\
19 . \\
19 . \\
22 . \\
21 .\end{array}$ & $\begin{array}{l}\text { EQUIVALENT } \\
\text { mrem } \\
2.1 \\
1.9 \\
2.1 \\
2.0 \\
1.9 \\
1.9 \\
2.2 \\
2.1\end{array}$ \\
\hline $\begin{aligned} * * * * & \text { HIT RETURN TO CO } \\
\text { BADGE } & -42 \text { SITE CS }-137\end{aligned}$ & $\begin{array}{l}\text { ONTINUE } * * \star * \\
7 D_{\text {INHALATIOI }}\end{array}$ & IN LUN INCIDENT-19890101 \\
\hline $\begin{array}{l}\text { WEIGHTED INTAKE (BQ): } \\
\text { WEIGHTED INTAKE (Bq): } \\
\text { WEIGHTED CEDE (USV): }\end{array}$ & $\begin{array}{l}2.40 E+03 \text { OVER } \\
2.40 E+03 \text { OVER } \\
2.07 E+01 \text { FROM }\end{array}$ & $\begin{array}{l}\text { MEASUREMENT PERIOD } \\
\text { INTAKE PERIOD } \\
\text { INTAKE PERIOD }\end{array}$ \\
\hline
\end{tabular}




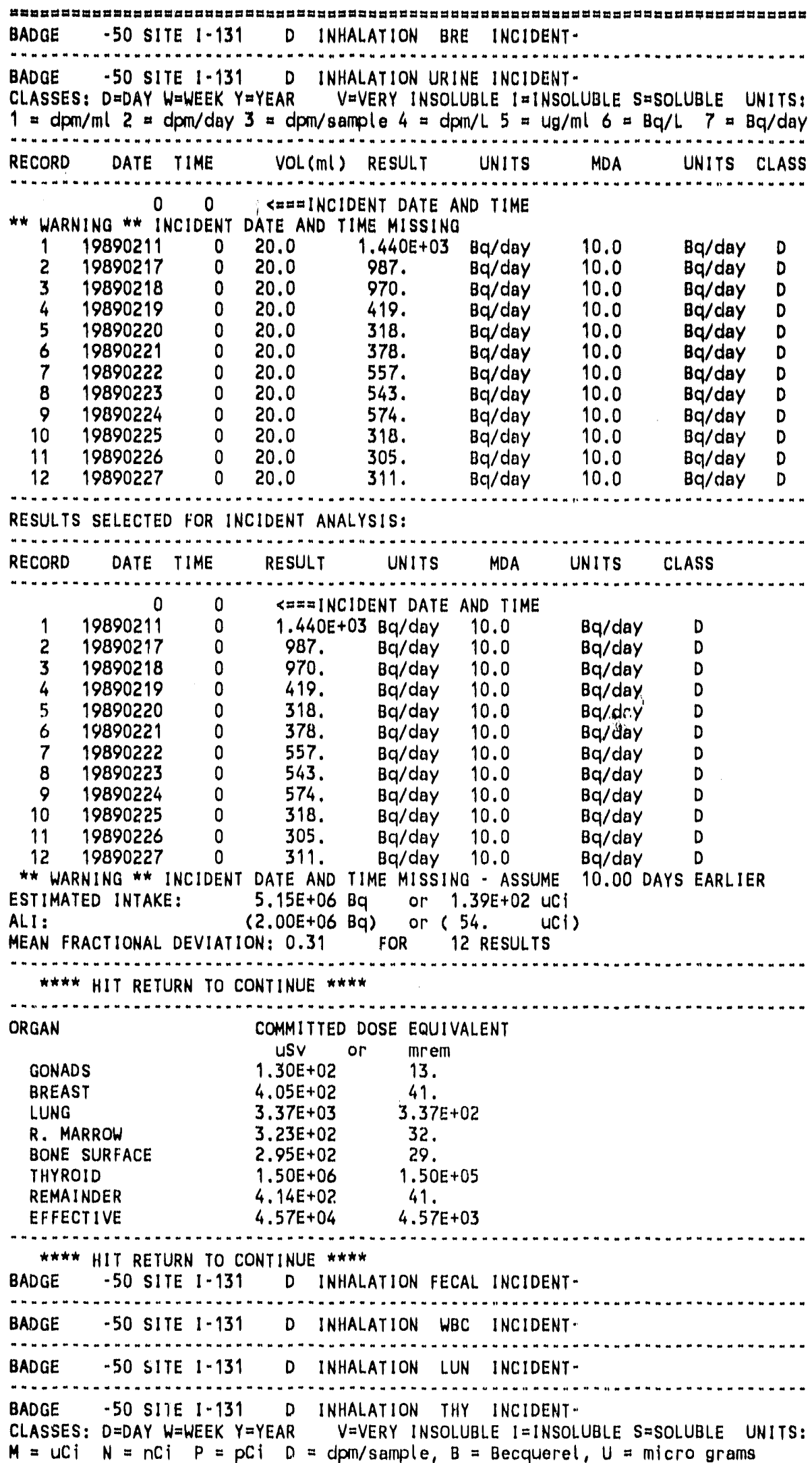




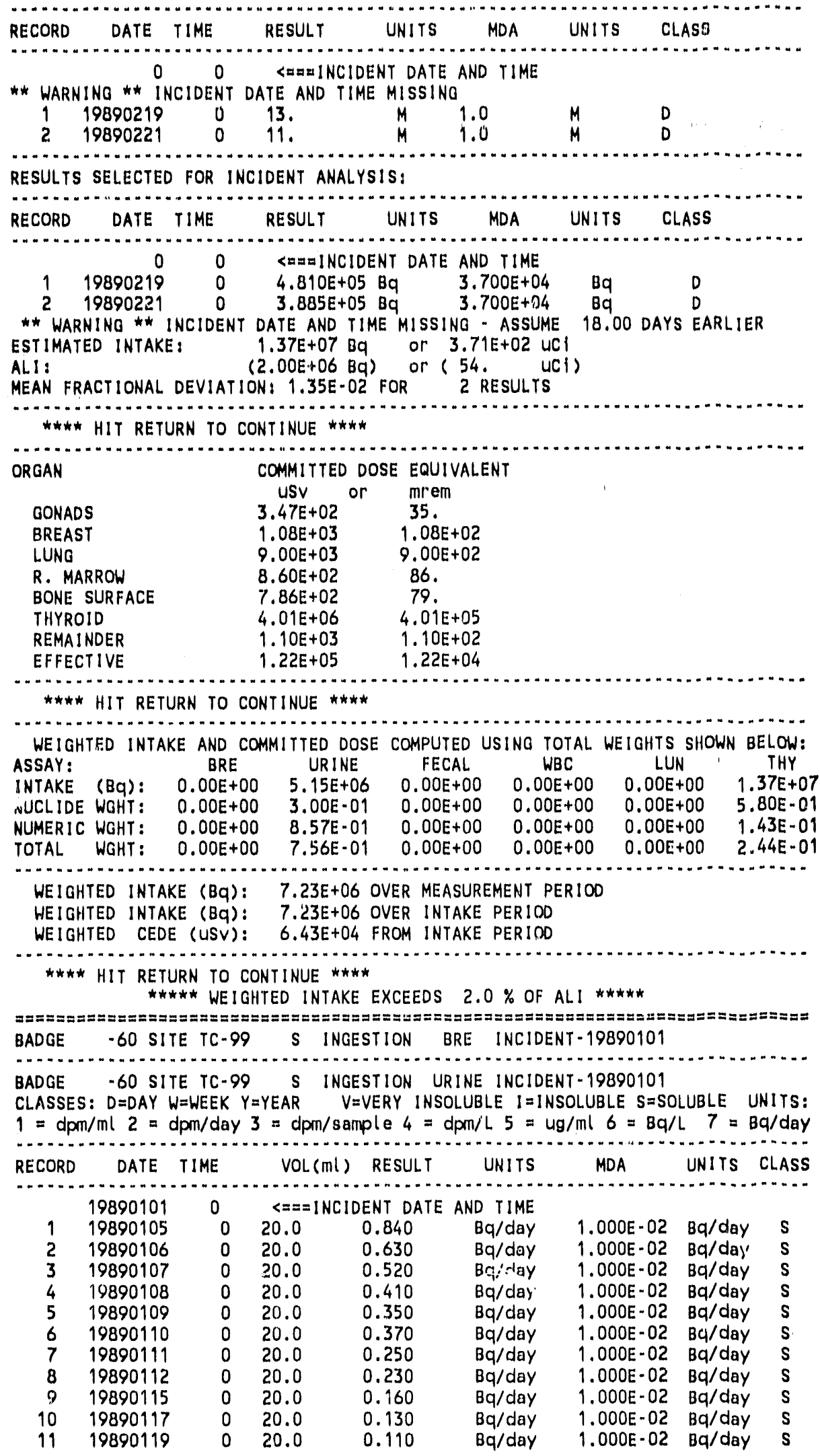


183

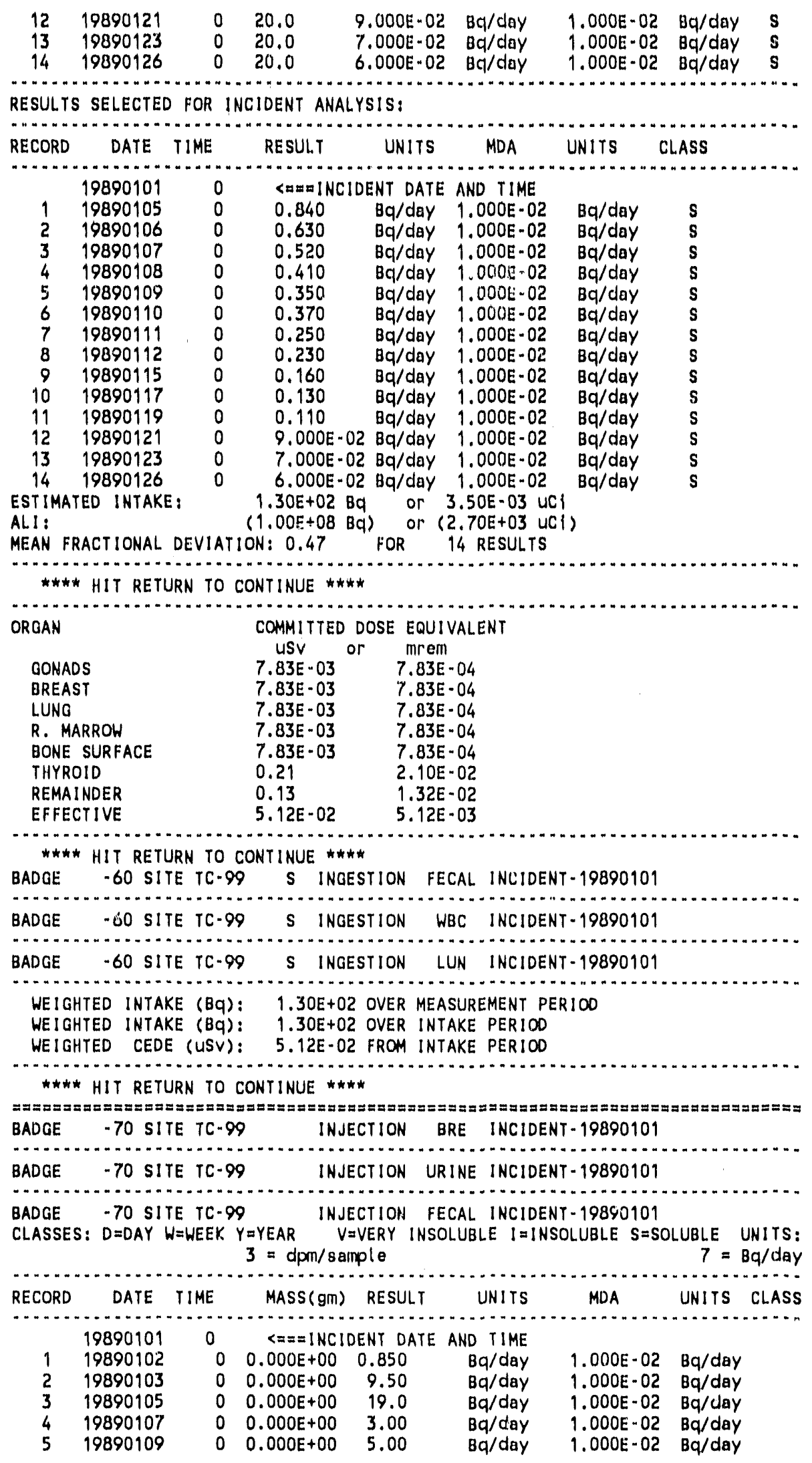




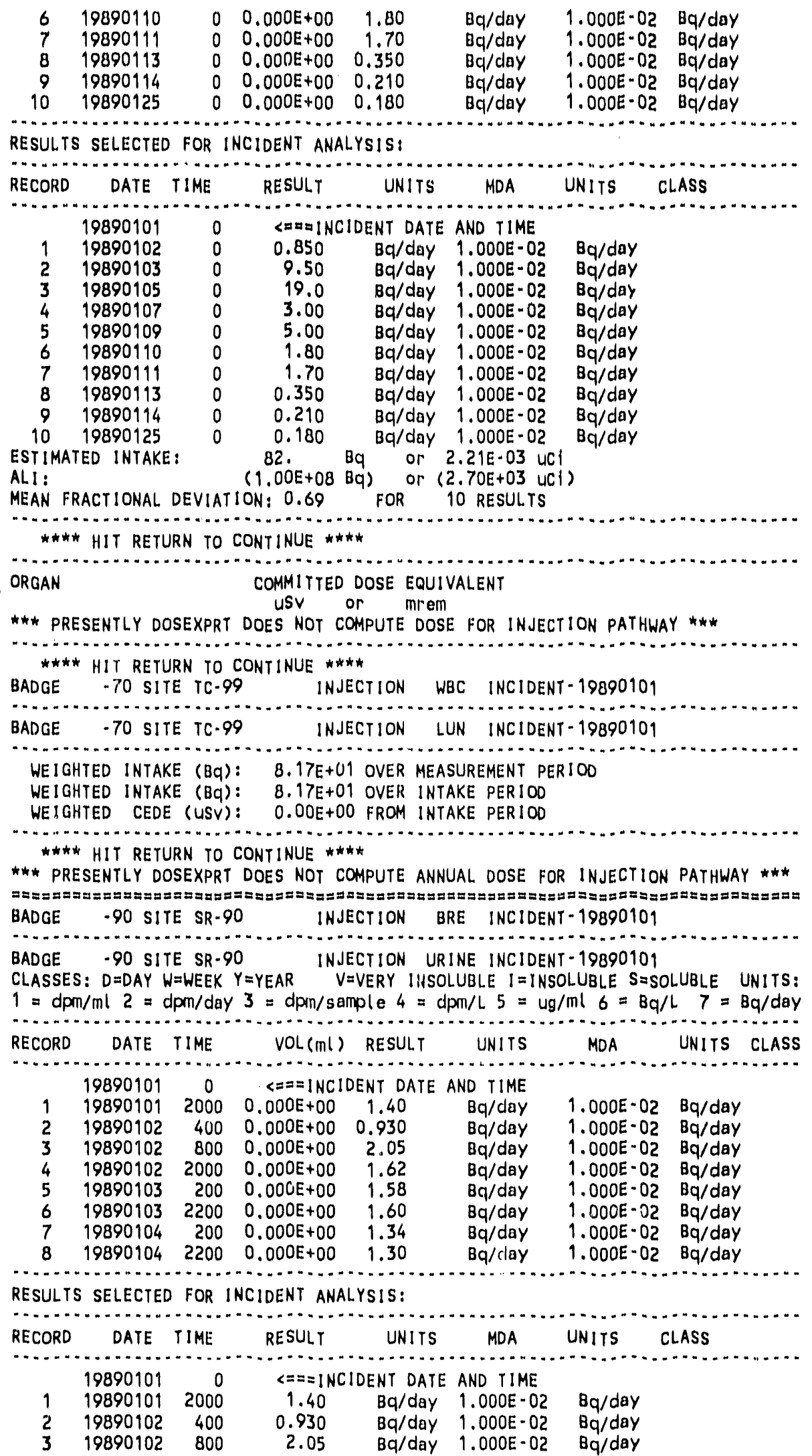


185

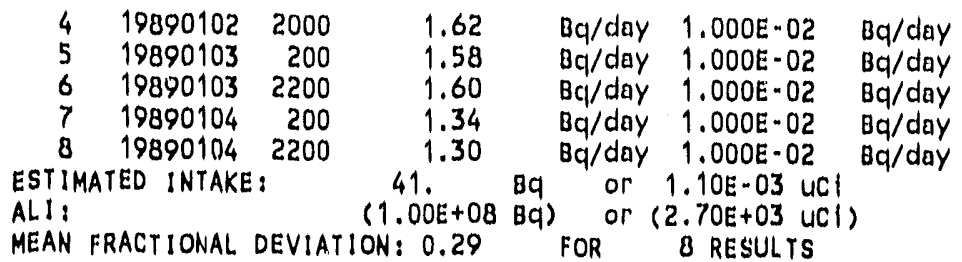

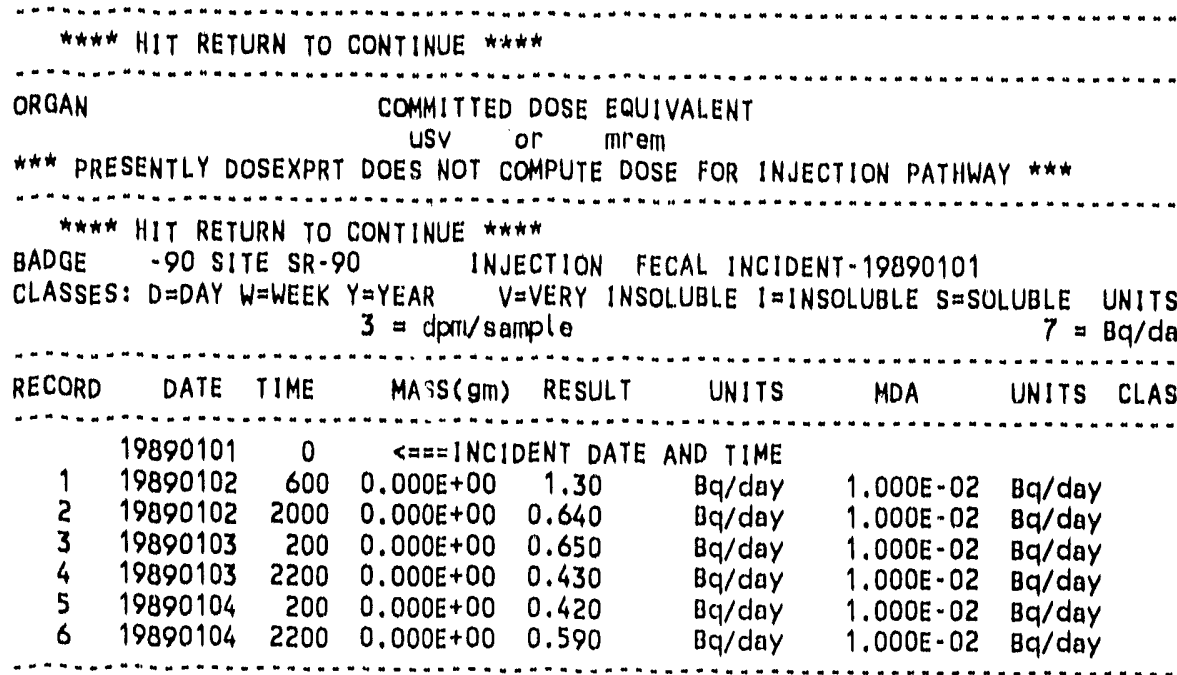

RESULTS SELECTED FOR INCIDENT ANALYSIS:

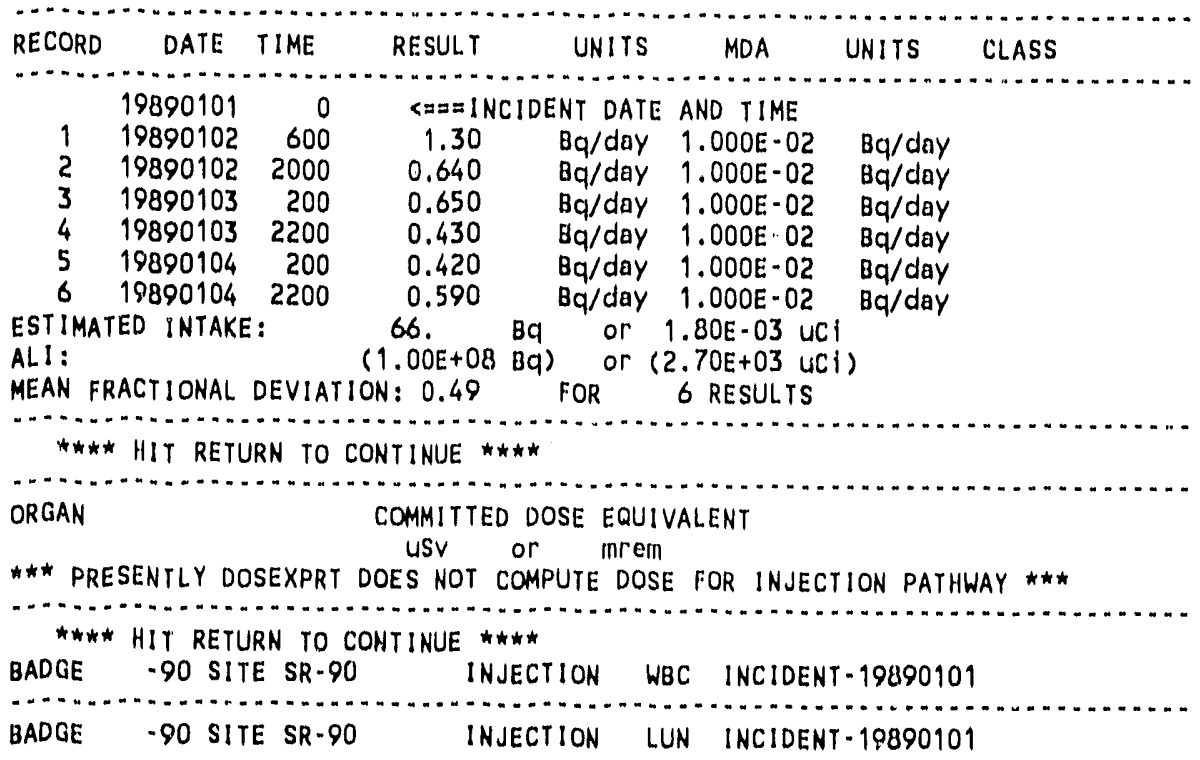

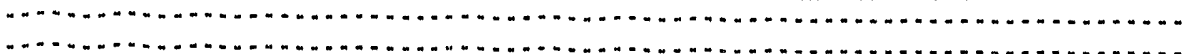

WEIGHTED INTAKE AND COMMITTED DOSE COMPUTED USING TOTAL WEIGHTS SHOWN BELOW: ASSAY: $\quad$ BRE URINE FECAL WBC LUN $\begin{array}{llllll}\text { INTAKE (Bq): } & 0.00 E+00 & 4.07 E+01 & 6.65 E+01 & 0.00 E+00 & 0.00 E+00\end{array}$ $\begin{array}{llllll}\text { NUCLIDE WGHT: } & 0.00 E+00 & 7.00 E-01 & 1.00 E-01 & 1.90 E-01 & 1.00 E-02 \\ \text { NUMERIC WGHT: } & 0.00 E+00 & 5.71 \mathrm{E}-01 & 4.29 \mathrm{E}-01 & 0.00 \mathrm{E}+00 & 0.00 \mathrm{E}+00\end{array}$

$\begin{array}{llllll}\text { NUMERIC WGHT: } & 0.00 E+00 & 5.71 E-01 & 4.29 E-01 & 0.00 E+00 & 0.00 E+00\end{array}$

TOTAL WGHT: $0.00 \mathrm{E}+00$ 9.03E-01 $9.68 \mathrm{E}-02 \quad 0.00 \mathrm{E}+00 \quad 0.00 \mathrm{E}+00$

WEIGHTED INTAKE $(\mathrm{Bq}): 4.32 E+01$ OVER MEASUREMENT PERIOD

WEIGHTED INTAKE (Bq): $4.32 E+01$ OVER INTAKE PERIOD

WELGHTED CEDE (USV): $0.00 E+00$ FROM INTAKE PER 100

**** HIT RETURN TO CONTINUE **** 


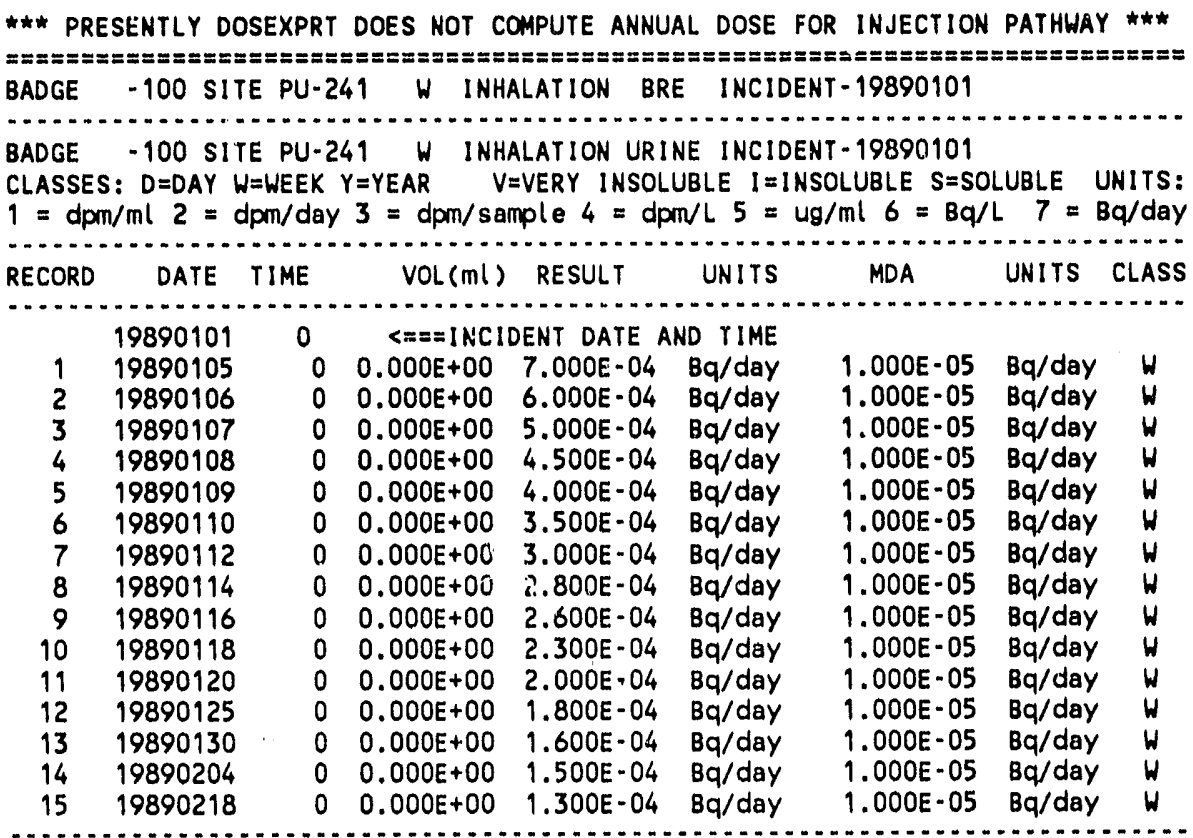

RESULTS SELECTED FOR INCIDENT ANALYSIS:

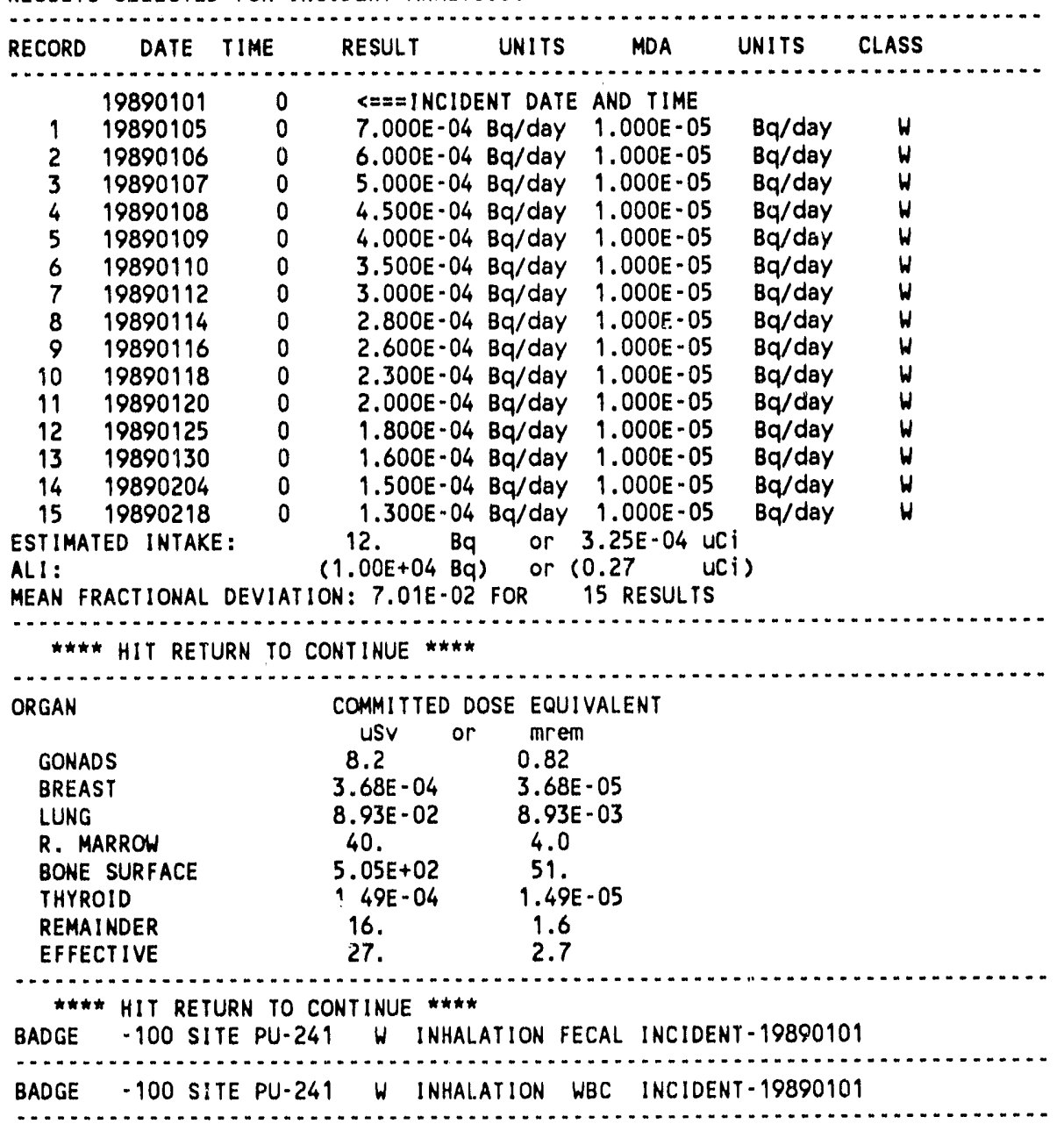




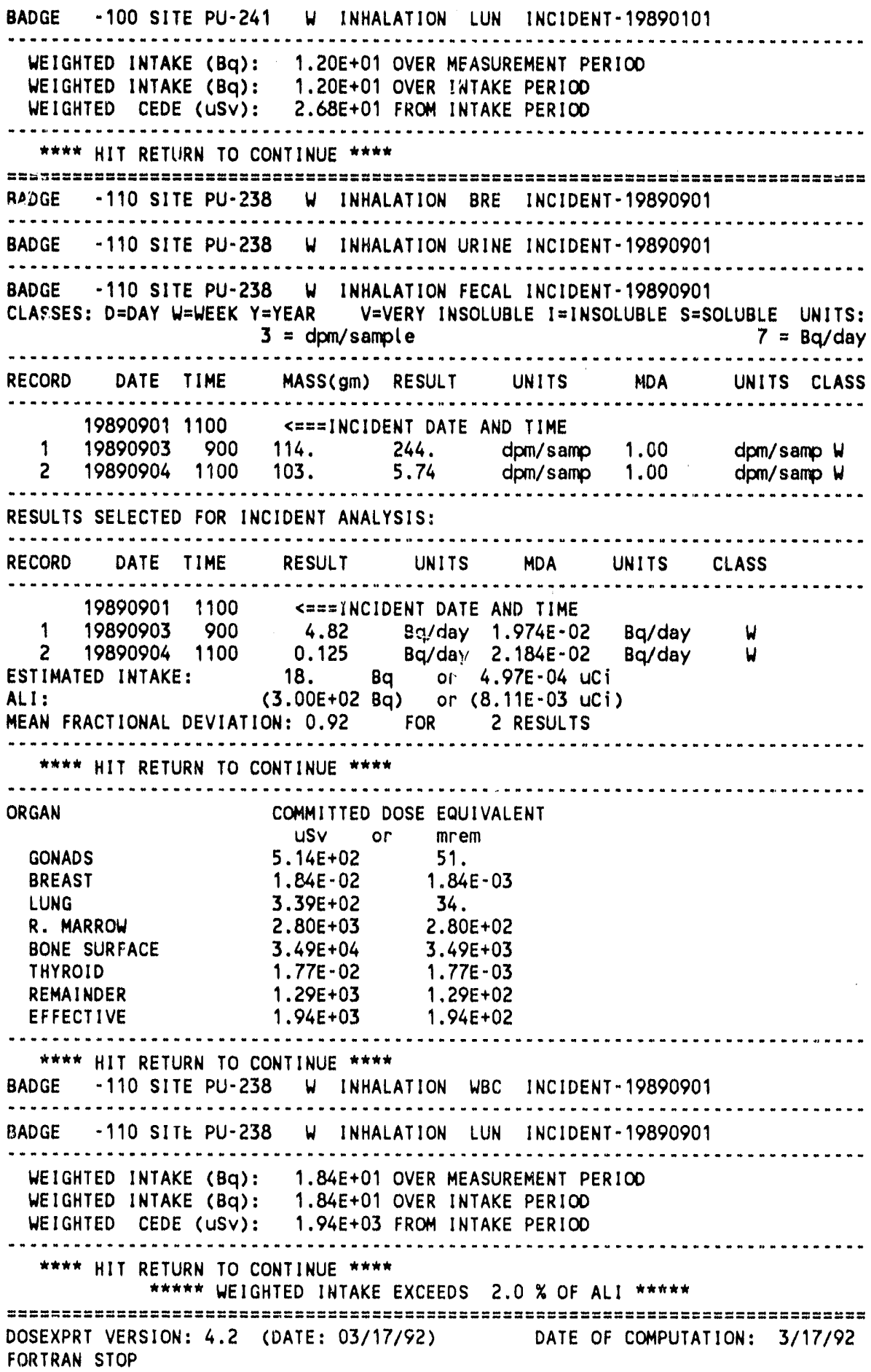




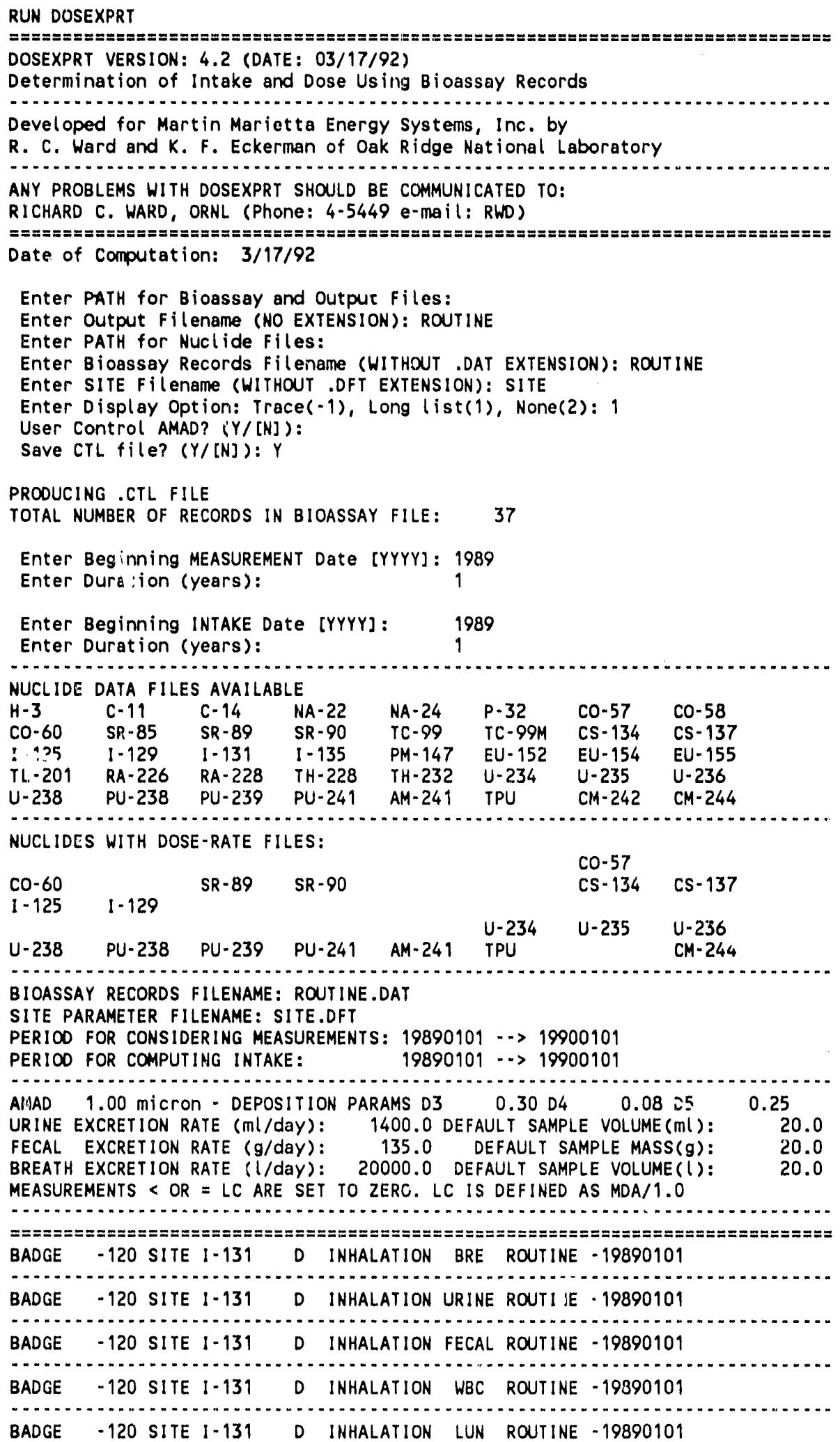




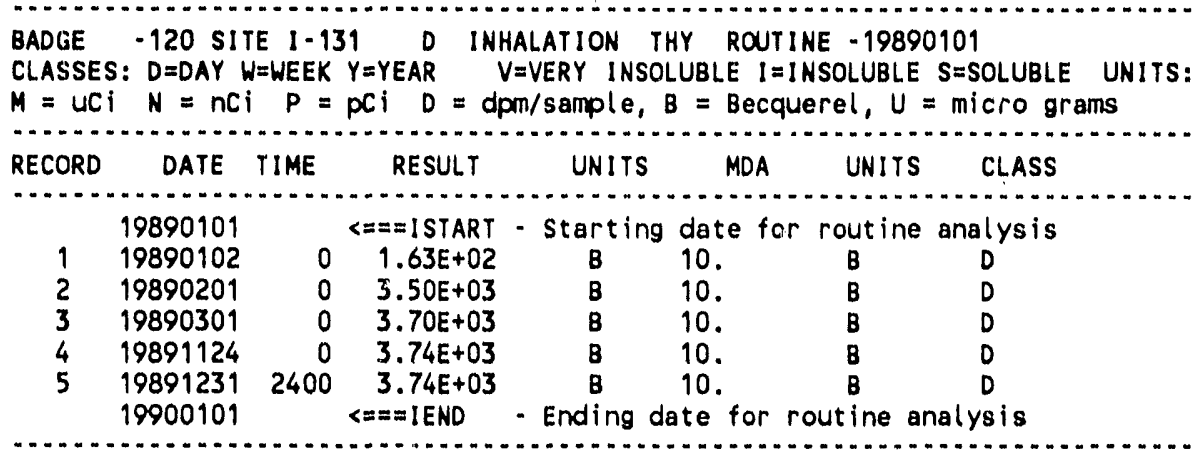

RESULTS SELECTED FOR ROUTINE ANALYSIS:

RESULTS SELECTED FOR ROUTINE ANALYSIS:

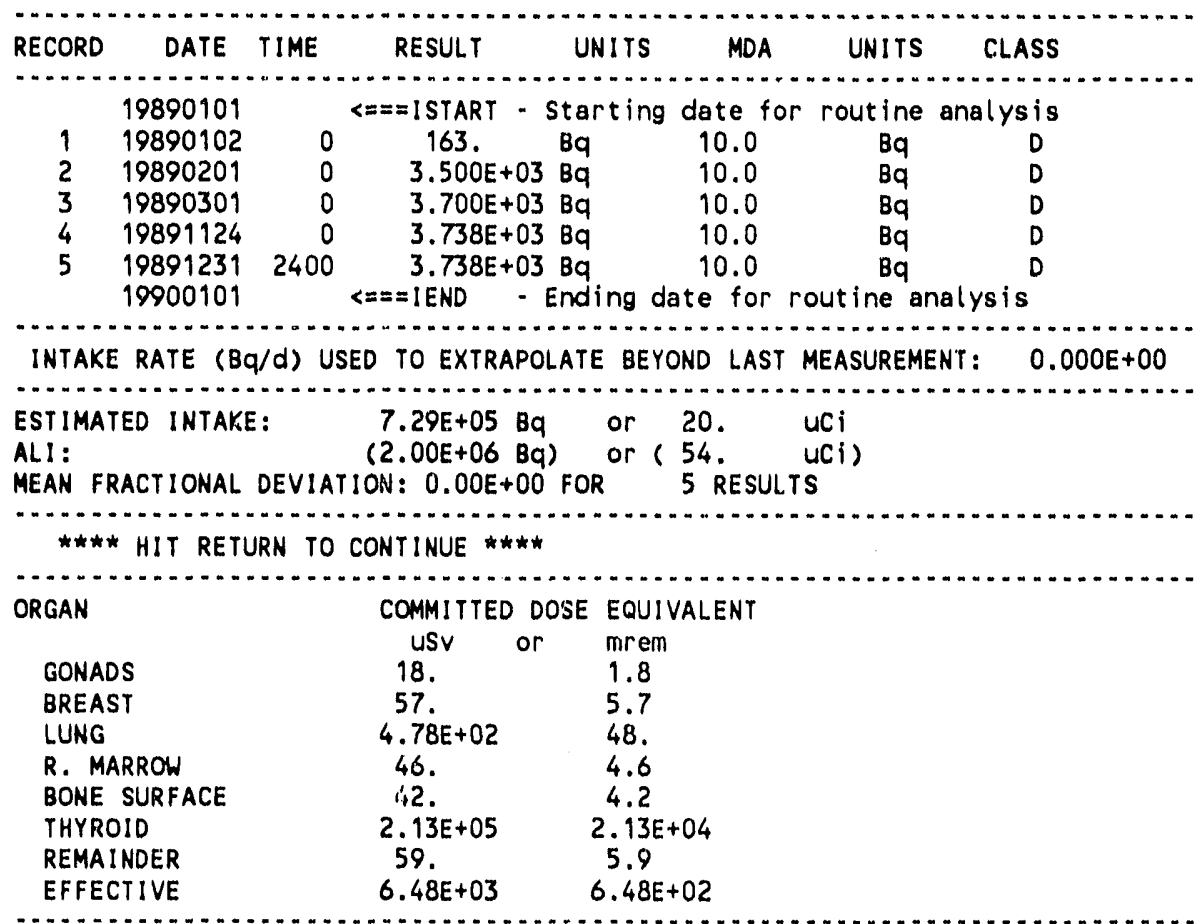

*** HIT RETURN TO CONTINUE $\star * \star *$
WEIGHTED INTAKE $(\mathrm{Bq}): \quad 7.29 E+05$ OVER MEASUREMENT PERIOD
WEIGHTED INTAKE $(\mathrm{Bq}): \quad 7.29 E+05$ OVER INTAKE PERIOD

WEIGHTED CEDE (USV): $6.48 E+03$ FROM INTAKE PERIDD

**** HIT RETURN TO CONTINUE ****

***** WEIGHTED INTAKE EXCEEDS $2.0 \%$ OF ALI $* * * * *$

+++++ ANNUAL EFFECTIVE DOSE EXCEEDS 10.0 MREM +++++

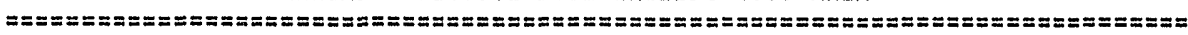

BADGE -131 SITE U-238 D INHALATION BRE ROUTINE - 19890101

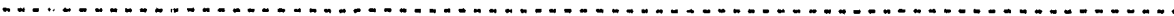

BADGE -13' SITE U-238 D INHALATION URINE ROUTINE - 19890101

BADGE - 131 SITE U-238 D INHALATION FECAL ROUTINE - 19890101

BADGE - 131 SITE U-238 D INHALATION WBC RCUTINE - 19890101

BADGE -131 SITE U-238 D INHALATION LUN ROUTINE -19890101

CLASSES: $D=D A Y$ W=WEEK $Y=Y E A R \quad V=V E R Y$ INSOLUBLE $I=I N S O L U B L E$ S=SOLUBLE UNITS:

$M=u C i \quad N=n C i \quad P=p C i \quad D=d p m /$ sample, $B=$ Becquerel, $U=$ micro grams

RECORD DATE TIME RESULT UNITS MDA UNITS CLASS 
190

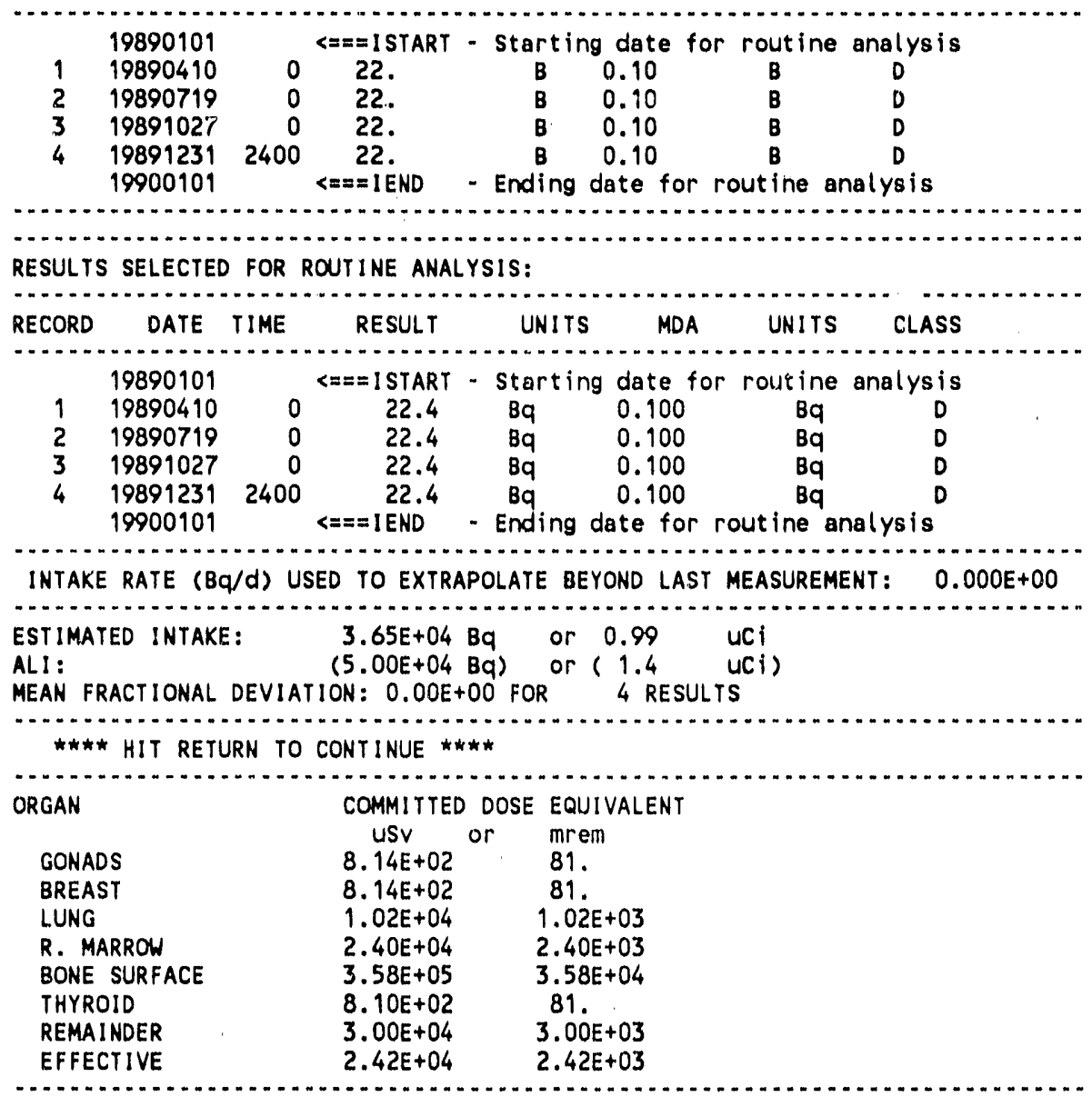

**** HIT RETURN TO CONTINUE $\star * \star \star *$

WEIGHTED INTAKE (Bq): 3.65 E +04 OVER MEASUREMENT PERIOD

WEIGHTED INTAKE (Bq): $3.65 E+04$ OVER INTAKE PERIOD

WEIGHTED CEDE (USV): $2.42 E+04$ FROM INTAKE PERIOD

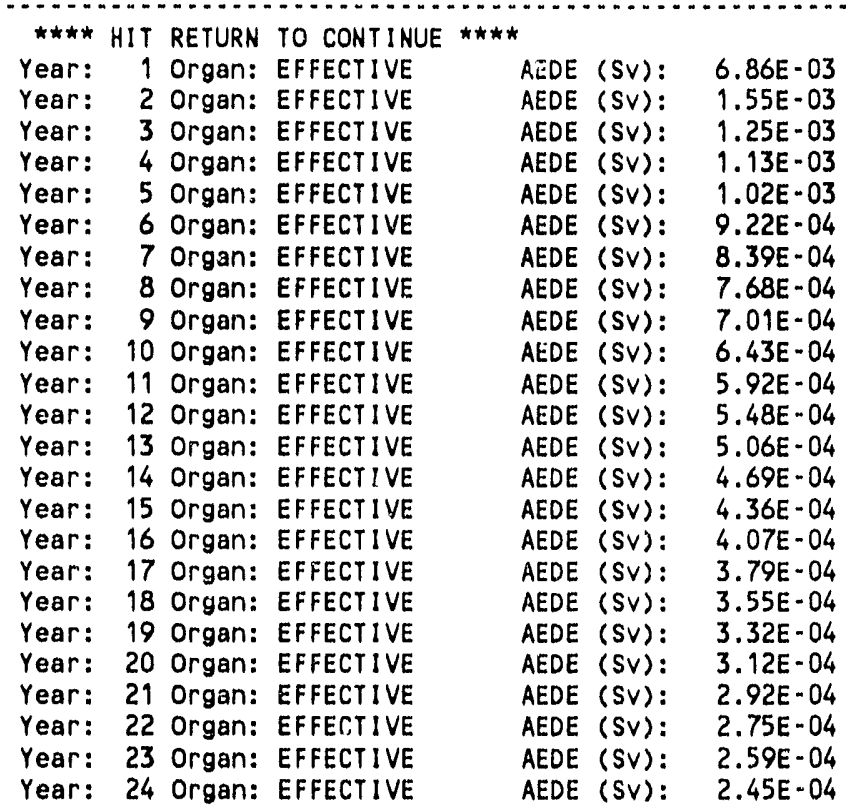




Year: 25 Organ: EFFECTIVE
Year: 26 Organ: EFFECTIVE
Year: 27 Organ: EFFECTIVE
Year: 28 Organ: EFFECTIVE
Year: 29 Organ: EFFECTIVE
Year: 30 Organ: EFFECTIVE
Year: 31 Organ: EFFECTIVE
Year: 32 Organ: EFFECTIVE
Year: 33 Organ: EFFECTIVE
Year: 34 Organ: EFFECTIVE
Year: 35 Organ: EFFECTIVE
Year: 36 Organ: EFFECTIVE
Year: 37 Organ: EFFECTIVE
Year: 38 Organ: EFFECTIVE
Year: 39 Organ: EFFECTIVE
Year: 40 Organ: EFFECTIVE
Year: 41 Organ: EFFECTIVE
Year: 42 Organ: EFFECTIVE
Year: 43 Organ: EFFECTIVE
Year: 44 Organ: EFFECTIVE
Year: 45 Organ: EFFECTIVE
Year: 46 Organ: EFFECTIVE
Year: 47 Organ: EFFECTIVE
Year: 48 Organ: EFFECTIVE
Year: 49 Organ: EFFECTIVE
Year: 50 Organ: EFFECTIVE
Year: 1 Organ: REMAINDER
Year: 1 Organ: THYROID
Year: 1 Organ: BONE SURFACE
Year: 1 Organ: R. MARROW
Year: 1 Organ: LUNG
Year: 9 Organ: BREAST
Year: 1 Orgar: GONADS

Year: 25 Organ: EFFECTIVE

Year: 26 Organ: EFFECTIVE

Year: 28 Organ: EFFECTIVE

Year: 29 Organ: EFFECTIVE

Year: 32 Organ: EFFECTIVE

Year: 33 Organ: EFFECTIVE

Year: 34 Organ: EFFECTIVE

Year: 37 Organ: EFFECTIVE

38 Organ: EFFECTIVE

Year: 40 Organ: EFFECTIVE

Year: 41 Organ: EFFECTIVE

42 Organ: EFFECTIVE

Year: 44 Organ: EFFECTIVE

Year: 45 Organ: EFFECTIVE

Year: 46 Crgan: EFFECTIVE

Year: 49 Organ: EFFECTIVE

50 Organ: EFFECTIVE

Year: 1 Organ: THYROID

I Organ: BONE SURFACE

Year: 1 Organ: BREAST

Year:

$\begin{array}{ll}\text { AEDE (SV): } & 2.30 E-04 \\ \text { AEDE (SV): } & 2.17 E-04 \\ \text { AEDE (SV): } & 2.05 E-04 \\ \text { AEDE (SV): } & 1.95 E-04 \\ \text { AEDE (SV): } & 1.83 E-04 \\ \text { AEDE (SV): } & 1.74 E-04 \\ \text { AEDE (SV): } & 1.64 E-04 \\ \text { AEDE (SV): } & 1.56 E-04 \\ \text { AEDE (SV): } & 1.48 E-04 \\ \text { AEDE (SV): } & 1.40 E-04 \\ \text { AEDE (SV): } & 1.33 E-04 \\ \text { AEDE (SV): } & 1.26 E-04 \\ \text { AEDE (SV): } & 1.19 E-04 \\ \text { AEDE (SV): } & 1.13 E-04 \\ \text { AEDE (SV): } & 1.07 E-04 \\ \text { AEDE (SV): } & 1.02 E-04 \\ \text { AEDE (SV): } & 9.69 E-05 \\ \text { AEDE (SV): } & 9.20 E-05 \\ \text { AEDE (SV): } & 8.74 E-05 \\ \text { AEDE (SV): } & 8.32 E-05 \\ \text { AEDE (SV): } & 7.88 E-05 \\ \text { AEDE (SV): } & 7.49 E-05 \\ \text { AEDE (SV): } & 7.11 E-05 \\ \text { AEDE (SV): } & 6.78 E-05 \\ \text { AEDE (SV): } & 6.42 E-05 \\ \text { AEDE (SV): } & 6.10 E-05 \\ \text { AEDE (SV): } & 1.53 E-02 \\ \text { AEDE (SV): } & 4.69 E-04 \\ \text { AEDE (SV): } & 2.17 E-02 \\ \text { AEDE (SV): } & 1.83 E-03 \\ \text { AEDE (SV): } & 1.00 E-02 \\ \text { AEDE (SV): } & 4.69 E-04 \\ \text { AEDE (SV): } & 4.69 E-04\end{array}$

AEDE (SV): $4.69 E-04$

+++++ ANNUAL EFFECTIVE DOSE EXCEEDS 10.0 MREM ++++t

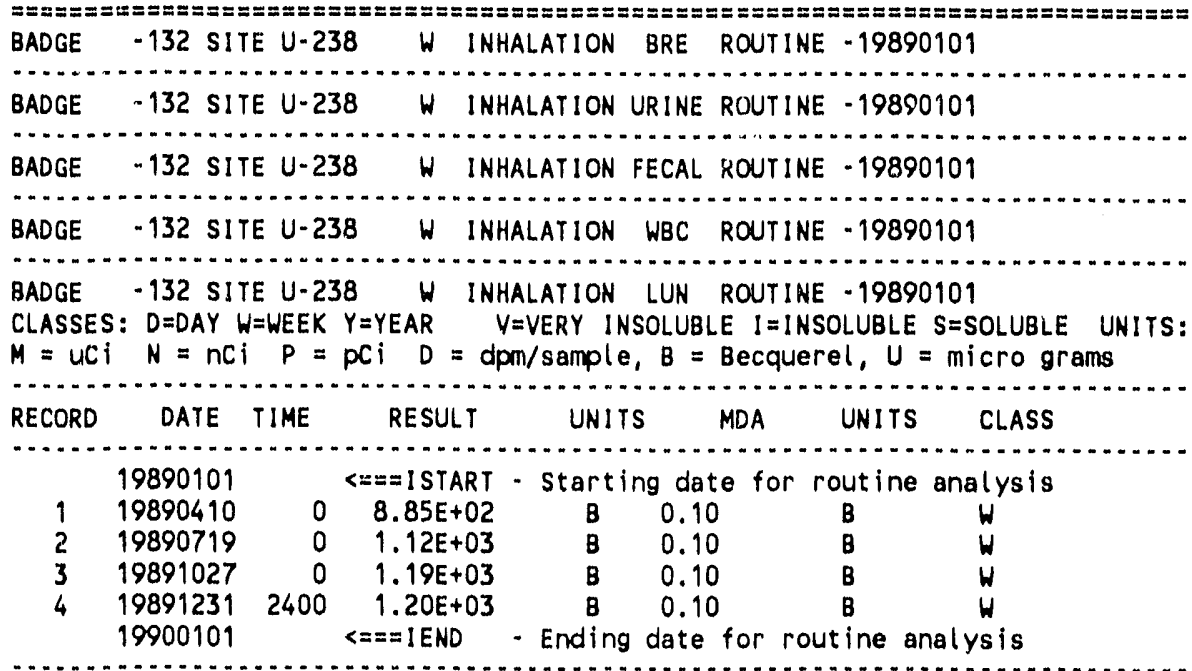

RESULTS SELECTED FOR ROUTINE ANALYSIS

RESULTS SELECTED FOR ROUTINE ANALYSIS:

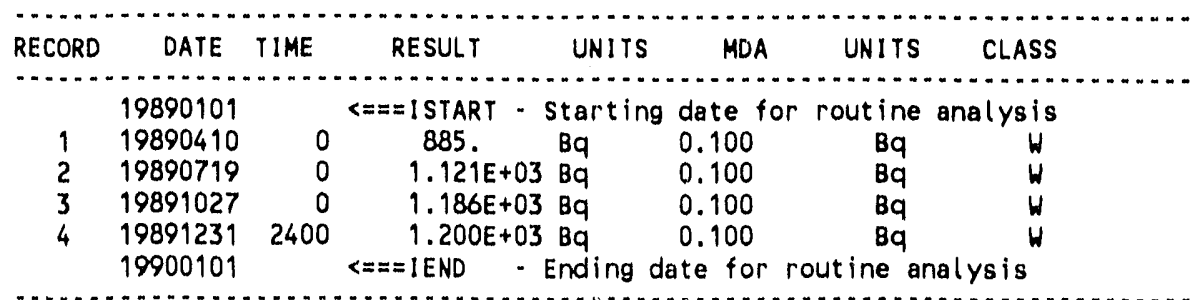


INTAKE RATE (Bq/d) USED TO EXTRAPOLATE BEYOND LAST MEASUREMENT: $\quad 0.000 E+00$

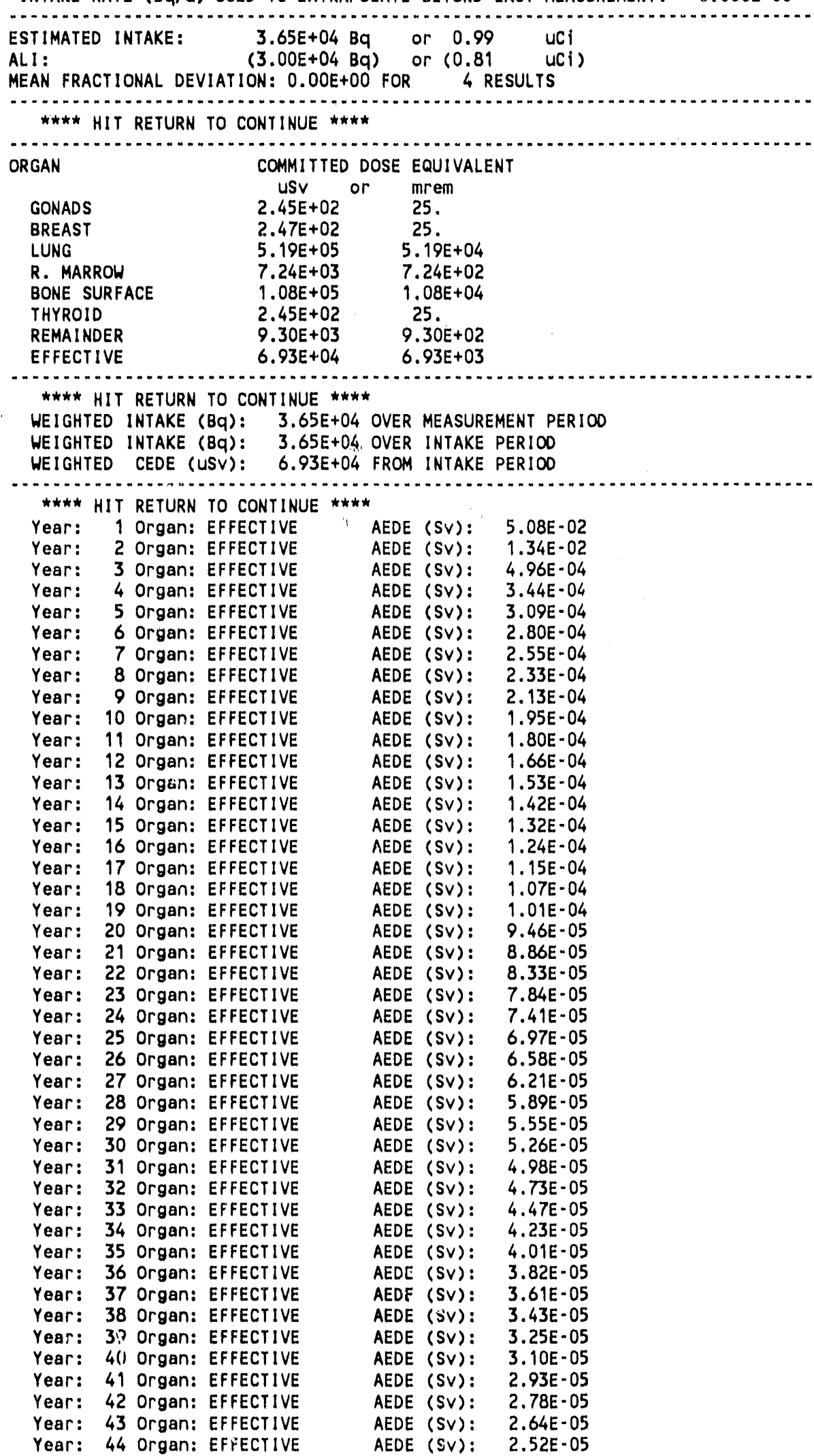




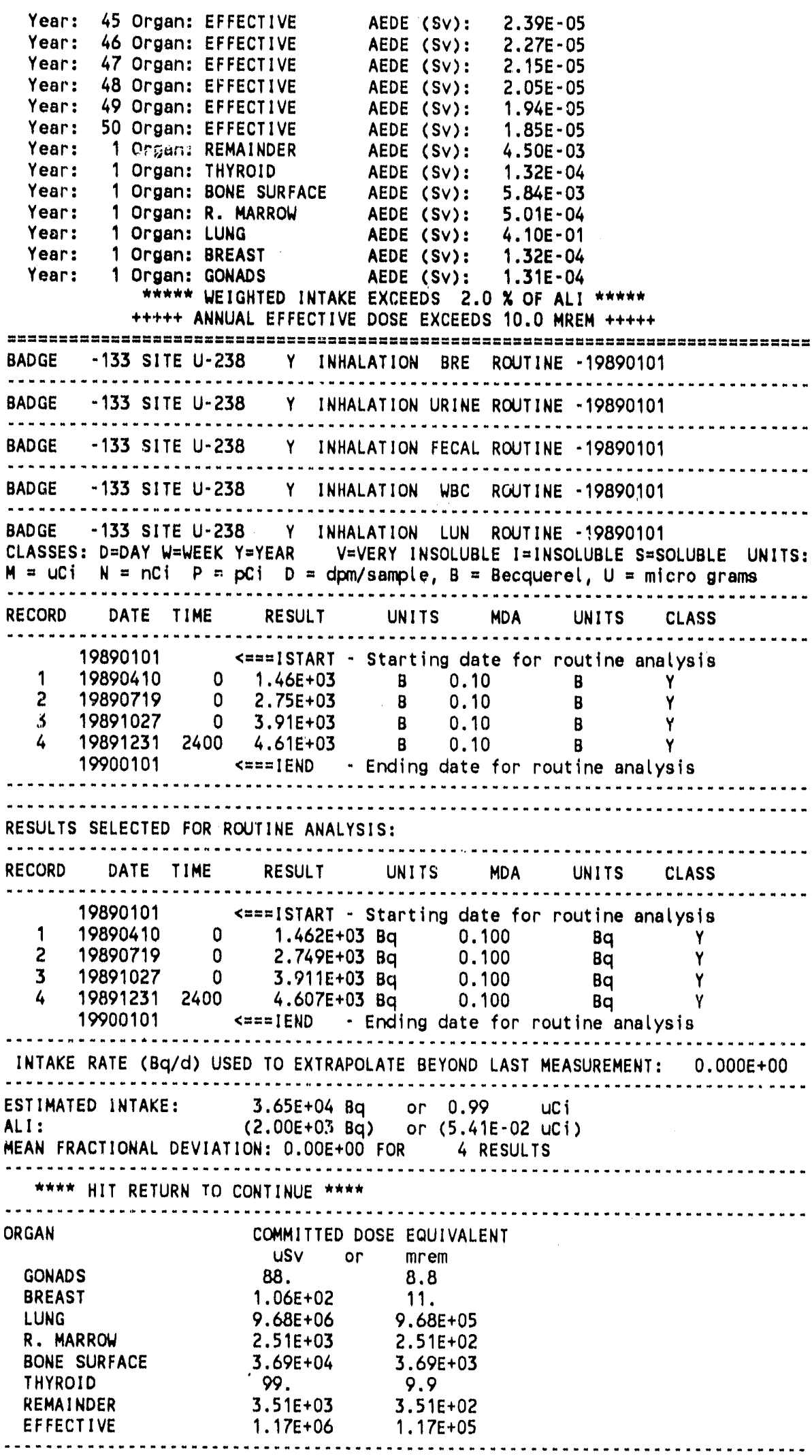

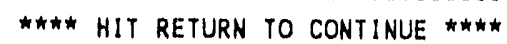


194

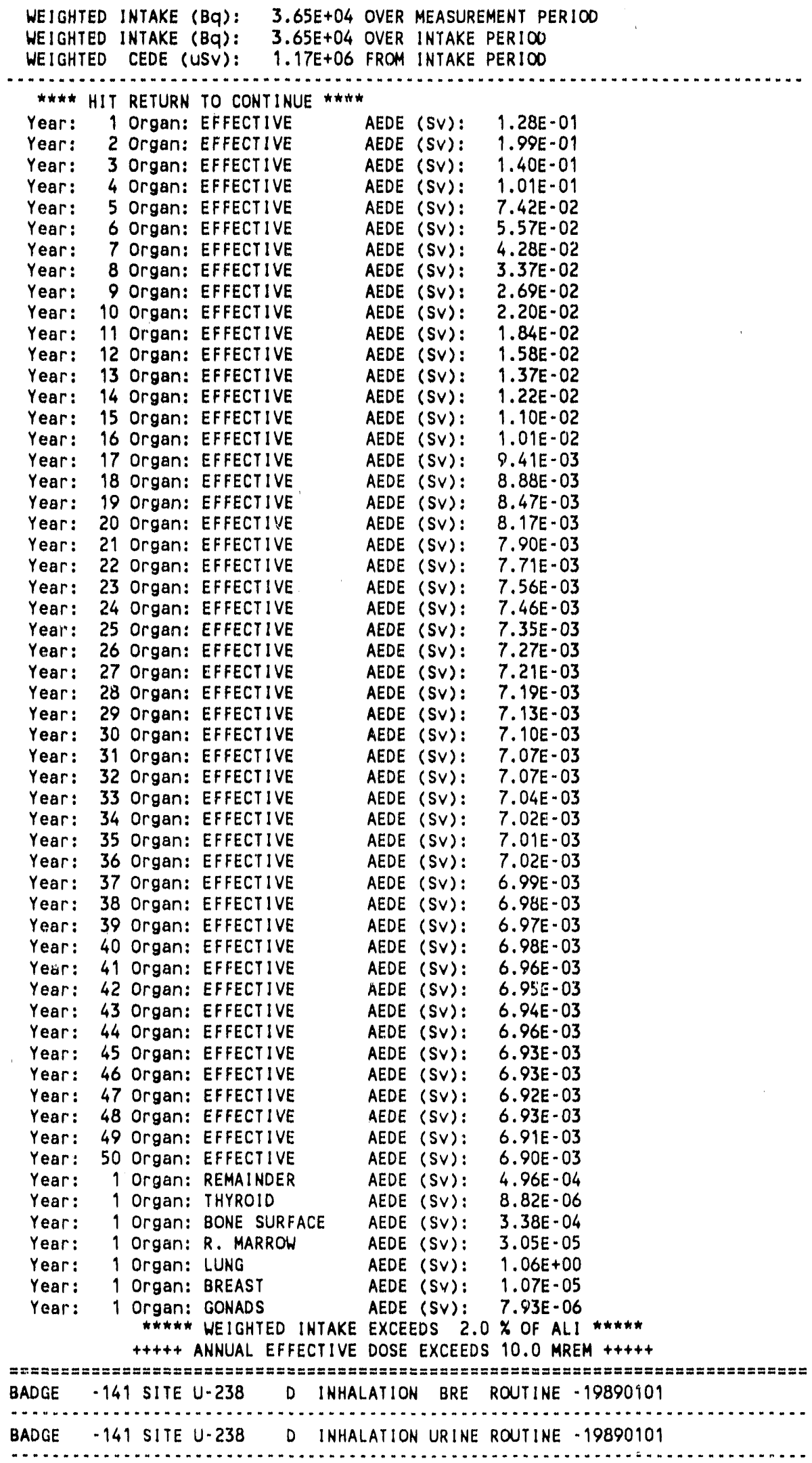




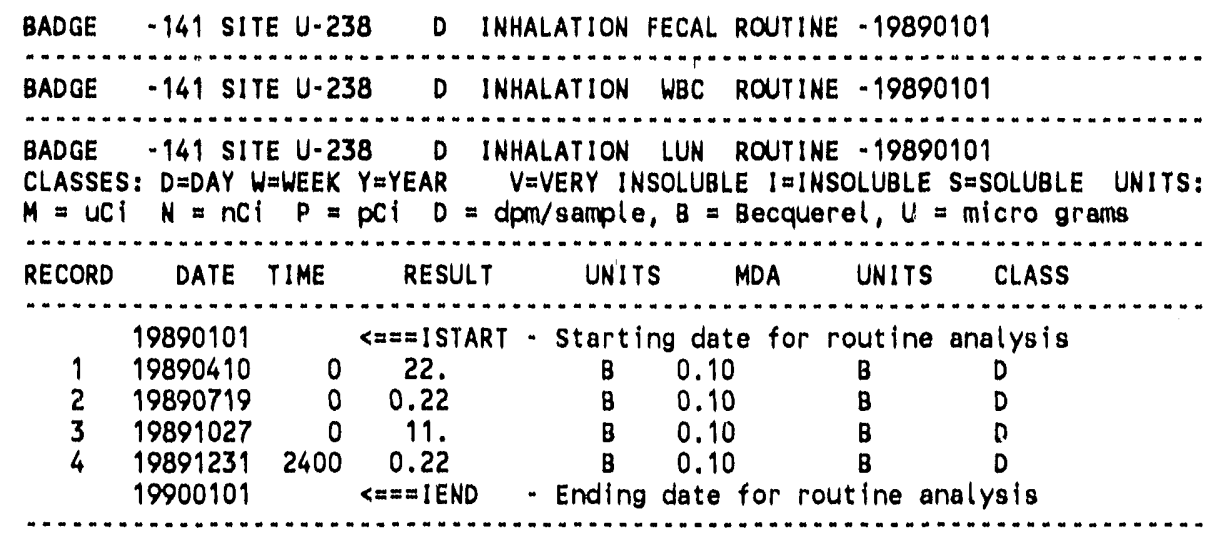

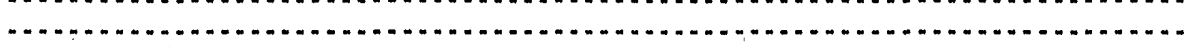

RESULTS SELECTED FOR ROUTINE ANALYSIS:

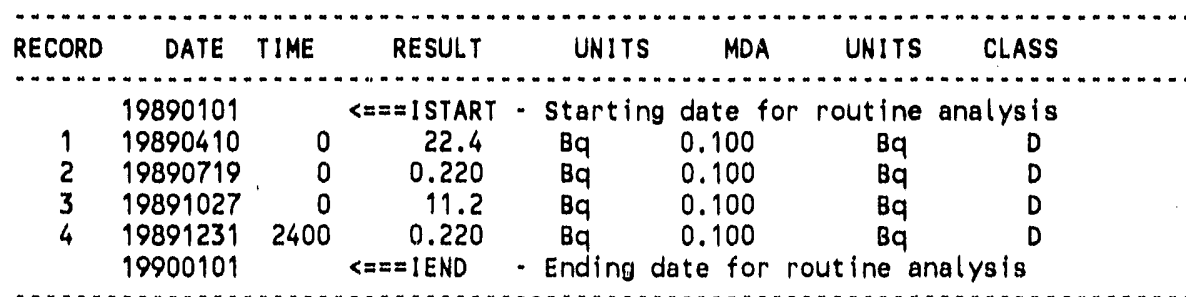

INTAKE RATE (Bq/d) USED TO EXTRAPOLATE BEYOND LAST MEASUREMENT: 0.000 E +00

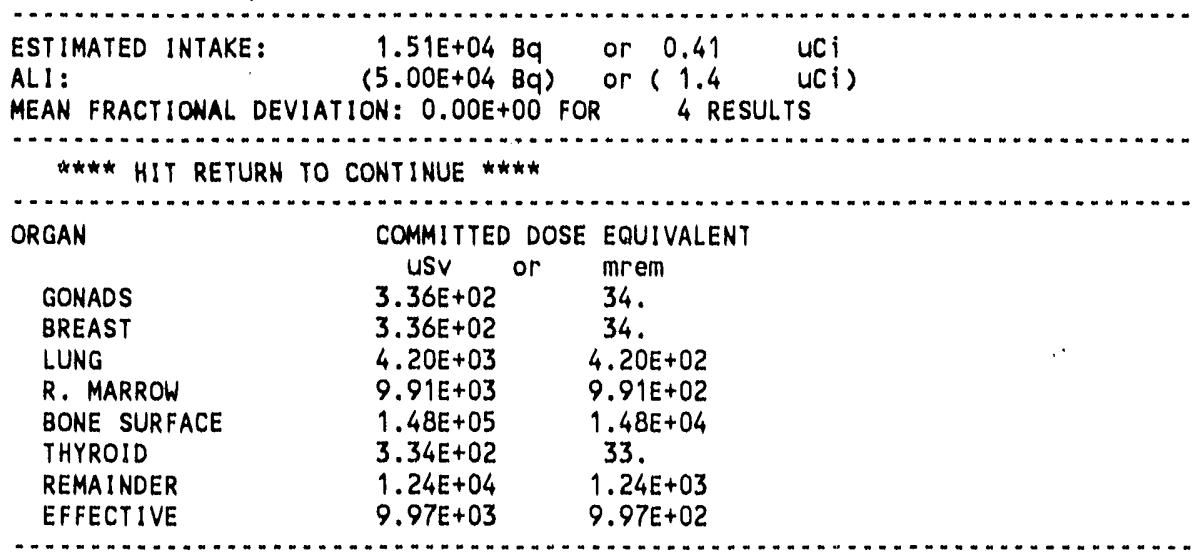

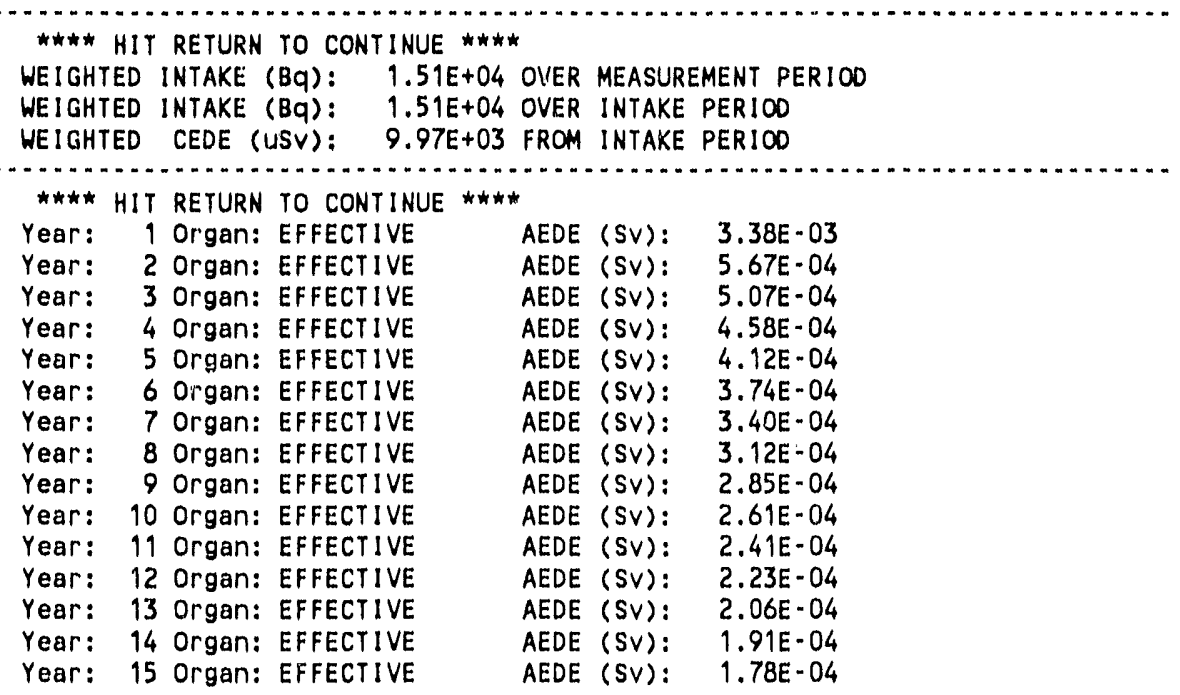




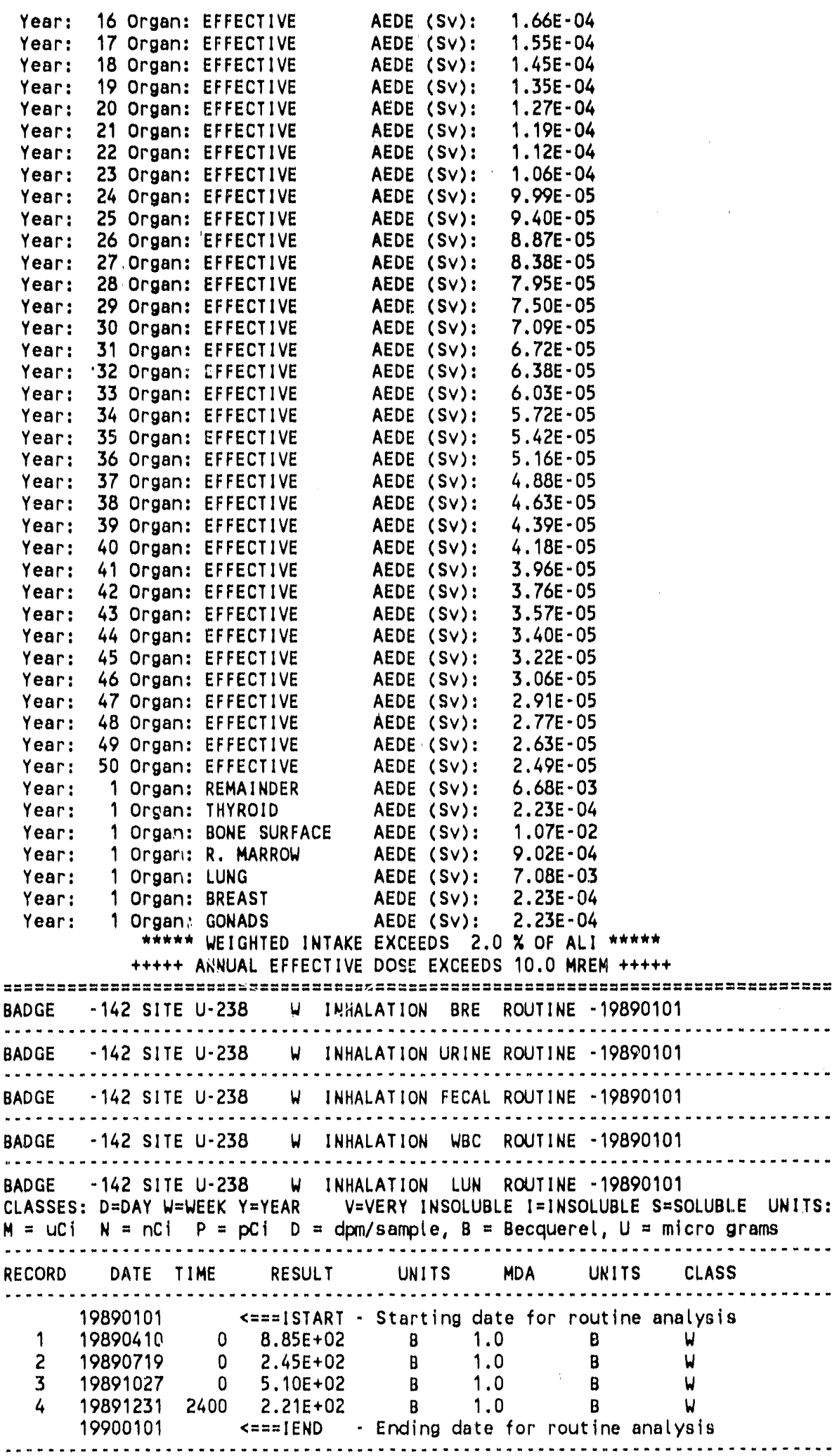




\begin{tabular}{|c|c|c|c|c|c|c|c|}
\hline ECORD & DATE & TIME & RESULT & UNITS & MDA & UNITS & CLASS \\
\hline $\begin{array}{l}1 \\
2 \\
3 \\
4\end{array}$ & $\begin{array}{l}19890101 \\
19890410 \\
19890719 \\
19891027 \\
19891231 \\
19900101\end{array}$ & $\begin{array}{r}0 \\
0 \\
0 \\
2400\end{array}$ & $\begin{aligned} &<== \pm \text { I START } \\
& 885 . \\
& 245 . \\
& 510 . \\
& 221 . \\
&<= \pm=1 \text { IEND }\end{aligned}$ & $\begin{array}{c}\text { - starting } \\
\mathrm{Bq} \\
\mathrm{Bq} \\
\mathrm{Bq} \\
\mathrm{Bq} \\
\text { - Ending }\end{array}$ & $\begin{array}{c}\text { g date fol } \\
1.00 \\
1.00 \\
1.00 \\
1.00 \\
\text { date for }\end{array}$ & $\begin{array}{c}\text { rout ine } \\
B q \\
B q \\
B q \\
B q\end{array}$ & analysis \\
\hline
\end{tabular}

INTAKE RATE (Bq/d) USED TO EXTRAPOLATE BEYOND LAST MEASUREMENT: $0.000 E+00$

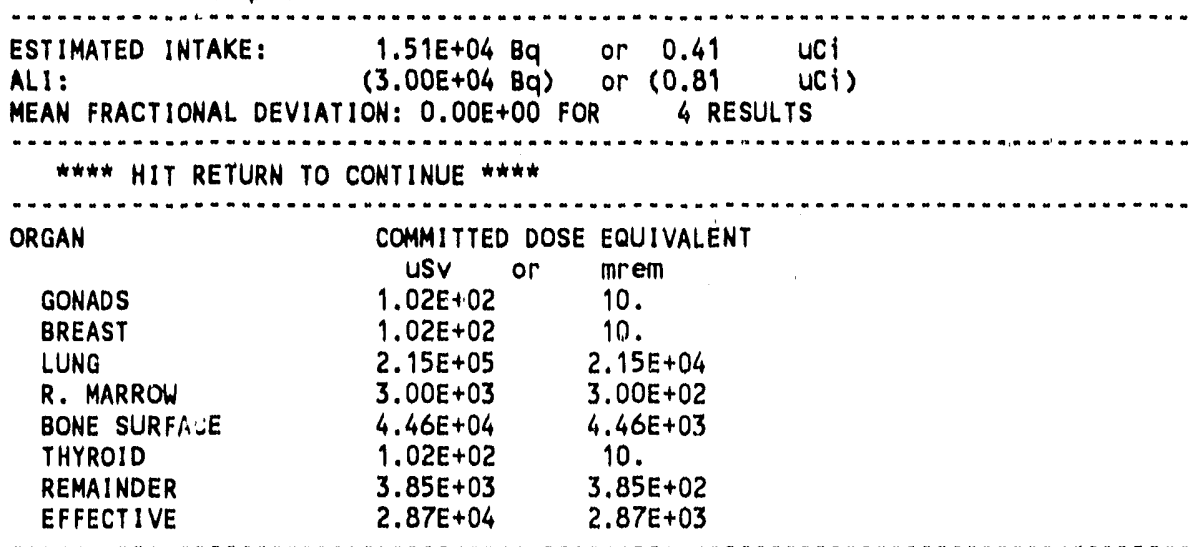

**** HIT RETURN TO CONTINUE $* * * *$

WEIGHTED INTAKE (Bq): $1.51 E+04$ OVER MEASUREMENT PERIO0

WEIGHTED INTAKE (Bq): $1.51 E+04$ OVER INTAKE PERIOD

WEIGHTED CEDE (USV): $2.87 E+04$ FROM INTAKE PERIOD

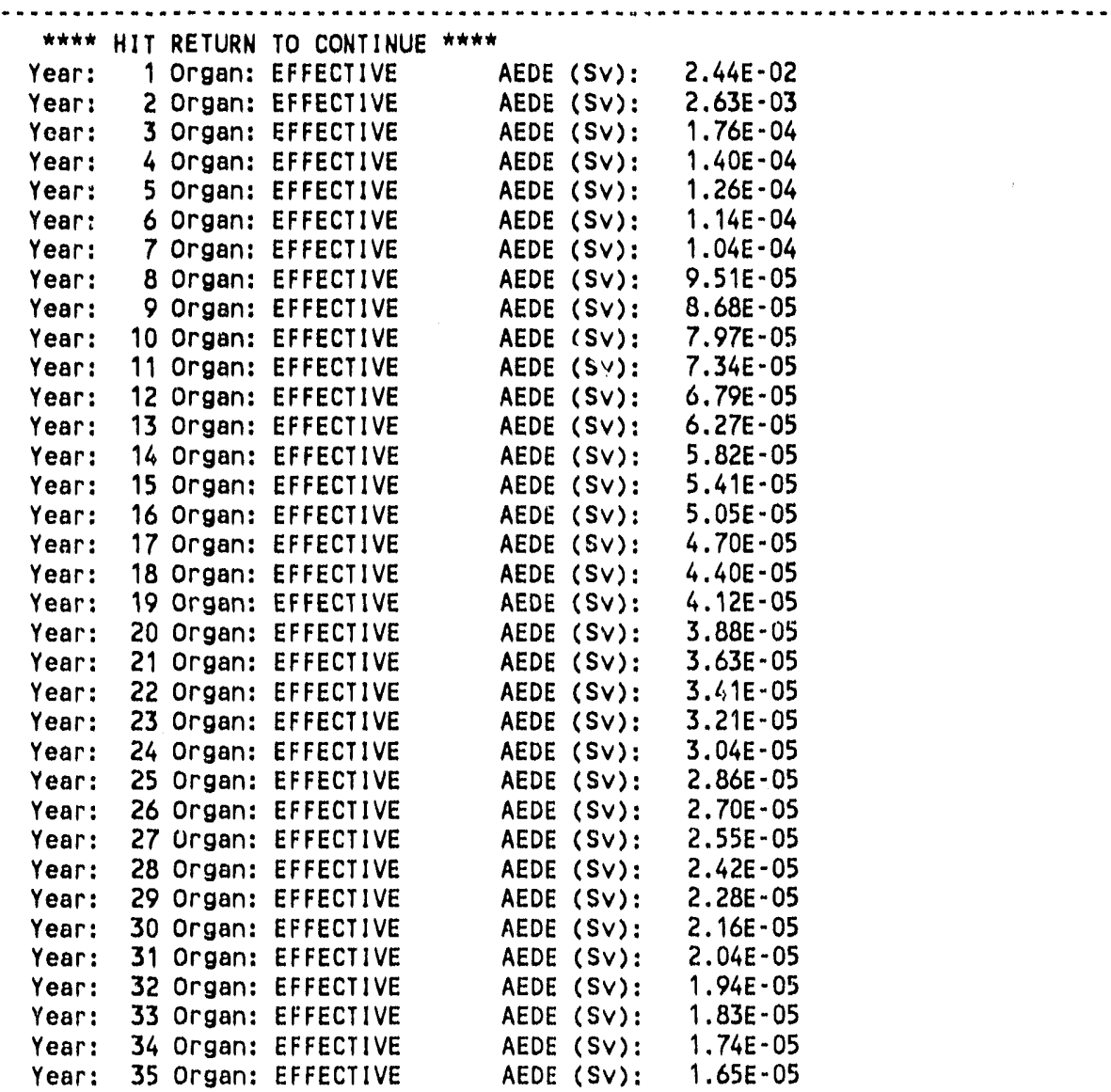




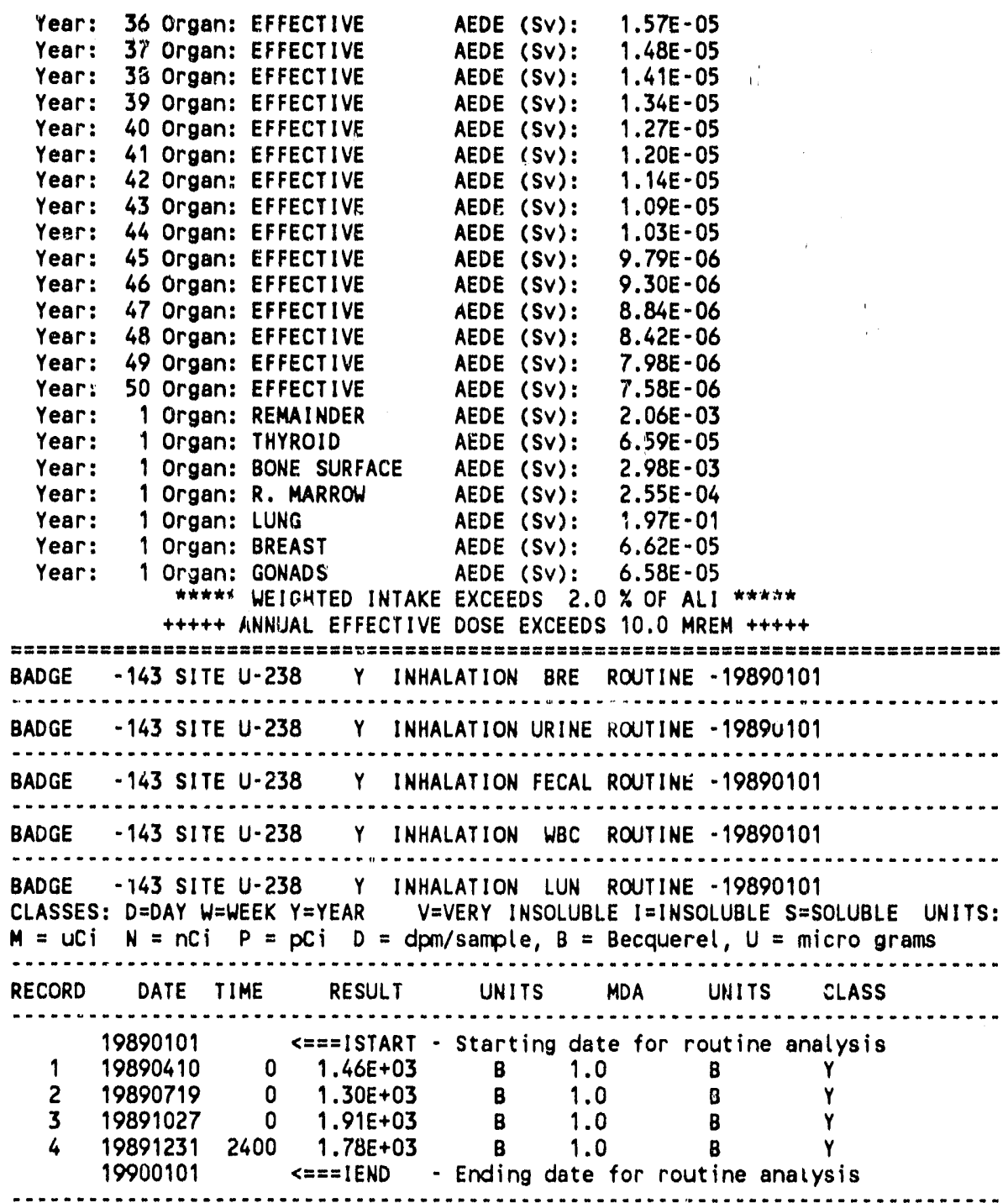

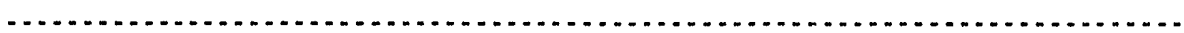

RESULTS SELECTED FOR ROUTINE ANALYSIS:

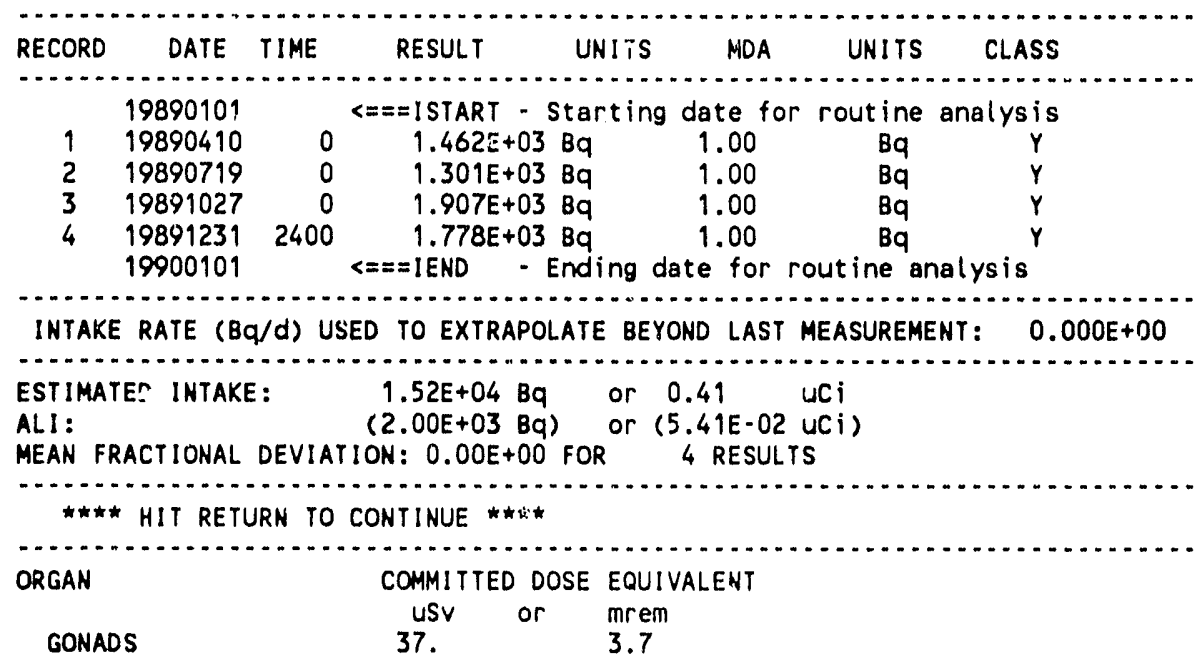




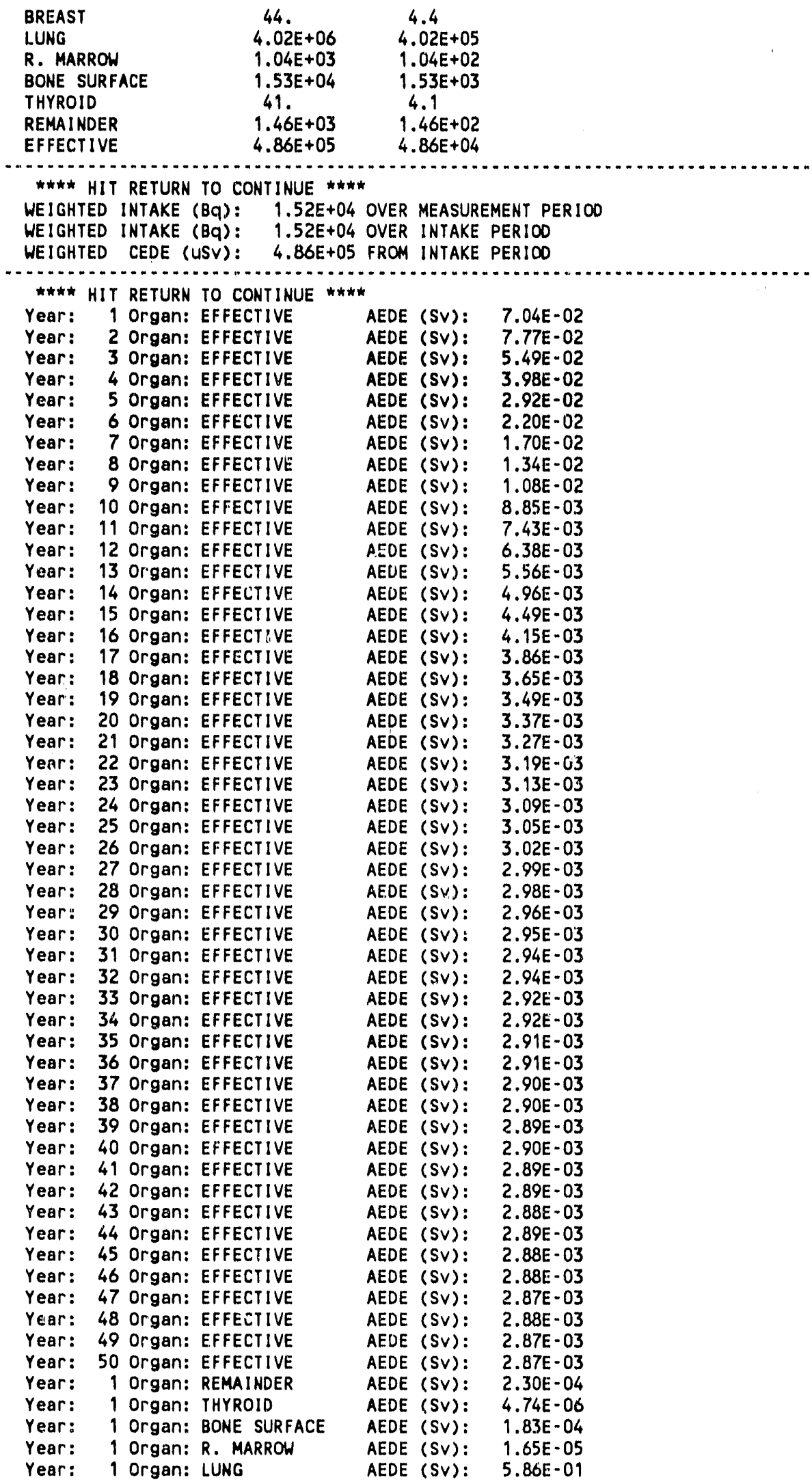




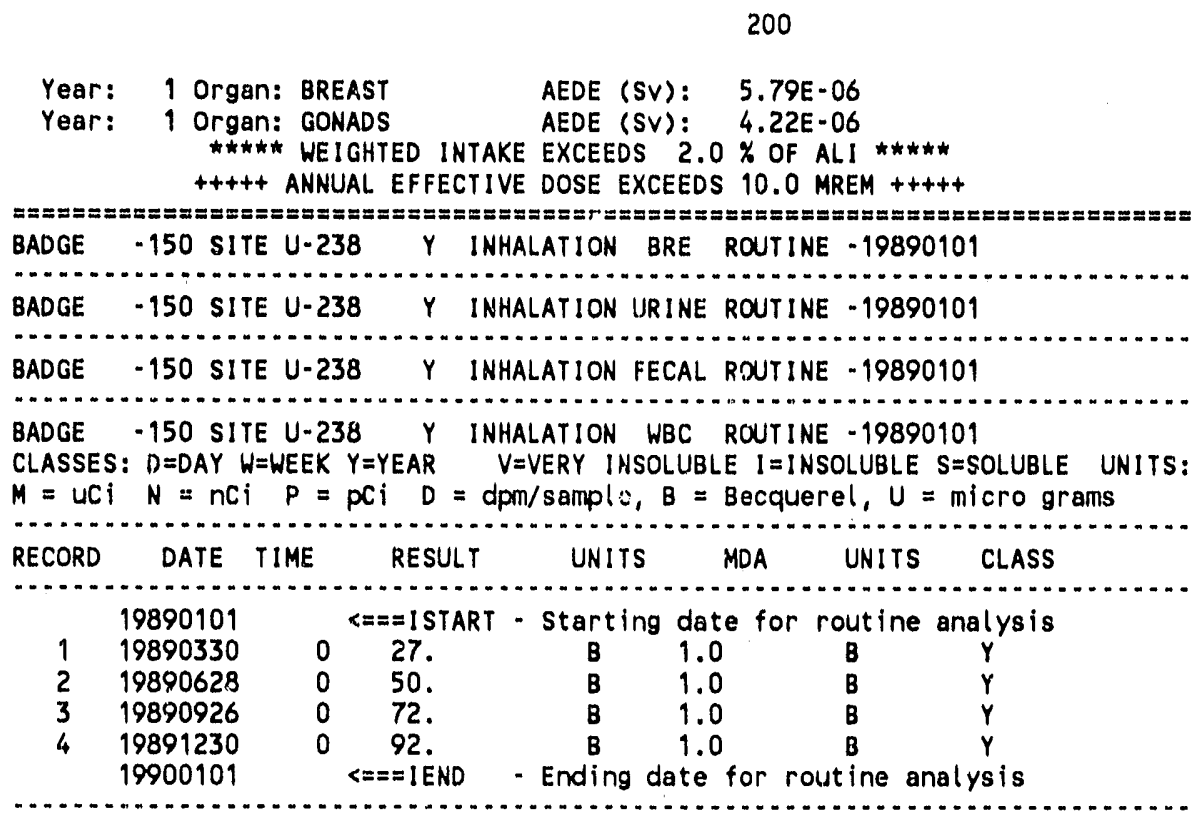

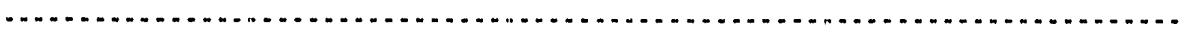

RESULTS SELECTED FOR ROUTINE ANALYSIS:

\begin{tabular}{|c|c|c|c|c|c|c|c|}
\hline RECORD & DATE & TIME & RESULT & UNITS & MDA & UNITS & CLASS \\
\hline $\begin{array}{l}1 \\
2 \\
3 \\
4\end{array}$ & $\begin{array}{l}19890101 \\
19890330 \\
19890628 \\
19890926 \\
19891230 \\
19900101\end{array}$ & $\begin{array}{l}0 \\
0 \\
0 \\
0\end{array}$ & $\begin{aligned} &<===\text { I START } 26.6 \\
& 50.2 \\
& 71.7 \\
& 92.5 \\
&<===\text { IEND }\end{aligned}$ & $\begin{array}{l}\text { - Starting } \\
B q \\
B q \\
B q \\
B q \\
\text { - Ending d }\end{array}$ & $\begin{array}{l}\text { date for } \\
1.00 \\
1.00 \\
1.00 \\
1.00 \\
\text { ate for }\end{array}$ & $\begin{array}{c}\text { rout ine } \\
B q \\
B q \\
B q \\
B q \\
\text { out ine an }\end{array}$ & $\begin{array}{r}\text { analys is } \\
Y \\
Y \\
y \\
Y \\
\text { alys is }\end{array}$ \\
\hline
\end{tabular}

INTAKE RAYE (Bq/d) USED TO EXTRAPOLATE BEYOND LAST MEASUREMENT: $2.000 E+00$

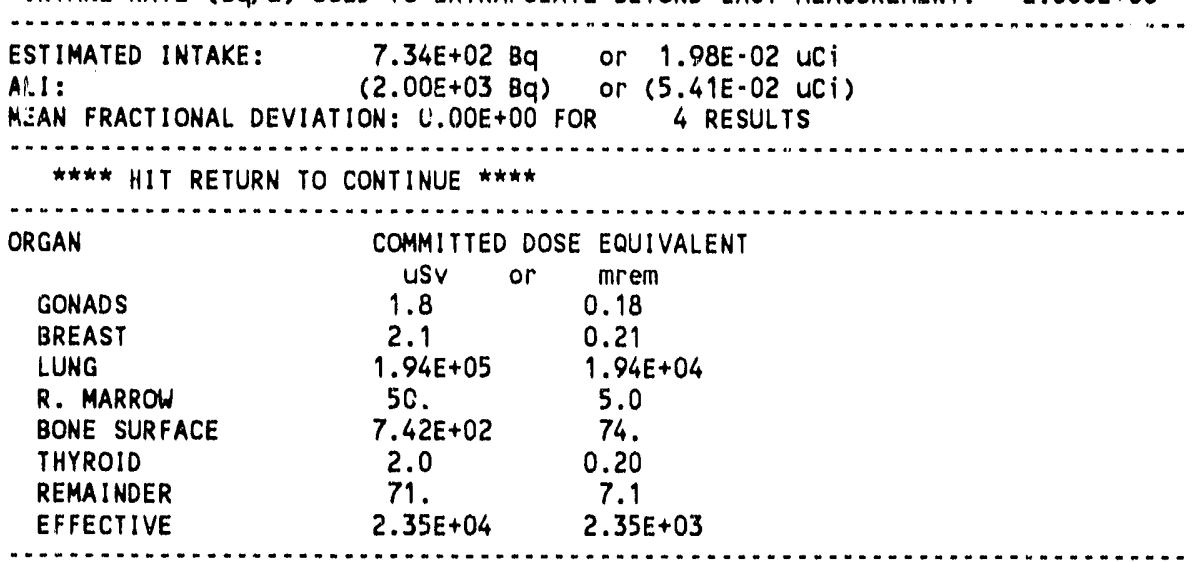

**** HIT RETURN TO CONTINUE ****

BADGE -150 SITE U-238 Y INHALATION LUN ROUTINE - 19890101

CLASSES: $D=D A Y$ W=WEEK $Y=Y E A R \quad V=V E R Y$ INSOLUBLE $1=1$ INSOLUBLE $S=$ SOLUBLE UNITS: $M=U C i \quad N=n C i \quad P=p C i \quad D=d p m /$ sample, $B=$ Becquerel, $U=$ micro grans

\begin{tabular}{|c|c|c|c|c|c|c|c|}
\hline RECORD & DATE & TIME & RESULT & UNITS & MDA & UNITS & CLASS \\
\hline $\begin{array}{l}1 \\
2 \\
3 \\
4\end{array}$ & $\begin{array}{l}1989010 \\
19890330 \\
19890628 \\
19890926 \\
19891230 \\
1990010\end{array}$ & $\begin{array}{l}0 \\
0 \\
0 \\
0\end{array}$ & $\begin{aligned}<== & =\text { ISTART } \\
& 13 . \\
& 25 . \\
& 36 . \\
& 46 . \\
<= & =\text { IEND }\end{aligned}$ & $\begin{array}{c}\text { Starting } \\
\text { B } \\
B \\
B \\
B \\
\text { Encing d }\end{array}$ & $\begin{array}{l}\text { date fo } \\
1.0 \\
1.0 \\
1.0 \\
1.0 \\
\text { ate for }\end{array}$ & $\begin{array}{c}\text { r routine } \\
B \\
B \\
B \\
B \\
\text { routine ar }\end{array}$ & $\begin{array}{c}\text { analysis } \\
y \\
y \\
y \\
y \\
\text { analys is }\end{array}$ \\
\hline
\end{tabular}




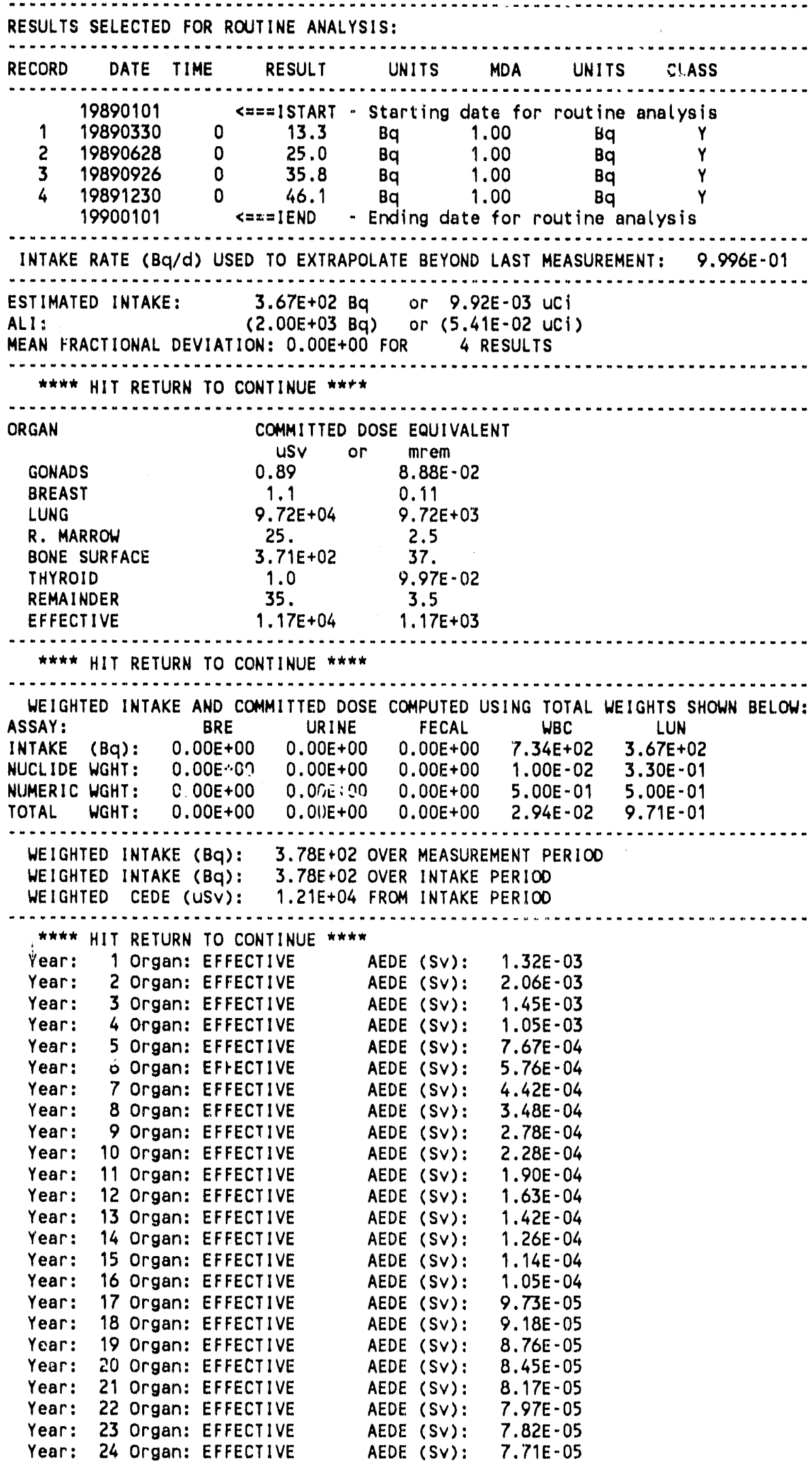




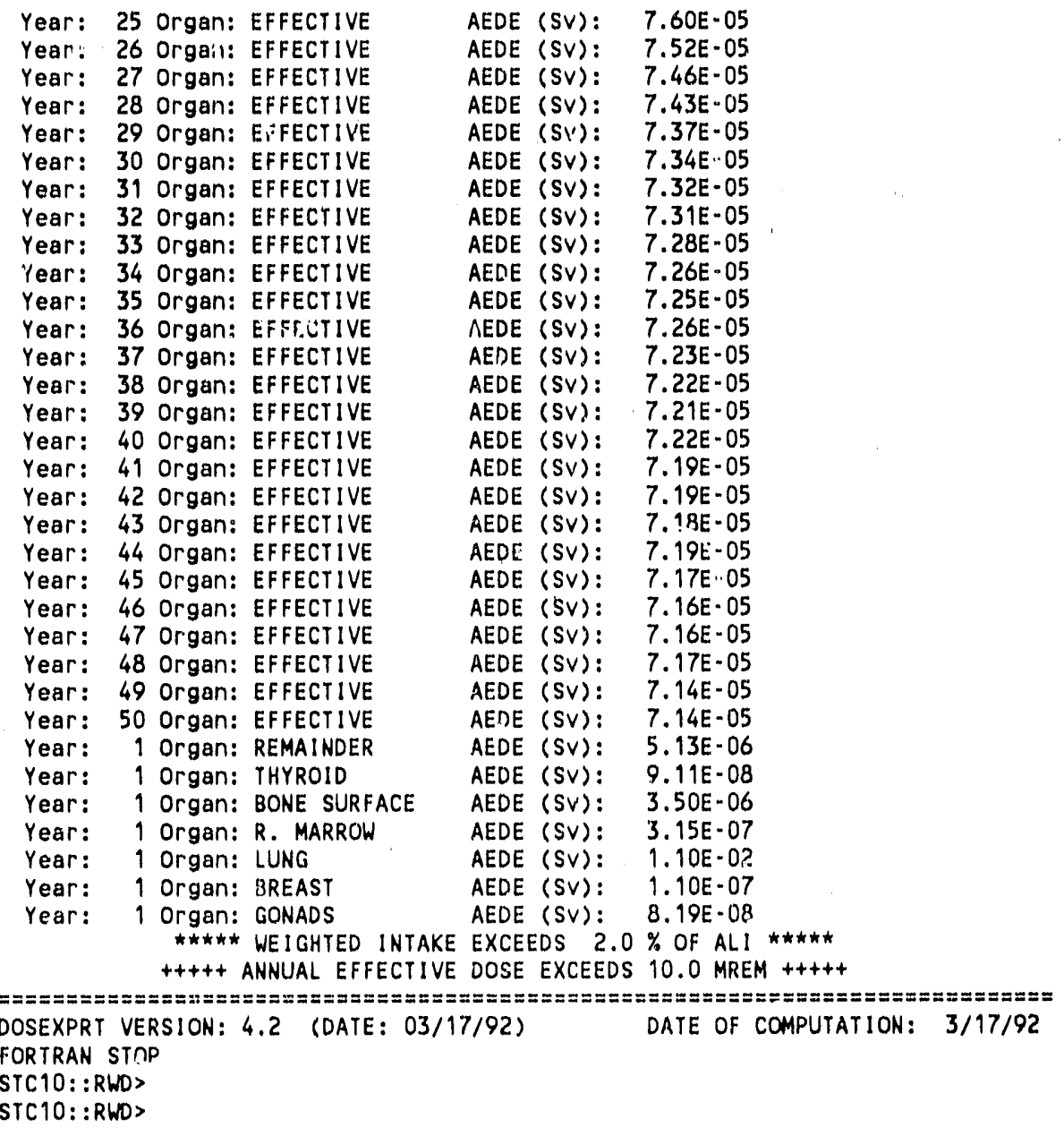




\section{Appendix K \\ LISTINGS OF DOSEXPRT OUTPUT FILES FOR EXAMPLE PROBLEMS}

This appendix contains ihe DOSEXPRT S28 output listings for the INCIDENT and ROUTINE examples discussed in the text. In addition, it contains the output listings from DOSREPORT.

\section{INCIDENT.S28}

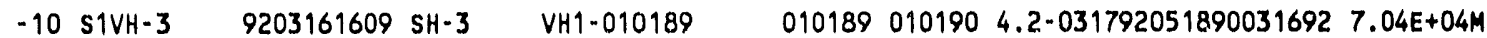

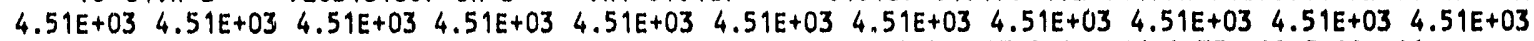
$\begin{array}{llllll}4.51 E+03 \quad 4.51 E+03 \quad 4.51 E+03 \quad 4.51 E+03 \quad 4.51 E+031989 & 1.00 E+00 & 1.40 E+03 \quad 2.00 E+01 & 1.35 E+02 & 2.00 E+01\end{array}$

$12.00 E+001.00 E+001.00 E+00$ RREO 0.000 U $1.000 * \mathrm{~F} 0.000$ WBCO.000 LUNO.000 ORGO.000 460001018901019011989

$\begin{array}{lllll}-20 \text { S1DI-131 } 9203161609 \text { SI-131 DH1-020189 } 010189010190 \quad 4.2-031792031291031692 & 1.96 E+02 M\end{array}$

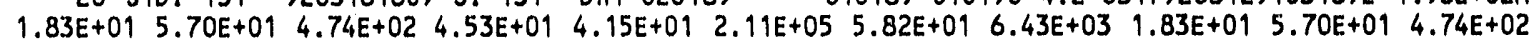

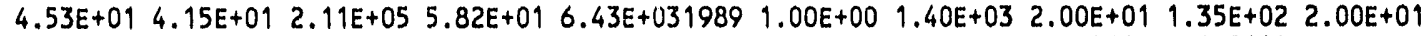

$i 2.00 E+001.00 E+001.00 E+00 B R E 0.000 \mathrm{U} \quad 0.756^{*} \mathrm{~F} \quad 0.000$ WBCO.000 LUNO.000 THYO.244* 650001018901019011989

-31 S1DU-238 9203161609 SU-238 DH1-020189 $0101890101904.2-031792051890031692 \quad 4.73 E-03 M$ $\begin{array}{lllllllllll}3.90 E-01 & 3.90 E-01 & 4.88 E+00 & 1.15 E+01 & 1.72 E+02 & 3.88 E-01 & 1.44 E+01 & 1.16 E+01 & 2.40 E-01 & 2.40 E-01 & 4.82 E+00\end{array}$

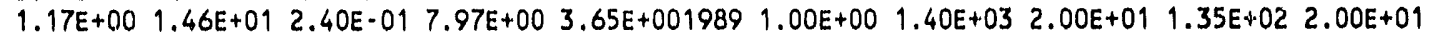

$12.00 E+001.00 E+00 \quad 1.00 E+00 B R E 0.000 \mathrm{U}$ 1.000* $\mathrm{F} \quad 0.000$ WBCO.000 LUNO.000 ORGO. 00 10001018901019011989

-32 S1DU-238 9203161609 SU-238 DH1-020189 $0101890101904.2-0317920518900316927.81 E-03 M$

$\begin{array}{lllllllllll}6.44 E-01 & 6.44 E-01 & 8.06 E+00 & 1.90 E+01 & 2.83 E+02 & 6.41 E-01 & 2.37 E+01 & 1.91 E+01 & 3.97 E-01 & 3.97 E-01 & 7.96 E+00\end{array}$

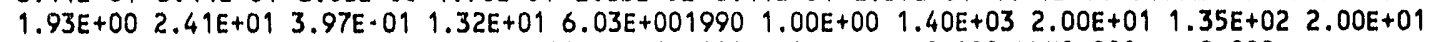

1 2.00E 1.00 1.00E+00 1.00E+DOBREO.000 U 1.000* 0.000 WBCO.000 I.UNO.000 ORGO.000 10001018901019011989

$\begin{array}{llllll}-33 \text { S1OU-238 } 9203161609 \text { SU-238 DH1-020189 } 010187010190 \quad 4.2-031792051890031692 & 4.90 E-04 M\end{array}$

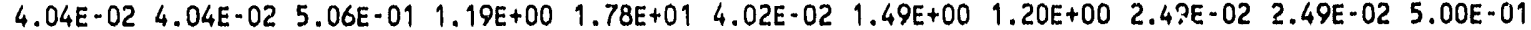

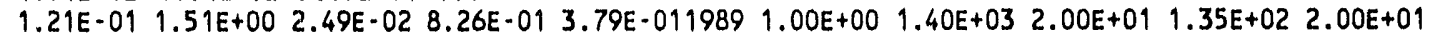

$12.00 E+001.00 E+001.00 E+00 B R E 0.000$ U $1.000 * F \quad 0.000$ WBC0.000 LUNO.000 ORGO.0กO 10001018901019011989

-41 S1DCS-1379203161609 SCS-137 DH1-010189 $0101890101904.2-031792051890031692 \quad 2.54 E-02 M$

8.21E-01 7.35E-01 8.27E-01 7.79E-01 7.44E-01 7.44E-01 8.56E-01 8.10E-01 7.46E-01 5.94E-01 7.45E-01

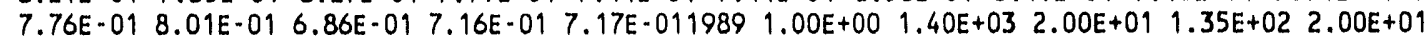

$12.00 E+001.00 E+00 \quad 1.00 E+00 B R E 0.000$ U $0.000 \mathrm{~F} \quad 0.000$ WBC $1.000 *$ LUNO.000 ORGO.000 10001018901019011989

-42 S1DCS-1379203161609 SCS-137 DH1-010189 010189 $010190 \quad 4.2-031792051890031692 \quad 6.49 E-02 M$

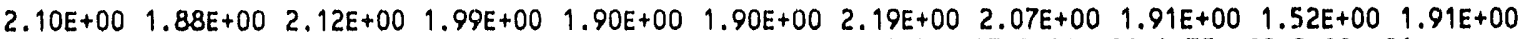

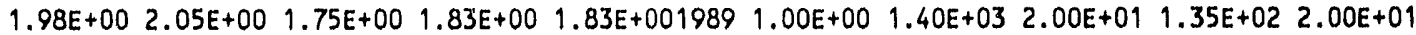

$12.00 E+001.00 E+001.00 E+00 B R E 0.000 \cup 0.000$ F 0.000 WBC $1.000 *$ LUNO.000 ORGO.000 100010189010190,1989

-50 S1DI-131 9203161609 SI-131 DH1+021189 $010189010190 \quad 4.2-0317920312910316929.81 E+01 M$

$\begin{array}{lllllllllll}9.19 E+00 & 2.86 E+01 & 2.38 E+02 & 2.28 E+01 & 2.08 E+01 & 1.06 E+05 & 2.92 E+01 & 3.23 E+03 & 9.19 E+00 & 2.86 E+01 & 2.38 E+02\end{array}$

$2.28 E+01 \quad 2.08 E+01 \quad 1.06 E+05 \quad 2.92 E+01 \quad 3.23 E+0319891.00 E+00 \quad 1.40 E+03 \quad 2.00 E+01 \quad 1.35 E+02 \quad 2.00 E+01$

$12.00 E+00 \quad 1.00 E+00 \quad 1.00 E+00 B R E 0.000$ U $0.756 * \mathrm{~F} \quad 0.000$ WBC 0.000 LUNO.000 THYO.244* 3300010189010190,1989

60 S1STC-99 9203161609 STC-99 SG1-010189 $0101890101904.2-031792051890031692 \quad 3.50 E-03 M$

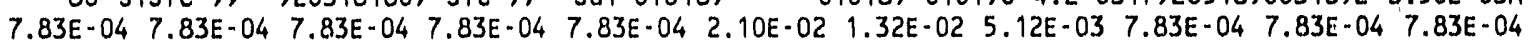

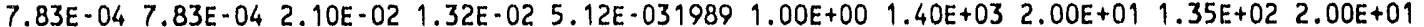

1 2. $00 E+001.00 E+001.00 E+008 R E 0.000$ U $1.000 * \mathrm{~F} \quad 0.000$ WBCO.000 LUNO.000 ORGO.000 10001018901019011989

-70 S1 TC-99 9203161609 STC-99 J1-010189 $0101890101904.2-031792051890031692 \quad 2.21 E-03 M$

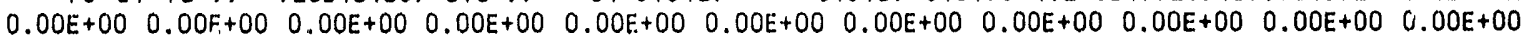

$\begin{array}{llllllllll}0.00 E+00 & 0.00 E+00 & 0.00 E+00 & 0.00 E+00 & 0.00 E+001989 & 1.00 E+00 & 1.40 E+03 & 2.00 E+01 & 1.35 E+02 & 2.00 E+01\end{array}$

$12.00 E+001.00 E+001.00 E+00 B R E 0.000$ U $0.000 \mathrm{~F} 1.000 * W B C 0.000$ LUNO.000 ORGO.000 001018901019001989 
-90 S1 SR-90 9203161609 SSR-90 J1-010189 $0101890101904.2-031792051890031692 \quad 1.17 E-03+4$ $\begin{array}{lllllllllllllll}0.00 E+00 & 0.00 E+00 & 0.00 E+00 & 0.00 E+00 & 0.00 E+00 & 0.00 E+00 & 0.00 E+00 & 0.00 E+00 & 0.00 E+00 & 0.00 E+00 & 0.00 E+00\end{array}$

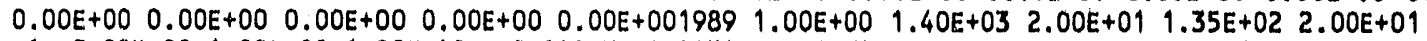

1 2.00E+00 1.00E+00 1.00E+OOBREO.000 U 0.903*F 0.097 *WBCO.000 LUNO.000 ORGO.000 001018901019001989

-100 S1WPU-2419203161609 SPU-241 WH1-010189 $0101890101904.2-031792042590031692 \quad 3.25 E-04 M$

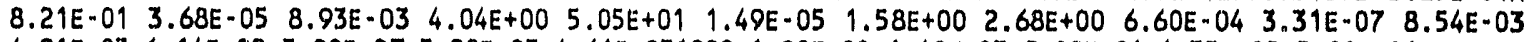

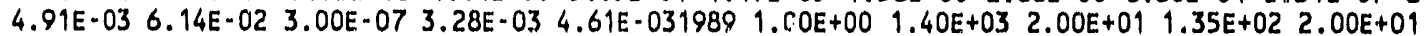

$12.00 E+001.00 E+001.00 E+00 B R E 0.000 \cup 1.000 * F \quad 0.000$ WBCO.000 LUNO.000 ORGO.000 10001018901019011989

-110 S1WPU-238 9203161609 SPU-238 WHI-0901891100 $010189010190 \quad 4.2-031792051889031692 \quad 4.97 E-04 M$

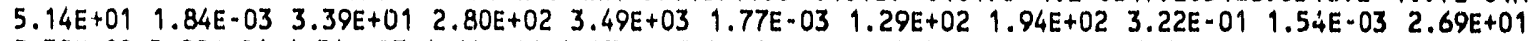
$2.38 E+002.98 E+01 \quad 1.54 E=03 \quad 1.60 E+00 \quad 4.97 E+0020391.00 E+00 \quad 1.40 E+03 \quad 2.00 E+01 \quad 1.35 E+022.00 E+01$

$12.00 E+00 \quad 1.00 E+00 \quad 1.00 E+00 B R E 0.000$ U $0.000 \mathrm{~F} \quad 1.000 * W B C 0.000$ LUNO.000 URGO.000 20001018901019011989

\section{ROUTINE.S28}

$\begin{array}{lllll}-120 \text { S3DI-131 } 9203161608 \text { SI-131 DH3-010189 } 010189010190 \quad 4.2-031792031291031692 & 1.97 E+01 M\end{array}$

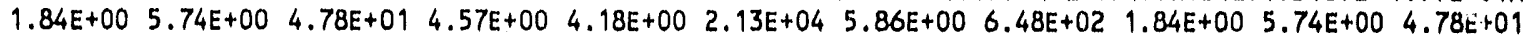
$4.57 E+00 \quad 4.18 E+002.13 E+04 \quad 5.86 E+00 \quad 6.48 E+0219891.00 E+00 \quad 1.40 E+03 \quad 2.00 E+01 \quad 1.35 E+02 \quad 2.00 E+01$

$12.00 E+00 \quad 1.00 E+001.00 E+00 B R E 0.000$ U $0.000 \mathrm{~F} \quad 0.000$ WBCO.000 LUNO.000 THY1.000* 70001018901019011989

- 131 S3Dli-238 9203161608 SU-238 DH3-010189 $0101890101904.2-031792051890031692 \quad 9.87 E-01 M$

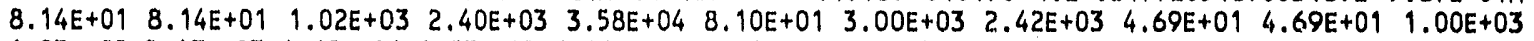

$\begin{array}{lllllll}1.83 E+02 & 2.17 E+03 \quad 4.69 E+01 & 1.53 E+03 \quad 6.86 E+022039 & 1.00 E+00 & 1.40 E+03 \quad 2.00 E+01 & 1.35 E+02 & 2.00 E+01\end{array}$

$12.00 E+00 \quad 1.00 E+001.00 E+00 B R E 0.000$ U $0.000 \mathrm{~F} \quad 0.000$ WBC 0.000 LUN $1.000^{*}$ ORGO.000 250001018901019011989

$\begin{array}{llllll}-132 \text { S3WU-238 } 9203161608 \text { SU-238 WH3-010189 } 010189010190 \quad 4.2-031792051890031692 & 9.88 E-01 M\end{array}$

$\begin{array}{lllllllllll}2.45 E+01 & 2.47 E+01 & 5.19 E+04 & 7.24 E+02 & 1.08 E+04 & 2.45 E+01 & 9.30 E+02 & 6.93 E+03 & 1.31 E+01 & 1.32 E+01 & 4.10 E+04\end{array}$

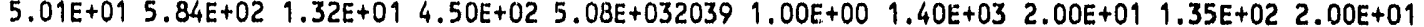

$12.00 E+001.00 E+001.00 E+00 B R E 0.000$ U $0.000 \mathrm{~F} \quad 0.000$ WBCO.000 LUN $1.000 * 0 R G 0.000$ 7000010189010190,1989

$\begin{array}{llllll}-133 \text { S3YU-238 } 9203161608 \text { SU-238 YH3-010189 } 010189010190 \quad 4.2-031792051890031692 & 9.87 E_{-}-01 M\end{array}$

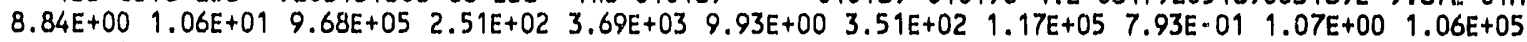

$3.05 E+003.38 E+018.82 E-014.96 E+01 \quad 1.28 E+0420391.00 E+00 \quad 1.40 E+03 \quad 2.00 E+011.35 E+022.00 E+01$

1 2.00E+00 1.00E+00 1.00E+OOBRE0.000 U $0.000 \mathrm{~F} \quad 0.000$ WBCO.000 LUN $1.000 *$ ORGO.000 11700001018901019011989

$\begin{array}{lllll}-141 \text { S3DU-238 } 9203161608 \text { SU-238 OH3-010187 } 010189010190 \quad 4.2-031792051890031692 & 4.07 E-01 M\end{array}$

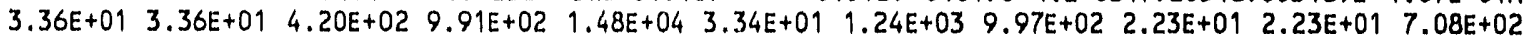

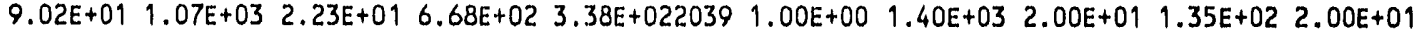

$12.00 E+001.00 E+001.00 E+00 B R E 0.000$ U $0.000 \mathrm{~F} \quad 0.000$ WBCO.000 LUN1.000*ORGO.000 100001018901019011989

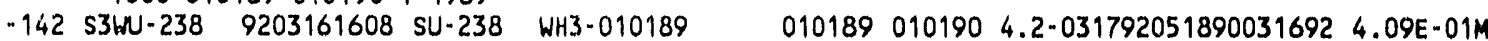

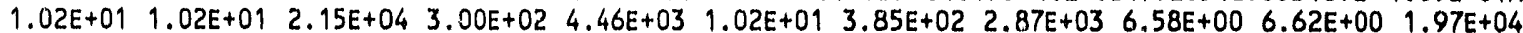

$2.55 E+012.98 E+02 \quad 6.59 E+00 \quad 2.06 E+02 \quad 2.44 E+032032 \quad 1.00 E+00 \quad 1.40 E+03 \quad 2.00 E+01 \quad 1.35 E+022.00 E+01$

$12.00 E+00 \quad 1.00 E+001.00 E+00 B R E 0.000$ U $0.000 \mathrm{~F} \quad 0.000$ WBCO.000 LUN1.000*ORGO.000 290001018901019011989

- 143 S3YU-238 9203161608 SU-238 YH3-010189 $010189010190 \quad 4.2-031792051890031692 \quad 4.10 E-01 M$

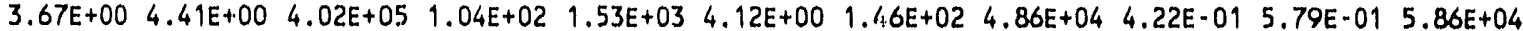

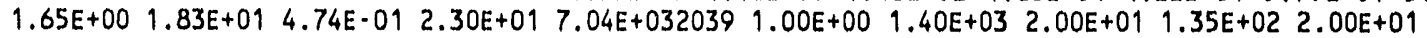

$12.00 E+00 \quad 1.00 E+00 \quad 1.00 E+00 B R E 0.000$ U $0.000 \mathrm{~F} \quad 0.000$ WBCO.000 LUN $1.000 *$ ORGO.000 4860001018901019011989

$\begin{array}{llllllll}-150 \text { S3YJ-238 } 9203161608 \text { SU-238 YH3-010189 } 010189010190 \quad 4.2-031792051890031692 & 1.02 E-02 M\end{array}$ 9.14E-02 $\quad 1.10 E-01 \quad 1.00 E+04 \quad 2.59 E+00 \quad 3.82 E+01 \quad 1.03 E-01 \quad 3.63 E+00 \quad 1.21 E+03 \quad 8.19 E-03 \quad 1.10 E-02 \quad 1.10 E+03$

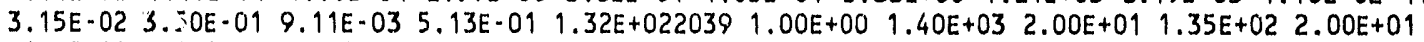

$12.00 E+001.00 E+001.00 E+00 B R E 0.000$ U 0.000 F 0.000 WBCO.029*LUNO.971*ORGO.000 $1300010189010190 \uparrow 1989$ 

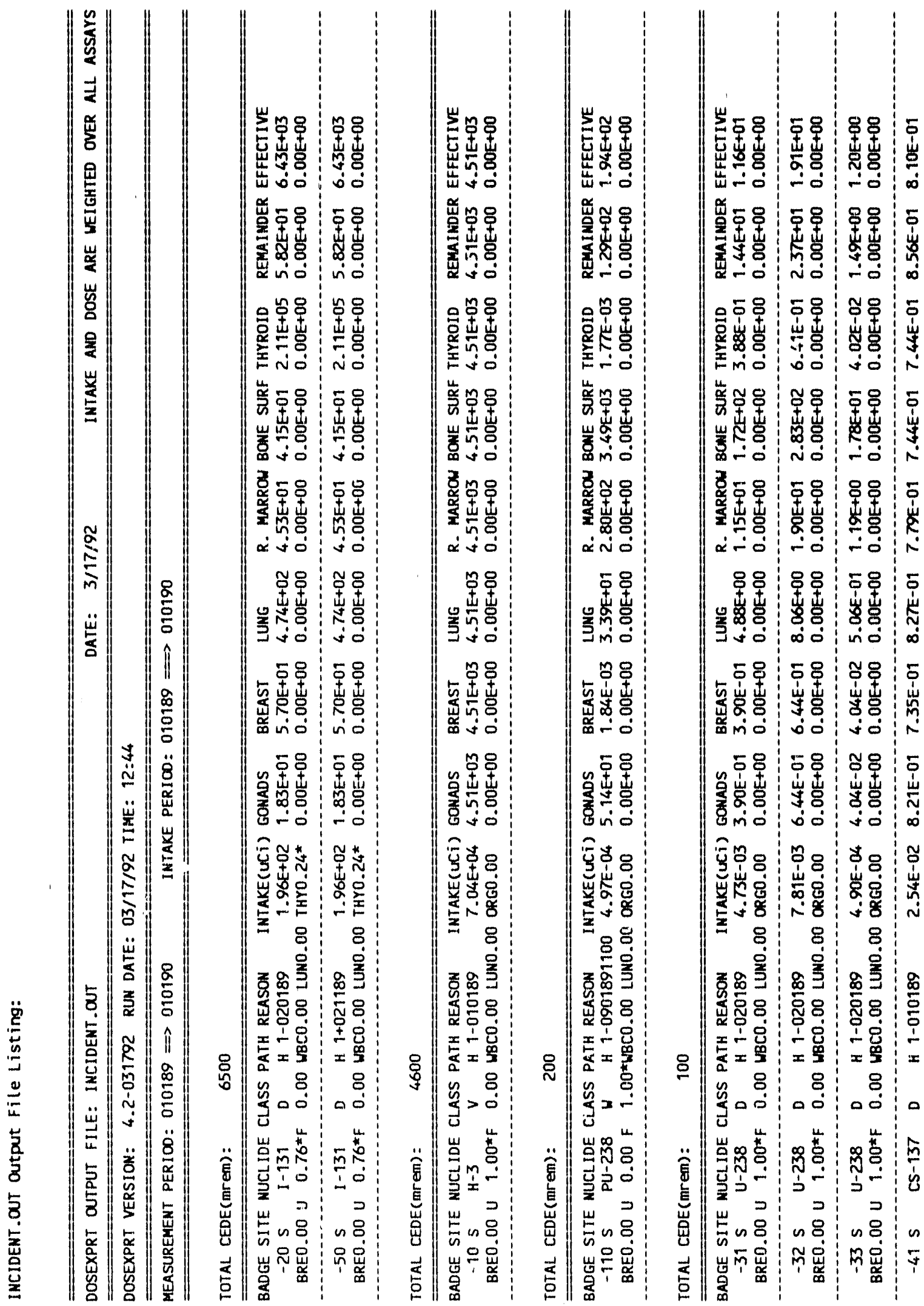


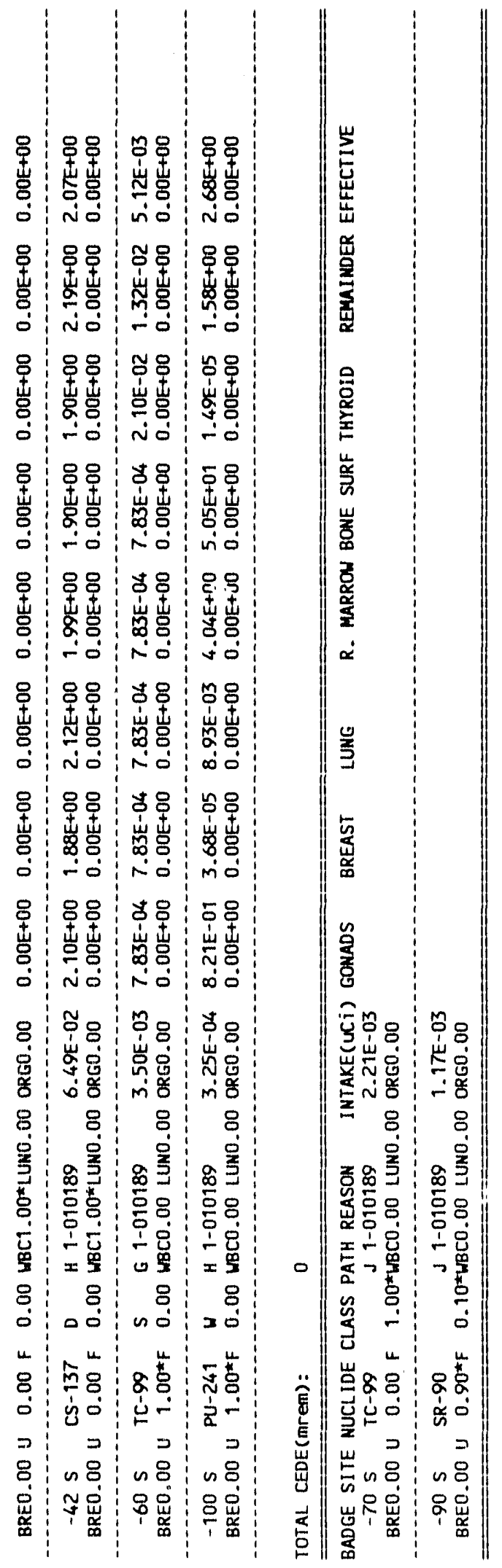




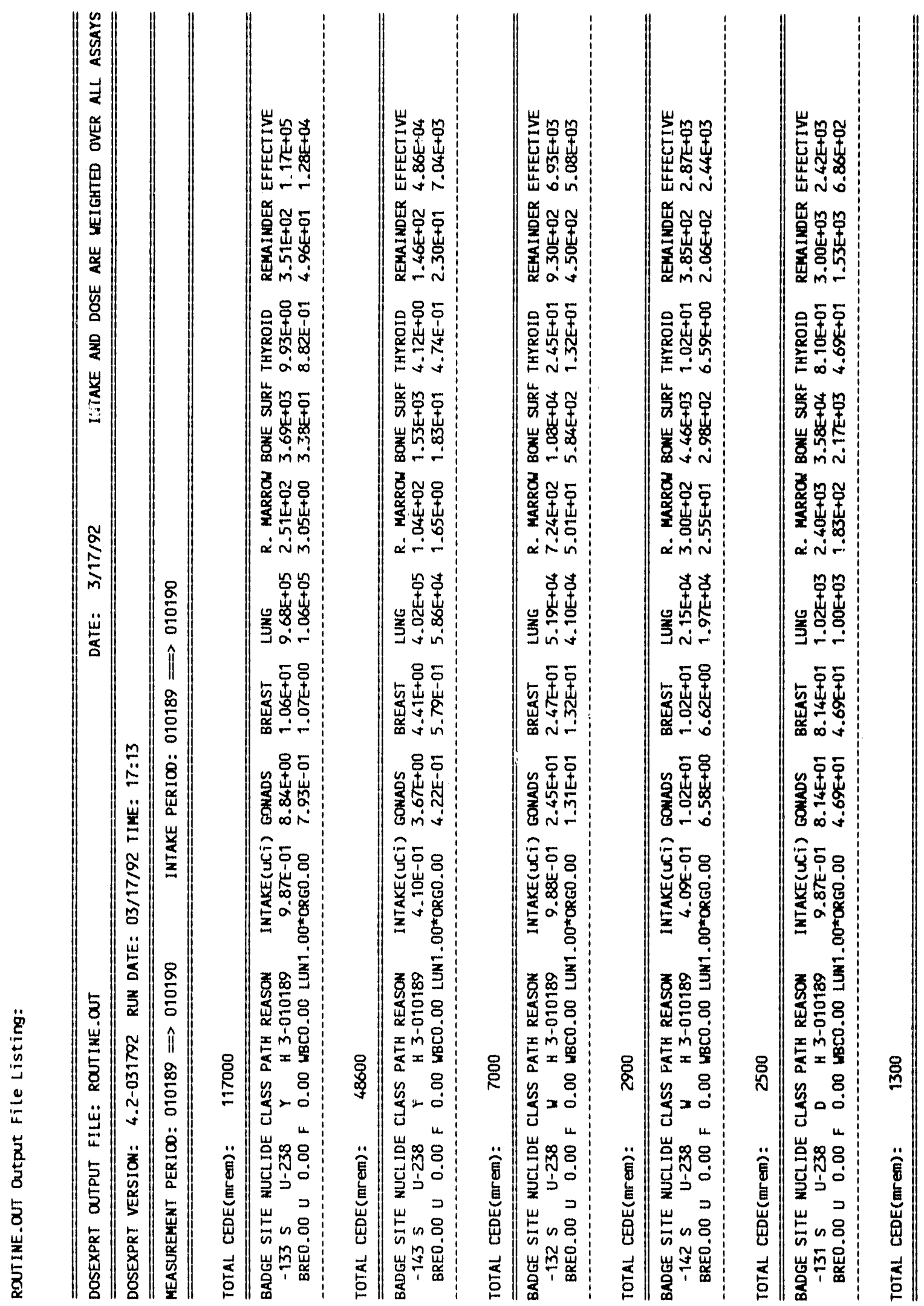




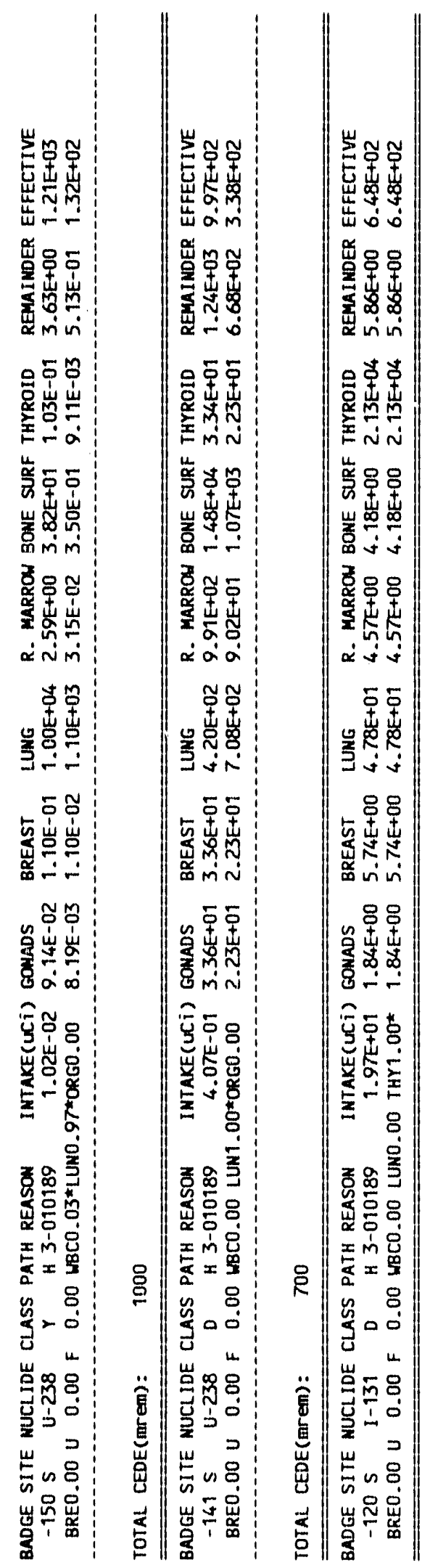




\section{Appendix L \\ LISTINGS OF DOSEXPRT AUXILIARY OUTPUT FILES FOR EXAMPLE PROBLEMS}

DOSEXPRT 4.2 produces some auxillary output files which are discussed in this appendix. The first two such files were added with Ver. 4.1 of DOSEXPRT. The first file (with extension ANI) lists the annual effective dose (in mrem) by year, projecting out 50 years, for incident exposure to nuclides that have dose-rate files. The format for the ANI file is as follows: 30 lines of text followed by, for each case, a header line and five lines containing the annual effective dose by year using exponential format with each number occupying ten spaces separated by a single space. The ANI file is uploaded into a data base on OHIS. The INCIDENT.ANI file produced from the INCIDENT data file is shown on the following page.

The second file (with extension ANR) lists the annual effective dose (in mrem) by year, projecting out 50 years, for routine exposure to nuclides that have dose-rate files. The format for the ANR file is the same as the ANI lile, except that the annual effective dose is listed until it drops below zero. The ANR lile is not uploaded into a data base on OHIS. The ROUTINE.ANR file produced from the ROUTINE data file is shown following the INCIDENT.ANI listing. 


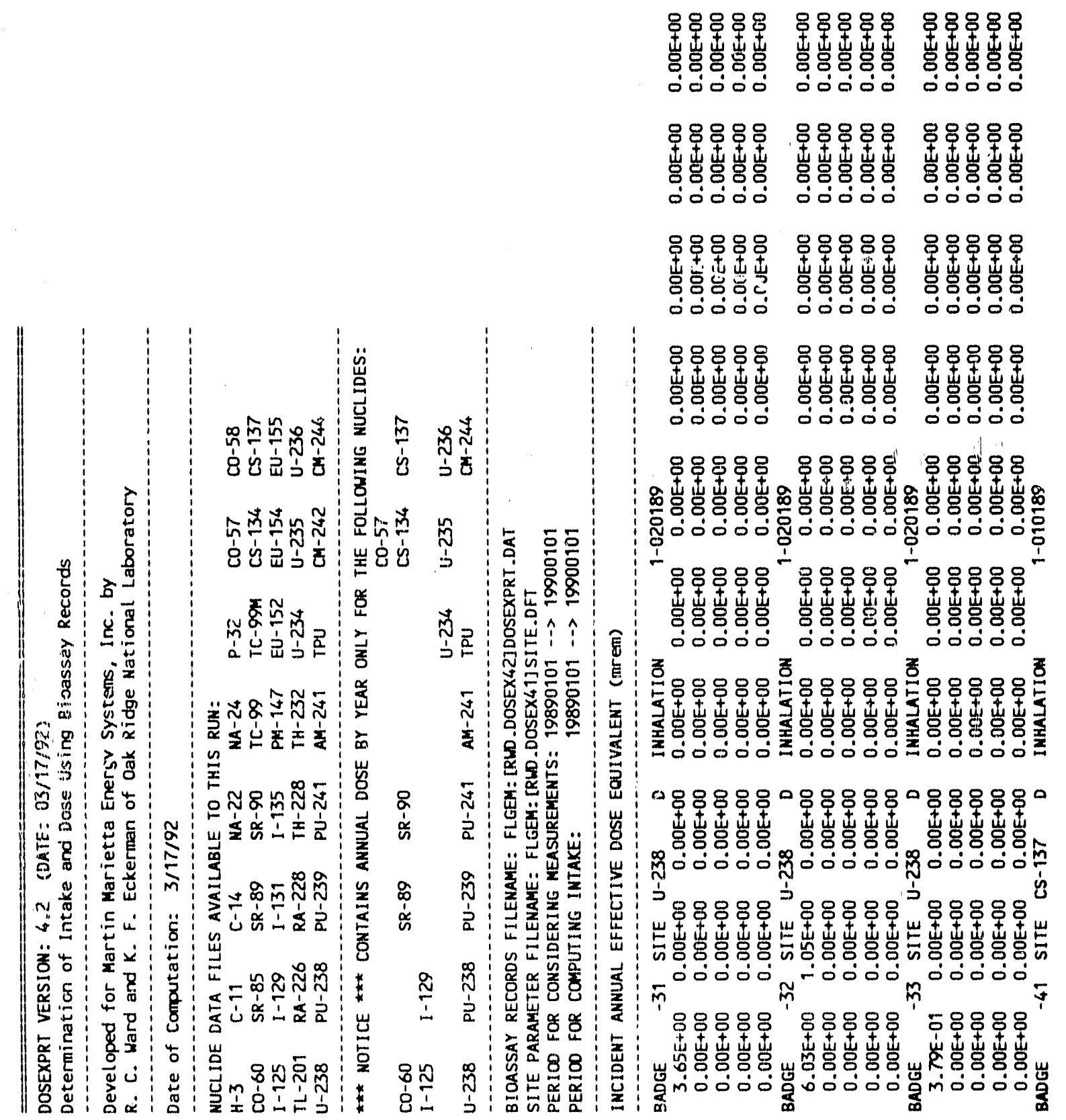



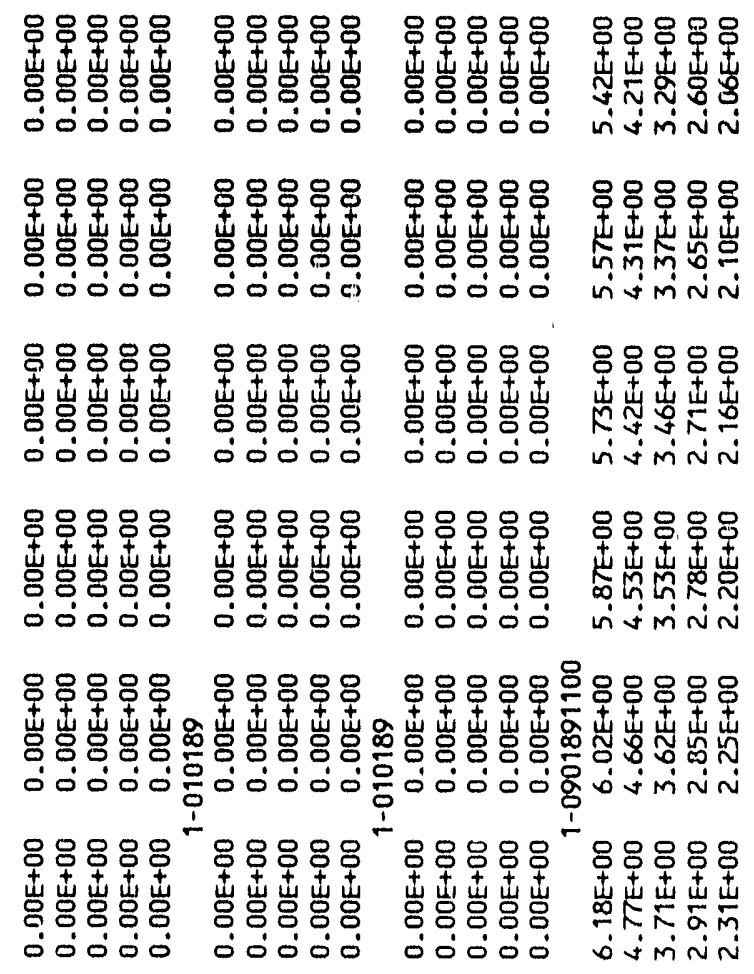

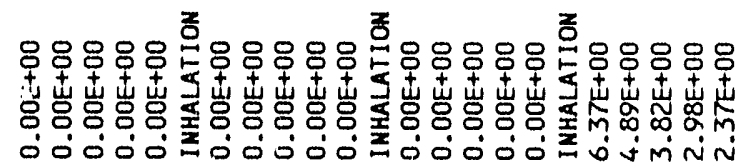

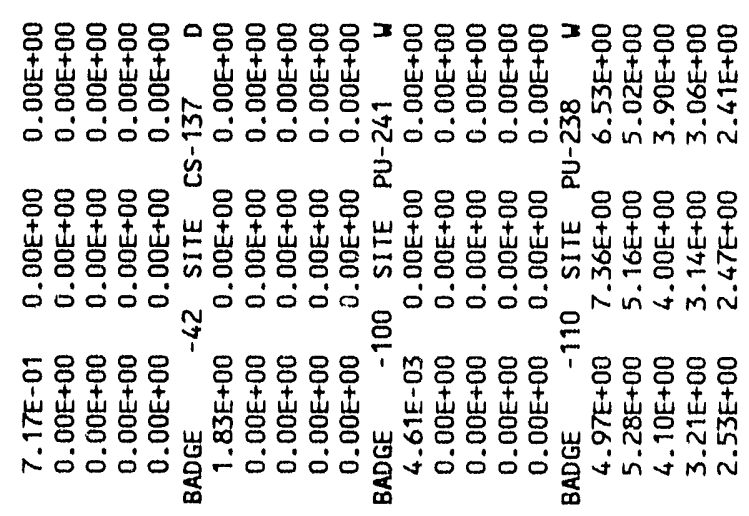




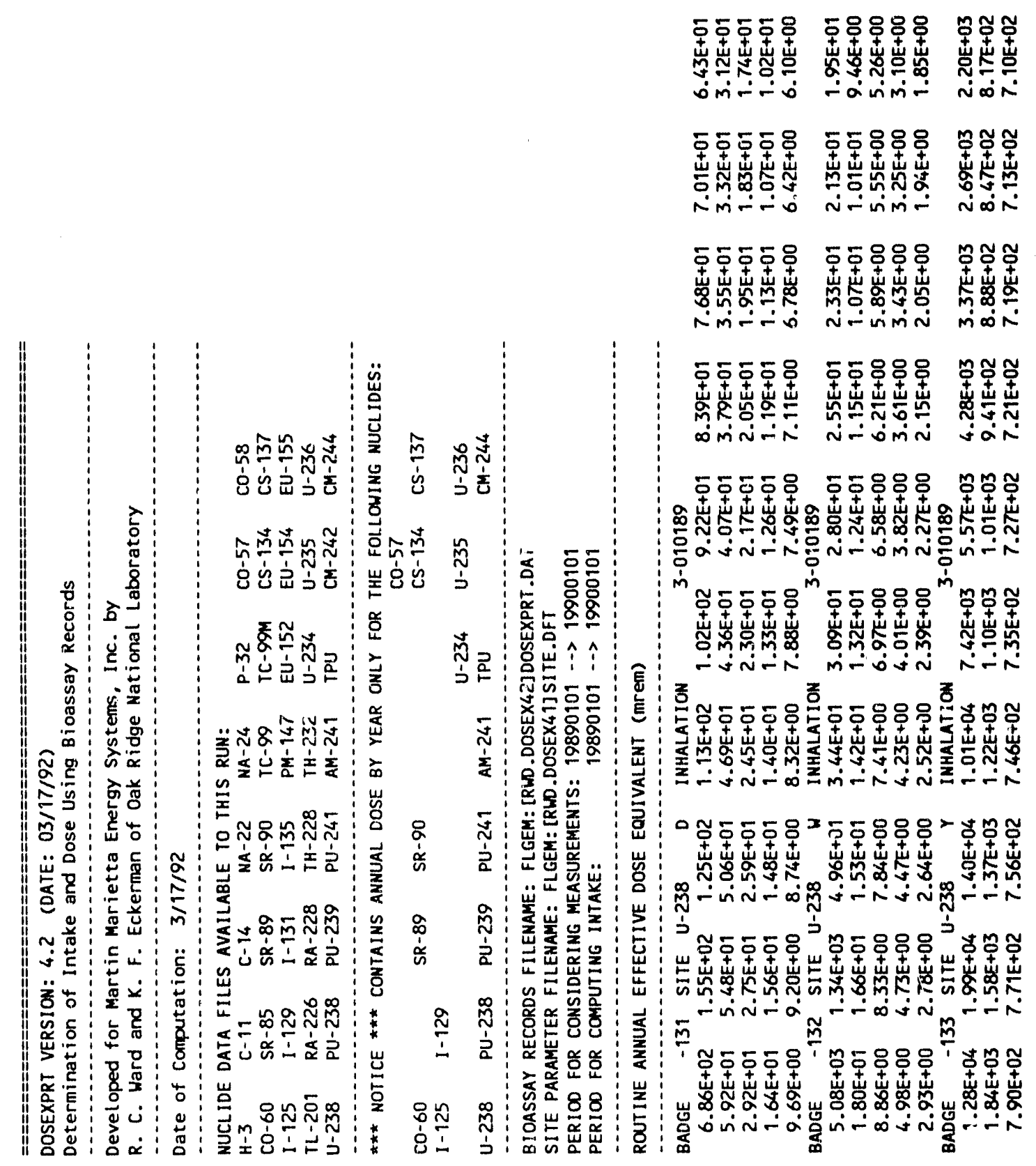




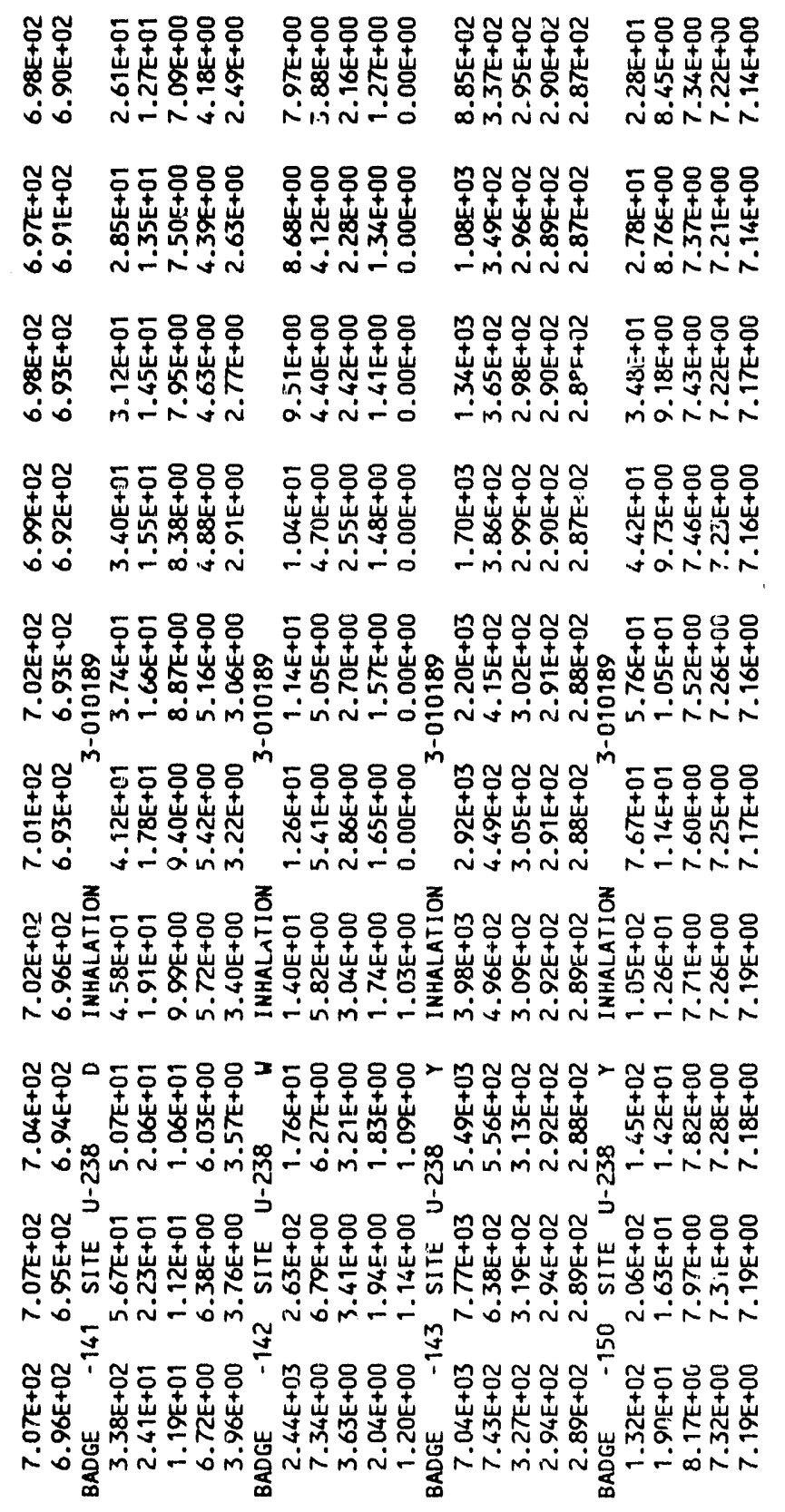


The DOSEXPRT 4.2 report program, DOSEREPORT, has been modified to produce three index files. These index files list the badge number and social security number for the selected cases in the same order as the sorted output (OUT) file. The first of these (with extension IX1) lists all cases with positive committed effective dose. The second (with extension IX2) lists all cases with zero committed effective dose but positive annual effective dose. The third (with extension IX3) lists all cases where errors (no nuclide file, measurement window or record errors) occurred. For the 1 NCIDENT and ROUTINE example data files, only the first index file contains any information, as there are no cases with record errors and no cases with zero committed effective dose and positive annual effective dose. The IX1 index files for the INCIDENT and ROUTINE examples are shown below:

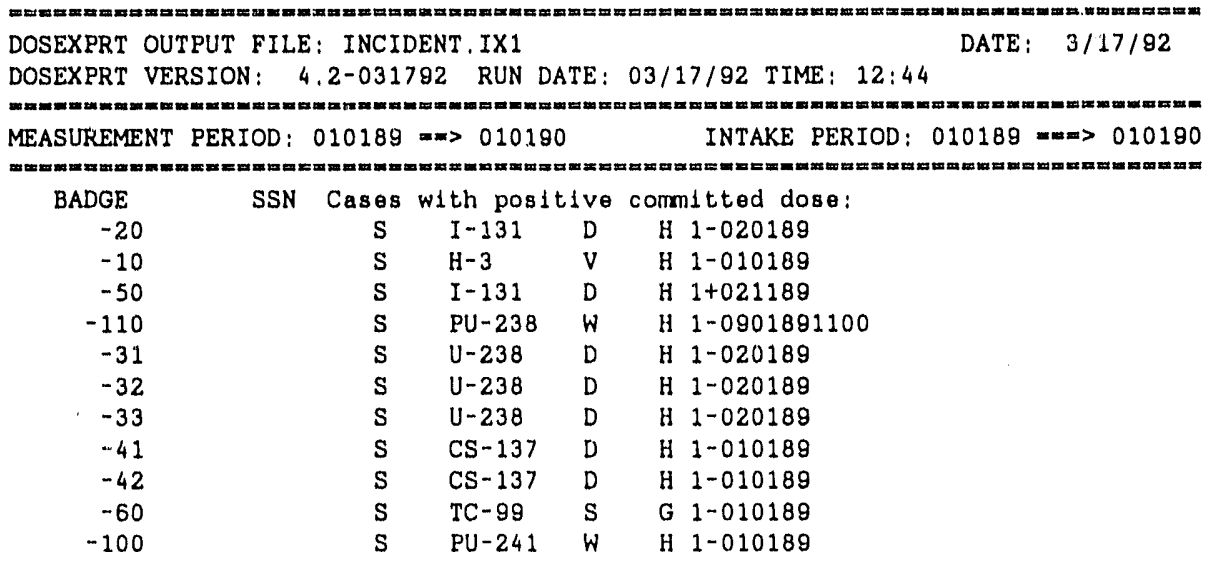

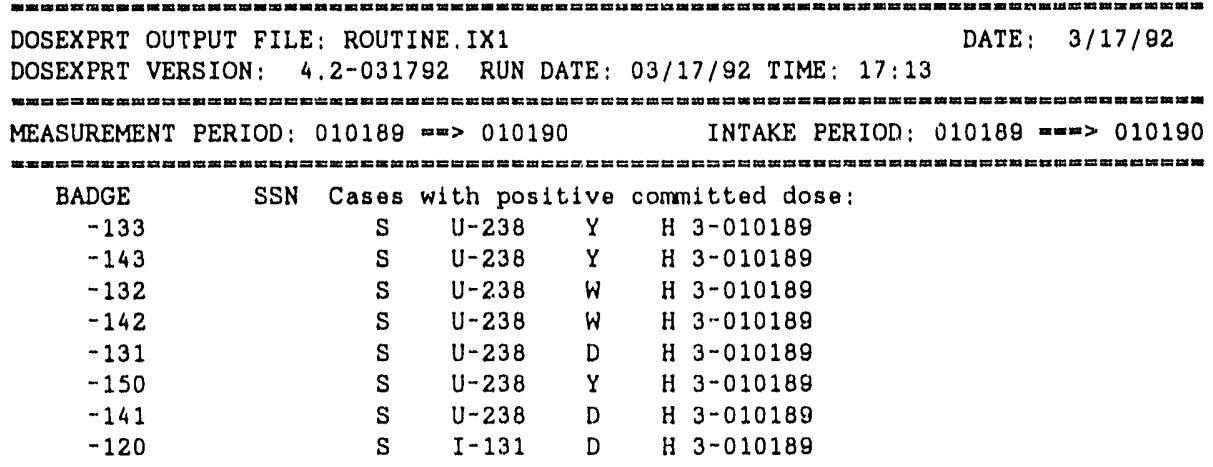




\section{Appendix M}

\section{DOSEXPRT VAX COM FILES}

When the user executes DOSEXPRT interactively from the HPIMS No. 4 menu, the VAX COM file DXINTER is executed. When the user executes DOSEXPRT as a batch process from the HPIMS No. 4 menu, the VAX COM file DXBATCH is executed. Each of these COM files sorts the input bioassay records using the VAX SORT utility. DXINTER then executes DOSEXPRT, sorts the resulting S28 output file and executes DOSREPORT. DXBATCH submits the VAX COM file DXR.UN as a VAX batch process. DXRUN executes DOSEXPRT, sorts the resulting S28 output file and executes DOS.EPORT. This appendix contains listings of these three VAX COM files, which are located in directory COM_DIR on the OHIS VAX.

\section{DXINTER.COM:}

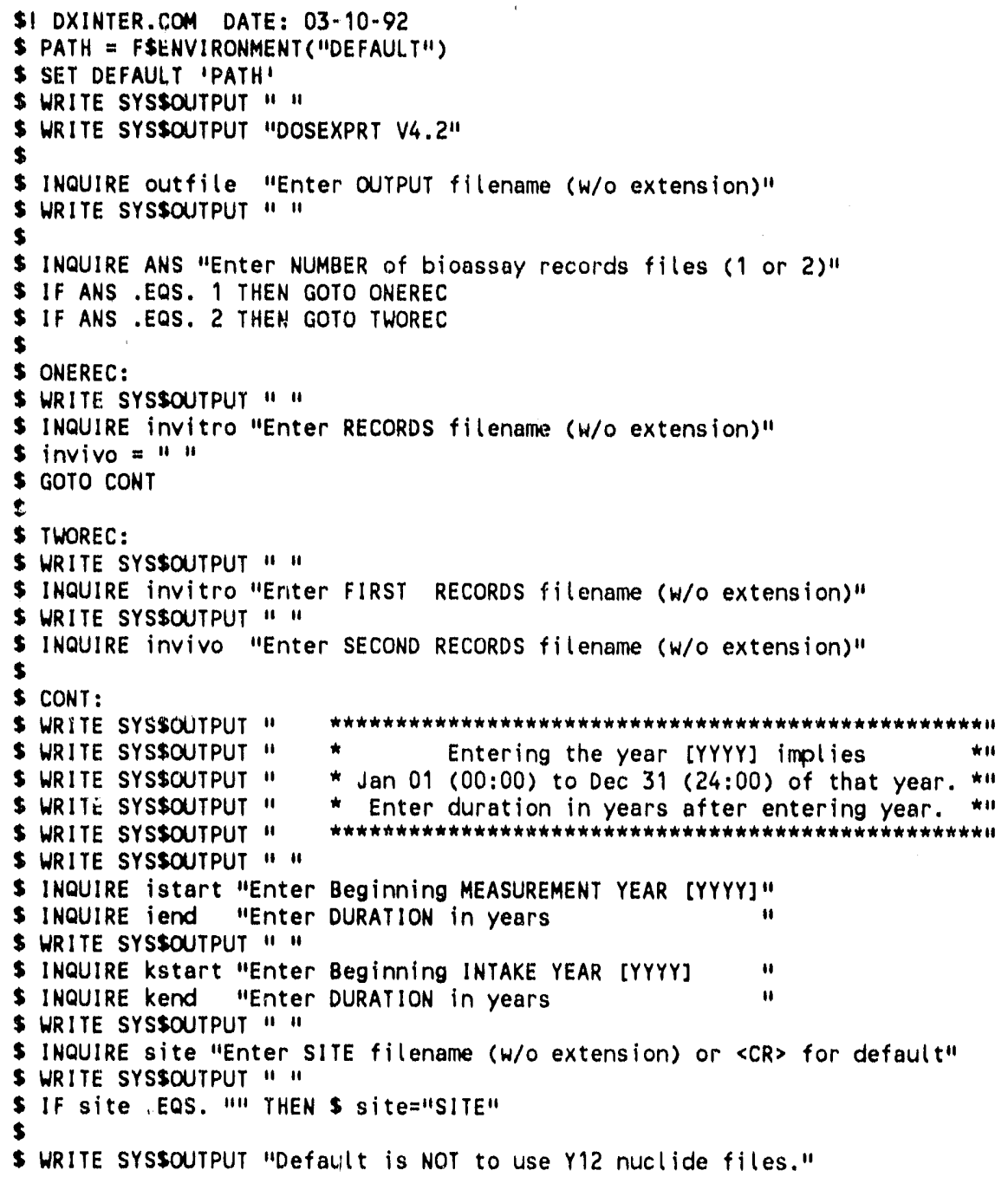




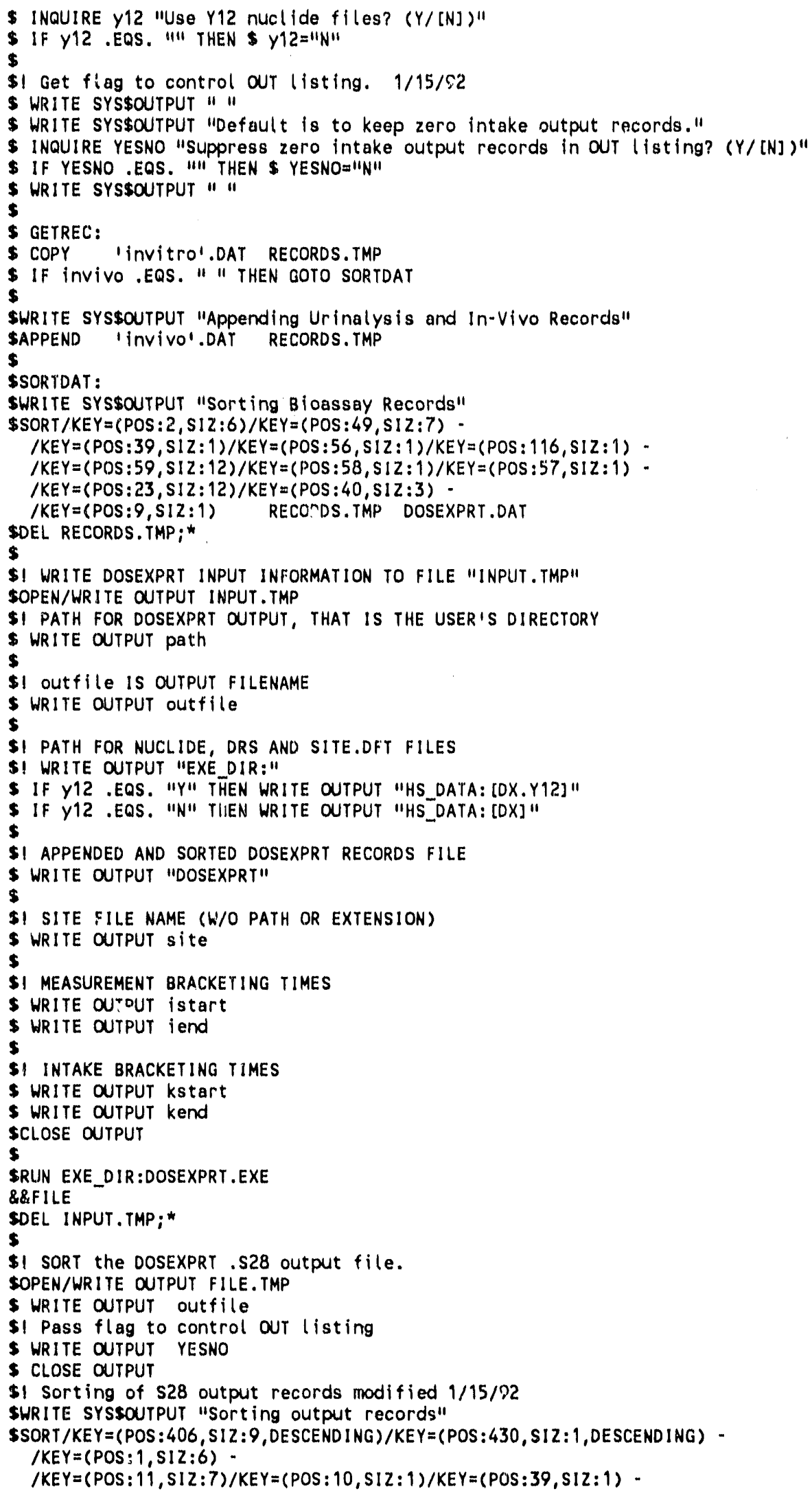




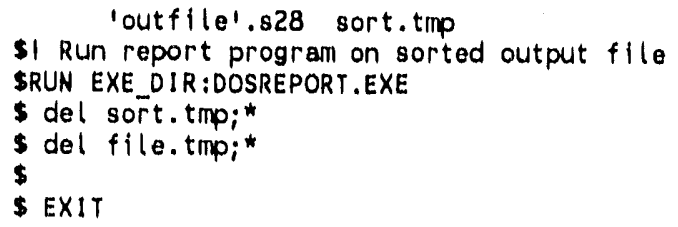

\section{DXBATCH.COM:}

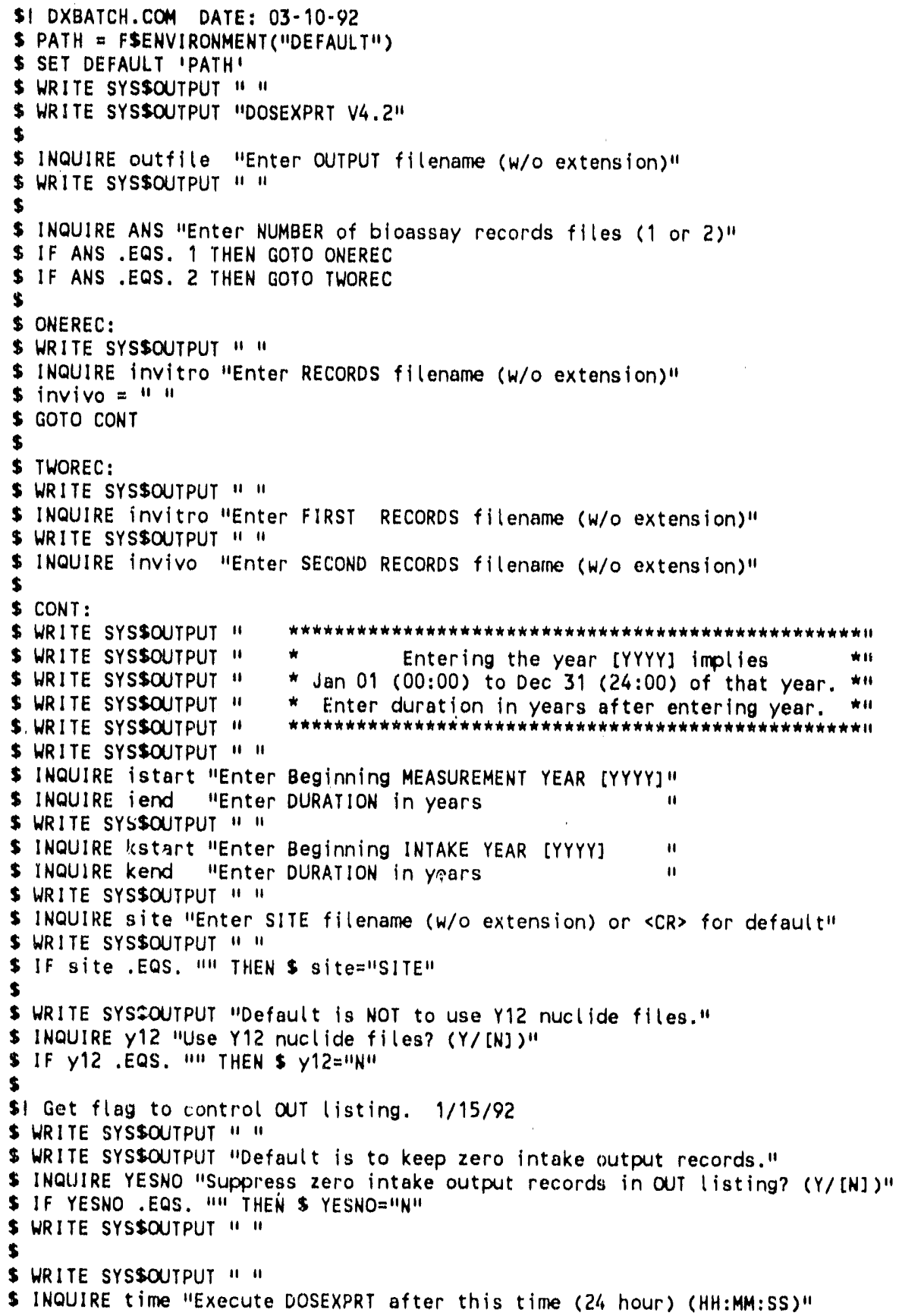




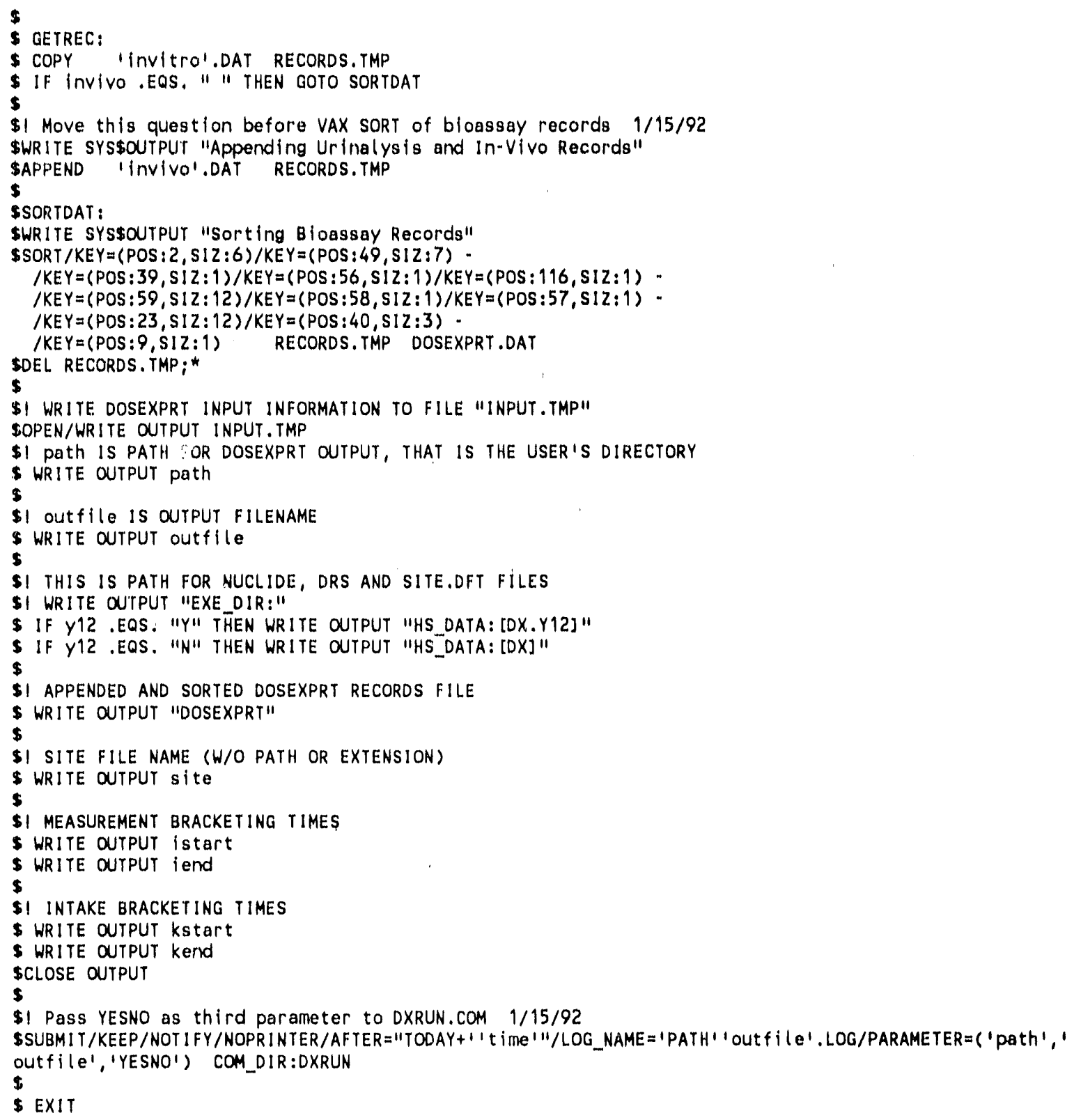

\section{DXRUN.COM:}

\$1 DXRUN.COM DATE: $01-31-92$

\$SET DEFAULT 'P1'

SSHOW DEFAUL.T

\$I EXECUTE DOSEXPRT PROGRAM - INPUT IS IN FILE INPUT.TMP

\$ RUN F.XE_DIR:DOSEXPRT.EXE

\&\&FILE

\$DEL INPUT.TMP; *

$\$$

\$! SORT the DOSEXPRT .S28 output file.

SOPEN/WRITE OUTPUT FILE.TMP

\$ WRITE OUTPUT P2 
$\$ 1$ Pass flag to control OUT l/sing $1 / 15 / 92$

\$ WRITE OUTPUT P3

$\$$ CLOSE OUTPUT

SWRITE SYSSOUTPUT "Sorting outpuit records"

$\$ 1$ Sorting of s28 output records modifled $1 / 15 / 92$

\$SORT/KEY $=(P O S: 406, S 12: 9$, DESCEND IHO) /KEY $=$ (POS:430, S12:1, DESCENDINO) -

/KEY $=(P O S: 1, S: Z: 6)$.

/KEY $=(P O S: 11$, S $12: 7) / K E Y=(P O S: 10, s 12: 1) / K E Y=(P O S: 39, s 12: 1)$ 'P2'.s28 sort.tmp

\$1 Run report program on sorted output flle

$\$$ RUN EXE DIR:DOSREPORT.EXE

$\$$ del sort.tmp; ${ }^{\star}$

\$ del file.tmp; *

$\$$

S EXIT 


\section{Appendix N}

\section{EXECUTING DOSEXPRT IN DEBUG/TEST MODE}

DOSEXPRT can be executed directly, bypassing the HPIMS No. 4 menu, for purposes of debugging or testing. This appendix describes how this is done. Testing of DOSEXPRT in the manner described here is done only by those who have authorization to perform tests or by the DOSEXPRT program developers.

At the prompt the user types: RUN EXE_DIR:DOSEXPRT. This will run Ver. 4.2 of DOSEXPRT. The user must enter the same information as when running the program off the HPIMS No. 4 menu, except for the following items:

- The user must specify the location (path) of the nuclide files, HS_DATA:[DX], and the location and name (without extension) of the default site lile, HS_DATA:[DX]SITE, or a user-modified site file. The path for the Y.12 uranium nuclide filles and corresponding site file is HS_DATA:[DX.Y12].

- The user must respond to three additional questions which control

- The display option, which can take the following values:

2 no display (header line only as when executed off the HPIMS NO. 4 menu),

1 long list (lists bioassay records, intake and cose),

-1 trace (lists trace information for debugging in addition to information listed in long listing);

- The value of AMAD used in computing the intake; and

- Whether to save or scratch the DOSEXPRT control file.

If the user selects either the long listing or the trace listing, in addition to the estimated intake, the user will see the mean-fractional deviation of the model predictions, based on the computed intake or intake rates, from the actual measurements. The mean-fractional deviation is computed as the sum, over all measurements, of the absolute value of the difference between the measurement and the predicted value divided by the prediction. The sum is then divided by the number of measurements to obtain the mean-fractional deviation.

To run the DOSREPORT program, the user must copy the file DOSREPORT.COM from FLGEM:[RWD] and type at the prompt: @DOSREPORT. The only input to the DOSREPORT program is the name of the DOSEXPRT S28 output file. DOSREPORT produces the corresponding OUT file in the user's area.

Those needing to run the DOSEXPRT code in the debug/test mode should contact the code developers. 
ORNL/TM-11857

\section{INTERNAL DISTRIBUTION}

1-3. J. M. Barber

4. R. S. Bogard

5. R. A. Boys

6-8. E. M. Brackett

9. H. M. Butler, Jr.

10. M. Cristy

11. E. Dixon

12-14. K. Duncan

15. C. E. Easterly

16-20. K. F. Eckerman

21-23. D. Farver

24. R. H. Fowler

25. A. M. Hallbick

26. R. N. Hamm

27. J. T. Holdeman

28. M. Hotchandani

29. J. B. Hunt

30. S. V. Kaye

31. G. D. Kerr

32. F. F. Knapp, Jr.

33. D. C. Kocher

34. R. W. Leggett

35. M. Mahathy

36. E. Maples

37-38. D. A. McLaughlin
39. J. C. Miller

40. R. L. Mlekodaj

41. G. L. Murphy

42. R. W. Oliver

43. S. R. Penrod

44. C. L. Pugh

45. G. R. Rao

46. D. E. Reichle

47. P. S. Rohwer

48. J. C. Ryman

49-51. C. H. Shappert

52. A. L. Sjoreen

53. R. E. Swaja

54. M. Thein

55. T. Vo-Dinh

56. E. R. Wagner

57-61. R. C. Ward

62. J. R. Watts

63. G. E. Whitesides

64. Central Research Library

65. ORNL Y-12 Research Library Document Reference Section

66. Laboratory Records Department

67. Laboratory Records, ORNL (RC)

68. ORNL Patent Office

\section{EXTERNAL DISTRIBUTION}

69. J. A. Auxier, Applied Science Laboratory, P.O. Box 549, Oak Ridge, TN 37831

70. W. J. Bair, Manager, Environment, Health and Safety Research Program, Battelle Pacific Northwest Laboratories, P.O. Box 999, Richland, WA 99352

71. B. B. Boecker, Inhalation Toxicology Research Institute, Lovelace Biomedical and Environmental Research Institute, P.O. Box 5890, Albuquerque, NM 87185

72. A. Bouville, National Cancer Institute, c/o U.S. Department of Energy/EML, 376 Hudson Street, New York, NY 10014 
73. R. S. Caswell, Nuclear Radiation Division, Rm. C-229, Bldg. 245, National Bureau of Standards, Washington, DC 20234

74. X. Chen, Radiation Health Division, Laboratory of Industrial Hygiene, Ministry of Public Health, 2 Xinkang Strect, Deshengmenwai, P.O. Box 8018, Beljing 100088 , People's Republic of China

75. D. J. Crawford-Brown, School of Public Health, Dept. of Environmental Sciences, University of North Carolina, Chapel Hill, NC 27514

76. L. T. Dillman, 184 W. Lincoln Ave., Delaware, OH 43015

77. Gunter Drexler, Gessellschaft lur Stranlen-und Umweltforschung mbH, Institut fur Strahlenschutz, Ingolstadter Landstrasse 1, D-8042, Neuherberg, Federal Republic of Germany

78. H. J. Durster, Health and Safety Executive, Regina House, 259 Old Marylebone Road, London NW1 5RR, U.K.

79. P. W. Durbin, 101-74B, Lawrence Berkeley Laboratory, University of California, Berkeley, CA 94720

80. N. H. Harley, Department of Environmental Medicine, New York University Medical Center, 550 First Avenue, New York, NY 10016

81. C. E. Iranzo, Paseo de la Castellana 201, Madrid 28046, Spain

82. Seymour Jablon, Medical Follow-up Agency, National Academy of Sciences, 2102 Constitution Avenue, N.W., Washington, DC 20418

83. Wolfgang Jacobi, Institut fur Stranlenschutz der Gesellschaft, fur stranlen-und Umweltforschung mbH, Ingolstadter Landstr. 1, D-8042 Neuberg, Federal Republic of Germany

84. J. Kruger, Nuclear Development Corporation, Private Bag X256, Pretoria 0001, South Africa

85. Emil Kunz, Institute of Hygiene \& Epidemiology, Radiation Hygiene Department, Srobarova 48, 10042 Parah 10-Vinohrady, Czechoslovakia

86. Gee-Fong Liang, Radiation Laboratory, Taiwan Power Company, P.O. Box 7, Shinmen, Taiwan 253, Republic of China

87. I. A. Likhtarev, All-Union Scientific Centre for Radiation Medicine, Melnikova Street 53, 252050 Kiev-50, Ukraine

88. Robert Loevinger, Radiation Physics C210, National Burcau of Standards, Gaithersburg, MD 20899 
89. W. M. Lowder, Physical and Technology Research Div., Er-74, Offlce of Health and Environmental Research, U.S. Department of Energy (GTN), Washington, DC 20545

90. Sidney Marks, Associate Manager, Environmental and Safety Research Programs, Battelle Pacific Northwest Laboratorles, P.O. Box 999, Richland, WA 99352

91. O. Matsuoka, Divison of Comparative Radiotoxicology, National Institute of Radiological Sciences, 9-1 Anagawa-4-chome, Chiba-shi, Japan, 260

92. C. B. Meinhold, Chief, Safety and Environmental Protection Division, Bldg. 525A, Brookhaven National Laboratory, Upton, NY 11973

93. H. Metivier, CEA - Centre d'Etudes de Bryyeres le Chatel, B.P. No. 12, 91680 Bruyeres le Chatel, France

94. W. A. Mills, 2915 Ascott Lane, Ulney, MD 20832

95. D. W. Moeller, 27 Wildwood Drive, Bedford, MA 01730

96. C. B. Nelson, U.S. Environmental Protection Agency, Office of Radiation Programs, ANR-461, 401 M Street, S.W. Washington, DC, 20460

97. J. C. Nenot, Institut de Protection et de Surete Nucleaire, Department de Protection, Services de Pathologie et de Protection Saitaire, Service de Protection Sanitaire, Centre d'Etudes Nucleaires, B.P. No. 6, 92260 Fontenay-aux-Roses, France

98. Nicole Parmentier, Republique Francaise, Commissariat A L'Energie Atomique, Department de Protection Sanitaire, Fontenay Aux Roses, France

99. J. W. Poston, Dept. of Nuclear Engineering, College of Engineering, Texas A\&M University, College Station, TX 77843

100. P. V. Ramzaev, Institute of Radiation Hygiene, 8 Mira ul, St. Petersburg 197101, Russia.

101. A. C. B. Richardson, U.S. Environmental Protection Agency, Office of Radiation Programs, ANR-461, 401 M Street, S.W. Washington, DC 204.60

102. J. S. Robertson, Human Health and Assessments Division, Office of Energy Research, ER-73, U.S. Department of Energy (GTN0, Washington, DC 20545

103. Gene Runkle, U.S. Department of Energy, Albuquerque Operations, Environmental Safety and Health Division, Albuquerque, NM 87115

104. E. L. Saenger, Eugene L. Saenger Radioisotope Laboratory, University of Cincinnati Hospital, Cincinnati General Division, 234 Goodman Street, Cincinnati, OH 45267

105. K. W. Skrable, University of Lowell, Lowell, MA 01854 
106. M. T. Stabin, Radiopharmaceutical Internal Dose Center, Oak Ridge Associated Universities, MERT, P.O. Box 117, Oak Ridge, TN 37831

107. J. N. Stannard, 17441 Plaza Animado, Apt. 132, San Diego, CA 92128

108. J. W. Stather, National Radiological Protection Board, Chilton, Didcot, Oxon, OX11 ORQ, U.K.

109. D. M. Taylor, Kernforschungszentrum Karlsruhe, Institute for Genetics \& Toxicology, Postfach 3640, D-7500 Karlsruhe 1, Federal Republic of Germany

110. J. W. Thiessen, Acting Associate Director, Office of Health and Environmental Research, ER-71, U.S. Department of Energy (GTN), Washington, DC 20545

111. R. H. Thomas, Occupational Health Office, Lawrence Berkeley Laboratory, 1 Cyclotron Road, 90-1106, Berkeley, CA 94720

112. D. Van As, Nuclear Development Corporation, Private Bag X256, Pretoria 0001, South Africa

113. B. W. Wactholz, Low Level Radiation Effects Branch, National Cancer Institute, Landow Bulilding 8C-09, 9000 R.ockville Pike, Bethesda, MD 20205

114. E. E. Watson, Radiopharmaceutical Internal Dose Center, Oak Ridge Associated Universities, MERT, P.O. Box 117, Oak Ridge, TN 37831

115. D. A. Weber, Brookhaven National Laboratory, Medical Department Bldg. 490, Upton, NY 11973-5000

116. L. R. Williams, Unit 43-2-3 Bangsar Puteri, Jalan Medang Serai, Bangsar, 59100 Kuala Lumpar, Malaysia

117. B. C. Winkler, Private Bag X256, Pretoria, 0001, South Africa

118. R. W. Wood, Physical and Technology Research Div., ER-74, Office of Health and Environmental Research, U.S. Department of Energy (GTN), Washington, DC 20545

119. W. A. Woolson, Science Applicaticons Incorporated, 1200 Prospect Street, P.O. Box 2351, La Jolla, CA 92038

120. M. E. Wrenn, Director, Radiobiclogy Division, Department of Pharmacology, School of Medicine, University of Utah Medical Center, Salt Lake City, UT 84112

121. Shlomo Yaniv, Health Effects Branch - MS 1130-SS, Division of Health, Siting and Waste Management, RES, U.S. Nuclear Regulatory Commission, Washington, DC 20555 
122. R. W. Young, Armed Forces Radiobiology Research Institute, Naval Medical Center, Bethesda, MD 20814-5145

123. Office of the Assistant Manager for Energy Research and Development, U.S. Department of Energy Field Office, Oak Ridge (DOE-OR), P.O. Box 2001, Oak Ridge, TN 37831

124-133. Office of Scientific and Technical Information, P.O. Box 62, Oak Ridge, TN 37831 


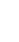

